\title{
Inter-firm cooperation in high-tech industries : a study of R\&D partnerships in pharmaceutical biotechnology
}

Citation for published version (APA):

Roijakkers, A. H. W. M. (2003). Inter-firm cooperation in high-tech industries : a study of R\&D partnerships in pharmaceutical biotechnology. [Doctoral Thesis, Maastricht University]. Universitaire Pers Maastricht. https://doi.org/10.26481/dis.20030919ar

Document status and date:

Published: 01/01/2003

DOI:

10.26481/dis.20030919ar

Document Version:

Publisher's PDF, also known as Version of record

\section{Please check the document version of this publication:}

- A submitted manuscript is the version of the article upon submission and before peer-review. There can be important differences between the submitted version and the official published version of record.

People interested in the research are advised to contact the author for the final version of the publication, or visit the DOI to the publisher's website.

- The final author version and the galley proof are versions of the publication after peer review.

- The final published version features the final layout of the paper including the volume, issue and page numbers.

Link to publication

\footnotetext{
General rights rights.

- You may freely distribute the URL identifying the publication in the public portal. please follow below link for the End User Agreement:

www.umlib.nl/taverne-license

Take down policy

If you believe that this document breaches copyright please contact us at:

repository@maastrichtuniversity.nl

providing details and we will investigate your claim.
}

Copyright and moral rights for the publications made accessible in the public portal are retained by the authors and/or other copyright owners and it is a condition of accessing publications that users recognise and abide by the legal requirements associated with these

- Users may download and print one copy of any publication from the public portal for the purpose of private study or research.

- You may not further distribute the material or use it for any profit-making activity or commercial gain

If the publication is distributed under the terms of Article $25 \mathrm{fa}$ of the Dutch Copyright Act, indicated by the "Taverne" license above, 


\section{INTER-FIRM COOPERATION IN HIGH-TECH INDUSTRIES}

A STUDY OF R\&D PARTNERSHIPS IN PHARMACEUTICAL BIOTECHNOLOGY 
Inter-firm cooperation in high-tech industries: a study of R\&D partnerships in pharmaceutical biotechnology

(c) A.H.W.M. Roijakkers, Maastricht 2003

Proefschrift Universiteit Maastricht

ISBN 90-5278-374-8

Opmaak in LTEX: Johan Willekens, Echt

Omslagontwerp: Jos van den Einde, Oosterhout

Druk: Datawyse/Universitaire Pers Maastricht 


\section{INTER-FIRM COOPERATION IN HIGH-TECH INDUSTRIES}

\section{A STUDY OF R\&D PARTNERSHIPS IN PHARMACEUTICAL BIOTECHNOLOGY}

PROEFSCHRIFT

TER VERKRIJGING VAN DE GRAAD VAN DOCTOR AAN DE UNIVERSTTEIT MAASTRICHT, OP GEZAG VAN DE RECTOR MAGNIFICUS,

PROF. DR. A.C. NIEUWENHUTJZEN KRUSEMAN, VOLGENS HET BESLUTT VAN HET COLLEGE VAN DECANEN, IN HET OPENBAAR TE VEROEDIGEN OP VRIJDAG 19 SEPTEMBER 2003 OM 14.00 UUR

DOOR

Anna Helena Wilmelmina Marla Roldakkers

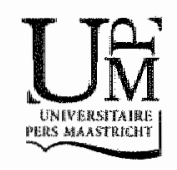




\section{Promotor:}

Prof. dr. J. Hagedoorn

\section{Beoordelingscommissie:}

Prof. dr. J.G.A.M. Lemmink (voorzitter)

Prof. dr. R. Cowan

Prof dr. W.W. Powell (Stanford University, California, USA) 


\title{
ACKNOWLEDGEMENTS
}

\author{
Johan Willekens \\ Pap en mam \\ Jo en Gertie Willekens \\ Desiree, Pieter, Lars en Britt Dörssers \\ John Hagedoon
}

Jos Lemmink, Robin Cowan, Woody Powell

Anthony Arundel

Sven Bakkes

Adela Butlolo

Myriam Cloodt

Geert Duysters

Jos van den Einde

Marc van Ehert

William Greene

Hans van Kranenburg

Sarianna Lundan

Stéphane Malo

Eva Nelissen

Ray Oakey

Ad van den Oord

Participants at the AoM meeting in Chicago, USA 1999

Participants at the HTSF conference in Manchester, UK 2001 Participants at the AIB meeting in San Juan, Puerto Rico 2002

Allard van Ritel

Frank Rothaermel

Wilfred Schoenmakers

Kitty van Straaten

Sara Villanueva-Alcántara

Alle collega's van Organisatie en Strategie

Bedankt!

Nadine Roijakkers

Maastricht, 2003 
Voor mijn vader (1948-2001), bedankt voor al het goede 


\section{CONTENTS}

Acknowledgements

1 Introduction 1 .

1.1 Introduction ........................ 1

1.2 Theoretical approaches to inter-firm collaboration ..... 5

1.3 Research questions . . . . . . . . . . . . . 6

1.4 The reasons for selecting the pharmaceutical industry . . . 7

1.5 Overview of the chapters ............... 10

2 The continuing dominance of established companies 13

2.1 Introduction . . . . . . . . . . . . . . . 13

2.2 History . . . . . . . . . . . . . . . . . . . . . . 16

2.3 Trends in science, technology, and drug discovery . . . . 20

2.4 Determinants of firm competitiveness . . . . . . . . 24

2.5 The survival of established companies . . . . . . . . . . . 30

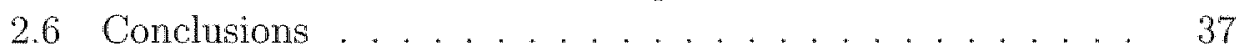

3 Trends in inter-firm R\&D partnering since 1975

3.1 Introduction . . . . . . . . . . . . . . 41

3.2 Historical pattern of R\&D partnerships . . . . . . . . . 43

3.3 Rationales for R\&D partnering . . . . . . . . . . . . 45

3.4 Modes of cooperation . . . . . . . . . . . . . . 49

3.5 International patterns in R\&D partnerships ....... 53

3.6 Conclusions ... . . . . . . . . . . . . . . 58

4 Small entrepreneurial firms and large companies $\quad 61$

4.1 Introduction . . . . . . . . . . . . . . 61

4.2 Innovation-the role of large and small companies . . . . . 63

4.3 Mutual dependence of large and small companies . . . . 66

4.4 Networks as the locus of innovation . . . . . . . . . 67

4.5 Research questions .................. . . 69

4.6 Research methodology and data . . . . . . . . . . 69

4.7 Trends in R\&D partnerships during 1985-1995 . . . . . . 74 
4.8 The structure of inter-firm R\&D networks . . . . . . . 80

4.9 Discussion and conclusions . . . . . . . . . . 88

5 How important is inter-organizational trust? 93

5.1 Introduction . . . . . . . . . . . . . . . . 93

5.2 Theory development and hypotheses ......... . . . . 95

5.3 Data, sample, and variables ............. 100

5.4 Statistical method . . . . . . . . . . . . 106

5.5 Results ....................... 108

5.6 Discussion . . . . . . . . . . . . . . . 111

5.7 Conclusions .................... 114

6 Partnering capabilities and technological competences 117

6.1 Introduction . . . . . . . . . . . . . . 117

6.2 Background and hypotheses . . . . . . . . . . . . 118

6.3 Research methods . . . . . . . . . . . . . . . . . 125

6.4 Results... . . . . . . . . . . . . . . . . . . . . . . . . . . . . . . . . . . . . . .

6.5 Discussion ....................... 140

6.6 Conclusions ........................... 144

7 Conclusions 147

7.1 Introduction . . . . . . . . . . . . . . 147

7.2 Perspectives for explaining inter-firm collaboration. . . . 148

7.3 R\&D collaboration: firm-based or network-oriented? . . . 157

7.4 Final remarks . . . . . . . . . . . . . . 171

Appendices

A Tho MPRIT-CA

A Te MERTT-CATI databank .............. 173

B Network participants appearing in the MDS graphs . . . . . 175

C The moasurement of trust in terms of repeated ties . . . . 181

\section{References}

Nederlandse samenvatting (Summary in Dutch) 199

Curriculum Vitae 


\section{LIST OF TABLES}

2.1 Chronology of landmarks ............... 18

2.2 R\&D intensities of the largest companies . . . . . . 27

4.1 Number of partnerships and participating companies . . . 77

4.2 Partnerships of the most active network participants .. 82

5.1 Descriptive statistics and correlations . . . . . . . . . 109

5.2 Fixed-effects panel logit estimates . . . . . . . . . . 110

6.1 Descriptives and correlation matrix ........... 135

6.2 Panel logit estimates . . . . . . . . . . . 136

7.1 Two perspectives on inter-firm collaboration ....... 149

7.2 Major theoretical and empirical findings of this thesis . . 170

\section{LIST OF FIGURES}

1.1 Outline of the thesis ............... 10

2.1 Industry R\&D expenditures . . . . . . . . . 26

3.1 The growth of partnerships ............. 43

3.2 The share of contractual modes . . . . . . . . . 52

3.3 Share of international and domestic partnerships . . . . . 55

3.4 International distribution of partnerships ......... 56

4.1 Partnerships in biotechnology-based industries . . . . . . 75

4.2 Number of partnerships . . . . . . . . . . . . 76

4.3 Number of partnerships per company . . . . . . . . 78

4.4 Number of partnerships per employee . . . . . . . . . 79

4.5 Partnerships between firms of similar and different sizes . . 80

4.6 Partnerships among cooperating companies, 1985-1987 . 83

4.7 Partnerships among cooperating companies, 1989-1991 . . 85

4.8 Partnerships among cooperating companies, 1993-1995 . . 87 

1

\section{INTRODUCTION}

\subsection{Introduction}

Ever since General Electric joined with Corning Glass Works in 1879 to develop Thomas Edison's first light bulb, companies in a wide range of industries have been engaging in inter-firm collaboration. Particularly in the most recent decades, there has been an unprecedented growth in interfirm partnerships by means of a variety of forms (Chesnais, 1988; Hergert and Morris, 1988; Hladik, 1985; OECD, 1992). In fact, many different forms of cooperation have arisen, such as licensing agreements, customersupplier relationships, research contracts and joint R\&D agreements, joint ventures, etc. See Auster (1987), Chesnais (1988), Dussauge and Garrette (1999), Hagedoorn (1990 and 1993), Narula (1999), Nooteboom (1999), Osborn and Baughn (1990), and Yoshino and Rangan (1995), for a number of widely accepted taxonomies of different modes of cooperation.

The particular motives of companies to enter into various sorts of interfirm partnerships are manifold (see amongst others, Das, Sen, and Songupta, 1998; Eisenhardt and Schoonhoven, 1996; Hagedoorn, 1993; Haklisch, 1986; Harrigan, 1985 and 1988; Hladik, 1985 and 1988; Lorenzoni and Lipparini, 1999; Obleros and MacDonald, 1988; Ohmae, 1985):

- The need to grow and expand into new product ranges and new, possibly foreign, markets;

- Jointly cope with uncertainty;

- The need to reduce, minimize, and share costs;

- Achieve economies of scale and scope;

- Monitor environmental changes and opportunities;

- The need to develop and incorporate new knowledge and capabilities. 
Traditionally, the focus of inter-firm collaboration would be on the final stages of the value chain where companies would jointly develop, coproduce, or market fairly simple products. More sensitive company activities that form the basis of competitive adwantage, such as R\&D, were generally conducted internally. Currently, however, companies cooperate in various activities across all stages of the value chain.

Although inter-firm collaboration has become an important aspect of company behaviour in a large number of industries, inter-firm partnerships play a particularly important role in high-tech industries and other sectors where learning and flexibility form the basis of competition (Ciborra, 1991; Dussauge and Garrette, 1999; Eisenhardt and Schoonhoven, 1996; Gomes-Casseres, 1996; Harrigan and Newman, 1990; Oster, 1992). Indeed, in most high-tech industries, such as pharmaceutical biotechnology and information technology, large numbers of inter-firm R\&D partnerships between companies have led to dense networks of inter-firm relationships (see Dussauge and Garrette, 1999; Hagedoorn, 1993 and 1996a; Hagedoorn and Schakenraad, 1990 and 1992; Link and Bauer, 1989; Mowery, 1988; Mytelka, 1991; Nooteboom, 1999). In this type of rapidly developing industry, advances in science and technology are widely dispersed. Successful exploitation of these important developments requires skills and capabilities that far exceed those that are internally possessed by most high-tech companies. Technological developments trigger the formation of various types of R\&D partnerships, which enable companies to maintain their Hexibility and learn from a variety of sources (i.e., research partners) about the many new commercial opportunities available to them.

This thesis studies the nature of inter-firm R\&D collaboration in the high-tech pharmaceutical biotechnology industry. Inter-firm R\&D partnerships are those inter-firm relationships that can be expected to have an influence on R\&D, innovation, and technological development. We will refer to $R \& D$ as the basic research and development activities that are aimed at increasing scientific or technological knowledge and the applica- 
tion of that knowledge to the creation of new and improved products and processes. Companies can cooperate in $\mathrm{R} \& \mathrm{D}$ through a specific set of organizational modes of cooperation where two or more partners, that remain independent economic agents and organizations, share some of their R\&D activities. These R\&D partnerships are primarily related to two basic categories of organizational forms, i.e., contractual agreements, such as research contracts and joint R\&D agreements, and equity-based partnerships, such as minority holdings and joint ventures. These different forms of cooperation constitute the most important forms of bilateral R\&D exchanges and joint R\&D undertaking (see also Hagedoorn, 2002).

Important research questions related to the subject of inter-firm R\&D collaboration in a high-tech setting are, for example: do high-tech companies strive for mutual gain from their joint research activities or do they aim to satisfy their own competitive interests? Do these companies choose to be flexible in their partnerships or is integration the most preferred basis of these interactions between companies? Has intensive cooperation in R\&D led to a high level of complementarity and specialization in. most high-tech industries? Does inter-organizational trust or, by contrast, opportunism play an important role in these sorts of partnerships? Questions such as these lead one to investigate the specific nature of inter-firm R\&D partnerships in high-tech industries. Inter-firm R\&D partnerships, their underlying motives, organizational setting, the companies involved in these partnerships, and the drivers of partnership formation are the main subjects studied in this thesis. The general research question guiding the thesis is then: is inter-firm R\&D collaboration in the high-tech pharmaceutical biotechnology industry most accurately characterized as firm-based or network-oriented? In a search for answers to this question, the thesis is largely empirical in nature. For the empirical analyses, we make use of the MERIT-Cooperative Agreements and Technology Indicators (CATI) database on pharmaceutical biotechnology R\&D partnerships that were 
formed during the period 1975-1998 (see appendix A for an extensive description of this database).

In studying various issues related to inter-firm $R \& D$ collaboration, this thesis mainly draws from several interesting theories that can all be classified into one of two basic categories depending on whether they wiew cooperation as the primary purpose of the high-tech firm or as a strategic tool that enables these companies to improve their competitive position: the firm-based view and the network-or partner-oriented perspective (Contractor and Lorange, 1988a; Hagedoorn and Osborn, 2002; Osborn and Hagedoorn, 1997). Both research traditions have already devoted considerable effort to studying the main purpose of the high-tech firm, the specific organization of high-tech industries, and the most important features characterizing inter-firm R\&D partnerships, but they clearly present opposing views on each of these relevant issues. While the firm-based view stresses the crucial rolle of independence, opportunism, and the use of detailed contracts in inter-firm R\&D collaboration, the network-oriented perspective emphasizes the more positive aspects of these sorts of partnerships, such as complementarity, the development of inter-organizational trust, and mutual gain.

The remaining part of this chapter is structured as follows. In the next section, we will describe these two different research traditions that provide us with a relevant theoretical context for studying the subject of inter-firm R\&D collaboration. Section 1.3 will introduce the research questions that have formed the basis of each of the core theoretical and empirical chapters in this thesis. In section 1.4, we briefly describe the pharmaceutical biotechnology industry with the aim of clarifying the most important reasons for selecting this particular sector as the main industrial setting for the thesis. Finally, section 1.5 provides an outline of the various issues that will be studied in each consecutive chapter. 


\subsection{Different theoretical approaches to inter-firm collaboration}

In trying to explain the nature of inter-firm R\&D partnering in the hightech pharmaceutical biotechnology industry, this thesis makes use of a number of theories that can all be classified into one of two broad-based, diametrically opposed, research traditions: the firm-based view and the network-oriented perspective (Contractor and Lorange, 1988a; Hagedoom and Osborn, 2002; Osborn and Hagedoom, 1997). Underlying both of these theoretical perspectives, there is a clear set of assumptions regarding the purpose of the high-tech firm, the organization of high-tech industries, and the specific features characterizing inter-firm R\&D partnerships.

In the firm-based view, we find an understanding of the high-tech firm and the nature of its relations that is for the most part based on neoclassical economic notions of competition. Researchers in this view generally agree that high-tech industries consist of large numbers of independent, "go-it-alone" companies, striving for competitive advantage in an impersonal, hostile market environment. In such a competitive setting, inter-firm R\&D partnerships are largely motivated by self-interest where each of the research partners tries to use the alliance to strengthen its competitive position vis-à-vis other companies. Because a high level of integration and mutual dependence in the R\&D partnership may compromise the competitive position and bargaining power of individual partners, hightech companies generally prefer to cooperate in research through flexible, contractual forms of partnerships rather than through equity-based agreements (Hamel, 1991; MacDonald, 1995; Porter, 1990; Reich and Mankin, 1986). As partnership formation is generally viewed as being primarily driven by the competitive, opportunistic behaviour of cooperating companies (see also Dyer, 1996; Harrigan, 1988; Kanter, 1994; Ohmae, 1989; Prahalad and Hamel, 1990), the use of formal, detailed contracts in interfirm R\&D collaboration also protects participating companies from their 
partner's probing of their competitive, technological knowledge (Kawasaki and MacMillan, 1986).

In contrast, in the network-oriented perspective, it is argued that the behaviour of high-tech companies and the interaction between these firms is driven as much by cooperation as it is by competition (see Contractor and Lorange, 2002; Gulati, 1998; Hagedoorn, 1995). As most of these researchers have so clearly pointed out, the organization of high-tech industries is fundamentally based on dense, tightly connected networks of trustful R\&D partnerships between highly integrated, interdependent companies. High-tech companies that participate in these equity-based R\&D networks are willing to set aside their immediate competitive interests and sacrifice part of their independence as embeddedness in such networks enables these companies to achieve a number of common, otherwise unreachable, goals (see also Gomes-Casseres, 1996; Gulati, 1999; Lorenzoni and Baden-Fuller, 1995; Lyles, 1994; Powell and Brantley, 1992). In these centrally coordinated knowledge networks, each of the network partners plays a specialized, complementary role in the innovation process, resulting in a high level of interdependence and inter-organizational trust between all participating companies (Hakansson and Johansson, 1993; Herrigel, 1993; Ring and van de Ven, 1992; Staber, 1998). The notion that high-tech companies can thus learn from a variety of specialized research partners has led many observers to conclude that embeddedness in knowledge networks gives these companies a competitive edge over firms that do not engage in R\&D partnerships (see amongst others, Ciborra, 1991; Gomes-Casseres, 1996; Hagedoorn, 1995; Jarillo, 1993; Lorenzoni and Baden-Fuller, 1995; Powell and Brantley, 1992).

\subsection{Research questions}

The main purpose of this thesis is to gain a better insight into the changing nature of inter-firm relationships in a high-tech setting. To achieve this 
goal, the general research question is: is inter-firm $R \& D$ collaboration in the high-tech pharmaceutical biotechnology industry most accurately characterized as firm-based or network-oriented?

In this thesis, we provide an empirical analysis of inter-firm R\&D partnering in the international pharmaceutical biotechnology industry. Specifically, we examine newly formed R\&D partnerships in this industry between 1975, the year in which biotechnology was first discovered, and 1998. Through a longitudinal analysis of various aspects related to R\&D partnerships, we intend to provide an overall picture of the nature of these partnerships in terms of their underlying motives, organizational setting, players, and the specific factors driving these relationships between companies. Thus, the main research question can be divided into four more specific research questions:

- What are the motives underlying inter-firm R\&D partnerships?

- What are the organizational characteristics of these partnerships?

- What are the roles played by different groups of cooperating companies?

- What are the main determinants of R\&D partnerships?

The main contributions of this thesis are that it studies inter-firm R\&D collaboration within the context of the two most important theoretical perspectives of partnerships and networks and that it studies this subject in a longitudinal research setting. So far, most studies of pharmaceutical biotechnology R\&D partnerships are based on survey research and, therefore, mainly of a cross-sectional nature. Studying various issues related to R\&D partnerships longitudinally can provide us with a better understanding of each of these relevant issues.

\subsection{The reasons for selecting the pharmaceutical industry}

The pharmaceutical industry provides us with a particularly interesting context for studying the changing nature of inter-firm relationships in a high-tech setting. There are three main reasons why this high-tech sector 
was selected as the primary industrial context for analysing various aspects related to inter-firm R\&D collaboration.

- Besides its important implications for drug research and development, the discovery of biotechnology has led to the development of a strong dual market structure in the pharmaceutical industry, mainly based on a large number of relatively small, research-intensive biotechnology firms and a small group of very large, established pharmaceutical companies (see Powell, 1996; Saviotti, 1998). Another important feature of the modern pharmaceutical biotechnology industry is the sharply increasing frequency of inter-firm R\&D partnerships between these two different groups of companies (see also Kenney, 1986; Powell, 1996; Rothaermel, 2000). While these developments are by no means unique to this industry, pharmaceutical biotechnology has been one of the areas of knowledge, which has given rise to the largest number of R\&D partnerships (see, for example, Hagedoom and Schakenraad, 1992; Hagedoorn, 1996a and 2002). From a theoretical point of view, it seems particularly important to understand the specifics of inter-firm R\&D collaboration in this sort of high-tech industry, e.g., the motives underlying most of these partnerships, the role played by small biotechnology firms and large pharmaceutical companies in cooperative $R \& D$ networks, and the most important factors determining wide-spread cooperation in drug research.

- In the traditional, organic chemistry-based pharmaceutical industry of the $1950 \mathrm{~s}$ and $1960 \mathrm{~s}$, inter-firm R\&D collaboration did not play a very importiant role. In the post-war era, large pharmaceutical companies can most accurately be characterized as highly independent companies that were mainly following a "go-it-alone" research strategy, involving hardly any formal R\&D partnerships with other large companies. While most of these dominant innovators were intensely cooperating in research with universities and other science-based institutions, they were primarily competing with other companies (Cockburn and Hen- 
derson, 2000; Faulkner and Orsenigo, 1989; Freeman, 1990; Galambos and Sturchio, 1998). With the emergence of biotechnology in the first half of the 1970s, however, the pharmaceutical industry witnessed a rather dramatic change in the nature of relationships between companies. As a result of a number of radical scientific and technological developments, pharmaceutical companies were more or less "forced" to adapt their research strategies to also include a large number of R\&D partnerships. Against this unique historical background, it is very interesting to examine the question whether these numerous, newly formed partnerships are truly of a cooperative nature in terms of their underlying motives, organizational forms, and driving forces, or whether they are still primarily of a competitive nature, oriented towards improving the competitive position of individual companies.

- With the possible exception of the important work of Gulati (1995a, 1995b, and 1999), Powell, Koput, and Smith-Doerr (1996), Rothaermel (2001), and a few others, so far, most contributions to the literature on pharmaceutical biotechnology R\&D partnerships and various other forms of cooperation are based on survey research and, therefore, usually of a cross-sectional nature. However, there is a pressing need to understand the longitudinal aspects of R\&D partnerships and networks, particularly how they evolve through time and co-evolve with the degree of maturity of different technologies, high-tech firms, and hightech industries. In the 1980s, a number of attempts were made to set up databases that would allow longitudinal research, but the work on most of these databases was terminated after a number of years. Apart from some "commerciall" databases, such as BioScan, there are few databases that generate both cross-sectional and longitudinal insight (Hagedoom, 2002; Hagedoom, Link, and Vonortas, 2000). The CATI database is one of the few still existing databases that allow us to conduct longitudinal research and thus study various trends in partnerships and networks over time. In this database, the pharmaceutical biotechnology industry 
is well represented. For each year since the discovery of biotechnology in 1975, it includes detailed information on individual partnerships and each of the companies participating in these agreements.

\subsection{Overview of the chapters}

In figure 1.1, an overview of the thesis is provided. It becomes clear from this figure that the main body of this thesis consists of one descriptive chapter (chapter 2) and four chapters that are based on an empirical analysis of the CATI data set (chapters $3,4,5$, and 6).

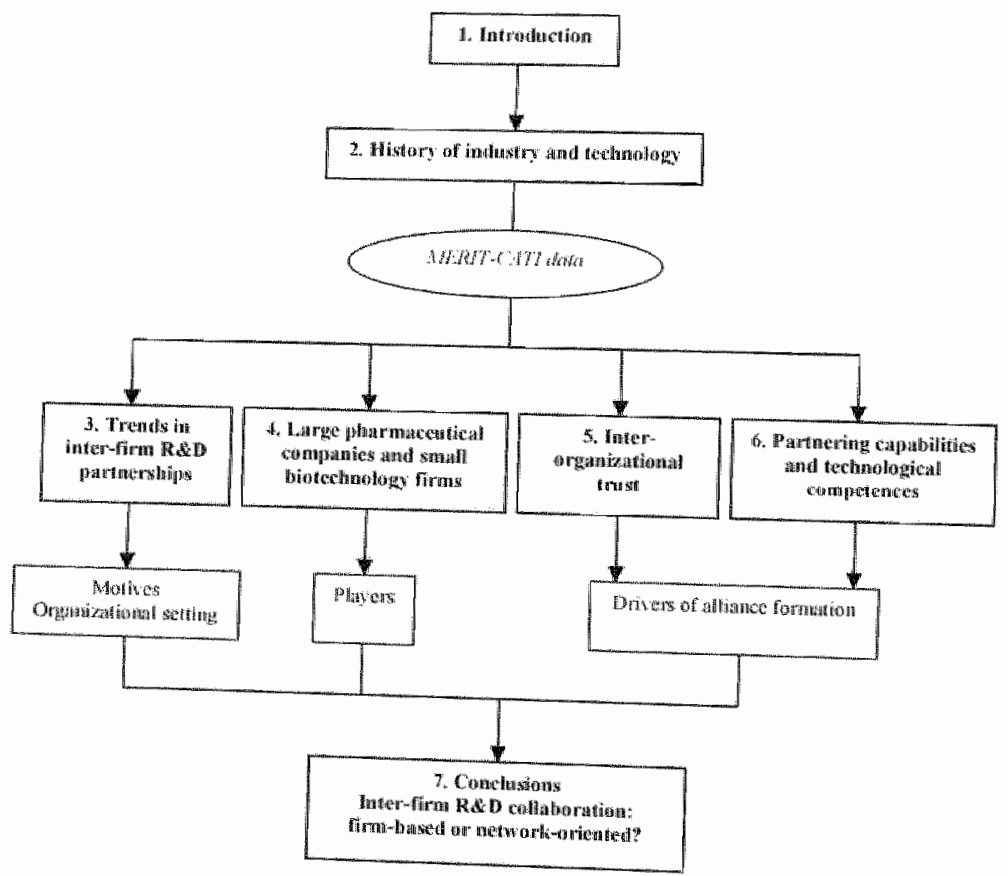

Figure 1.1: Outline of the thesis. 
Chapter 2 introduces the pharmaceutical industry as a high-tech sector that has experienced a series of dramatic changes since its inception in the $1940 \mathrm{~s}$, discusses the most important scientific and technological developments, and the emergence of a large number of inter-firm R\&D partnerships between large pharmaceutical companies and small, new biotechnology firms. We investigate how large companies were able to survive the radical shift to biotechnology by building on their unique, firm-specific skills and capabilities.

Chapter 3 provides an historical analysis that gives insight into the most. important trends and patterns in pharmaceutical biotechnology R\&D partnerships since the discovery of biotechnology in 1975. It discusses general growth patterns in these partnerships, focussing on their underlying motives and major developments in their specific organizational setting over time (see figure 1.1). Using country-level data, we also investigate some important international patterns in the formation of R\&D partmerships within the Triad regions (i.e., Asia, Europe, and North America).

Chapter 4 investigates the structural evolution of inter-firm R\&D networks over time. The CATI database allows us to conduct a detailed analysis of these networks in terms of density, major network players, and group formation (see also figure 1.1). Insights from Schumpeterian theory are combined with the current alliance literature to investigate whether complementary resources and capabilities that are possessed by small, entrepreneurial biotechnology firms and large, established pharmaceutical companies have led to a high level of mutual dependence between these two groups of companies. MDS analysis is used to graphically represent the development of R\&D networks and the changing role of different groups of players over time.

Chapters 5 and 6 discuss the results of panel analyses, both examining the most important drivers of R\&D partnership formation amongst groups of high-tech pharmaceutical biotechnology companies (see also figure 1.1). Chapter 5 analyses the role of an important partner- or network-oriented 
determinant of partnership formation, i.e, inter-organizational trust, making use of fixed-effects binomial logit models. The results of these analyses are discussed within the theoretical context of important streams of literature on trust and the existing literature on dual market structures, considering the specifics of inter-firm R\&D collaboration between groups of companies that are substantially different in terms of their size and bargaining power.

Chapter 6 is then mainly concerned with the empirical analysis of the role of a relatively large number of firm-based determinants with regard to the propensity of pharmaceutical biotechnology companies to continue forming R\&D partnerships. Binomial panel logit models are used to investigate the effect of the general experience of companies with setting up partnerships, their specific strategic network positioning, their networking efficiency, and their technological competences on partnering propensity. The results enable us to determine if cooperating companies can learn from their experience and use their unique, firm-specific partnering capabilities to optimally benefit from their existing and future partnerships.

Finally, within the context of both perspectives of inter-firm R\&D collaboration, chapter 7 provides a discussion of the main theoretical and empirical findings of this thesis in terms of motives, organizational setting; players, and the most important drivers of R\&D partnership formation. This chapter combines all the results presented in chapters $2-6$ and, as such, attempts to provide an answer to the main research question as presented in section 1.3 : is inter-firm R\&D collaboration in the high-tech pharmaceutical biotechnology industry most accurately characterized as firm-based or network-oriented? 
2

\section{BIOTECHNOLOGICAL REVOLUTION AND THE CONTINUING DOMINANCE OF ESTABLISHED COMPANIES}

\subsection{Introduction}

Technological change is difficult for any company to manage (see Baum, 1996; Hannan and Freeman, 1977 and 1989; Kaufman, 1971; Nelson and Winter, 1982; Rosenbloom and Christensen, 1998; Utterback and Suarez, 1993). However, it is particularly difficult for large, established companies to diversify into new technological fields or even recognize the need to change, because these companies invested large amounts of resources in building up their existing knowledge base (Henderson, 1993; Henderson and Clark, 1990; Tolbert and Zucker, 1996; Zucker and Darby, 1997). In addition, the accumulated knowledge base of established high-tech companies is an important source of the company's financial success (Reinganum, 1983 and 1989; Waring, 1993). Indeed, technological advance arising within an industry is an effective means of increasing sales and net income of the established companies in an industry. Because the economic value of existing skills and capabilities will be lost from a radical shift in technological direction, these companies will continue to build on their existing knowledge base for as long as they can (see also Ahuja and Lampert, 2001; Dosi, 1982; Dougherty and Heller, 1994; Henderson, 1993; Reinganum, 1983 and 1989).

However, when a radical change in technology originates outside the industry and uses a different set of skills and capabilities, or complementary assets (Teece, 1986), from those required to practice the old technology, new entrants may eventually replace existing companies (Tushman and Anderson (1986) refer to this type of change as competence-destroying 
technological change). The skills, capabilities, and knowledge base of established companies then constitute a significant barrier to the absorption of the new technology (see Cohen and Levinthal, 1989 and 1990). Particularly, it will be impossible for companies to incorporate the new technology into their existing knowledge base if they continue to invest in the old one. A new technology that substitutes the old technology thus creates better entry conditions for new firms, because it is extremely difficult for existing companies to recognize the need to change if the old technology continues to produce high returns on investment and will only be completely substituted by the new technology in dre time (see also Zucker and Darby, 1997 ).

On the other hand, if the new technology uses the same complementary assets as those required to practice the old technology, then existing companies tend to have an advantage over new entrants (Gort and Klepper, 1982; Rosenbloom and Christensen, 1998; Rothaermel, 2000). In other words, if innovation is largely dependent on particular skills and capabilities and if this knowledge base is difficult to access for new firms, existing companies have a considerable chance of survival. The survival of existing companies is enhanced by the experience these companies have built up in using their unique set of skills and capabilities to avoid being driven out of the industry by new entrants (Rothaermel, 2000 and 2001). These theoretical insights provide us with a context for analysing the latest technological shift in the pharmaceutical industry, the shift to recombinant DNA technology and hybridoma technology, and the survival of established companies.

The pharmacentical industry provides us with a unique setting for studying the strategic responses of large, established companies to the discovery of a radically new technology. Throughout the 20 th century, the industry experienced a series of decisive technological changes, starting with significant advances in synthetic organic chemistry, which formed the general knowledge base for drug discovery in the 1950s and 1960s (Achilladelis and Antonakis, 2001; OTA, 1991 and 1993; Pisano, 1994; Schwartzman, 
1976). In the 1970s, a wave of scientific breakthroughs in the biological sciences ultimately led to the development of a new, much more concentrated, style of R\&D, i.e., rational drug design (Della Valle and Gambardella, 1993; OTA, 1991 and 1993). The next, partially overlapping, but much more radical technological shift was grounded in recombinant DNA technology and hybridoma technology, and is generally referred to as the biotechnological revolution (Achilladelis and Antonakis, 2001; Galambos and Sturchio, 1998; Orsenigo, 1989; Rothaermel, 2000; Zucker and Darby, 1997).

From the viewpoint of the large, established pharmaceutical companies, this latest shift to biotechnology, a new research strategy largely outside their accumulated skills and capabilities, was rather different from previous technological changes in the industry: for the first time, commercialisation of a new technology was carried out by new entrants (Pisano, 1990; Sapienza, 1989; Senker and Sharp, 1997). In the 1950s, 1960s, and 1970s, established companies typically dominated innovation in the pharmaceutical industry. However, in the 1980s, new firms led the shift to biotechnology while existing companies were only slowly acknowledging the important potential applications of the new technology. Although their initial reaction to the emergence of biotechnology was a rather slow one, by the mid-1990s, many pharmaceutical companies had established significant capabilities in recombinant DNA technology and molecular biology (Zucker and Darby, 1996 and 1997). They gained access to the new knowledge base by creating various sorts of inter-firm partnerships with the new biotechnology firms (Arora and Gambardella, 1990; Barley, Freeman, and Hybels, 1992; Hagedoorn, 1996a; Hagedoorn and Schakenraad, 1990 and 1992; Pisano and Wheelwright, 1995; Powell, 1996 and 1998). These inter-firm partnerships added a completely new element to the tight networks of academia-industry cooperation that traditionally sustained innovation in the pharmaceutical industry (see Cockburn and Henderson, 2000; Freeman, 1990; Galambos and Sturchio, 1998). This poses two questions that are important from a theoretical point of view: 
- Why did new entrants first commercialise biotechnology? Why did existing companies not seize upon important scientific breakthroughs in the 1970s, especially as the companies concerned have a strong tradition in R\&D and have been able to sustain a high rate of innovation over many decades (see Galambos and Sturchio, 1998; Reekie and Weber, 1979; Schwartzman, 1976; Taggart, 1993; Walsh, 1984; Walsh and Galimberti, 1993)?

- If existing companies were so clearly lagging behind the new firms that were leading the innovation, why did new entrants not replace existing companies?

In the next section, we will first describe the early development of the modem pharmaceutical industry. Section 2.3 discusses major scientific and technological developments that ultimately led up to the biotechnological revolution in drug discovery and explains why the emergence of biotechnology was so different from previous technological shifts in the industry. This is followed by a discussion of the factors that determine the competitiveness of pharmaceutical companies. Section 2.5 presents a discussion of the two questions stated above from a theoretical perspective. Some conclusions to be drawn from this chapter are discussed in the last section.

\subsection{History}

A chronology of key events in the development of the pharmacentical industry is given in table 2.1, which provides the reader with a quick overview of the major scientific and technological developments in the pharmaceutical industry. As is evident from the table, until the Second World War, there was little sign of what would eventually emerge as the modern pharmaceutical industry in the 1940s. Early efforts to develop new drugs took place in the late $19 t$ th century and were the result of a unique cross-fertilization between individual scientists and industry (see also Cockburn and Henderson, 2000; Freeman, 1990; Galambos and Sturchio, 1998). Particularly, 
they were triggered by William Perkins' attempts to manufacture synthetic quinine from aniline. He actually succeded in producing the first artificial dye, aniline purple. Large European chemical companies were quick to take advantage of this important discovery by developing the necessary capabi]ities in R\&D and production (Baumler, 1968; Beer, 1959; Behnisch, 1986; Lesch, 1993; Taggart, 1993; Verg, 1988). They began to synthesize a wide range of artificial dyes and, as a by-product of their chemical operations, these companies were also capable of producing a number of chemicals and compounds with significant therapeutic uses.

The German chemical company Bayer, for example, successfully developed aspirin in 1899. Aspirin has become one of the most widely used drugs since Bayer started to produce it on a commercial scale. Another German company (Hoechst) actively supported the work of the German bacteriologist Paul Ehrlich, which involved using synthetic dyes as a transport system for carrying drugs to particular parts of the human body. Eventually, after some 600 molecular manipulations, he produced Salvarsan, which was a highly effective drug against syphilis (Taggart, 1993). The pharmaceutical branches of Bayer and Hoechst, and to a lesser extent those of Swiss chemical companies (e.g., Ciba Geigy), are typically viewed as the first modern pharmaceutical companies and, by being adopted as role models by many European and US drug manufacturers, they helped shape the structure and practices of the pharmaceutical industry (Bammler, 1968; Lesch, 1993; Sharp, Patel, and Pavitt, 1996; Verg, 1988). Although some further drug research took place at the turn of the 20 th century, very few new drugs were discovered and marketed in the next twenty-five years (Sneader, 1985). This was mainly due to the larger chemical and dyestuff operations of many companies that greatly overshadowed their search for new drugs.

The groundwork for what would ultimately unfold as the pharmaceutical industry was laid in 1928 when Alexander Fleming, a bacteriologist at London's St. Mary's Hospital, first discovered the anti-bacterial properties of penicillium mold (see table 2.1). It took another twelve years before Ox- 


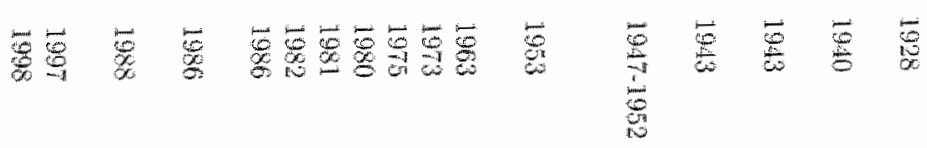

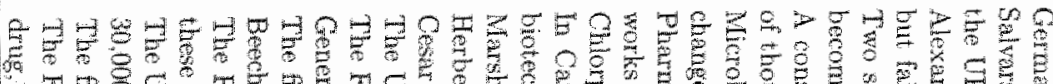
н

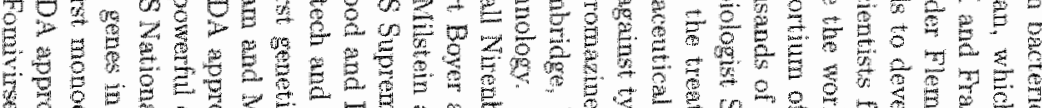
7. \%

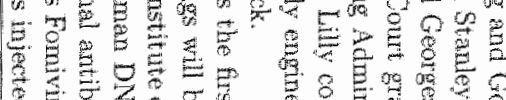

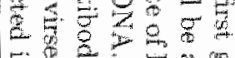

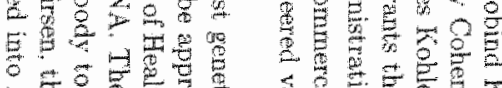

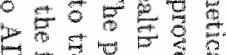

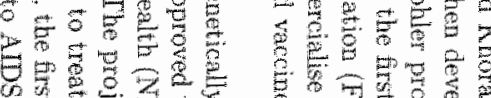

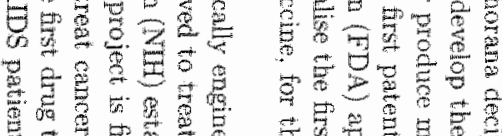

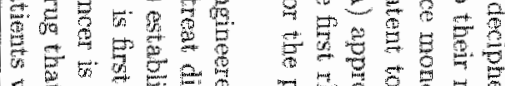

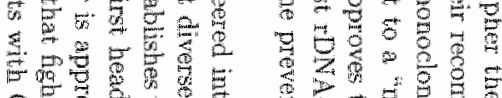

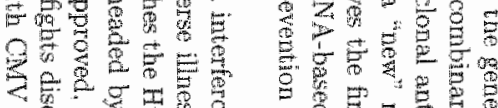

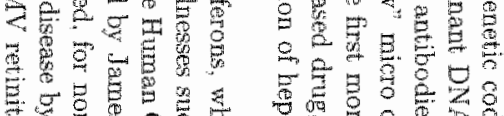

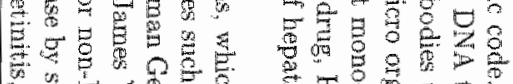

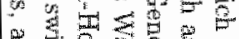
3.928 可诘

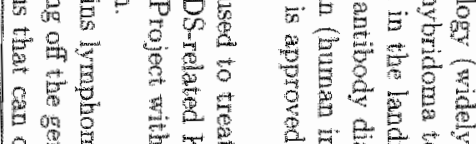

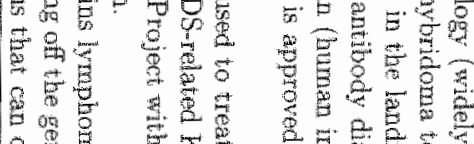

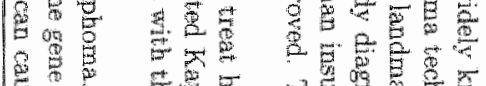

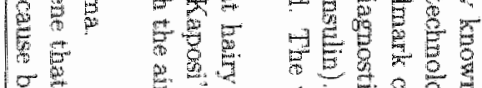

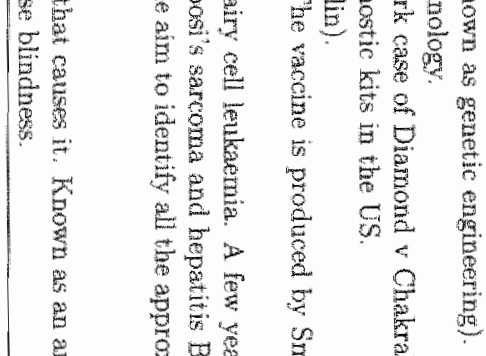

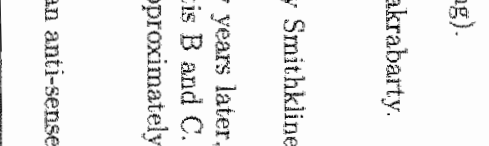

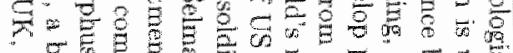
$E$

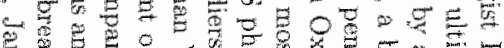

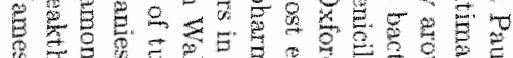

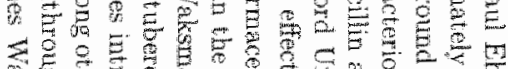

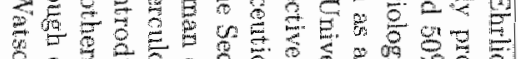

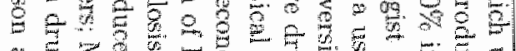

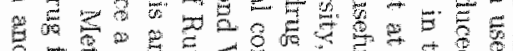

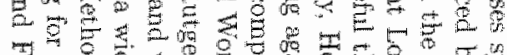
एक

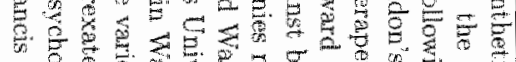

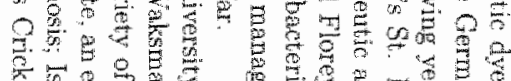

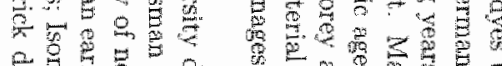

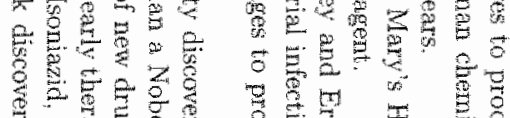

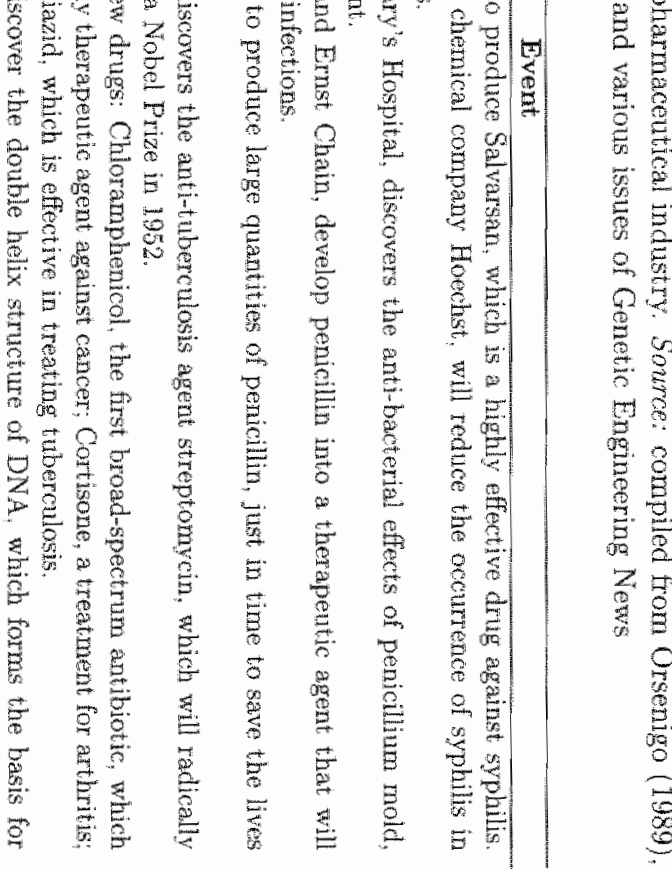

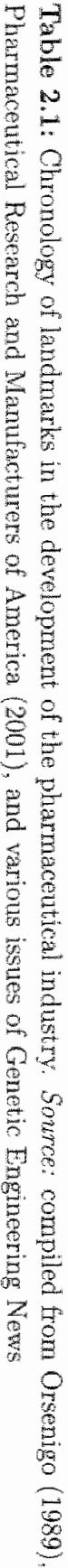


ford University scientists Howard Florey and Emst Chain developed penicillin into a potentially useful therapeutic agent. Even then, it required heavy investments by a consortium of US companies (including Pfizer, Eli Lilly, and Squibb) to develop the deep-tank fermentation techniques that allowed for the mass production of penicillin (Hacking, 1986; Marstrand, 1981; Taggart, 1993). Due to the extensive wartime needs for safe antibiotics, companies increasingly recognized the importance of investing in drug research and development (Achilladelis and Antonakis, 2001). Furthermore, in 1948, the US Patent and Trademark Office (USPTO) granted the first patents for artificial antibiotics, which guaranteed the reaping of profits from investments in drug research (Bogner and Thomas, 1994). This constituted an important development for the pharmaceutical industry: it led to the formation of specialized antibiotic firms, whose main purpose was the development of new drugs, entirely independent of chemical operations.

Often founded as branches of chemical/dyestuff companies, many of the current industry leaders becane actively involved in drug research and manufacturing in the 1940s: Bayer and Hoechst from Germany, UKbased Glaxo, Beecham, and the Wellcome Foundation, the Swiss companies Roche and Ciba Geigy, and Pfizer, Eli Lilly, Merck, and Abbott Laboratories from the US. With a significant delay, the first Asian companies (e.g., Takeda and Yamanouchi from Japan) entered the industry in the second half of the 1960s. Based on technology imported from the US, these firms started with the production of antibiotics, including penicillin.

In the following years, the search for drugs quickly intensified, which led to an increasing number of new drugs emanating from tight networks of academia-industry cooperation (see also PhRMA, 2001; Taggart, 1993). In 1943, Rutgers University microbiologist Selman Waksman discovered the anti-tuberculosis agent streptomycin, which was ultimately developed by a pharmaceutical company. This was followed by the introduction of a wide variety of important new drugs, beginning with Chloramphenicol, the first broad-spectrum antibiotic, in 1947; Methotrexate, an early therapen- 
tic agent against cancer, in 1948; and, during the first half of the 1950s, the development of Chlorpromazine, a breakthrough drug for psychosis, Isoniazid, a treatment for tuberculosis, and mary more, all patented, drugs (see also table 2.1). Thus, within a relatively short period of time, the modern phamaceutical industry had emerged as an R\&D-intensive industry that is heavily dependent on continuing flows of new drugs, close cooperation with scientists, and strong patent protection.

\subsection{Major trends in science, technology, and drug discovery}

Before the emergence of biotechnology, the pharmaceutical industry had already experienced a series of decisive technological changes, each of which forced established companies to develop new skills and capabilities in R\&D (see also table 2.1). In each of these technological shifts, applied research and commercialisation were typically concentrated in a few large, wellfinanced pharmaceutical companies. Innovation at these firms was linked to tight networks of relations with universities and other science-based institutions (Cockburn and Henderson, 2000; Freeman, 1990; Galambos and Sturchio, 1998).

With significant advances in synthetic organic chemistry, the discovery of new drugs began as a chemical science, focusing on chemical structures. and related activity. In the days following the Second World War, little was known about the biological processes of disease and drug interactions; at best, drug development was a trial-and-error effort, based on the mass screening of chemical compounds (Pisano, 1994; Schwartzman, 1976). The fermentation skills of the antibiotic companies in the $1940 \mathrm{~s}$ and $1950 \mathrm{~s}$ prom vided an alternative knowledge base for some firms, primarily located in the US.

In the 1970s, a major shift from trial-and-error techniques occurred when a series of breakthroughs in the biological sciences (i.e., biology, biochemistry, and pharmacology) provided the basis for a new, much more 
concentrated, style of $R \& D$, based on increased knowledge of how the human body functions. Rational drug design enabled scientists to develop drugs that interact with a particular disease. The increased knowledge of biological processes, however, ultimately led to a much more radical technological shift in the 1980 s with the emergence of biotechnology as an alternative to organic chemistry as the general knowledge base for drug research (Achilladelis and Antonakis, 2001; Della Valle and Gambardella, 1993; Galambos and Sturchio, 1998; OTA, 1991; Zucker and Darby, 1997).

\subsubsection{Random (mass) screening}

In the 1950s and 1960s, research skills in mass screening drawn from the organic chemistry of the dye tracles typically dominated the search for new drugs. These skills comprise the random screening of chemical compounds, both natural and synthetic ones, for potential therapeutic activity. Around 10,000 chemicals and compounds are screened every year, only a few of which will ultimately be brought to market (Warden, 1979). Despite these poor odds of commercial success and the high costs involved with maintaining huge libraries of chemical compounds, this traditional approach to discovering new drugs has provided the industry with many path-breaking new drugs (OTA, 1991).

Penicillin, for example, was developed from penicillium mold and other powerful antibiotics, including streptomycin and bacitracin, were found by extracting chemicals from natural products and screening them for clinical reactions (Achilladelis and Antonakis, 2001; Mann, 1984; OTA, 1991). Aspirin (acetylsalicylate) was found by screening compounds chemically similar to salicylate, a conventional treatment for pain. Testing chemical modifications of salicylate is an carly example of the research strategy that pharmaceutical companies were following for many years. This particular strategy used to be based on information about certain clinical effects of known chemicals that companies retrieved by chance, however, it involved little knowledge of how the drugs actually worked (OTA, 1993). In recent 
years, this traditional chemical route toward innovation has become increasingly costly and provides fewer drugs (Grabowski and Vemon, 1994; Pisano and Wheelwright, 1995; Walker and Walker, 1986).

\subsubsection{Rational drug design}

The traditional chemical approach to drug discovery was certainly not an "irrational" endeavour, however, the rationale behind this research strategy was not grounded in knowledge of biochemistry. The extraction and screening of natural chemicals for antibiotics, for example, followed a reasonable strategy, but did not rest on knowledge of the actual workings of the drugs. As scientists increasingly shifted their focus toward chronic diseases such as cancer and various types of neurological illnesses, finding new drugs became more and more dependent on information about the development process of particular conditions (Della Valle and Gambardella, 1993; OTA, 1993).

Rational drug design has been made possible by the increase in information about cellular mechanisms and control, which is necessary for the development of new drugs to attack chronic diseases. In essence, rational drug design reversed the traditional approach to drug discovery by working backward from a known chemical entity. Rather than screening chemicals and compounds for certain clinical effects, the molecular mechanism underlying these effects is used to guide a specific drug research strategy. Since the 1970 s, random screening has thus been increasingly angmented by significant advances in the biological sciences, which have enabled scientists to use a more mechanistic approach to drug design (OTA, 1991 and 1993; Schwartzman, 1976; Zucker and Darby, 1997).

\subsubsection{Biotechnological revolution}

Rational drug design allowed for more targeted drug research, based on an increased body of knowledge of the disease process. However, increased 
knowledge of biochemistry and molecular biology eventually led to another, partially overlapping, but much more radical technological shift in the 1980s: the emergence of biotechnology. It was particularly triggered by two key scientific successes in the first half of the 1970s. The first one was the discovery in 1973 by Herbert Boyer and Stanley Cohen, two scientists at the University of California and Stanford University respectively, that deoxyribonucleic acid (DNA) could be cut, recombined, and inserted into a foreign bacterium that would then express a new gene (see table 2.1). Particularly, they inserted pieces of frog DNA into the genes of the bacterium E. coli, which started to produce protieins encoded by the foreign DNA. Also, even more miraculously, its offspring exhibited the same production capacity as the modified bacterium (Barley et al., 1992; Cohen, Chang, Boyer, and Helling, 1973). Scientists immediately recognized the enormous potential of the technique now known as recombinant DNA or rDNA: it provides researchers with the means to use plants, animals, and cells as cheap production facilities for large quantities of particular, desired proteins.

The second important discovery occurred two years later, in 1975, when Cesar Milstein and Georges Kohler of the British Laboratory of Molecular Biology, Cambridge, UK succeeded in fusing cells from a mouse myeloma with cells retrieved from mouse B-lymphocytes to create a hybridoma (see also table 2.1). Hybridomas can be defined as self-replicating cell lines that produce antibodies (i.e., stronger, more resistant cells) and can be grown in vitro or in the peritoneal cavity of a mouse. Because each hybridoma produces only one type of antibody, the antibodies were referred to as monoclonal antibodies or MABs. Hybridoma technology is a method to produce, at low cost, large quantities of specific antibodies (see also Barley et al., 1992; Fransman, 1991; McMillan, Narin, and Deeds, 2000; Orsenigo, 1989; Senker, 1998).

In most of the literature dealing with the effects of biotechnology on the pharmaceutical industry (see e.g., Galambos and Sturchio, 1998; Orsenigo, 
1989; Rothaermel, 2000; Walsh and Galimberti, 1993; Zucker and Darby, 1997), the shift to recombinant DNA technology and molecular biology is referred to as the biotechnological revolution. This is because the advent of biotechnology has transformed drug discovery in two fundamental ways. First, pharmaceutical companies make use of the knowledge base underlying biotechnology that draws on a larger number of scientific disciplines: in addition to biochemistry, now molecular biology, genetics, immunology, and various other disciplines provide the scientific foundations for biotechnology (Fransman, 1991).

Second, biotechnology has provided the pharmaceutical industry with a whole new set of research tools (Fildes, 1990; Hamilton, Villa, and Dibner, 1990). They involve the ex ante design of synthetic molecules with very specific properties, rather than the reliance on the slow and costly random screening method. Although the drug that is ultimately derived can be a synthesized chemical, its development process depends heavily on techniques from biotechnology. In this case, companies make use of the information provided by biotechnology, allowing the discovery aspect of their drug research strategy to be more specific and targeted. Consequently, biotechnology has generated significant and completely different opportunities for imnovation in the pharmaceutical industry (Orsenigo, 1989; OTA, 1991).

\subsection{Determinants of firm competitiveness}

Competitiveness and financial success of companies in the pharmaceutical industry depend to a large extent on the skills and capabilities these companies have developed in $R \& D$, regulation, and marketing (Bogner and Thomas, 1994; OTA, 1991; Reekie and Weber, 1979; Schwartzman, 1976; Taggart, 1993; Walsh and Galimberti, 1993). In recent years, however, the costs involved in carrying out these activities have increased significantly; This has led to a situation where pharmaceutical companies have to invest 
large amounts of resources in the development and maintenance of these capabilities.

\subsubsection{Research and development}

The modern pharmaceutical industry is heavily dependent on continuing flows of new drugs, which are the result of research and development. The profitability, and ultimately the survival, of pharmaceutical companies depend on the maintenance of a competitive position. In turn, the competitive position is determined by the rate of innovation. Thus, arnong the established companies in the industry, there are few recorded cases where a company has cut back on R\&D expenditure, even during periods of falling profits (Cool, Roller, and Leleux, 1999; OTA, 1991; Roberts, 1999; Taggert, 1993).

However, as the importance of innovation has increased, so have the costs of R\&D efforts (DiMasi, 1995; Fildes, 1990; OECD, 2001; OTA, 1991; PhRMA, 2002; Pisano and Wheelwright, 1995; Schwartzman, 1976; Sharp et al., 1996). In part, this is due to increasingly stringent government regulation (see section 2.4.2); in part, it is due to the new directions of innovation. Because traditional mass screening methods resulted in ever fewer drugs, companies began to explore alternative routes toward innovation, which ultimately led to the development of the high-cost, rational approach to drug discovery (Freeman, 1990; Grabowski and Vernon, 1994; Pisano and Wheelwright, 1995; Sharp, 1990). Furthermore, with growing frequency, R\&D departments of pharmaceutical companies direct their attention toward chronic diseases for which finding a cure is a lengthy and expensive process (Della Valle and Gambardella, 1993; OTA, 1993; Sharp et al., 1996). The industry's latest shift to biotechnology has also significantly added to costs in the sense that it requires a level of sophistication in research strategy and technological knowledge that is without precedent in the pharmaceutical industry. 


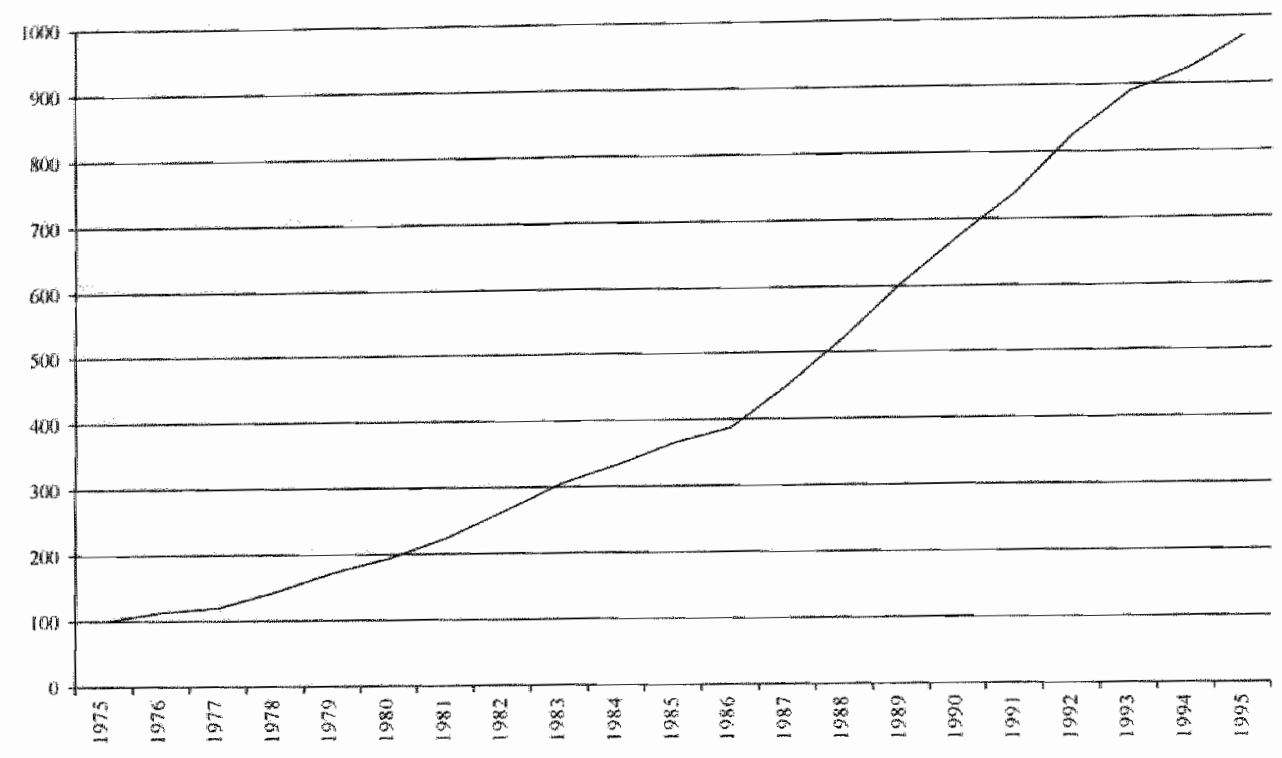

Wigure 2.1: Pharmacoutical industry R\&D expenditures, $1975-1995(1975=100)$. Source: Organization for Economic Cooperation and Development, Analytical Business Enterprise R\&D Database, Paris, April 1999

The actual growth pattern in pharmaceutical industry R\&D expenditures is presented in figure 2.1. All numbers are indexed on the base year 1975. We see a strong growth pattern in the level of R\&D spending by the pharmaceutical industry during the past two and a half decades, although most of this growth took place during the second half of the 1980 s and the first half of the 1990s. During the 1970 s and the first half of the 1980 s, the amount spent on R\&D by pharmaceutical companies followed a pattern of relatively slow growth. Particularly, the index number reached a level of around 335 in 1984, which is nearly 3.5 times higher than the number that we found for 1975 . We see a rapid acceleration of this particular growth pattern since the second half of the 1980 s. From 1985 to 1989 , the index number almost doubled to slightly over 600 in 1989. During the 1990s, R\&D expenditures continued to rise at a rapid pace, reaching an index 
Table 2.2: R\&D intensities of the world's largest pharmaceuticall companies, 1999. Souref: Financial Times FT 500 (http//ww ft.com/ft500/), 1.1 May 2001, and own calculations based on information from Worldsoope and arimual reports

\begin{tabular}{lcc}
\hline Company name & Country of origin & R\&D expenditures as \% of revenues \\
\hline 1. Pfirer & US & 17.10 \\
2. Wamer Lambert & US & 9.74 \\
3. Merck & US & 6.32 \\
4. Glaxo Wellowne & UK & 14.95 \\
5. Smithkline Beecham & UK & 12.15 \\
6. Johnson and Johnson & US & 9.46 \\
7. Novartis & Switzerland & 13.02 \\
8. Bristol Myers Squibb & US & 9.11 \\
9. Eli Lilly & US & 17.99 \\
10. Roche & Switzerland & 13.66 \\
1. Astra (1998) & Sweden & 18.65 \\
12. Zeneca (1998) & UK & 12.89 \\
13. Sohering Plough & US & 12.98 \\
\hline
\end{tabular}

number of 972 in 1995 or, compared to the base year, an amount spent on R\&D that is nearly 9 times higher than in 1975.

So far, we have presented the general trend in the level of R\&D spending by the pharmaceutical industry as a whole. In the following, we examine R\&D expenditures at a more disaggregated level, i.e., at the level of individual companies. Table 2.2 shows, for the 13 largest pharmaceutical companies, the total amount of resources spent on R\&D as a proportion of revenues. We selected these companies based on the Financial Times 500 , which provides a listing of the world's largest companies ranked by their market capitalization. Some of the largest companies that are listed in this table have recently merged to form new companies (e.g., Pfizer and Warner Lambert in 2000), other companies are the result of a merger between two firms that took place many years ago (e.g., Bristol Myers and Squibb in

\footnotetext{
Pfizer merged with Warner Lambert in 2000 to create the new company Pfizer.

Glaxo Welloome merged with Smithkline Beecham in 2000 to create Glaxosmithkins.

* Novartis is the result of at merger between Ciba Geigy and Sandoz in 1996.

${ }^{4}$ Bristol Myers Squibb is the outcome of a merger between Bristol Myers and Squibb in 1989.

"Astra merged with Zeneca in 1999 to form Astrazeneca.
} 
1989). Overall, these 13 companies allocated around 12 percent of their revenues to the search for new drugs at the end of the previous century. The individual companies' allocations vary from just over 6 percent for Merck to over 18 percent for Astra.

\subsubsection{Regulation}

As mentioned in the previous section, high costs of R\&D are partly due to increasingly strict regulation by governments. In 1962, the US government established pre-market approval requirements in an effort to alleviate increased public concerns about the safety, quality, and effectiveness of new drugs. During the 1960s, most Western countries established similar administrative procedures for new drug approval. The next three decades saw these procedures become increasingly onerous (Bogner and Thomas, 1994; OECD, 1989; PhRMA, 2001; Sharp et al., 1996). Particularly in the US, drug development is a tightly regulated process, which can take up to 12 years or more than half of the drug's effective patent life. Pharmaceutical companies spend much of the drug development time conducting expensive clinical trials required to prove the safety of the drug and waiting for Food and Drug Administration (FDA) review and approval (Barley et al., 1992; OTA, 1991).

Competitiveness and financial success of companies in the pharmaceutical industry depend on the skills and capabilities these companies have developed for coping effectively with regulatory agencies. In fact, companies that possess certain skills for dealing with regulatory agencies have a decisive advantage over competitors in high-cost, intensive drug research. Particularly, these companies spend significantly less time in the approval process, develop and market higher numbers of new drugs, and accumulate substantially larger amounts of resources for future research (Bogner and Thomas, 1994). 


\subsubsection{Marketing}

Skills in complying with drug-approval processes have become an important source of competitive advantage since the 1960s. Another growing source of advantage is the ability of companies to successfully market their drugs to physicians (see Barley et al., 1992; Bogner and Thomas, 1994; Della Valle and Gambardella, 1993; Hakansson, Kjellberg, and Lundgren, 1993; OTA, 1991; Taggart, 1993). Pharmaceuticals marketing differs from almost all other consumer goods in that the buying decision is not made by the final consumer: the drug is prescribed by the physician and paid for by the patient, with the state making a varying contribution to the cost of treatment. In addition, pharmaceutical companies may advertise their drugs only to physicians (Barley et al., 1992; Bogner and Thomas, 1994; OTA, 1991; Taggart, 1993). Before the 1950s, direct marketing to physicians did not exist. However, the creation of "prescription-only" drugs in the 1940s, along with the increased flow of new, synthetic antibiotics, brought about the need to develop skills for influencing the physician (Temin, 1990).

The most effective way in which a pharmaceutical company may influence the prescribing behaviour of physicians is through regular office visits by sales representatives. These sales representatives must be highly knowledgeable about diseases and their treatment, and about the side effects involved in using the company's drugs (OTA, 1991; Taggart, 1993). Furthermore, they need to be educated about such issues as medical culture, distribution, pricing, regulation, and so on, where foreign markets may differ substantially from domestic markets (Layman, 1988). The training cost of such a sales representative is extremely high as it takes up to a full year before a new employee becomes fully effective (Taggart, 1993). Thus, since the 1950s, established pharmaceutical companies have allocated large amounts of resources to building up specialized sales forces directed at physicians, which fit into the medical cultures of the various countries in which they sell. 


\subsection{Biotechnological revolution and the survival of established companies}

The biotechnological revolution is an outstanding example of the type of radical technological shift that is most likely to result in the replacement of previously dominant innovators by new entrants that have faster access to the new knowledge base. Indeed, the knowledge base underlying biotechnology draws on a completely new set of scientific disciplines (Fransman, 1991). Furthermore, the technology has enabled scientists to design molecules with very specific properties while the research strategy that pharmaceutical companies were following in the 1970 s and 1980 s involved the nearly random screening of molecules to discover ones that were effective (Fildes, 1990; Hamilton et al., 1990).

Unquestionably, large, established pharmaceutical companies were slow to respond to the discovery of biotechnology. Well after recombinant DNA technology and hybridoma technology first became possible in the 1970s, established companies continued to build on their existing knowledge base that was largely corresponding to the old technologies they had developed. Because older technologies were still producing high returns on investment, established companies were unwilling to reallocate their resources to the new technology (Barley et al., 1992; Galambos and Sturchio, 1998; Saviotti, 1998; Walsh and Galimberti, 1993; Zucker and Darby, 1996 and 1997). Their preoccupation with older technologies thus prevented these companies from building up a new knowledge base in recombinant DNA technology and molecular biology. In other words, the accumulated knowledge base of established pharmaceutical companies formed a major barrier to the absorption of biotechnology (see Cohen and Levinthal, 1989 and 1990).

By not taking advantage of the important discovery of biotechnology, existing companies left the window of opportunity open for new entrants. In the US and the UK, a large number of new biotechnology firms were set up 
to exploit commercial opportunities following the scientific breakthroughs of the 1970s (Grabowsky and Vernon, 1994; Kenney, 1986; Oakey, 1990; Orsenigo, 1989; Pisano, 1990; Sapienza, 1989; Senker and Sharp, 1997). These companies were set up with the aim of producing new drugs for sale to final consumers, however, many of them failed to do so. The main difficulties facing new firms were a shortage of finance and a lack of the complementary assets (Teece, 1986) required to successfully commercialise biotechnology (Barley et al., 1992; Deeds and Hill, 1996; Greis, Dibner, and Bean, 1995; Walsh and Galimberti, 1993).

Thus, entry of new firms did not replace the important role played by existing companies. In fact, established companies turned out to possess a unique set of complementary assets in R\&D and marketing that were not made redundant by the discovery of biotechnology, but that continued to form the basis of innovation in the pharmaceutical industry (Rothaermel, 2000 and 2001; Saviotti, 1998). Existing companies were able to use their skills and capabilities to gain access to the new knowledge base through numerous inter-firm partnerships with the new firms (Arora and Gambardella, 1990; Barley et al., 1992; Hagedoorn, 1996a; Hagedoorn and Schakenraad, 1990 and 1992; Pisano and Wheelwright, 1995; Powell, 1996 and 1998). This suggests that many pharmaceutical companies ultimately followed a strategy of change, incorporating the new technology into their existing knowledge base rather than pursuing under-investment and incompetence as responses to a radical technological shift.

In section 2.5.1, we will describe in some more detail the strategic responses of large pharmaceutical companies to the discovery of biotechnology. This allows us to answer the first question that was posed in the introduction to this chapter: why was the technology first commercialised by new entrants rather than by existing companies that have for many decades been the dominant innovators in the pharmaceutical industry? In section 2.5.2, we will provide an answer to the second research question, 
why did new entrants not replace existing companies, by discussing the main difficulties faced by new firms entering the pharmaceutical industry.

\subsubsection{Established companies and their strategies}

When the first new biotechnology firms were beginning to appear in the 1970 s, existing companies were entering a period of strategic re-orientation. and organizational restructuring in general, as a result of decreasing returns from R\&D and the exploitation of traditional screening methods. Bayer, Hoechst, Rhone Poulenc, Ciba Geigy, Sandoz, ICI, and American Cyanamid, for example, all underwent (major or minor) restructuring from the mid-1970s to early 1980s (Achilladelis and Antonakis, 2001; Galambos and Sturchio, 1998; Walsh and Galimberti, 1993). One of the main objectives was to achieve greater economies of scale and scope. This led to a shift in R\&D toward research that would lead to higher value-added production (Achilladelis and Antonakis, 2001; Barley et al, 1992; Bogner and Thomas, 1994; OTA, 1991; Taggart, 1993). Bayer, for example, increased its investment in biological research from 30 percent of R\&D in 1970 to 57 percent of R\&D in 1988 (Walsh and Galimberti, 1993). Furthermore, it led to the establishment of small groups to carry out exploratory research across a broader range of scientific disciplines and to identify new commercial opportunities (Galambos and Sturchio, 1998; Walsh and Galimberti, 1993).

As part of this new research strategy, established companies were moving away from traditional forms of screening and synthetic organic chemistry toward the new, much more concentrated, style of R\&D in biochemistry. In an effort to apply their increased knowledge of biological processes across various types of illnesses, these companies increasingly shifted their focus toward biochemical research (Achilladelis and Antonakis, 2001; Bogner and Thomas, 1994; Galambos and Sturchio, 1998; OTA, 1991; Walsh and Galimberti, 1993). Merck, for example, launched a major biochemical research program in 1975. This program would ultimately yield 
two new drugs, enalapril maleate (a treatment for hypertension) and lovastatin (a drug to lower cholesterol levels). The pipelines at several other companies already contained a number of unusually promising drug candidates. Scientists at Smithkline and French, for example, were about to bring to conclusion more than a decade of biochemical research by producing Tagamet, which is the first H2-antagonist anti-ulcer drug. Glaxo was following a similar research strategy for the development of its own ulcer treatment (Zantac). Another large company (Squibb) was developing captopril, a compound to prevent increases in blood pressure, which was the result of several years of biochemical research (Galambos and Sturchio, 1998).

Thus, in the 1970s and well into the 1980s, established companies were heavily involved in large-scale, intensive biochemical research, because these research programs were providing them with many path-breaking new drugs (Barley et al, 1992; Galambos and Sturchio, 1998; Saviotti. 1998; Walsh and Galimberti, 1993; Zucker and Darby, 1996 and 1997). In fact, by the end of the 1980s, most of the world's "blockbuster" drugs had emerged from the new style of $R \& D$ in biochemistry. Many of these drugs were treatments for ulcers, hypertiension, or arthritis. Several were generating worldwide sales of around a billion US dollars each year (Galambos and Sturchio, 1998). Meanwhile, the traditional chemical approach to drug discovery also continued to provide the industry with a wide variety of important new drugs (Bogner and Thomas, 1994).

Among the exploratory activities mentioned, were investigations into biotechnology at quite an early stage (see also Achilladelis and Antonakis, 2001; Barley et al., 1992; Galambos and Sturchio, 1998; Grabowski and Vernon, 1994; Rothaermel, 2001; Senker, 1998; Zucker and Darby, 1997). Bayer, for example, maintained a small molecular biology group at its Wuppertal facilities during the 1970s. The Swiss pharmaceutical company Ciba Geigy set up molecular biology and human cell biology groups at the FMI in Basel in 1975. The company invested heavily in this independent 
research foundation in exchange for the exclusive right to commercially exploit its results. ICI set up a Bioscience Group in its Corporate Research Laboratories in 1976 (Walsh and Galimberti, 1993).

Despite these explorations in the 1970s, established companies did not make their first serious investments in biotechnology until the $1980 \mathrm{~s}$. By that time, a large number of new firms had already entered the industry (Kenney, 1986; Oakey, 1990; Orsenigo, 1989; Senker and Sharp, 1997). Rather than relying solely on in-house R\&D as a strategy to enter the new technological field, existing companies created numerous inter-firm partnerships with the new biotechnology firms (Arora and Gambardella, 1990; Barley et al., 1992; Hagedoom, 1996a; Hagedoorn and Schakenraad, 1990 and 1992; Pisano and Wheelwright, 1995; Powell, 1996 and 1998). In exchange for access to the research skills of these new firms, large companies provided their smaller partners with regulatory expertise and financial support. In fact, in 1982, pharmaceutical companies invested around 120 million US dollars in new biotechnology firms (OTA, 1984). Because there was great uncertainty among pharmaceutical executives as to which technology they should pursue, this strategy constituted a lower risk strategy than developing the necessary capabilities from scratch (see also Walsh and Galimberti, 1993).

As mentioned before, pharmaceutical companies have always complemented their in-house R\&D with external capabilities that they access through their many relations with individual scientists. However, by creating inter-firm R\&D partnerships with new biotechnology firms, companies were essentially adding a new element to their traditional networks of cooperation (Cockburn and Henderson, 2000; Freeman, 1990; Galambos and Sturchio, 1998). Indeed, although these companies have a strong tradition of cooperating in research with universities and other science-based institutions, they only had relations with other companies at a later stage of drug development, e.g., toxicity testing (Faulkner and Orsenigo, 1989).

While they aimed their initial strategies at exploring the commercial 
opportunities of biotechnology, in the second half of the 1980s, many pharmaceutical companies began to develop longer-term strategies toward the new technology (Achilladelis and Antonakis, 2001; Barley et al., 1992; Galambos and Sturchio, 1998; Walsh and Galimberti, 1993). Once these companies were able to determine which technology would be crucial to their future competitiveness, they began to develop this in-house capability. One important way of doing so quickly was to acquire a successful biotechnollogy firm, preferably a (former) partner of which they already had knowledge of its capabilities. This led to a wave of acquisitions and mergers between existing companies and new firms during the second half of the 1980s and the first half of the 1990s (OTA, 1991; Walsh and Galimberti, 1993; Senker, 1998). A well-known example of this new strategy is the acquisition of the first and largest of the biotechnology firms, Genentech, by Hoffman LaRoche in 1990 . By the micl-1990s, existing companies had established significant capabilities in their selected technologies, however, they continued to cooperate with new biotechnology firms to explore new ones.

\subsubsection{Complementary assets as barriers to entry}

With the slow reaction of large, established pharmaceutical companies to the important discovery of biotechnology, new entrants have played an extremely important role in the early diffusion of the new technology (see also Grabowsky and Vernon, 1994; Kenney, 1986; Oakey, 1990 and 1993; Orsenigo, 1989; Senker, 1998; Senker and Sharp, 1997). Despite their crucial role in applied research and commercialisation, most of these new firms were unable to produce a drug or generate any profits. In fact, of the 43 firms that were set up in the US in 1981, only six of these companies were making a profit in 1990 (OTA, 1991 and 1993). We have argued in the above that the main problems facing new biotechnology firms were a shortage of finance and a lack of the complementary assets, skills, and capabilities (Teece, 1986) necessary for successful commercialisation of the 
technological knowledge they clearly possessed (see also Barley et al., 1992; Deeds and Hill, 1996; Greis et al., 1995; Walsh and Galimberti, 1993).

To commercialise biotechnology, firms needed large networks of physicians prepared to carry out tests on the safety, quality, and effectiveness of new drugs and later to prescribe them to their patients (Barley et al., 1992; Bogner and Thomas, 1994; Della Valle and Gambardella, 1993; Hakansson et al., 1993; OTA, 1991; Taggart 1993). To educate these doctors about a completely new class of drugs and their therapeutic uses, and about the side effects involved in using these products, companies needed large enough sales forces to give adequate coverage of all doctors (OTA, 1991; Taggart, 1993). In addition, they needed well-established relationships with regulatory agencies (e.g., the FDA) in order to negotiate the necessary clinical trials and to quickly steer the new drug through the approval process (Barley et al., 1992; Bogner and Thomas, 1994; Senker, 1998; Walsh and Galimberti, 1993). These kinds of skills and capabilities, or networks of established relationships have to be built up over many years while complying with drug-approval processes also requires heavy investments in R\&D and marketing (see also Bogner and Thomas, 1994; OTA, 1991; Pisano and Wheelwright, 1995; Sharp et al., 1996; Taggart, 1993; Walsh and Galimberti, 1993).

To effectively deal with their initial difficulties, new biotechnology firms could follow one of two strategies or, in some cases, a combination of the other two strategies. The first strategy open to them was to act as a supplier of "knowledge services" such as information, consultancy, and contract R\&D, or intermediate products such as reagents, enzymes, or specialist equipment, to other pharmaceutical companies instead of selling new drugs to final consumers (Saviotti, 1998; Smith and Fleck, 1988; Walsh and Galimberti, 1993). In this role, new firms would essentially act as the external R\&D department for an existing company, either by conducting contract research or through inter-firm R\&D partnerships with existing companies (Arora and Gambardella, 1990; Barley et al., 1992; 
Hagedoorn, 1996a; Hagedoorn and Schakenraad, 1990 and 1992; Pisano and Wheelwright, 1995; Powell, 1996 and 1998). Most of the UK-based biotechnology firms (e.g., Biogen, British Biotechnology, Cambridge Antibody Technology, Celltech, and Oxford Biosciences), whose main source of continued finance was their own profits, were companies selling mainly services rather than drugs. Forty percent of these firms did contract research while services accounted for over 50 percent of revenues for 35 percent of these companies (Oakey, Faulkner, Cooper, and Walsh, 1990).

The other strategy open to new firms was to engage in inter-firm partnerships with existing companies in order to gain access to their funds and their complementary assets, sharing expertise in biotechnology in retum (Barley et al., 1992; Deeds and Hill, 1996; Greis et al., 1995; Pisano, 1991; Powell, 1996 and 1998). These inter-firm partnerships constituted an important element in the initial strategies of the companies dealing with the commercialisation of biotechnology. Indeed, even the most successful of the new biotechnology firms (e.g., Amgen, Biogen, Cetus, Celltech, Chiron, and a few others) only succeeded in marketing new drugs as a result of various sorts of inter-firm partnerships with large, established pharmaceutical companies (see also Walsh and Galimberti, 1993).

\subsection{Conclusions}

The biotechnological revolution is largely based on important developments in biochemistry, molecular biology, and genetics, which constitute a radical departure from the knowledge base previously used by pharmaceutical companies (Achilladelis and Antonakis, 2001; Fransman, 1991; Galambos and Sturchio, 1998; Orsenigo, 1989; OTA, 1991; Rothaermel, 2000; Zucker and Darby, 1997). Although large, established pharmaceutical companies have generally been among the most R\&D-intensive and innovative companies in the economy, these companies were only slowly acknowledging the important potential applications of the radically new technology in the 
1970 s and 1980s. Indeed, the moves toward mergers and acquisitions on the one hand, and the building up of a new knowledge base in molecular biology on the other, were late ones in this field. Their first move was to establish small research groups whose primary task was to carry out exploratory basic research and to identify new commercial opportunities (Galambos and Sturchio, 1998; Walsh and Galimberti, 1993). Their second move was a collaborative strategy based on numerous inter-firm R\&D partnerships with new, research-intensive biotechnology firms (Arora and Gambardella, 1990; Barley et al., 1992; Hagedoorn, 1996a; Hagedoorn and Schakenraad, 1990 and 1992; Pisano and Wheelwright, 1995; Powell, 1996 and 1998). The third stage was undertaken once some of the uncertainty had been reduced, and when companies had identified both commercial opportunities and less promising technologies (and abandoned the latter): increased in-house R\&D, mergers and acquisitions, and more traditional, close cooperation with scientists (OTA, 1991; Walsh and Galimberti, 1993; Senker, 1998).

Neither the size of the companies concerned nor the corresponding lack of flexibility in redirecting a large and bureaucratic organization can explain the pace with which established companies responded to the discovery of biotechnology. After all, the companies that responded most effectively to the opportunities for innovation provided by biochemistry in the 1970 s and 1980 s were already very large and bureaucratic. On balance, large companies such as Merck, Smithkline and French, Glaxo, and Squibb had done an excellent job of coping with that earlier shift to biochemistry (Achilladelis and Antonakis, 2001; Barley et al., 1992; Bogner and Thomas, 1994; Galambos and Sturchio, 1998; Henderson and Cockburn, 1996; OTA, 1991; Walsh and Galimberti, 1993). Furthermore, once these companies began to read and respond to important developments in biotechnology, most of them were able to establish significant capabilities in the new technology rather quickly (Zucker and Darby, 1996 and 1997). In the 1970s, however, many pharmaceutical companies carefully worked out a strategy 
of caution toward the new technology. Because older technologies (i.e., random screening and rational drug design) were still producing high returns on investment, this strategy involved a continuing focus on the old technologies they had established (Bogner and Thomas, 1994; Galambos and Sturchio, 1998; Saviotti, 1998; Walsh and Galimberti, 1993; Zucker and Darby, 1996 and 1997).

Existing companies' preoccupation with older technologies could have put these companies at a disadvantage in the 1970s and 1980s, when a large number of new firms were entering the pharmaceutical industry with potentially competence-destroying new technologies (Cohen and Levinthal, 1989 and 1990; Tushman and Anderson, 1986; Zucker and Darby, 1997). However, established companies were able to use their existing knowledge base to their advantage. Particularly, the accumulated skills, capabilities, and knowledge base of established companies allowed these companies to negotiate inter-firm partnerships with the new biotechnology firms, which gave them access to the new knowledge base (Arora and Gambardella, 1990; Powell, 1996 and 1998; Rothaermel, 2000 and 2001). In these partnerships, the speed with which established companies were able to build up a new knowledge base in molecular biology depended as much on their ability to absorb external technological knowledge as it depended on their in-house R\&D. In this sense, we can argue that the new entrants' skills for exploiting biotechnology were not, after all, really competence destroying (see also Rothaermel, 2000 and 2001; Saviotti, 1998). If the new technology had been a competence-destroying technology in Schumpeter's (1934) sense ("gales of creative destruction"), successful exploitation of biotechnology would have required the use of a completely new set of complementary assets, skills, and capabilities (Teece, 1986).

Because biotechnology uses the same complementary assets as those required to practice older technologies, existing companies had a significant advantage over new entrants (see also Gort and Klepper, 1982; Rosenbloom and Christensen, 1998; Rothaermel, 2000; Saviotti, 1998). The need for 
large amounts of resources, complementary assets, and regulatory expertise are factors mentioned in this chapter that serve both to determine the competitiveness of existing companies and to bar entry by new firms. Indeed, these kinds of skills and capabilities are difficult to access for new firms. To successfully compete in the pharmaceutical industry, most of these new biotechnology firms were thus more or less "forced" to cooperate with existing companies in order to gain access to their funds and their complementary assets (Barley et al., 1992; Deeds and Hill, 1996; Greis et al, 1995; Pisano, 1991; Powell, 1996 and 1998).

By the mid-1990s, a new pattern of innovation had emerged in the pharmaceutical industry where innovation was largely concentrated in dense networks of inter-firm R\&D partnerships between existing companies and new firms. Inter-firm cooperation now played a crucial role in that process and was likely to remain important for many years to come (Arora and Gambardella, 1990; Barley et al., 1992; Hagedoorn, 1996a; Powell, 1996 and 1998). Given the improved biotechnology capabilities of established companies, however, it appears that these companies will continue to dominate the search for new drugs, their development, and marketing. The skills, capabilities, and market power of established companies proved strong enough to absorb technological knowledge originating outside the industry (Rothaermel, 2000 and 2001). In the $1970 \mathrm{~s}$ and $1980 \mathrm{~s}$, these companies therefore continued to build on their existing knowledge base, imnovated in a lower risk way than most of the new firms, and ultimately incorporated the new technology into their accumulated knowledge base. This suggests that the largest pharmaceutical companies have maintained the ability to develop and implement new strategies of change, which ensure their contimuing dominance in the rapidly changing technological environment in which they operate. 
3

TRENDS IN INTER-FIRM R\&D PARTNERING SINCE $1975^{\circ}$

\subsection{Introduction}

Until recently, R\&D was not an activity that researchers expected to see carried out in cooperation between different companies. In particular for high-tech industries, such as information technology and biotechnology, where state-of-the-art research and technological know-how are critical to competitive success, the sharing of R\&D activities by competing companies seemed a rather unusual aspect of corporate behaviour. This is probably one of the main reasons why the growth of the number of inter-firm R\&D partnerships during the 1980s and the 1990s has attracted so much attention in recent years, both in the academic literature and in the popular press.

In the present chapter, we will attempt to contribute to the understanding of inter-firm collaboration in $R \& D$ with an analysis of some basic trends and patterns in the forming of R\&D partnerships in the international pharmaceutical biotechnology industry. The biotechnology industry is one of the main examples of current industries where we find a large number of R\&D partnerships, in particular between large and small companies (Hagedoorn, 1996a; Hagedoorn and Roijakkers, 2002; Kenney, 1986; Powell, 1996). Data from the MERIT-CATI database (see appendix A) suggest that over 65 percent of all the biotechnology R\&D partnerships are related to pharmacentical biotechnology ${ }^{7}$. Because of the dominance of this par-

\footnotetext{
This chapter is based on Roijakkers, N. and Hagedoom, J. 2003. Inter-firm R\&D partnering in high technology industries - Patterns in the international biotechnology industry since 1975 . In J. Dumming and G. Boyd (eds.), Alliance capitalism and corporate management: entreprenewnal cooperation in knowledge-based economies. Cheltenham: Edward Elgar, 63-91.

7 See figure 4.1 for the distribution of newly established R\&D partmerships in writus biotechnology-based industries.
} 
ticular sub-sector in the biotechnology industry, with so few partnerships found in other biotechnology sectors, our contribution focuses on collaboration between companies in the pharmaceutical biotechnology industry.

A part from a sectoral restriction, we will also limit the analysis to those inter-firm agreements for which the transfer of technology or the creation of new technology through $R \& D$ are central to the agreement. $R \& D$ refers to the standard research and development activities that are aimed at increasing scientific or technical knowledge and the application of that knowledge to the creation of new and improved products and processes. We will confine the analysis to particular modes of partnering such as joint ventures for which common R\&D or technology sharing is a major objective, joint R\&D agreements, and minority holdings coupled with research contracts. We have chosen the period from 1975 to 1998 , because this period covers the years in which inter-firm partnering has risen rapidly, in pharmaceutical biotechnology as well as in many other fields of technology and sectors of industry (Hagedoorn, 1996a).

In section 3.2, we first present and explain the growth pattern in R\&D partnering since 1975. This is followed by a discussion of the major factors that could motivate companies to enter into various sorts of R\&D partnerships. Although the rationales for cooperation are numerous, we restrict our attention to those rationales that are important for firms in the pharmaceutical biotechnology industry (see Hagedoorn (1993) for a. more general overview of motives for R\&D partnerships). Section 3.4 is devoted to a discussion of the different organizational features of basic categories of modes of cooperation. In that section, we also pay attention to the analysis of changes in the distribution of different categories of partnerships. Next, we discuss international patterns of partnering in terms of changes in the historical distribution of domestic and international partnerships, with special reference to the Triad regions (Asia, Europe, and North America). Section 3.6 presents some conclusions. 


\subsection{Historical pattern of R\&D partnerships}

In order to assess the importance and magnitude of alliance activity, we examine the number of newly established R\&D partnerships as they appear in the CATI database. Figure 3.1 shows the growth pattern of annually, newly made R\&D partnerships in the pharmaceutical biotechnology industry for the period 1975-1998. The numbers are calculated as three-year moving averages to show the general trend in the data while correcting for yearly fluctuations.

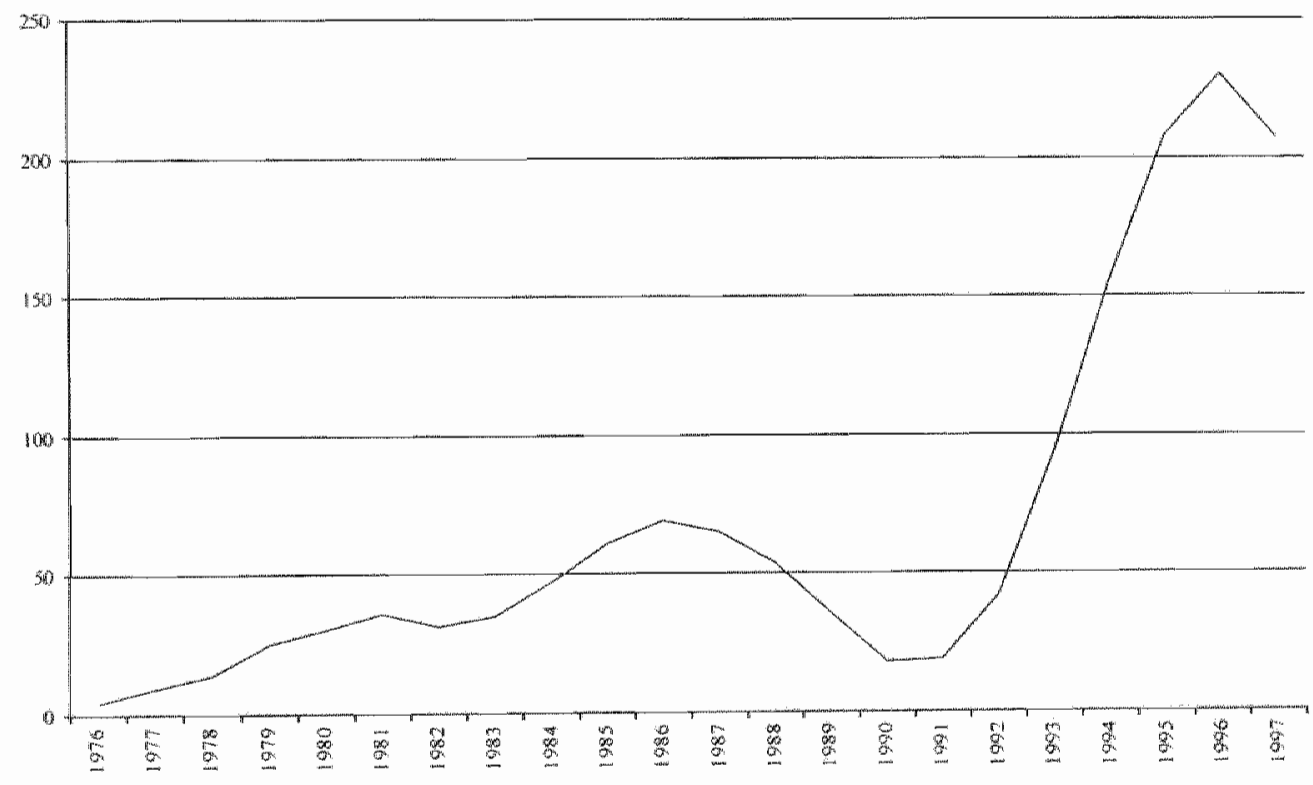

Figure 3.1: The growth of newly established R\&D partnerships, threc-ycar moving averages, $1975-1998$.

During the second half of the 1970s, there is a gradual increase of the number of newly established R\&D partnerships from fewer than 5 new partmerships in 1976 to around 15 new agreements in 1978. The end of the 1970 s witnessed a rather sudden increase in the number of new partnerships as nearly 25 alliances were established in 1979. This particular growth 
pattern is continued well into the first half of the 1980s. Apart from a small drop in 1982, those years mark a rather steep increase of the number of annually formed partnerships from about 30 in 1980 to nearly 70 new alliances made in 1986. The last couple of years of the 1980 s show a substantial drop in the newly made R\&D partmerships to slightly more than 35 alliances in 1989. During the early 1990s, the number of newly made alliances drops even further to fewer than 20 agreements in 1991, after which this number takes off again to reach a level of about 230 new partnerships in 1996. At the end of the period of our analysis, the number of annually made alliances is decreasing again to slightly over 200 new partnerships in 1997. However, this number is still considerably higher than the figures found for most years since the early 1980s.

All in all, the historical data on R\&D partnering in the pharmaceutical biotechnology industry reveal, despite some irregularities, an overall growth pattern in the number of annually made R\&D partnerships since the mid1970s. During the late 1970s, we see a rather steady growth pattern while the 1980 s and particularly the 1990s show a more accelerated growth trend with clear peaks in 1986 and 1996 as well as a significant drop in alliance activity in 1990. This particular, seemingly cyclical, growth pattern is quite identical to the pattern found for other inclustries (see Hagedoorn, 1996a).

One possible explanation for the specific pattern in the newly established R\&D partnerships, found in the CATI database, is related to the volatility of financial markets during the second half of the $1980 \mathrm{~s}$. In the first years of the $1980 \mathrm{~s}$, venture capital firms invested large amounts of financial resources in capital-intensive R\&D projects carried out by new biotechnology firms (Hakansson et al., 1993; Senker, 1996; Walsh, Niosi, and Mustar, 1995). Originally based on university research that led to major scientific and technological changes, nearly all of the new biotechnology companies were founded to commercially exploit promising new technologies such as recombinant DNA technology and hybridoma technology. For 
most, if not all, of these small firms, venture capital constituted the single largest source of funding.

After the 1987 Wall Street crash, however, venture capitalists became increasingly hesitant to provide the funds for new biotechnology firms since most of them failed to introduce new, breakthrough drugs (Barley et al., 1992; Galambos and Sturchio, 1998; Smith and Fleck, 1988; Walsh and Galimberti, 1993). The decreasing availability of venture capital during the second half of the 1980 s caused an initial shakeout in the industry with mumerous biotechnology firms filing for bankruptcy. The lower number of potential biotechnology R\&D partners available to large pharmaceutical companies may provicle a tentative explanation for the substantial decrease in the number of newly established partnerships during the final years of the 1980s. Also during these years, the major source of funding for new biotechnology firms shifted from venture capital firms to large pharmaceutical companies, which shows up in the gradual growth of newly made R\&D partnerships during the first half of the 1990s (see also Barley et al., 1992; Senker and Sharp, 1997; Smith and Fleck, 1988).

\subsection{Rationales for $\mathrm{R} \& \mathrm{D}$ partnering}

In the literature, the explanation for the overall increase of alliance activity is generally related to the motives that "force" companies to collaborate on R\&D. Major factors mentioned in that context are related to important industrial and technological changes in the 1980 s and 1990 s that have led to increased interdisciplinarity of scientific and technological developments, higher risks surrounding $\mathbb{R} \& D$, increasing costs of $R \& D$ projects, and evershortening innovation cycles that favour collaboration (see Contractor and Lorange, 1988a; Dussauge and Garrette, 1999; Hagedoorn, 1993 and 1996a; Mowery, 1988; Mytelka, 1991; Nooteboom, 1999; OECD, 1992). In this section, we restrict our attention to those rationales that are important for 
firms that are engaged in biotechnological activities, in particular large, established pharmaceutical companies and new biotechnology firms.

For large pharmaceutical companies, their motives to enter into R\&D partnerships frequently have both a cost-economizing background as well as a strategic intent (see also Eisenhardt and Schoonhoven, 1996; Hagedoom, 1993; Hagedoorn et al., 2000; Lorenzoni and Lipparini, 1999; Mowery, Oxley, and Silverman, 1998). The cost-economizing motivation appears to particularly play a role when we consider the period that covers the first years of the 1980s. Around this time, the pharmaceutical industry at large was confronted with a dramatic increase of $R \& D$ costs ${ }^{8}$ and at the same time, a declining number of new, innovative drug compounds resulting from the more traditional chemical route to innovation (Grabowski and Vernon, 1994; Pisano and Wheelwright, 1995; Walker and Walker, 1986).

As a result of these developments, large companies such as Bayer, Ciba. Geigy, and Eli Lilly were beginning to reposition themselves in an attempt to achieve greater economies of scale and scope in R\&D. One of their main goals was to carry out exploratory basic research across a broader range of new scientific and technological areas in order to identify and take advantage of the many commercial opportunities that were opening up in these fields (Galambos and Sturchio, 1998; Hagedoorn, 1995; Hamel, 1991; Walsh and Galimberti, 1993). However, even the largest, well-financed pharmaceutical companies were finding it more and more difficult to finance both basic and applied research across the entire range of relevant new opportunities. This problem induced many of these firms to seek access to external technological research and knowledge by establishing partnerships with others (Barley et al., 1992; Hagedoorn, 1993; Pisano and Wheelwright, 1995; Powell, 1996 and 1998).

During the early 1980s, pharmaceutical companies began to develop and maintain numerous formal partnerships with external sources of the new technology, i.e., small biotechnology firms, most of them US-based,

See section 2.4.1, for a description of the specific growth pattern in $\mathbb{R} \& \mathrm{D}$ costs since 1975 . 
and research universities in order to gain a window on the scientific advances in molecular biology and recombinant DNA technology (Arora and Gambardella, 1990; Barley et al., 1992; Hagedoorn and Roijakkers, 2002; Powell, 1996). In these cases, the strategic intent of $R \& D$ partnerships became more apparent. Adopting this strategy allowed these firms to keep their main R\&D activities within their own domain while jointly performing R\&D with biotechnology companies in this new, high-risk area of R\&D of which the future importance for their technological capabilities was too unclear to justify any sudden changes in the existing research strategy.

If established companies are motivated to enter partnerships mainly to lower the cost of some of their R\&D activities as well as to explore new technological opportunities beyond their current domain (Arora and Gambardella, 1990; Doz, 1988; Pisano, 1991; Shan, Walker, and Kogut, 1994), small firms in turn primarily have a cost-economizing rationale (Senker and Sharp, 1997). Although biotechnology firms developed a reputation for their R\&D capabilities and applied laboratory research in advanced biotechnology, most of them failed to develop new drugs for sale to final customers. According to Walsh and Galimberti (1993), this was mainly due to a shortage of funds, an extended development cycle, a lower level of demand than anticipated, and their inability to combine obviously novel forms of technical knowledge with knowledge of approval procedures, production, and marketing.

The instability of capital markets in the final years of the 1980 s has been an important motivating factor for small biotechnology firms to form various kinds of partnerships. In section 3.2 , we already mentioned that during the first half of the 1980 s, the initial capital requirements of USbased start-ups were primarily met by venture capital firms (Hakansson et al., 1993; Senker, 1996; Walsh et al., 1995). Between 1980 and 1983, the mosit successful biotechnology firms that were founded on the basis of academic breakthroughs, such as Genentech, were the first to go public and launch initial stock offerings (IPOs) (Barley et al., 1992). Some of these 
had disappointing results, but the stock market boom of 1983 triggered a series of initial public offerings and a period of heavy speculation in the stocks of new biotechnology firms. The strong market for initial stock offerings also stimulated many venture capital firms to provide the funding for large numbers of new start-ups, often on just the promise of a new technology. Besides recombinant DNA technology, the ability to produce, at low cost, large quantities of monoclonal antibodies triggered the founding of many entrepreneurial companies as well as a wave of enthusiasm amongst, investors.

Because development work took longer than anticipated, however, and many new biotechnology-based drugs proved to be less promising when subjected to rigorous clinical testing, even the oldest biotechnology firms were slow in introducing new, breakthrough products (Galambos and Sturchio, 1998; Smith and Fleck, 1988). Venture capital firms typically receive their financing through partnerships, which are normally based on strict contractual arrangements with respect to payback dates. The low chances of recapturing their investments within a relatively short period of time made these firms less willing to finance costly research and development and clinical trials (Barley et al., 1992). As was mentioned in section 3.2, after the stock market collapse of 1987 , investors became extremely cautious about the potential for new biotechnology-based drugs and their interest in initial public offerings began to diminish. Unable as yet to produce their own working capital, small firms were consequently experiencing increasing pressure to finance their $R \& D$ by entering into partnerships with large pharmaceutical firms (Senker and Sharp, 1997; Smith and Fleck, 1988).

As discussed in chapter 2, another problem confronting small firms was a lack of complementary skills, assets, and technologies (Teece, 1986) necessary for the successful commercial exploitation of the state-of-the-art technological knowledge they clearly possessed. Recombinant DNA technology may provide new routes to existing as well as to new drugs, but the required technological know-how must be combined with knowledge 
of the worldwide market introduction and distribution of safe and effective pharmaceutical products, among others. Such complementary forms of knowledge are possessed by large pharmaceutical companies, which in the past were the dominant imnovators in the pharmaceutical industry. In modern biotechnology, it has become common practice for small firms to share their scientific and technical expertise and/or patents in biotechnology with large pharmaceutical firms in exchange for access to the larger firms' financial resources and established organizational capabilities in clinical research, regulatory affairs, manufacturing, and marketing (Della Valle and Gambardella, 1993; Hakansson et al., 1993; Larson, 1992; Rothaermel, 2000).

\subsection{Modes of cooperation}

In the previous sections, we have discussed $R \& D$ partnerships in general terms. However, it has to be stressed that in the pharmaceutical biotechnology industry, R\&D partnering takes place through a specific number of organizational modes. In this section, we distinguish between a group of equity-based partnerships, such as joint ventures and minority holdings, and a group of contractual agreements, such as joint R\&D agreements and R\&D contracts. As these modes of cooperation will feature so prominently in the following analysis, we will briefly discuss these modes somewhat further.

Joint ventures are probably the oldest and most well-known form of inter-firm partnering (Berg, Duncan, and Friedman, 1982; Hladik, 1985). Traditionally, this mode of cooperation accounted for the majority of partnerships in many sectors of industry. In a joint venture, two or more separate parent companies agree to combine their resources and skills in a distinct organizational unit or "company" that is characterized by shared equity ownership. In the context of R\&D partnering, joint ventures have shared R\&D as a specific company objective as well as production, mar- 
keting, sales, etc. From this brief description of joint ventures, it is obvious that equity participation is used in an attempt to lower transaction costs between the parent companies. Because equity participation creates a relatively high degree of organizational interdependence among the participating companies, the chances of cheating on other partners can be reduced to a large extent. If one partner does not behave in a responsible way, then the whole venture suffers and equity diminishes for all parent companies (Buckley and Casson, 1988).

Minority holdings are another type of equity-based partnerships where one company obtains a rather small interest (substantially less than 50 percent) in another. In the pharmaceutical biotechnology industry, minority holdings are often coupled with technology exchange agreements. Particularly, large pharmaceutical companies are well known to invest in small biotechnology companies in order to explore a promising new field of technology without investing the full amount of resources that would be needed for internal development. If the technology of the small firm becomes more important to the pharmaceutical firm, a takeover can be considered.

During the past decades, a number of contractual forms of $R \& D$ partnering, in particular joint R\&D agreements, have become an alternative to equity-based partnerships. We understand joint R\&D agreements to cover technology and R\&D sharing by two or more companies through the joint undertaking of research and development projects with shared resources. Research contracts are examples of non-equity partnerships that regulate R\&D partnering in which one company, usually a large one, contracts another, frequently small, company, to perform particular research projects. Non-equity agreements are used extensively by large pharmaceutical companies in the pharmaceutical biotechnology industry in order to raise their ability to switch from research in one technology to another (Barley et al., 1992; Obleros and MacDonald, 1988).

Recent studies have established that non-equity, contractual forms of 
R\&D partnerships, such as joint R\&D agreements and research contracts, have become very important modes of inter-firm collaboration as their numbers and share in the total of partnerships has far exceeded that of equity-based partnerships (Hagedoorn, 1996a; Hagedoorn and Narula, 1996). Whereas equity agreements are often established in order to raise mutual dependence, an increasing number of companies prefer a more flexible relationship with other companies. Especially in high-tech industries such as pharmaceutical biotechnology that are characterized by the increasing complexity of technologies, rapid technological changes, and the increasing costs of $R \& D$, even the largest firms are no longer able to monitor all the technological developments that are important for their core markets. Cooperation through more flexible types of agreements enables these firms to monitor several technological developments, and at the same time, let them concentrate on a few, most promising, projects internally (Harrigan, 1985 and 1988). If certain technologies turn out to be less successful, contractual arrangements can be terminated relatively easily with only a small financial loss.

Figure 3.2 shows the gradual increase in the relative importance of contractual arrangements compared to equity-sharing partnerships, which is in congruence with previous contributions. All numbers are calculated as three-year moving averages and expressed as percentages of the total number of annually, newly established R\&D partnerships. During the late 1970 s, when there were only a small number of R\&D partnerships, approximately 60 percent of the newly made partnerships in the pharmaceutical biotechnology industry were equity-based agreements. The majority of these equity-sharing partnerships are of the minority holding type. Less than 20 percent of all the R\&D partnerships, as found in the CATI databank, are R\&D joint ventures. Since the 1980s, the share of contractual arrangements has increased from about 60 percent during most of the eighties to approximately 85 percent in the nineties. In general, companies seem to prefer joint R\&D agreements to R\&D contracts. However, the number of 


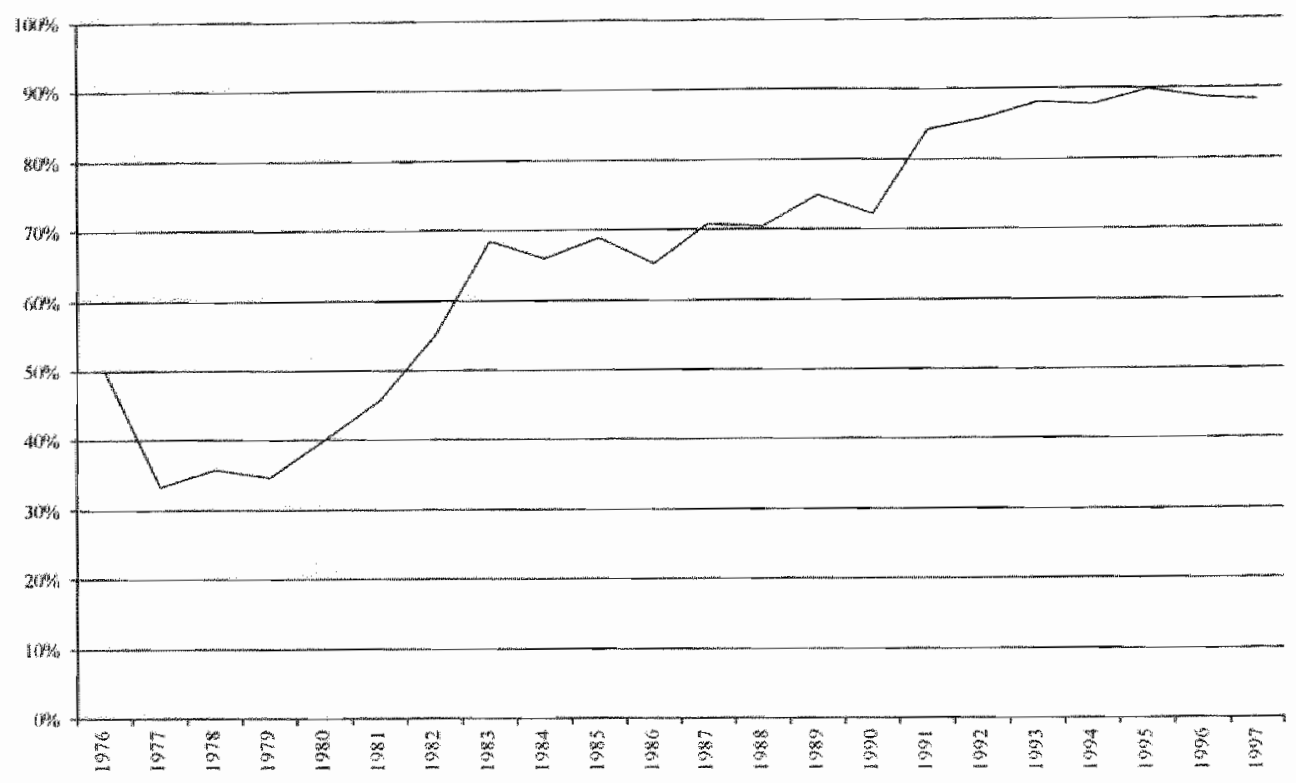

Figure 3.2: The share (\%) of contractual modes in all newly established R\&D partnerships, three-year moving averages, $1975-1998$.

yearly established R\&D contracts, found in the CATI database, indicates an increasing popularity of this mode of partnering in recent years.

So far, we have presented a general overview of major trends in R\&D partnerships in the pharmaceutical biotechnology industry since 1975, examining both growth data and the distribution according to major organizational characteristics of these partnerships. These overall trends in inter-firm R\&D partnering indicate the following:

- By and large, companies seem to increasingly prefer contractual partnerships to equity-based arrangements.

- The growth of annually, newly made R\&D partnerships in the pharmaceutical biotechnology industry since the early 1980 s is primarily caused by an increase in the number of contractual agreements such as joint R\&D agreements. 


\subsection{International patterns in R\&D partnerships}

A considerable number of scholars in business as well as in economics have paid attention to the "globalisation" of the world economy (see e.g., Bartlett, Doz, and Hedlund, 1990; Cantwell, 1991; Dunning, 1988 and 1993; Hirschey and Caves, 1981; Pearce, 1989; Reich, 1990 and 1991; Vernon, 1966 and 1979). Globalisation is an important and critical feature of today's high-tech industries such as pharmaceutical biotechnology where increased international competition between companies forces them to pursue international strategies. Through these international strategies, companies seek not only foreign market entry, but they also seek foreign assets (both of a tangible and an intangible nature), and build international inter-firm partnerships for international sourcing of $R \& D$, production, and supply. Mary authors (Contractor and Lorange, 1988a; Dunning, 1993; Duysters and Hagedoorn, 1996a; Ohmae, 1990; Yoshino and Rangan, 1995) have stressed the critical role that inter-firm R\&D partnering plays in the internationalisation strategies of a growing number of companies. Consequently, one could expect that the share of international R\&D partnerships in the total number of R\&D partnerships should have increased during the past two and a half decades.

In this section, we will see to what extent inter-firm pharmaceutical biotechnology R\&D partnerships have become more internationalised. We will pay special attention to partnerships made between companjes from Asia (Japan and South Korea), Europe (the EU and EFTA countries), and North America (US and Canada). Previous work by Freeman and Hagedoorn (1994) and Ohmae (1985 and 1990), already revealed that the majority of R\&D partnerships are made between companies from within the Triad regions (Japan, Europe, and North America). South Korea is mentioned by Freeman and Hagedoorn (1994) and Duysters and Hagedoom (2000) as a recent "player" of some importance. In the following, R\&D partnerships between companies from Asia, Europe, and North America 
are considered as intemational alliances, i.e., inter-Triadic partnerships. Intra-European partnerships are seen as regional or domestic partnerships, as are partnerships made within either Asia or North America. All other combinations outside the Triad regions are treated as a miscellaneous category.

Figure 3.3 demonstrates that a large share of the sample of pharmacentical biotechnology R\&D partnerships is of an intra-regional or domestic nature during the second half of the 1970 s as well as the 1980s. However, this share has declined over the past decades, from an average of about 55 percent for most of the 1980s to somewhat higher than 45 percent during the 1990s. For most of the 1990s, the share of international, inter-Triadic, partnerships has been higher than the domestic and regional alliances. During the final years of the 1990s, the share of domestic alliances has risen again relative to international partnerships. Also, during the most recent years, we see a growth of the share of other combinations to a still relatively small share of around 2 percent.

So far, we have described the general pattern in international pharmaceutical biotechnology R\&D partnering. In the following, we examine the role played by the different international economic and trading blocks at a more disaggregated level (see figure 3.4 ). If one looks at the overall pattern in R\&D partnering during the past two and a half decades, it becomes clear that companies from the Triad participate in over 98 percent of all R\&D partnerships. North America clearly dominates R\&D partnering in the pharmaceutical biotechnology industry. Over 70 percent of the R\&D partnerships, as found in CATI, for the past two and a half decades have at least one North American partner. During the 1970s and 1980s, the share of partnerships involving at least one North American partner gradwally eroded from around 82 percent in the second half of the $1970 \mathrm{~s}$ to less than 75 percent in the final years of the $1980 \mathrm{~s}$. This share increased again to more than 85 percent during the 1990s. Partnerships within North America (of which the majority share stands for intra-US R\&D partner- 


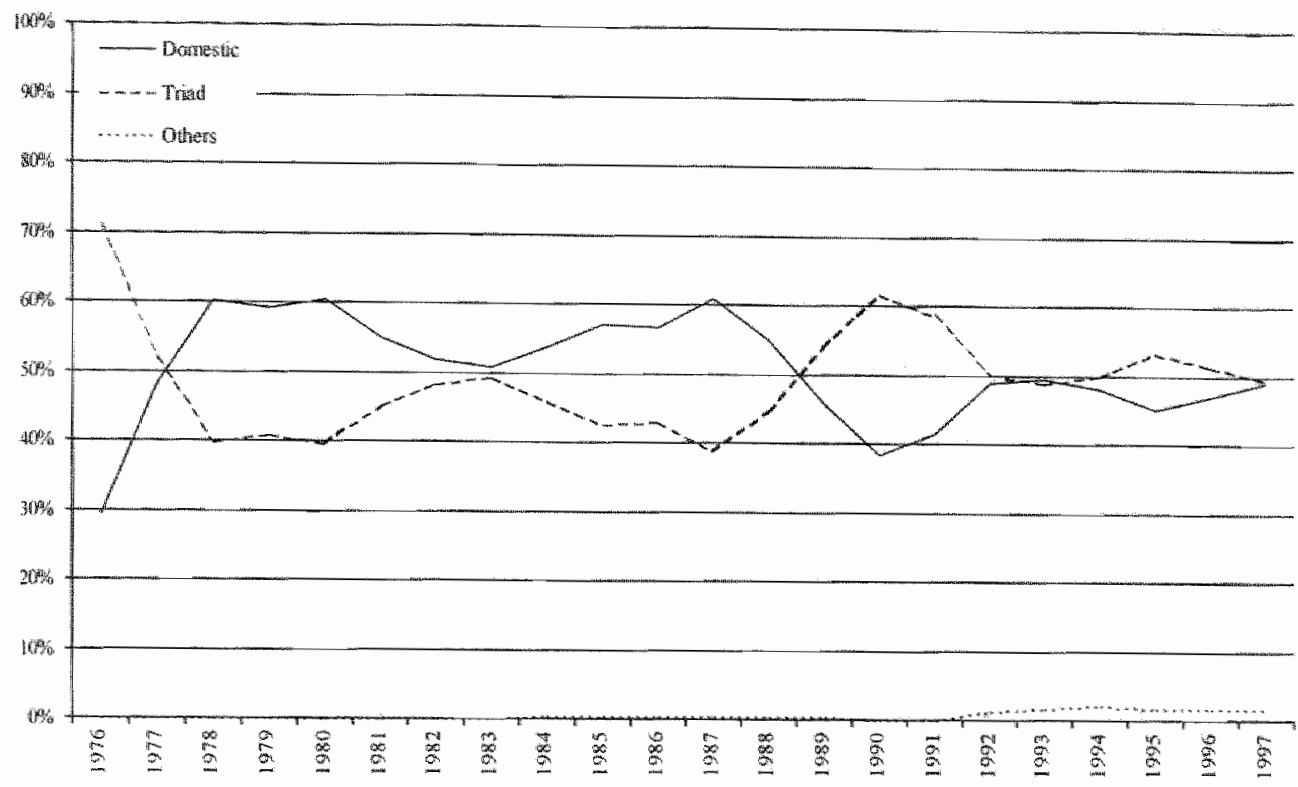

Figure 3.3: Share (\%) of international and domestic (regional) partnerships in newly established R\&D partnerships, three-year moving averages, 1975 - 1998.

ing; US-Canadian partnerships and intra-Canadian partnerships account, for less than 4 percent) account for around 40 percent of all the R\&D partnerships in all periods.

During the second half of the 1970 s, more than 37 percent of the interfirm R\&D partnerships were made between European and North American companies. This share reached a level of less than 26 percent during the 1980s, after which it increased again to over 39 percent in the $1990 \mathrm{~s}$. These shares are substantially higher than the shares found for intra-European R\&D partnerships in identical periods. The share of intra-European partnerships dropped from slightly over 11 percent in the 1970 s to around 10 percent in the early 1980s. The second half of the 1980s marks a sudden increase in the share of intra-European partnerships to nearly 16 percent. During the 1990 s, less than 10 percent of all R\&D partnerships were made between two or more European firms. 

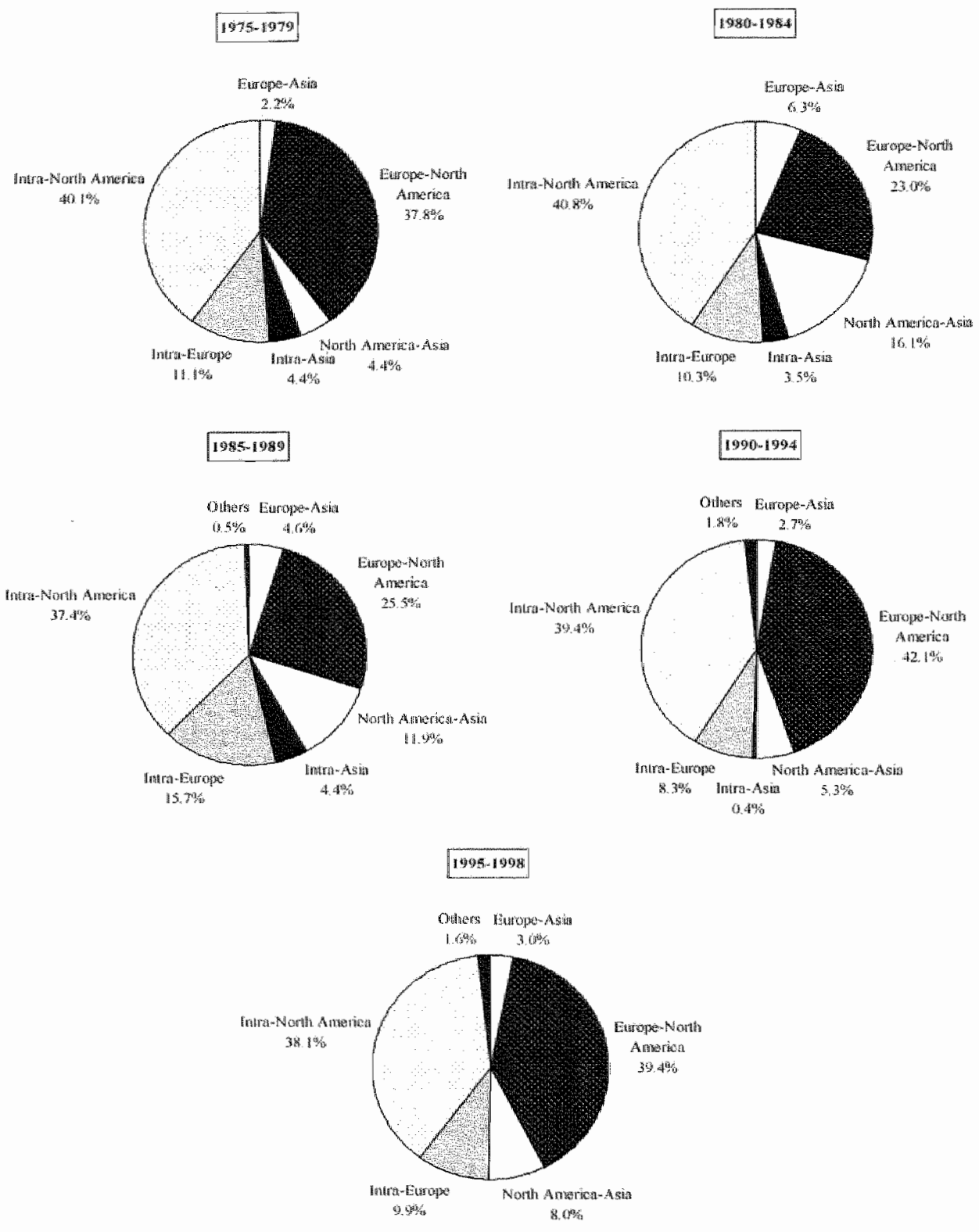

Figure 3.4: Intermational distribution of R\&D partnerships, 1975-1998. 
North American-Asian R\&D partnering has gradually grown from about 4 percent during the 1970 s to about 16 percent during the first half of the 1980s. This share eroded to slightly less than 12 percent in the late 1980 s and to only 5 percent in the first years of the 1990s. The share of R\&D partnerships made between companies from North America and Asia reached 8 percent during the most recent years. Intra-Asian or intraJapanese R\&D partnerships and partnerships between Europe and Asia remain at a relatively low level of less than 7 percent during the last two and a half decades.

Further analysis of this data (detailed figures are not shown here), reveals some striking developments in the overall distribution of R\&D partnerships at the level of countries. First of all, Swiss firms and companies from the UK and Germany play an important role in Europe-US R\&D partnering in all periods considered. The overall dominance of R\&D partnering between Europe and the US by UK firms is a development that dates back to the late 1980s. During the 1970s, less than 5 percent of these alliances were made between UK-based companies and US companies and in the first half of the $1980 \mathrm{~s}$, partnerships between firms from the UK and US companies accounted for even less than 3 percent of all partnerships. However, the second half of the 1980s marks a sudden increase in the share of UK-US partnerships to over 7 percent. This increase continues well into the 1990s and ultimately reaches a level of more than 11 percent. During the last two and a half decades, we also observe R\&D partnerships between US companies and companies from France, Sweden, and the Netherlands, although these shares remain relatively low.

Second, while UK-based firms and companies from Switzerland and Germany have dominated Europe-US R\&D partnering in the pharmaceutical biotechnology industry during the past decades, these firms have also played an important role in inter-firm partnering between two or more European companies. Particularly, during the 1980 s and the 1990s, 23 percent of these partnerships were established within the UK. A few 
other important country dyads: Switzerland-Germany, UK-Sweden, and Germany-France.

Third, Japan-US partnerships represent the largest share of all AsiaNorth America pharmaceutical biotechnology R\&D partnering during the 1970 s, the $1980 \mathrm{~s}$ as well as the 1990s. During the $1980 \mathrm{~s}$ and the 1990s, South Korea appears as a relatively important partner to the US besides Japarl.

Fourth, if we take a closer look at the pattern in $R \& D$ partnering between companies from Asia and Europe, it becomes clear that companies from Japan, Switzerland, and the UK participated in the majority of these alliances during the late 1970 s and the 1980s. During the 1990s, Japan-UK partnerships as well as Japan-Germany partnering, and to a lesser extent partnerships between Japanese firms and French companies have dominated R\&D partnering between Asia and Europe. Besides Japan, South Korea appears as an important partner for French companies.

\subsection{Conclusions}

The increasing costs of $R \& D$ projects, the need to search for alternative routes to pharmaceutical innovation, the speed of developments in major scientific areas such as molecular biology and recombinant DNA technology, and the high risks surrounding pharmaceutical biotechnology R\&D describe much of the strategic and cost-related factors that have motivated large pharmaceutical companies to enter into various sorts of R\&D partnerships. Major aspects of the partnering behaviour of small biotechnology firms can be found in attempts to obtain access to skills, assets, and technologies that would complement their state-of-the-art R\&D capabilities and a shortage of venture capital. As all these phenomena have become critical in the current process of inter-firm competition in the combined pharmaceutical and biotechnology industry, it is no surprise that the 
absolute number of R\&D partnerships has increased dramatically during the past decades.

This growth is, to a very large degree, caused by the number of contractual agreements, i.e., joint R\&D agreements and R\&D contracts. Equitysharing agreements (i.e., minority holdings), once the most prominent form of inter-firm R\&D partnering, have largely been replaced by contractual arrangements as about 85 percent of the recently established partnerships are of a contractual nature. This development suggests that partnering in the pharmaceutical biotechnology industry demands organizational flexibility with the actual form of the partnership fitted to the strategic needs of the companies that are involved. In this industry where factors such as the increasing interdisciplinarity of technological fields ${ }^{9}$, rapid scientific advances, and the high costs of R\&D projects significantly affect inter-firm competition, companies strive to increase their organizational flexibility by engaging in numerous short-term R\&D projects with multiple partners.

As demonstrated in section 3.5, the increase of alliances in the pharmacentical biotechnology industry has also led to a larger number of international or inter-Triadic partnerships. In relative terms, the growth of these international partnerships has superseded the increase in the number of domestic partnerships or alliances in the same economic region. An explanation for this specific pattern can be found in the foreign sources of biotechnological know-how that companies seek through international R\&D partnerships. In that context, the dominance of North America, particularly the US, reflects the important role that this continent plays as a major source of R\&D resources and capabilities in pharmaceutical biotechnology. This dominance has not only led companies from other countries, particularly the UK, Switzerland, and Germany, to actively search for R\&D partnerships with North American companies, the North American dominance of technological development in the pharmaceutical biotechnology

\footnotetext{
9 An example would be the rapidy expanding field of bioinfomatics (Fransman, 1991). As the name suggests, this is the use of information technology in the screening and identification of DNA.
} 
industry has led to a situation where a large percentage of $R \& D$ partnerships are formed between companies within the US. 


\section{SMALL ENTREPRENEURIAL FIRMS AND LARGE COMPANIES IN INTER-FIRM R\&D NETWORKS ${ }^{10}$}

\subsection{Introduction}

This chapter studies the role played by small entrepreneurial firms and large companies in the international pharmaceutical biotechnology industry. The pharmaceutical biotechnology industry is one of the main examples of current industries that are characterised by "hyper-competition" (D'Aveni, 1994) with a high degree of uncertainty about the combined effects of both new technologies and new market structures. It is an example of an industry with Schumpeterian competition where revolutionary changes in technology and innovative, new products and processes have the potential to threaten the position of existing market-leaders and their product-market positions (Porter Liebeskind, Lumerman Oliver, Zucker, and Brewer, 1996). It is also a sector where we find a large number of R\&D partnerships, in particular between large and small companies (Hagedoorn, 1996a; Kenney, 1986; Powell, 1996).

Throughout this chapter, we will refer to the pharmaceutical biotechnology "industry" although, given the above-mentioned characteristics, this is probably an incorrect term as its status as a separate industrial sector is still somewhat unciear. Strictly taken, pharmaceutical biotechnology is not yet a regular industrial sector, but a hybrid form of an "industry" with established companies, i.e., from the pharmaceutical sector, and a wide

wh This chapter is based on Hagedoorn, J. and Roijakkers, N. 2002. Small entrepteneurial firm and large companies in inter-firm R\&D networks - The international biotechnology industry. In M. Hiti, D. Freland, M. Camp, and D. Sexton (eds.), Strategro entreprenewrship: creating a new mindset. London: Blackwell, 223-252. Furthermore, the chapter was selected for inclusion in the Best Paper Proceedings of the High Technology Small Firms Conference, which was laeld at Manchester Business School, Manchester, UK, from 31 May until 1 Thne 2001. 
range of new biotechnology companies that are science based and technology driven, but still with relatively few regular products and limited manufacturing capabilities (Powell et al., 1996). In other words, when we use the term industry in this chapter, we recognise that we are mainly analysing a group of companies that are engaged in $R \& D$, innovation, and the manufacturing of products and processes that can be labelled as biotechnological activities.

This chapter concentrates on the analysis of inter-firm networks of R\&D partnerships and the role played by different groups of companies. This analysis of the role of different groups of companies and the structure of networks in the pharmaceutical biotechnology industry follows the suggestion made by Hitt and Ireland (2000) and Shan et aI. (1994) that the study of network structures and the role played by different groups of companies is of eminent importance to understanding emerging sectors such as the pharmaceutical biotechnology industry. Within these networks, we will pay special attention to the role of small entrepreneurial firms that are known to play such an important role in this industry (Kenney, 1986; Powell et al., 1996).

We have chosen the period from 1985 to 1995 , because this period is expected to encompass the end of the first period of the growth of the pharmaceutical biotechnology industry with the emergence of a large number of small biotechnology companies during the 1980s and a first phase of some maturation where the commercialisation of biotechnology is becoming more important (Arora and Gambardella, 1990; Galambos and Sturchio, 1998). This period also covers the years in which inter-firm partnering has risen rapidly, in this sector as well as in many other fields of technology and sectors of industry (Hagedoorn, 1996a).

In section 4.2 , we will first discuss the different roles that large companies and small entrepreneurial firms play in generating innovative output and major technological changes. The perspective that is chosen in this chapter is clearly influenced by the Schumpeterian tradition in the study 
of innovation. In sections 4.3 and 4.4 , we also pay attention to the complementarities of large and small firms in the networks of R\&D partnerships that have become so important in the pharmaceutical biotechnology industry. These sections lead us to a set of three research questions that will guide the empirical analysis of this chapter. These research questions focus on the general structure of the inter-firm networks of R\&D partnerships, changes in the position of small, entrepreneurial biotechnology firms, and the role of large pharmaceutical companies. After a description of some methodological issues and an explanation of the data used in our analysis, the second part of the chapter is devoted to an empirical analysis that concentrates on the main issues introduced with the research questions. In section 4.7 , we first analyse some basic trends in R\&D partnerships since the mid-1980s. This is followed by an in-depth analysis of the changes in the inter-firm R\&D networks where attention is paid to groups of companies as well as to the nodal players in the different networks that emerge over time. In section 4.9 , we discuss our main findings and we draw some major conclusions from this chapter.

\subsection{Innovation - the role of large companies and small entrepreneurial firms}

Our understanding of the importance of innovation and our perception of the role played by different categories of companies, such as large conpanies and relatively small entrepreneurial firms, can be clearly placed within the Schumpeterian tradition. We follow Schumpeter (1934) where innovation is described in the context of "new combinations" that replace existing products and markets. As suggested by Hagedoorn (1996b) and others, we understand these Schumpeterian new combinations as "technical" innovations in terms of new products or new quality of products, new methods of production, or new sources of supply of raw materials. These technical innovations have to be distinguished from "market or organizational" 
innovations, which are new combinations in terms of new markets or new industry structures.

For the pharmaceutical industry, modern biotechnology is a clear example of a set of new combinations with new technologies and state-of-the-art scientific understanding that create a technological discontinuity. In the context of this technological discontinuity, innovations not only affect the introduction of new products and new processes, but these technical innovations also come with new "players," i.e., companies that restructure parts of the pharmaceutical industry that has gradually become mature (Powell, 1996; Powell et al., 1996). These new scientific and technical innovations from biotechnology that are currently introduced, are largely based on immunology and molecular biology, including recombinant DNA technology, whereas the "traditional" pharmaceutical industry and its innovations are largely based on organic chemistry. Some observers understand these changes to be so fundamental that they describe the technological discontimuity in the pharmaceutical industry, as caused by modern biotechnology. as a clear shift in the existing technological paradigm (Della Valle and Gambardella, 1993; Orsenigo, 1989; Walsh and Galimberti, 1993).

When we consider the innovative role played by both large companies and smaller entrepreneurial firms, there is also a strong Schumpeterian flavour to our understanding of the contribution of these different categories of comparies. The importance of the entrepreneurial company as a major generator of new innowations is most clearly stressed in the "early" Schumpeter (1934). In this early work, entrepreneurial companies are small, independent companies that act as major agents of change within new industries. These entrepreneurial companies are innovators that successfully introduce new products of which the development is expected to be largely financed through extermal sources and not so much through internal financial resources (cash flow). In modern strategic management terminology: this Schumpeterian entrepreneurship is based on proactive strategies that capitalize on firm-specific advantages and innovative capabilities, financed 
through bank loans and venture capital. The Schumpeterian entrepreneur is not necessarily a strictly rational, economically maximizing agent, a risk taker, or a capitalist, as in the "classical" theories of entrepreneurship by Knight and Say (Marco, 1985), but primarily an agent of change who is searching for new opportunities (Hagedoorn, 1996b; Santarelli and Pesciarelli, 1990).

Many elements of these Schumpeterian entrepreneurial firms are clearly present in the pharmaceutical biotechnology industry. In fact, both Kenney (1986) and Powell et al. (1996) depict small biotechnology firms as an ideal type of modern entrepreneurial companies. As mentioned by Arora and Gambardella (1990), Barley et al. (1992), Pisano (1991), and Powell et al. (1996), small, new biotechnology companies are frequently financed through venture capital or loans and equity participation of large companies. Originally based on university research that led to major scientific and technological changes, nearly all of the small biotechnology companies also started as new entrants to the pharmaceutical industry (Kenney, 1986; Pisano, 1990; Powell, 1996).

In terms of their organizational setting and their organizational culture, most of the small biotechnology companies are quite different from the "standard" company that one finds in traditional industries. New biotechnology companies seem to be driven by scientific discoveries and innovative performance and not only by regular profit seeking (Lumerman Oliver and Porter Liebeskind, 1997). In addition, the "academic culture" within these innovation-driven and loosely organized companies, with their informal, non-hierarchical structures, sets them apart from many other "traditional" companies (Pisano, 1991; Powell, 1996).

If we look at the role of large companies in Schumpeter, we have to understand that there is also an important role for these large companies in many publications by Schumpeter. Specifically the "older" Schumpeter (1942) pictures a world of "modern, trustified capitalism" where large, science-based companies dominate the innovative environment and where 
imnovation has become routinized in large research laboratories and R\&D departments. It is this particular perspective on the role of large companies that has for a long period, during the 1950s, 1960s, and 1970s, dominated the understanding of the role of large companies as the main source of innovation (see Kamien and Schwartz, 1982; Scherer, 1984).

In the combined biotechnology and pharmaceutical industry, the role of large companies is most clearly found in the dominant role that these companies play in the more traditional pharmaceutical sub-sectors (Arora and Gambardella, 1990). Large companies, with their extensive R\&D activities and their long-term experience with time-consuming clinical trials, have come to dominate the innovation process in the traditional pharmaceutical industry. This dominance is based on their leading role in incremental innovation, exploiting their current organic chemical knowledge base, and their ability to expand existing portfolios of drugs.

\subsection{Mutual dependence of large and small companies}

Some authors (Hakansson et al., 1993; Kenney, 1986; Rothaermel, 2000) stress the importance of complementarity between small entrepreneurial firms and large companies, in particular in high-tech industries. The basis for this complementarity is to be found in the variety of resources, capabilities, and complementary innovative expertise such as those described in section 4.2 .

During the 1980s, when modern biotechnology became relevant to the pharmaceutical industry, a certain degree of mutual dependence developed almost instantaneously between large pharmaceutical companies and a group of relatively small, new biotechnology firms (Arora and Gambardella, 1990; Pisano, 1991; Powell, 1996). These small biotechnology companies, most of them US-based, have developed a reputation for their R\&D capabilities and applied laboratory research in advanced biotechnology at the scientific and technological frontier. Large pharmaceutical companies were 
already known for their vast body of engineering know-how necessary for scaling up from a laboratory setting to the actual manufacturing process of new drugs. "They also have the "deep pockets" that are necessary for the extensive and costly clinical testing required as part of the government regulatory process for new therapeutic drugs and new diagnostic products. Furthermore, large companies are known for their financial resources that enable them to deal with the costs of the final stage of commercialisation and the successful worldwide market introduction and distribution of safe and effective pharmaceutical products.

The obvious complementarities between both groups of companies during the early period of modern biotechnology led to a mutual dependence as companies started to collaborate on various projects (Laamanen and Autio, 1996; Slowinski, Seelig, and Hull, 1996). This mutual dependence in cooperative projects consisted of financial support and regulatory expertise provided by large pharmaceutical companies to small, entrepreneurial biotechnology companies, in return for which large companies acquired access to the research skills of these small biotechnology companies (Arora and Gambardella, 1990; Barley et al., 1992; Pisano, 1991; Powell, 1996; Shan et al., 1994). With the increasing number of new drugs based on pharmaceutical biotechnology, collaboration between small entrepreneurial firms and large companies also provides the first group with access to new markets and distribution facilities.

\subsection{Networks as the locus of innovation}

The mutual dependence of large pharmaceutical companies and small, entrepreneurial biotechnology firms also meant that the locus of innovation in the pharmaceutical industry has gradually changed. Collaboration by these different companies is part of a broader trend in many industries and technologies where the interdisciplinarity of fields of science and technology, the dependence on a substantial stock of knowledge, and the costs of 
R\&D force even the largest companies to collaborate with others (Hagedoorn, 1993). In the pharmaceutical biotechnology industry, these general developments together with sector-specific scientific and technological developments have led to a situation where large pharmaceutical companies are no longer the sole locus of innovation (Arora and Gambardella, 1990). As in so many other industries and fields of technology, extensive collaboration in this sector has led to rather dense networks of companies that enter into ail sorts of partnerships with a large number of other companies (Hagedoorn, 1990 and 1993; Powell et al., 1996). In the pharmaceutical. biotechnology industry, this mutual knowledge resource dependency between groups of large and small companies has led to dense networks of R\&D collaboration between a variety of companies where small firms play an important role in this new locus of innovation.

Some authors (e.g., Arora and Gambardella, 1990; Oakey, 1993; Saviotti, 1998) mention that the network-like structure of this locus of innovation, with both intensive inter-firm collaboration in general and specific cooperation between large companies and small entrepreneurial firms, could be a temporary phenomenon that coincides with the immaturity of biotcchnology as a new technological paradigm developed during the 1980s. As the industry matures, small entrepreneurial companies could be taken over or their services could become redundant. Large companies could become more important for the new biotechnology-based pharmaceutical industry as such, as well as for the inter-firm R\&D networks that have developed over time.

Others (e.g., Pisano, 1991; Powell, 1996; Powell et al., 1996; Segers, 1992; Senker and Sharp, 1997), however, seem to expect that these networks of R\&D collaboration in the pharmaceutical biotechnology industry are of a more long-term nature, because functionally specialized companies can easily maintain various relations with each other through distinctive transactions. In particular, the "nodal" role of small biotechnology companies, both in terms of their critical role as carriers of new scientific knowl- 
edge and in their role as major network players with multiple partnerships, is expected to be a long-term affair that will affect the continuation of a network-like structure of innovation in the pharmacentical biotechnology industry for decades (Galambos and Sturchio, 1998; Powell, 1996; Senker and Sharp, 1997).

\subsection{Research questions}

As the pharmaceutical biotechnology industry gradually became somewhat more mature, some phenomena and patterns, discussed in the previous sections, that characterized the R\&D networks of the 1980 s, might successively have become less significant during the 1990 s while new patterns were emerging. In that context, one has to consider in particular the density of networks that followed the growth in R\&D cooperation and the role of different groups of companies in these networks. The literature discussed in section 4.4 clearly suggests a number of specific research questions that will guide our empirical investigation in the following sections. These research questions are:

- Are inter-firm networks in the pharmaceutical biotechnology industry becoming less dense or is their density increasing?

- Is the well-established role of small biotechnology firms as nodal players in these inter-firm networks decreasing over time?

- Are R\&D partnerships between large pharmaceutical companies becoming a more important element in these networks of innovation?

\subsection{Research methodollogy and data}

The core of this chapter is found in the empirical analysis of the evolution of the structure of inter-firm alliance networks in pharmacentical biotechnology and the role played by different categories of cooperating firms. 
Most attention is paid to measuring variation in network density over time and analysing the extent to which small, entrepreneurial biotechnology firms and/or large pharmaceutical companies play a central role in these networks.

Based on our first research question, which refers to increasing or decreasing density of inter-firm networks, we expect that an increasing or decreasing network density will show up in a growing or declining average number of partnerships per firm. To study this aspect of network structure, we calculated the ratio of the total number of R\&D partnerships between firms to the number of participating companies for each year. The total number of partnerships for each year was obtained by counting the number of dyads (relations between two firms) at the level of cooperating firms.

In the present context, we do not consider the calculation of standard network density indices as a meaningful alternative to the density indicator that we propose. A standard network density index is defined as the ratio of the actual number of partnerships between firms to the possible number of links. Comparing these indices from one year to the next year requires that the calculations be based on a constant number of network participants over time (Barley eti al., 1992). One option is to compute density indices based on a constant subset of the most active players. Many small biotechnology firms in our sample have engaged in only one partnership during the period of investigation. If we would base our analysis on a constant subset of the most active players, many small firms would disappear from the sample, which is not a desired outcome in light of our research objectives.

Our second research question considers the role of small, entrepreneurial biotechnology firms as major network participants. In that context, we compare the partnering behaviour of small firms to large companies. To evaluate these alliance activities, we calculated the number of R\&D partnerships per employee for both groups of firms. We first classified each of the firms in our sample into one of three distinct size categories based on their number of employees during the period of study. Firms with less 
than or equal to 500 employees are regarded as small and those having between 501 and 5,000 employees are considered as medium-sized companies. Firms with over 5,001 employees are classified as large companies. We created a separate category for academic or governmental institutions. Due to the small size and/or private status of some firms, we could only obtain information on their size for a few years. We classified these firms into one of the three categories based on the available information.

For small, entrepreneurial biotechnology firms and large pharmaceutical companies, we calculated, for both categories, the ratio of the total number of R\&D partnerships between companies to the number of cooperating firms for each year. The total number of partnerships for each year was obtained by counting the number of dyads at the level of cooperating firms. For both small and large firms, we divided the results obtained by the means of the appropriate employee categories to control for any size effects on alliance activity. We transformed the mean numbers of employees into a logarithmic scale (natural logarithm) to account for size differentials, which are unrelated to technological activities of companies. Small biotechnology firms typically employ mainly R\&D specialists and therefore they have, compared to large pharmaceutical firms, lower numbers of employees in many other functional areas, such as production, marketing, sales, etc.

For our third research question, which looks at the role of R\&D partnerships among large pharmaceutical firms, we examine the distribution of partnerships between firms of similar and different size classes. If large firms have come to play a more central role in partnerships than small entrepreneurial firms, we expect the number of partnerships between large firms to have increased as well. An intensification of R\&D partnering between large and small firms would point at ongoing complementarity between both categories of cooperating firms. For each year, we calculated the total numbers of clyads between large firms, small firms, and between large and small companies as percentages of the overall numbers of dyads in that year. These overall numbers also include R\&D partnerships involv- 
ing medium-sized firms. However, given the limited role of medium-sized companies (about 10 percent of the sample) and the emphasis in our research questions on large and small companies, the group of medium-sized firms receives no attention in this chapter.

In order to provide some further details about the evolution of networks and the role played by small biotechnology firms and large pharmaceutical companies, we will represent these networks using a non-metric multidimensional scaling (MDS) technique. MDS is a data reduction procedure somewhat comparable to principal component analysis and other factoranalytical methods. One of the main advantages of MDS is that it can usually, but not necessarily, fit an appropriate model in two-dimensional pictures. More specifically, MDS offers a scaling of similarity data into points lying in an X-dimensional space. The purpose of this method is to provide coordinates for these points in such a way that distances between pairs of points fit as closely as possible to the observed similarities. In order to facilitate interpretation, the solution is given in two dimensions provided that the fit of the model is acceptable. A stress value indicates the goodness-of-fit of the configuration, as this measures the proportion of the variance of the disparities that is accounted for by the MDS model, implying that lower values indicate a better goodness of fit (Hair, Anderson, Tatham, and Lundgren, 1994).

Our analysis is restricted to periods of three years since it is technically impossible to picture all firms in the network when more than three years of data are added. MDS plots are presented for the periods 1985-1987, 1989-1991, and 1993-1995. Comparing these three periods allows us to add a dynamic perspective to our analysis. To improve the interpretation of the pictures, it is useful to draw lines of different styles and thickness between companies, indicating different degrees of cooperation intensity.

For our analyses, we make use of two types of data: firm size clata and data on R\&D partnerships. To describe network participants in terms of their size, we collected information on the number of employees of each 
firm from various sources such as the Institute for Biotechnology Information, the US Securities and Exchange Commission, World Scope Global Researcher, Amadeus, and Dun and Bradstreet's Linkages.

The data on R\&D partnerships are taken from the MERIT-CATI information system (see appendix A). This databank contains information on nearly 10,000 cooperative agreements in various sectors, ranging from hightech sectors such as information technology and pharmaceutical biotechnology to less technology-intensive sectors such as chemicals and heavy electrical equipment. Cooperative agreements are defined as mutual interests between independent industrial partners that are not linked through majority ownership. In the CATI database, only those agreements are being recorded that involve either a technology transfer or some form of jointly undertaken R\&D. Information is also collected on joint ventures in which new technology is received from at least one of the partners, or on joint ventures having some $R \& D$ program. Other types of agreements such as production and marketing partnerships are not included. Agreements formed between companies and governmental or academic institutions are generally not included in the database unless they involve at least two commercial companies.

This chapter focuses on those partnerships that were established in the period 1985-1995. In the CATI databank, a total of 720 global R\&D agreements involving 475 biotechnology and pharmaceutical companies were recorded during this time frame. Our data include equity agreements, which comprise joint ventures and minority holdings, as well as non-equity partnerships that consist of joint R\&D agreements and R\&D contracts. The data exclude agreements that are established within the context of national and international, government-sponsored R\&D cost-sharing programs. Our sample of 475 participating firms comprises 111 large companies, 308 small ones, and 53 firms of medium size. We include three academic or govermmental institutions. For our purpose, the most relevant 
information for each partnership is the number of companies involved, their names as well as the year in which the agreement was established.

This sample is representative for the pharmaceutical biotechnology industry during the period 1985-1995. Various sources indicate that during this period there are about 100 large pharmacentical companies with a clear interest in biotechnology (OECD, 1993; OTA, 1988; Walsh and Galimberti, 1993). About two-thirds of the industry during this period consists of small and relatively young firms (Pisano, Shan, and Teece, 1988; Van Vliet, 1998; Walsh, Niosi, and Mustar, 1995).

\subsection{Trends in R\&D partnerships during the period 1985-1995}

Some general background to the more detailed analysis of the R\&D networks in the pharmaceutical biotechnology industry is given in figures 4.1 and 4.2. Figure 4.1 demonstrates the importance of pharmaceutical biotechnology in R\&D partnering. Over 65 percent of all the biotechnology R\&D partnerships in the CATI database are related to pharmaceutical biotechnology. In the most recent years that we analyse, pharmaceutical biotechnology even reaches a share of over 70 percent of all biotechnology partnerships. The dominance of this particular sub-sector in the biotechnology industry, with so few partnerships found in other biotechnology sectors, is one of the main reasons why our contribution focuses on the pharmaceutical biotechnology industry.

Figure 4.2 presents the trend in the growth of newly made R\&D partnerships in pharmaceutical biotechnology during the period 1985-1995, as found in the CATI database. This development can be characterised as a flattened U-shaped growth pattern. The growth in the number of new R\&D partnerships drops from about 70 partnerships made annually, as found for the mid-1980s, to about 20 alliances during the early $1990 \mathrm{~s}$, after which the growth pattern is restored wit] a steep increase up to over 100 newly established R\&D partnerships during the mid-1990s. This par- 


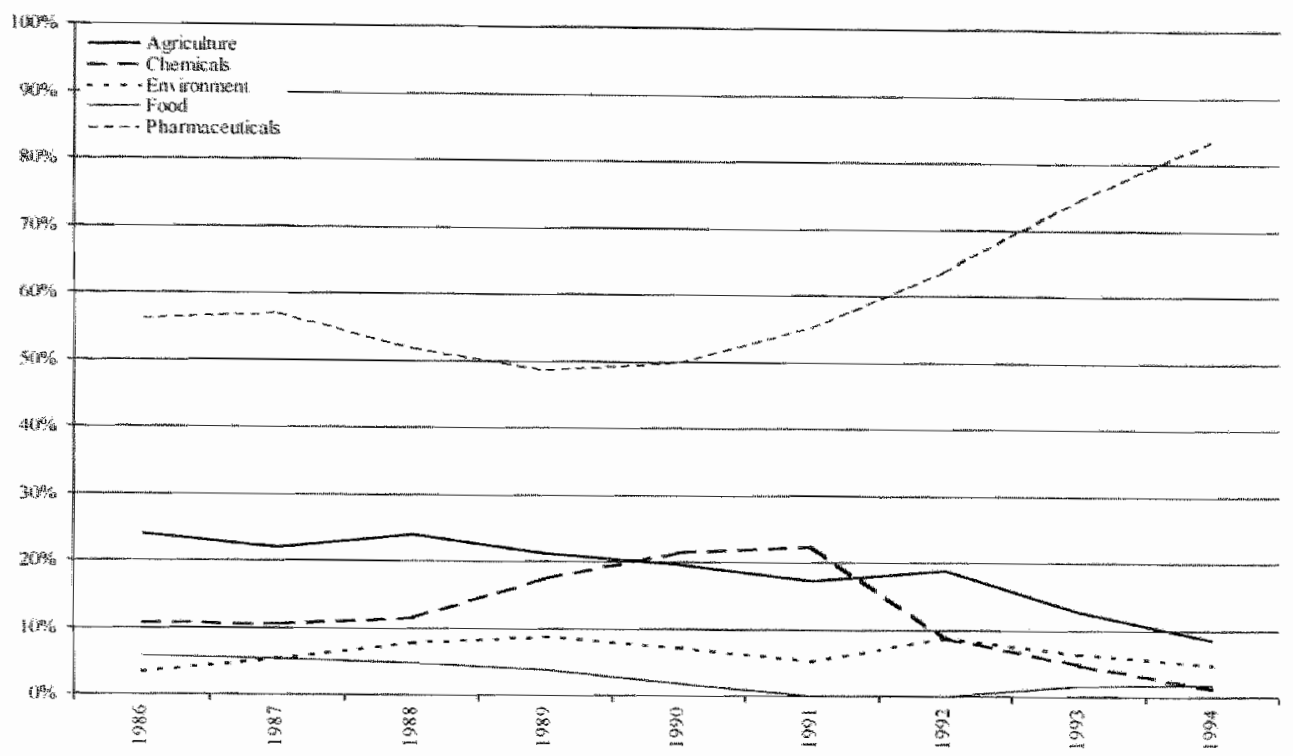

Figure 4.1: Distribution of newly established R\&D partnerships in various biotechnology based industries, three-year moving averages, 1985-1995.

ticular growth pattern is quite identical to the pattern found for other industries (Hagedoorn, 1996a). In the previous chapter, section 3.2, we have provided a tentative explanation for the specific pattern in the newly established pharmaceutical biotechnology partnerships during the period $1985-1995$.

As a first step in the analysis of the inter-firm R\&D networks and also to assess the evolution of network density, we calculated the number of annually, newly made R\&D partnerships per firm as they appear in the CATI databank. Information on these numbers of new R\&D partnerships and participating firms is given in table 4.1. Figure 4.3 shows the total number of newly established partnerships per firm in the pharmaceutical biotechnology industry for the period 1985-1995. These numbers are calculated as three-year moving averages to present the overall trend in the data while correcting for yearly fluctuations. For 1995, we added the actual 


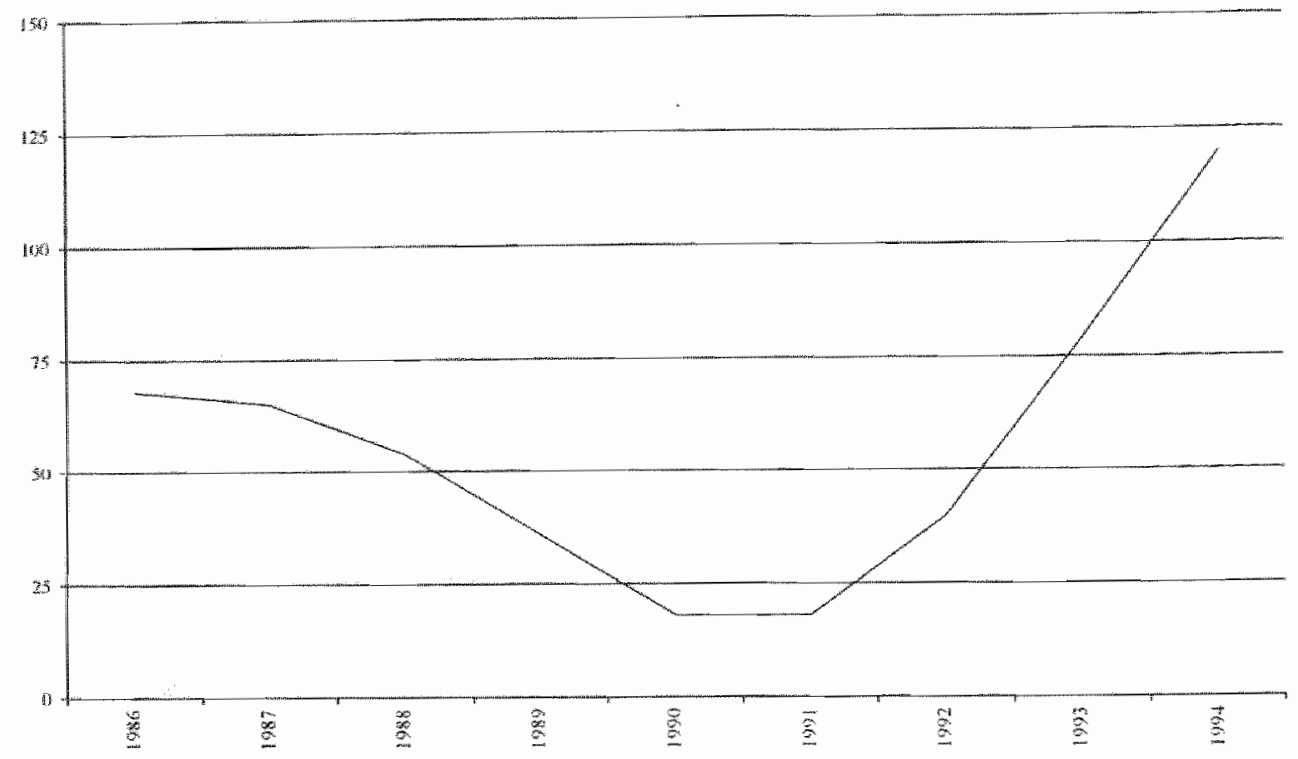

Figure 4.2: Number of newly established R\&D partmerships, three-year mowing averages, $1985-$ 1995.

value to the graph to be able to visualize the strong growth in alliance activity in the last three years of abservation. Figure 4.3 pictures a U-shaped pattern in the average number of newly made R\&D partnerships per firm. It demonstrates that, apart from a small increase in 1987, the final years of the 1980 s are characterized by a sharp decrease in the number of partnerships per firm from 1.9 in 1986 to 1.5 in 1989 . The first years of the 1990 s show a further decline in the average number of R\&D partnerships per firm to a level of 1.2 in 1990 . This is followed by a short period of stabilization, which is continued by a sharp rise of new partnerships per firm from 1992 onwards. In 1995, the steep upward trend arrives at a level of 1.85 new partnerships per firm.

As an indicator of the magnitude of R\&D alliance activities of both small biotechnology firms and large pharmaceutical companies, we computed the number of annually, newly established R\&D partnerships per employee 
Table 4.1: Number of newly established R\&D partnerships and participating companies, 1985 . 1995.

\begin{tabular}{lcc}
\hline Year & Number of partinerships & Number of companies \\
\hline 1985 & 164 & 85 \\
1986 & 158 & 79 \\
1987 & 128 & 75 \\
1988 & 172 & 84 \\
1989 & 76 & 56 \\
1990 & 14 & 13 \\
1991 & 18 & 15 \\
1992 & 78 & 55 \\
1993 & 170 & 106 \\
1994 & 250 & 163 \\
1995 & 332 & 179 \\
\hline
\end{tabular}

(logarithmic scale) for both categories of cooperating companies. Figure 4.4 shows the specific trend for the number of new R\&D partnerships for these groups of companies. The data in this graph are also shown as three-year moving averages, with the exception of 1995 for which we present the actual values of that year. We notice that for small firms, the average number of new R\&D partnerships decreased gradually during the final years of the 1980s from about 0.7 in 1986 to fewer than 0.55 in 1989 and this number declined even further to about 0.5 in 1990 . In 1991, the number of new R\&D partnerships was still at a level of around 0.5. From 1992 onwards, this number steadily increases and reaches the value of about 0.6 in 1995 .

The same pattern of decline in the average number of R\&D partnerships during the second half of the 1980 s is also found for large firms, albeit at a slightly lower level. Apart from a small increase in 1987, the final years of the 1980 s are characterized by a gradual decrease in the average number of partnerships from 0.4 in 1986 to fewer than 0.35 in 1989. After a further decline in 1990 to around 0.3 agreements, the number of newly made R\&D partnerships took off again during the first half of the $1990 \mathrm{~s}$, which is characterized by a rather steep increase to 0.6 in 1995 . This number is somewhat higher than the value we found for small firms in the same year. 


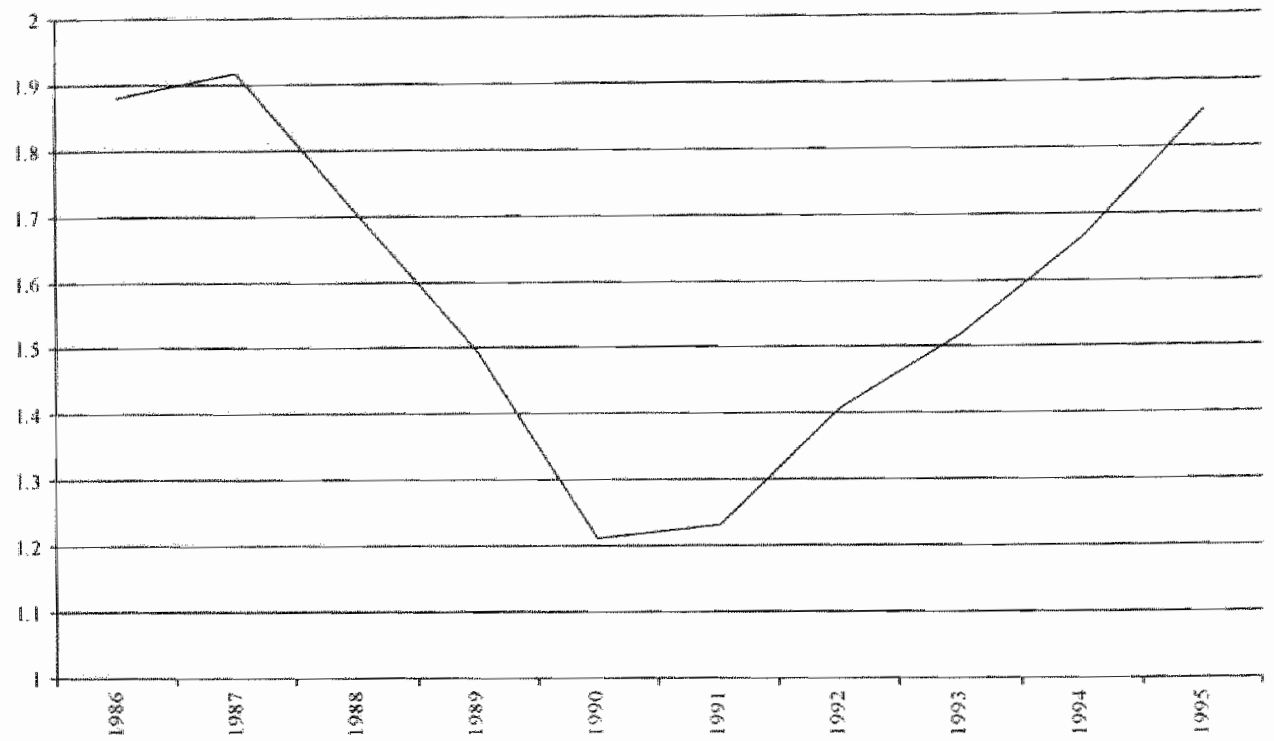

Figure 4.3: Number of newly established R\&D partnerships per company, three-year moving averages, 1985-1995.

To evaluate the importance and magnitude of R\&D partnerships within and between different categories of companies, we calculated the number of annually, newly established R\&D partnerships for large companies, small firms, and combinations of both. Figure 4.5 shows the evolution of the number of newly made partnerships between firms of similar and different sizes. All numbers are calculated as three-year moving averages and expressed as percentages of the total number of annually, newly established R\&D partinerships.

If we consider the specific trend for the share of R\&D partnerships between large pharmaceutical firms, we see that during the second half of the 1980s, there is a gradual decline from an average share of more than 23 percent in the mid-1980s to around 15 percent in 1989 . During the first years of the 1990s, the share of R\&D partnerships between large firms decreased even further to a level of less than 5 percent in 1992; in 1993 this 


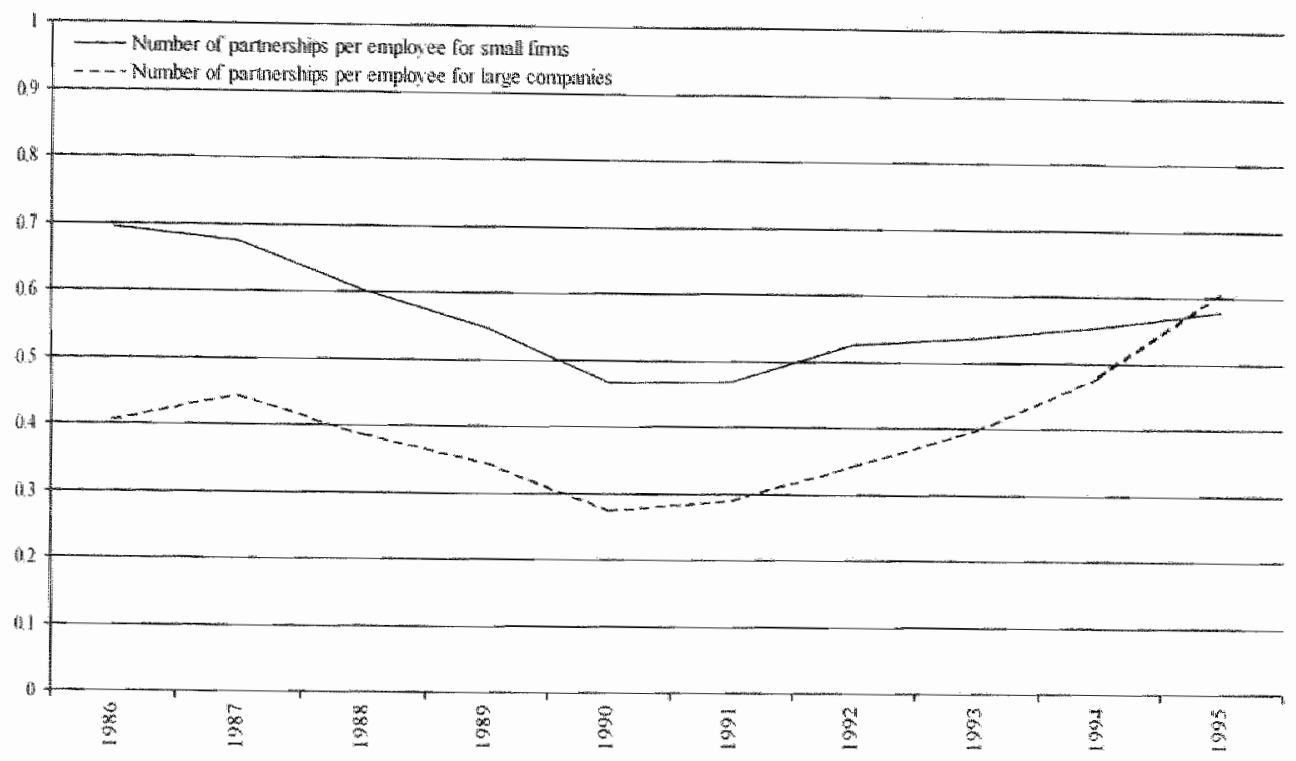

Figure 4.4: Number of newly established R\&D partnerships per employee for smail firms and large companies, mean numbers of enployees are log values, three-year moving averages, $1985-$ 1995.

share reached nearly 7 percent. After this small increase, the clownward trend set in again until it arrived at a small share of less than 6 percent in 1994.

During the final years of the 1980 s, the share of partnerships between small biotechnology firms in all R\&D alliances steadily declined from an average of slightly less than 7 percent in 1986 to around 2 percent in 1989. This share reached nearly 5 percent in 1990 after which the upward trend continued until it arrived at a level of more than 16 percent in 1993. In 1994, the share clecreased again to slightly more than 12 percent.

Examining the particular trend for the share of R\&D partnerships between large pharmaceutical firms and small biotechnology companies, we see that during the late 1980s, there is a sharp increase from an average share of slightly more than 41 percent in the mid-1980s to nearly 64 per- 


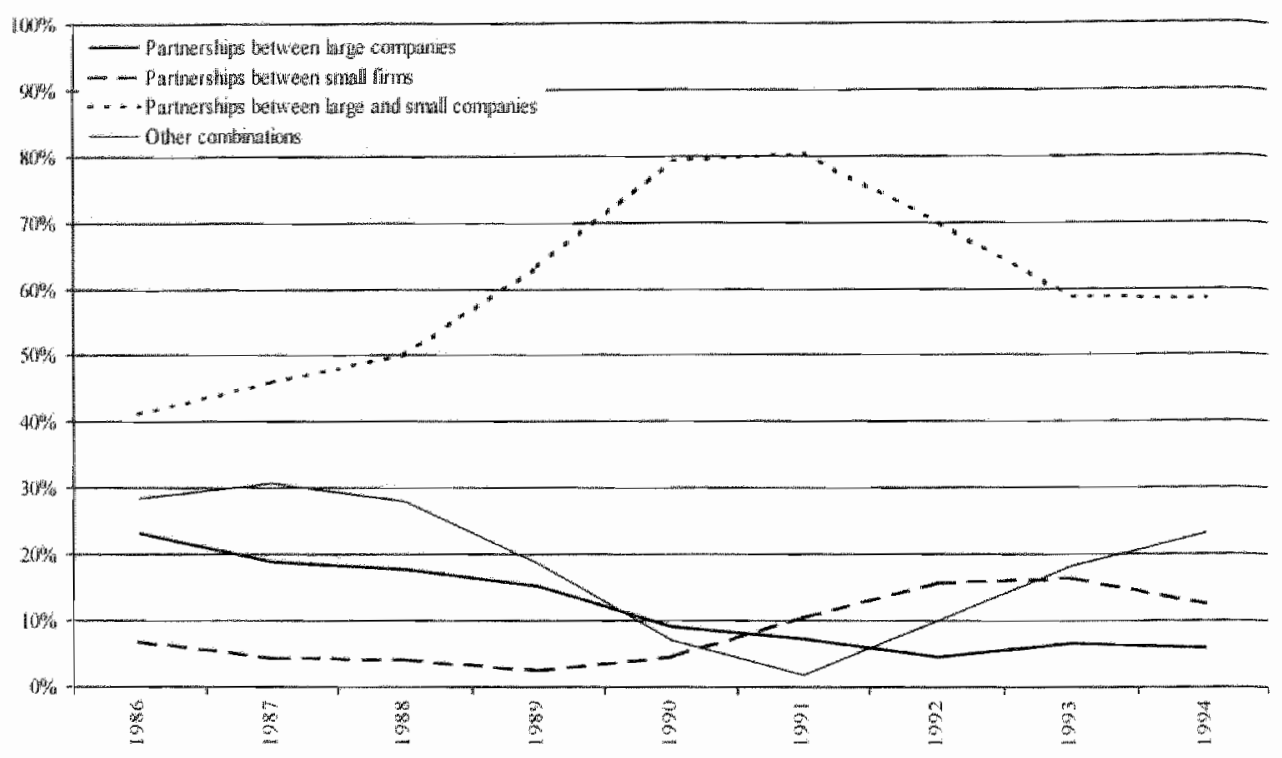

Figure 4.5: Distribution of newly established R\&D partnerships between companies of similar and different sizes, three-year moving averages, 1985-1995.

cent in 1989. During the first years of the $1990 \mathrm{~s}$, the average share of R\&D partnerships between large and small firms stabilized at a level of around 80 percent. After this short period of stabilization in the early 1990s, a sharp downward trend set in from 1992 onwards. It reached a level of less than 59 percent in 1993 and 1994.

\subsection{The structure of inter-firm R\&D networks}

After having identified the basic trends in R\&D partmering, we now turn to the particular evolution of R\&D networks. We examine networks of R\&D partnerships at two distinct levels. First, we describe the basic characteristics of the overall network, mainly focusing on density in order to evaluate changes in the intensity of partnerships between firms. We then evaluate the importance of particular players for the overall structure of 
the networks by examining the role of the most intensely cooperating firms in pharmaceutical biotechnology.

Figures 4.6-4.8 give us a graphical representation of the R\&D partnerships in the pharmaceutical biotechnology industry in the periods 1985 1987, 1989-1991, and 1993-1995. Solid lines represent one partnership between companies whereas dotted lines indicate two or three partnerships. Thick solid lines indicate four or five alliances. See appendix B for company codes. For all MDS solutions presented in this chapter, Kruskal's stress values range from good to very good (Kruskal and Wish, 1978), varying from 0.027 for the period 1985-1987 to 0.004 for the period 19891991. For an evaluation of the importance of small biotechnology firms and large pharmaceutical companies in R\&D partnering, we refer to table 4.2. This table lists the twenty-five network participants with the most R\&D partnerships in the pharmaceutical biotechnology industry during the periods 1985-1987, 1989-1991, and 1993-1995.

The MDS plot for the period 1985-1987 (figure 4.6) shows a rather dense network in which cooperation is not concentrated in any particular part of the network and the multitude of lines connects most of the companies in the network, either in a direct or indirect way. Although most firms are comected to at least two other partners, we also see quite a few one-onone links. Many companies have engaged in at least two R\&D partnerships with one particular firm. This is illustrative for the growth in the number of partnerships per firm during that period.

If we look at the leading companies of the pharmaceutical biotechnology network in the period 1985-1987, we see that a number of small biotechnology companies such as Biogen, Celltech, and California Biotechnology keep very nodal positions in the network (see figure 4.6). These companies also rank high on the list of most intensely cooperating companies (table 4.2). Apparently, many small biotechnology firms are attractive partners for large pharmaceutical corporations. Furthermore, the network is characterized by many strongly tied couples of small and large firms. A 


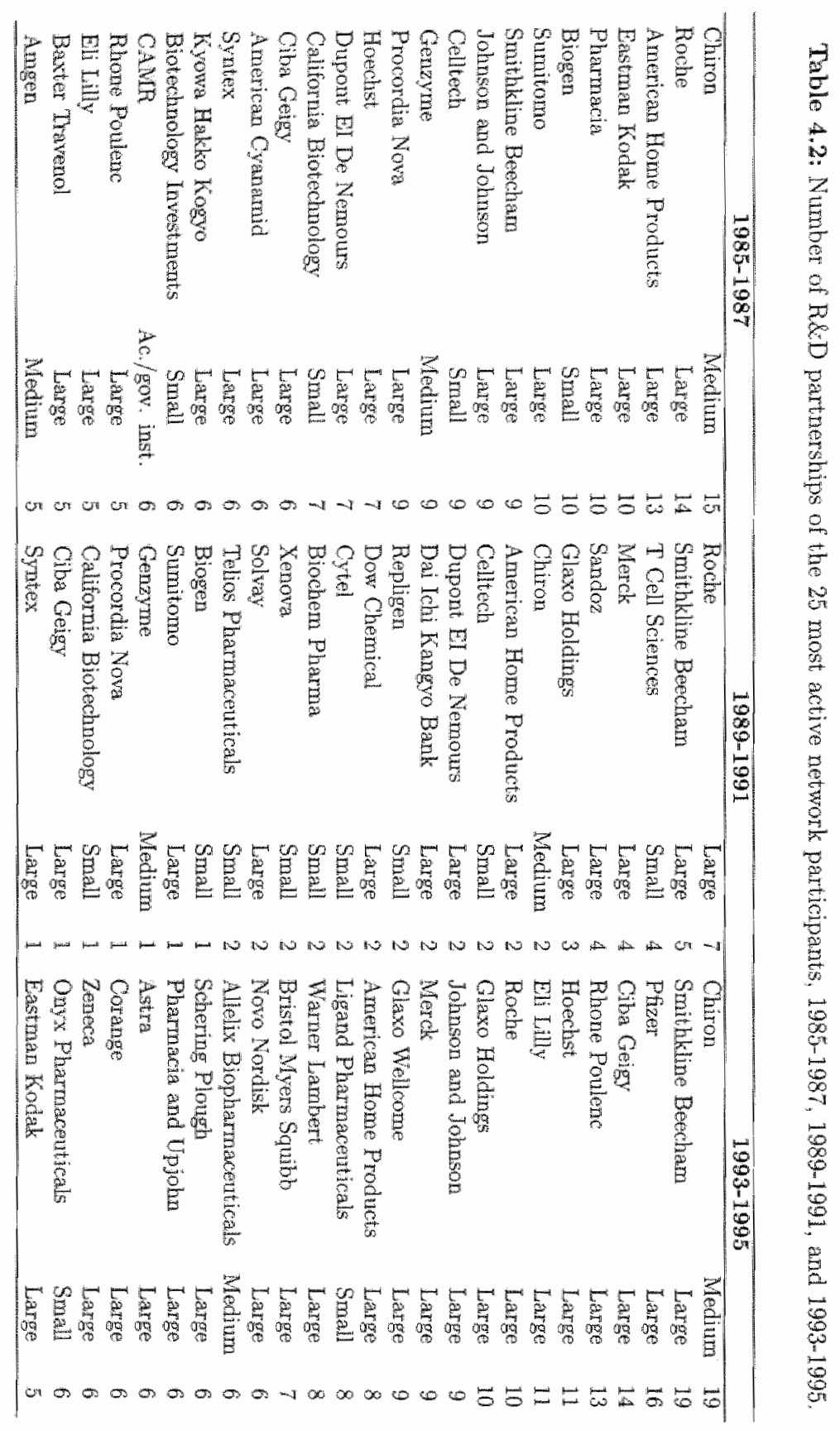




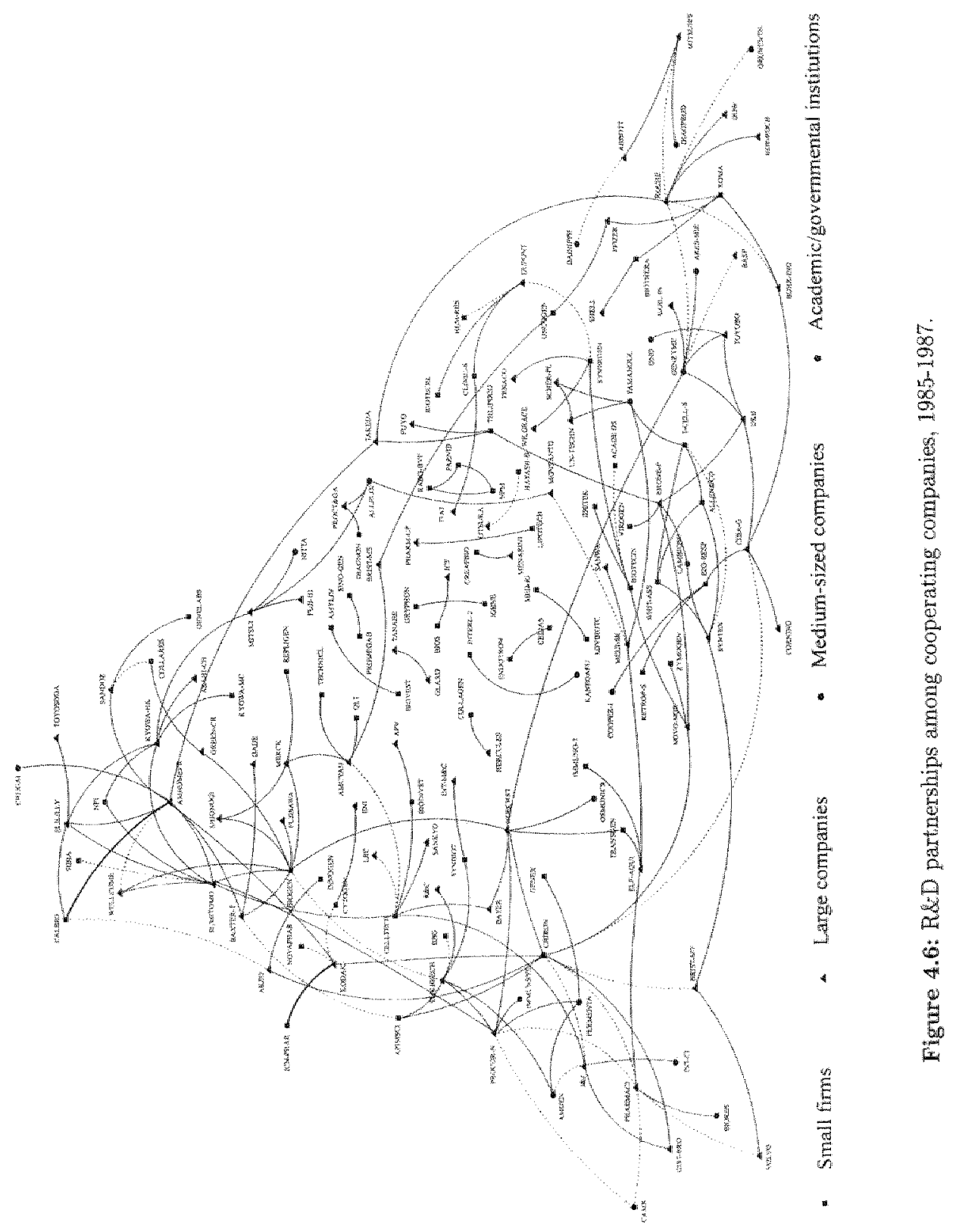


few important ties: Biogen and Smithkline Beecham, Celltech and American Cyanamid, California Biotechnology and American Home Products. Smithkline Beecham is found in the middle of an R\&D network with specialized biotechnology companies such as Applied Immune Sciences and British Biotechnology, as well as a number of large-sized companies such as Procordia Nova. American Home Products, another leading pharmaceutical company, is mainly connected to large partners such as Eastman Kodak and Sumitomo.

Turning to the next period (1989-1991), we find a somewhat different pattern (see figure 4.7). The MDS solution shows an extremely sparse network that involves seventy-five firms of which the vast majority are part of clusters of firms that are all centred around three focal players: Roche, Smithkline Beecham, and Merck. Although some firms are linked to more than one partner, we observe mostly one-on-one partnerships. The majority of firms are connected to one specific partner through no more than one R\&D partnership.

In the years 1989-1991, the group of most partner-intensive companies in the network for the pharmaceutical biotechnology industry covers a number of leading phamaceutical companies as well as many small biotechnology firms (see table 4.2). We notice that the small biotechnology firms that have already been mentioned, changed their positions in the rank order of leading R\&D partnering firms while several new, small firms such as $T$ Cell Sciences and Repligen entered the top ranking of cooperating companies. It is obvious that in this period, R\&D partnering has not led to a dense network and we therefore focus on the somewhat denser clusters of cooperating firms that were found (see figure 4.7).

At the top left-hand side of figure 4.7, we can see one cluster involving a number of small and large cooperating companies, which are all centred around the leading pharmaceutical company Smithkline Beecham. A very nodal position in this cluster is held by $T$ Cell Sciences, which is also closely tied to the core of the cluster. Within this cluster, Smithkline Beecham is 


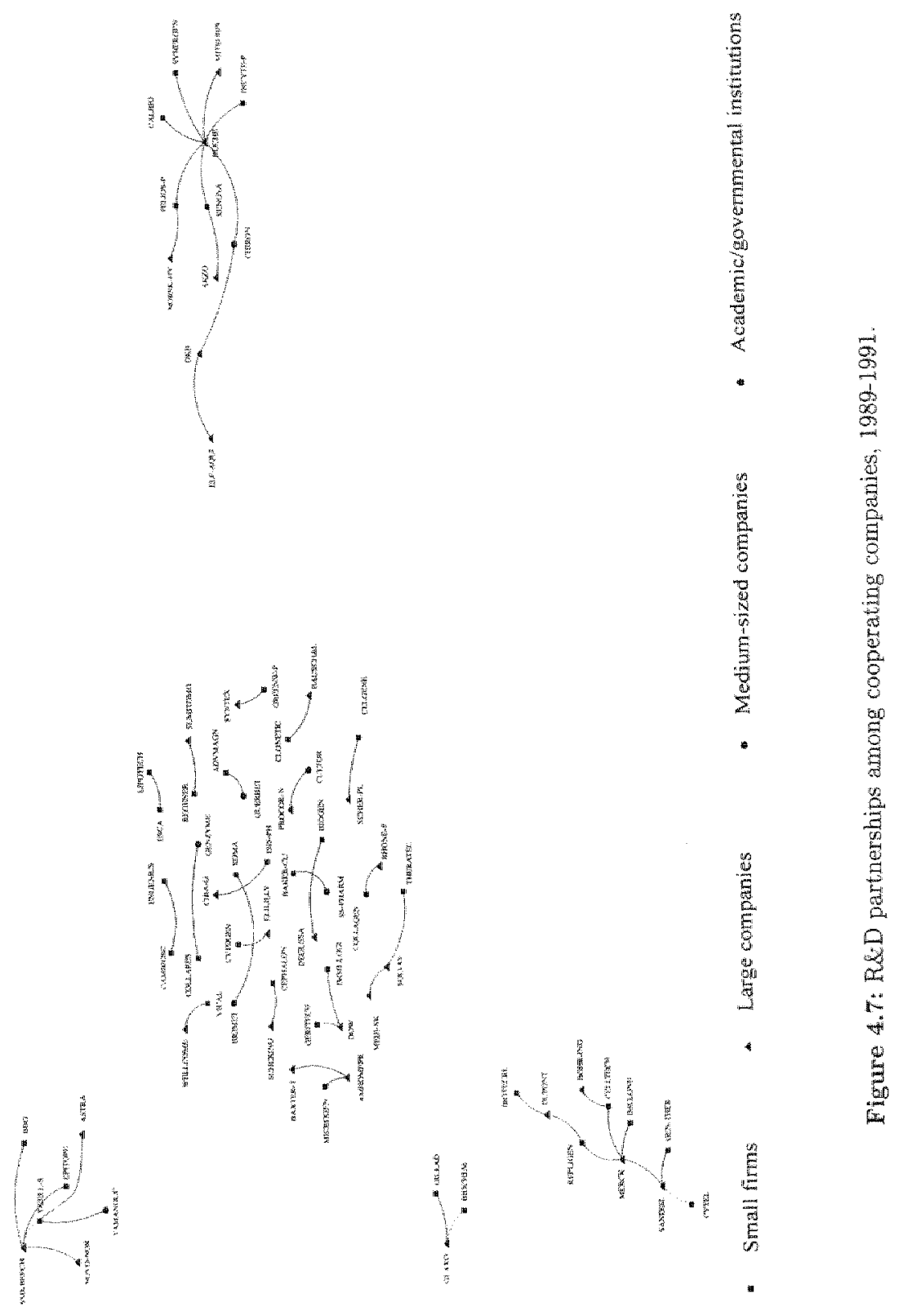


mainly connected to small biotechnology firms. Glaxo Holdings is found in the middle of a second, somewhat smaller, R\&D network with two specialized biotechnology companies, Biochem Pharma and Gilead Sciences. The strong ties between Glaxo Holdings and Biochem Pharma form the core of this cluster.

A third mixed cluster of small biotechnology firms and large pharmaceutical companies is found at the bottom left-hand side of figure 4.7. The core of this cluster is formed by two large pharmaceutical companies, Merck and Sandoz. If we study this particular cluster, we see that these large firms are mainly tied to a number of small biotechnology firms such as Celltech and Repligen that also hold nodal positions in the network. A large cluster of small and large firms is located at the right-hand side. This cluster is basically centred around the large pharmaceutical company Roche that is found in the middle of an R\&D network with many specialized biotechnology companies. Two nodal biotechnology companies, Xenova and Telios Pharmaceuticals, hold important positions in this cluster.

The network density in the pharmaceutical biotechnology sector shows a substantial increase if one compares the period 1993-1995 (see figure 4.8) with 1989-1991. During the period 1993-1995, the many newly created R\&D partnerships between biotechnology companies and pharmaceutical firms resulted in a much denser network structure in which cooperation is mainly concentrated at the right-hand side of figure 4.8. Nearly all companies in this dense part of the network are either directly or indirectly connected to each other. However, as indicated by the network pattern at the left-hand side of figure 4.8 , there are still a large number of one-on-one links in other parts of the network. In addition, the number of firms that are connected to one particular partner through at least two partnerships has increased, which is illustrative for the increase in the number of R\&D partnerships per firm during this period.

Small firms that held strong positions in the rank order of most intensely cooperating firms during the period 1989-1991, have left the group 


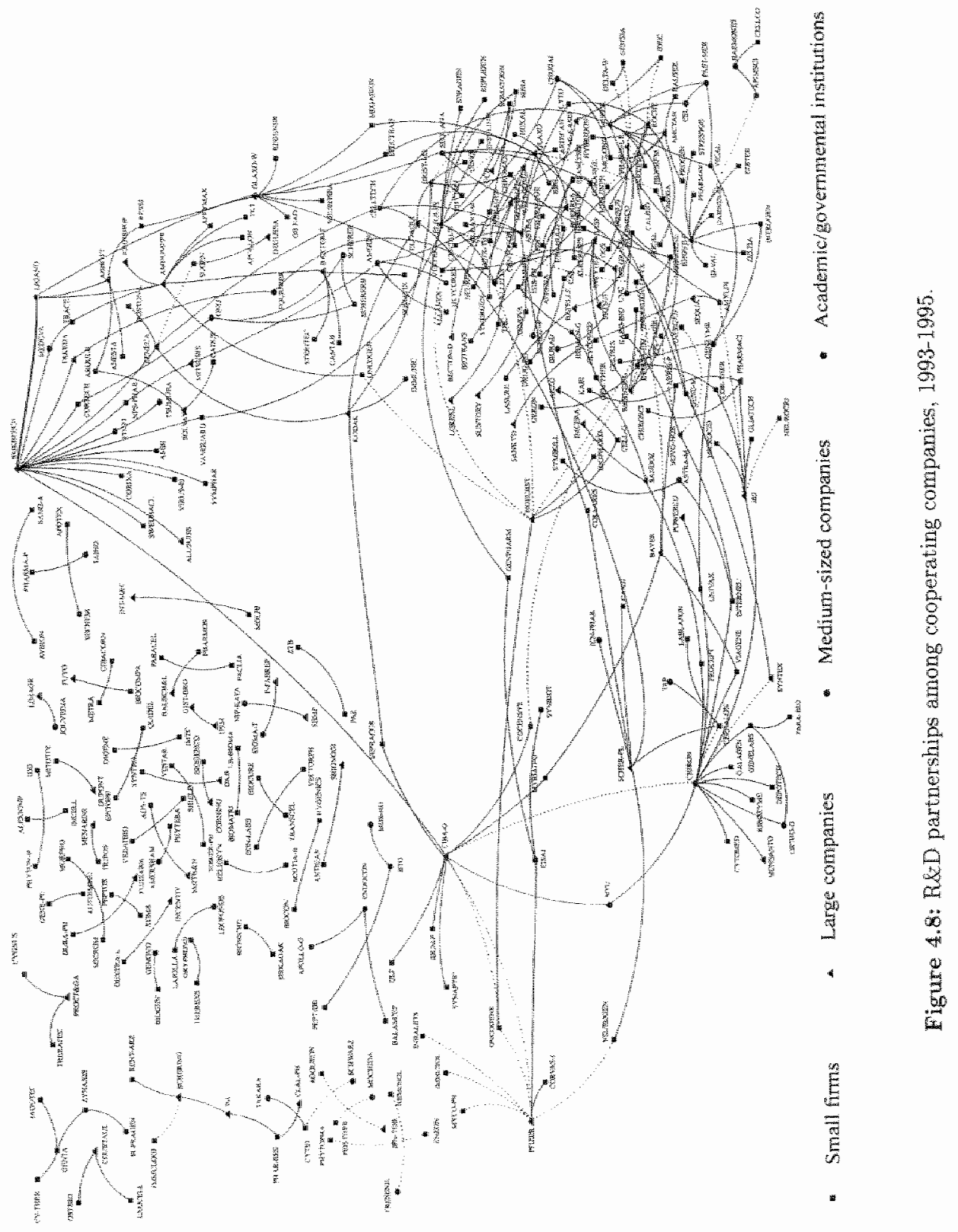


of leading cooperating firms for the period 1993-1995. Only two new, young biotechnology firms, Ligand and Onyx, have entered this group (see table 4.2). The top of the network for the pharmaceutical biotechnology industry during this time period covers only leading pharmaceutical companies such as Smithkline Beecham, Pfizer, and Ciba Geigy that all hold nodal positions in the network. Ligand is strongly tied to Smithkline Beecham as well as to other large pharmaceutical firms such as Glaxo Wellcome (see figure 4.8). Onyx is tightly related to large companies such as Eli Lilly and Warner Lambert. Apart from R\&D partmerships with two nodal biotechnology companjes, these large pharmaceutical firms are mainly connected to a wide variety of other small partners. In addition to this, some specific partnerships between large companies can be observed, such as the ties between Smithkline Beecham and Ciba Geigy and Warner Lambert and BASF.

\subsection{Discussion and conclusions}

This chapter aims at improving the understanding of the specific evolution of $R \& D$ partnerships and the related inter-firm networks in the pharmaceutical biotechnology industry. In that context, we pay extensive attention to the complementary role of small entrepreneurial firms and large pharmaceutical companies in these R\&D networks.

As also found in previous research (Hagedoorn, 1993; Kenney, 1986; Powell et al., 1996), the widespread collaboration between different groups of cooperating firms in the pharmaceutical biotechnology industry has led to rather dense network-like structures of joint innovative activities. Small, entrepreneurial biotechnology companies play an important role in these R\&D networks. This role for small firms can clearly be understood in the light of the Schumpeterian tradition where entrepreneurial firms are viewed as important generators of innovative change within new industries. In particular, during the 1980 s, the nodal role of small, new biotechnology 
frms coincides with major scientific and technological breakthroughs introduced by many of these new entrants to the pharmaceutical industry (Powell, 1996).

However, as the field of biotechnology has gradually matured, entrepreneurial biotechnology firms could have become less important for the newly developed R\&D networks while large companies may have become more dominant. This more dominant role for large, science-based firms in a more routinized innovative environment is particularly stressed in the later writings of Schumpeter (1942), see also Scherer (1984). Recent contributions (e.g., Senker and Sharp, 1997) expect, however, that the nodal role of small biotechnology firms, as major players with multiple partnerships in R\&D networks, will not decrease as the technology becomes more mature.

Our analysis reveals that during the second half of the 1980 s, the R\&D partnership-intensity of small firms was higher than for large companies. The more detailed analysis of the periods 1985-1987 and 1989-1991 shows that numerous entrepreneurial biotechnology firms kept very nodal positions in $R \& D$ networks, albeit next to several large pharmaceutical companies that were also well represented.

One of the other major observations in this chapter is the strong increase in the R\&D alliance-intensity for large firms during the first half of the 1990s. At the end of the period, this alliance-intensity of large firms exceeds the intensity found for small firms. The changing role of large pharmaceutical companies is also found in the analysis of the overall R\&D network of the period 1993-1995. This analysis shows that only two young biotechnology firms hold strong positions in the rank order of most intensely cooperating firms and that the top positions of the network are mainly taken by leading pharmaceutical companies that hold nodal positions in the overall network.

In congruence with "early" Schumpeterian views, these results are indicative of the significant role played by small, entrepreneurial biotechnology firms in imnovation, particularly during the $1980 \mathrm{~s}$ when modern. 
biotechnology first became relevant to the pharmaceutical industry. The early 1990s, however, seem to demonstrate a decreasing importance of these small firms in inter-firm R\&D networks if compared to the role of large pharmaceutical companies. These large companies developed into more dominant players with multiple partnerships, a change that is clearly more in line with expectations based on the later writings of Schumpeter.

The complementarity of the imnovative capabilities of small, entrepreneurial biotechnology firms and large pharmaceutical companies has formed the basis for numerous $R \& D$ partnerships between these two groups of firms. An increasingly dominant role of large firms in all sorts of innovative activities might render these complementarities less obvious. The intensity of specific cooperation between groups of small and large companies, as well as of inter-firm collaboration in general, is then likely to drop off (Arora and Gambardella, 1990; Saviotti, 1998). However, others (Powell, 1996; Senker and Sharp, 1997) expect that entrepreneurial firms will continue to play a critical role in $R \& D$ networks with large companies and that intensive R\&D collaboration in the pharmaceutical biotechnology industry will therefore be of a more long-term nature.

Our analysis of the evolution of inter-firm R\&D partnerships in the pharmaceutical biotechnology industry reveals that during the first half of the 1990s, there is an explosive growth in the number of R\&D partnerships per firm, accompanied by a strong increase in network density. This latter phenomenon is mainly due to an increase in the number of firms that are connected to one particular partner through at least two R\&D partnerships. In all of this, R\&D partnershijs between two or more large firms played only a minor role and this share of large-large cooperation was even gradually decreasing. Partnerships between large firms and small entrepreneurial companies, however, remained important throughout the period. The detailed analysis of the periods 1985-1987, 1989-1991, and 1993-1995 demonstrates that R\&D networks in the pharmaceutical biotech- 
nology industry are mainly characterized by many strongly tied couples of entrepreneurial biotechnology firms and large companies.

Our findings suggest that the 1990 s have introduced a period of intensified R\&D cooperation leading to denser inter-firm networks in the pharmaceutical biotechnology industry. In these networks, the dominant role of entrepreneurial biotechnology firms as major players with many partnerships seems to be decreasing. However, as large pharmaceutical firms have increasingly become nodal players in R\&D networks, their most preferred partners continue to be small biotechnology firms, implying a continuing mutual dependence between these two groups of firms. 
J

\section{HOW IMPORTANT IS INTER-ORGANIZATIONAL TRUST?}

\subsection{Introduction}

Untill recently, most of the social sciences literature on the role of trust concentrated primarily on trust in the context of individuals or small groups. However, the current management and organization literature (see section 5.2 .1 for an elaborate discussion of this literature) increasingly focuses on trust between organizations. This inter-organizational trust is frequently understood and measured in the context of the repeated ties between two or: more separate organizations such as companies. Many contributions that focus on inter-firm partnerships analyse this inter-organizational trust to explain the current growth in these partnerships. See appendix $\mathrm{C}$ for an overview of empirical studies in leading journals, using repeated ties to measure inter-organizational trust.

As explained in more detail in section 5.2.1, the broad body of relevant literature that has emerged, appears largely influenced by four different approaches: transaction cost economics based governance approach, a relationship-centred trust perspective, and two separate bodies of literature that combine elements of the other two approaches. Although there are some clear differences between these literatures, inter-organizational trust plays an important role in their understanding of the formation of subsequent inter-firm partnerships.

In this chapter, we will analyse the role of inter-organizational trust in an industry with a strong dual market structure, i.e., the pharmaceutical biotechnology industry. Such a dual market structure is largely determined by, on the one hand, a group of large, integrated, international, and established companies and, on the other hand, a group of relatively small, 
specialized companies. The dual market structure in the pharmaceutical biotechnology industry is apparent in the role played by a small group of very large pharmaceutical companies and a large group of relatively small biotechnology companies (Powell, 1996; Saviotti, 1998). In the previous chapter, we have already established that inter-firm partnering in pharmaceutical biotechnology is rather specific in terms of the concentration of inter-firm R\&D partnering within these two groups of companies (see also Kenney, 1986; Powell, 1996; Rothaermel, 2000). To the best of our knowledge, the current literature on the effect of inter-organizational trust on subsequent inter-firm partnering has paid no attention to the specific setting of a dual market structure in a high-tech industry. Early, seminal contributions to the analysis of dual market structures, however, did reveal the impact of such market structures on innovative performance, productivity, earnings, financial issues, labour relations, and marketing practices (see Averitt, 1968; Bowring, 1986). It is the objective of this chapter to investigate whether in this sort of industry, the effect of inter-organizational trust on subsequent inter-firm partnering might also be different from what is known from many studies on other industries with more evenly distributed populations of companies.

As mentioned before, the relationship between inter-organizational trust and inter-firm partnering has been developed in a relatively large number of contributions from a number of research traditions. In the next section, we will discuss these different literatures and their particular understanding of the role of inter-organizational trust in inter-firm collaboration to provide the background for the hypotheses. This is followed by a discussion of two hypotheses that stipulate the expected effect of inter-organizational trust on subsequent partnering. Section 5.3 describes the specific characteristics of the data set, sample, and the variables used in the analysis. In order to test our hypotheses, we constructed a longitudinal, or panel, data set that contains information about the $\mathrm{R} \& \mathrm{D}$ partnering behaviour of pairs of pharmaceutical biotechnology companies. This data set also comprises 
some information about the companies in these pairs, such as their location and size. In section 5.4, we discuss the use of a logit method to analyse panel data. This methodological section is followed by section 5.5 , which reports the results of the study. Section 5.6 provides a discussion of our findings. Some conclusions to be drawn from this chapter are discussed in the final section.

\subsection{Theory development and hypotheses}

\subsubsection{The role of inter-organizational trust in inter-firm partmering}

The current literature on inter-organizational trust and inter-firm partnerships appears largely influenced by four approaches:

- A predominantly transaction cost economics based governance approach;

- A relationship-centred perspective on networks of collaborating firms;

- A synthesis of the governance and the relationship-centred approaches;

- A learning perspective that also combines elements of the other two approaches, but with a strong emphasis on the learning experience within repeated ties.

Although the governance approach has its roots in a number of theoretical traditions, largely derived from several streams of economics (agency theory, game theory, and contributions from institutional economics), it owes the greater part of its intellectual heritage to transaction cost economics. From this latter perspective (Williamson, 1975, 1985, and 1996), trust between companies, or better: the initial lack of inter-organizational trust, has to be understood in the context of the possible opportunistic behaviour and bounded rationality of companies. Both opportunistic behaviour and bounded rationality are expected to affect the transactions 
and economic relationships of companies. When it comes to the understanding of inter-firm partnering, issues such as small numbers bargaining: the incomplete nature of many contracts, and the opportunism of economic subjects play a major role in the analyses from this theoretical perspective. Inter-organizational trust in inter-firm relationships will only emerge if adequate safeguards prevent companies from abusing the possibilities for opportunistic behaviour. This opportunistic behaviour is assumed to exist particularly in "hybrids" in between market transaction and integration. In other words, from this perspective, the self-interested and opportunistic behaviour of companies has to be balanced by adequate legal, economic, and ownership safeguards, regardless of whether inter-organizational trust. develops gradually or not at all.

A rather different perception of the role of inter-organizational trust is found in a predominantly continental, European network perspective. In this approach, trust in relationships between companies is seen as an important element in understanding the nature of inter-firm partnerships in e.g., industrial marketing and customer-supplier relationships (Hakansson and Johansson, 1993; Johansson and Matissson, 1987) and in homogeneous industrial districts and regional networks (Herrigel, 1993; Lazerson, 1993; Staber, 1998). At the core of this relationship-centred approach, we find an understanding of partnership formation where the interaction between firms is based on the quality of their information exchange and the mutual trust at the very start of their joint activities. In contrast with the transaction cost economics based governance approach, repeated ties are expected to induce shared interests that invite further partnering and information sharing where companies adapt to each other's demands within a growing number of partnerships (Johansson and Mattson, 1987). In the words of Madhok (1995: 58,59), "(...) mutual adaptation facilitates the exchange and creates efficiency by reducing friction and enhancing coordination. An expectation of repeat interaction over the longer term further cements the bonding between the actors. Thus, instead of frequency of 
interaction increasing the associated transaction costs, greater knowledge of each other, through more willing information sharing in a situation of repeat interaction, improves the capability to mutually adapt and harness the synergies better." From this perspective, inter-organizational trust is essentially a positive force that has long-term effects on the behaviour of partnering companies as it develops further when pairs of companies increase the frequency of their continued interaction (see also Nooteboom, Berger, and Noorderhaven, 1997).

This relationship-centred approach shares the importance attached to the positive perception of inter-organizational trust with some other recent contributions to the management and organization literature on partnership formation (Gulati, 1995a; Ring and van de Ven, 1992; Zaheer, McEvily, and Perrone, 1998). However, there is at least one major difference. In the relationship-centred approach, inter-organizational trust is an "a priori" condition for any relationship between companies. Interorganizational trust will increase over time with repeated ties, but trust itself is present from the start in order to facilitate the foundation of the relationship between two companies. In contributions such as those by Gulati (1995a), Ring and van de Ven (1992), Saxton (1997), and Zaheer et al. (1998), inter-organizational trust is understood to be based on repeated ties with a particular partner. In that context, equity participation in an inter-firm partnership is seen as a necessary safeguard at the initial stages of collaboration. With the increasing frequency of cooperation between partners, inter-organizational trust can develop further and the role of equity-based safeguards will gradually decrease. This line of thinking appears to take a theoretical perspective in between the governance approach and the relationship-centred perspective on collaborating firms. On the one hand, in contrast with the governance approach, these contributions emphasize the crucial role of inter-organizational trust and they stress that safeguards, such as equity participation, play a diminishing role. On the other hand, in contrast with the relationship-centred approach, inter- 
organizational trust is expected to only develop gradually through repeated ties and equity-based safeguards and legal protections still do play a role at the initial stages of inter-organizational trust building.

Elements of the literatures discussed in the above also play an important role in the fourth approach to understanding inter-organizational trust and inter-firm collaboration where inter-active learning through cooperation and repeated ties is a focal point in the analysis (Lundvall, 1993). In that context, inter-organizational trust in pairs of companies that are compatible in terms of the level of their capabilities and the complementarity in their specific competences, is an important prerequisite without which learning would be impossible. Research has indeed established that partnerships are undertaken by pairs of companies that are on the one hand complementary in certain capabilities, but that are also somewhat similar in many of their activities in order to be able to collaborate successfully (Hagedoorn, 1993; Mowery et, al., 1998; Mytelka, 1991). When companies are entering into partnerships with "equals," whether these shared activities are aimed at joint marketing, joint production, or joint R\&D, a major element in this partnering is to learn about new markets, new production methods, new technologies, or to acquire new research capabilities. This learning experience is expected to be crucial to understanding inter-firm collaboration in a variety of different forms of partnerships where companies engage in repeated ties with other companies (Ciborra, 1991; Lyles, 1994).

What we have seen so far is that, despite some basic differences, a number of literatures stress the importance of inter-organizational trust in understanding subsequent inter-firm partnering. Some authors emphasize that inter-organizational trust has to gradually develop once it turns out that legal and ownership safeguards are no longer necessary or these safeguards will only play a limited role in repeated ties. Others stress that inter-organizational trust is so basic to any inter-firm partnership that without trust, it will be difficult to nurture such a relationship and elements 
of common activities, such as joint R\&D, will not emerge if trust does not play a major role from the beginning of the partnership. However, regardless of these differences, it is obvious that in each of these perspectives, with the possible exception of a "traditional" transaction cost economics based governance approach, inter-organizational trust plays a crucial role in understanding the existing and subsequent partnerships between firms.

\subsubsection{The effect of inter-organizational trust on subsequent partnerships}

Most of the literatures discussed in section 5.2.1 indicatie that interorganizational trust is an important element of inter-firm partnering, whether it comes at the start of a collaborative effort or whether it gradually develops as companies continue to partner. In other words, interorganizational trust is expected to be embedded in the specific relationship between companies. Inter-organizational trust is also assumed to grow in pairs of companies that share a common history of collaboration through repeated ties. According to many contributions (Gulati, 1995a; Hakansson and Johansson, 1993; Herrigel, 1993; Lazerson, 1993; Madhok, 1995; Staber, 1998; Zaheer et all., 1998), this shared history of partnering leads to a gradual increase in inter-organizational trust. This increased interorganizational trust will have a positive effect on subsequent partnerships between the same companies (see also Chung, Singh, and Lee, 2000).

For others, inter-organizational trust will not only develop through repeated ties, the frequency of previous partnerships will enable pairs of companies to improve their joint learning, which increases the probability that they will also collaborate in the future (Ciborra, 1991; Luncivall, 1993; Lyles, 1994). Therefore, the general idea behind most literatures on interorganizational trust is that growing numbers of repeated ties in specific pairs of companies, indicating increasing inter-organizational trust, has a positive effect on their subsequent partnerships (see appendix C). Hence: 
Hypothesis 1: The greater the inter-organizational trust in pairs of partnering companies, the greater the likelihood that these pairs will establish subsequent partnerships.

The first hypothesis refers to the effect of inter-organizational trust in general, i.e., all repeated ties in pairs of companies, regardless of the specific markets in which these companies form their partnerships. In other words, the first hypothesis refers to the degree to which companies collaborate with each other, regardless of whether their previous partnerships were in their main product-markets or in other, secondary product-markets. However, it is also interesting to consider the extent to which inter-organizational trust in pairs of companies develops in their main industrial activity. This reflects the role that sector-specific inter-organizational trust plays in the formation of subsequent partnerships.

The literature appears to have paid no attention to this issue of sectorspecific inter-organizational trust. However, we can follow the line of argument presented for the first hypothesis while adding that, if interorganizational trust is important, it is specifically the partnering amongst companies competing in similar main product-markets that requires interorganizational trust. The more these competitors are involved in joint efforts, the more sector-specific inter-organizational trust will develop in these pairs of companies. Hence:

Hypothesis 2: The greater the sector-specific inter-organizational trust in. pairs of companies, the greater the likelihood that these pairs will establish subsequent partnerships.

\subsection{Data, sample, and variables}

\subsubsection{Data}

This chapter focuses on the pharmaceutical biotechnology industry, a sector where we find a large number of $R \& D$ partnerships and where this form 
of inter-firm partnering is an important aspect of the behaviour of many companies (Barley et al., 1992; Powell et al., 1996; Rothaermel, 2000). In order to test the hypotheses, we constructed a data set on pairs of pharmaceutical biotechnology companies with R\&D partnerships. This data set was obtained from the MERIT-CATI database (see appendix A), a comprehensive database that contains information on R\&D partnerships (Hagedoom, 1996a; Mowery et al., 1998). This database comprises information on thousands of technology-related inter-firm partnerships in various industries, ranging from high-tech sectors such as pharmaceutical biotechnology to less technology-intensive sectors such as chemicals. In order to systematically collect information on inter-firm partnerships, various sources were consulted from the international financial and specialized technical press. The databank contains information on each R\&D partnership and some information on companies participating in these partnerships.

\subsubsection{Sample}

The sample of pairs of pharmaceutical biotechnology companies that forms the starting point for our study comprises a total of 804 pairs of partnering companies that are cooperating through 882 R\&D partnerships during the period 1991-1998. We checked whether partners in these alliances are indeed separate companies and not connected through common governance, using information from Disclosure.

In technical terms, what we study are balanced panels, that is, all pairs of companies in our sample were in the risk set during the entire period of observation. This means that they are assumed to have had the opportunity to form R\&D partnerships during the entire period. Therefore, we had to exclude pairs with companies that were established since 1992 and pairs with companies that ceased to exist during this period, either through a take-over or due to bankruptcy. These procedures led to a sample of 34 pairs of pharmaceutical biotechnology companies that might cooperate through multiple partnerships leading to 272 observations. 


\subsubsection{Variables}

The dependent variable, R\&D partnerships, is a dichotomously coded variable for the occurrence of an R\&D partnership for each year during the period 1991-1998. Each dependent variable takes the value of one when the companies in a pair entered into an R\&D partnership with each other during a particular year and it takes the value of zero if this did not occur in the given year. Pairs can experience more than one partnership during a given year.

For each pair of companies, we calculated two R\&D partnering-related measures of inter-organizational trust as the independent variables for each year during the period 1991-1998. These measures were calculated until the end of the five-year period preceding the given year, so the starting year for measuring these independent variables is 1986. We use this five-year moving window approach, because only partnerships formed during these few previous years are likely to affect current partnering behaviour (see Gulati, 1995b). This approach also enables us to control for left censoring in the data set. To verify the results of this approach, we will also apply a cumulative method. This cumulative approach assumes that all R\&D partnering activity that has taken place before a given year, can influence partnership formation.

The central independent variables used in the analysis are inter-organizational trust and intra-sector inter-organizational trust. Inter-organizational trust reflects repeated ties through all common R\&D partnerships between the companies in a pair, including those made in other industries than pharmaceutical biotechnology (hypothesis 1). Intra-sector inter-organizational trust regards only the number of pharmaceutical biotechnology partnerships made between the companies in a pair (hypothesis 2).

We include various control variables in the analysis, each of which are expected to influence the R\&D partnering behaviour of companies. Differ- 
ent organizational modes of R\&D cooperation such as contractual agreements and equity-based partnerships, are expected to affect the partnering behaviour of firms in different ways. In equity-based R\&D partnerships, such as joint ventures, two or more partnering companies typically share control over a number of common activities besides R\&D, and as such, the organizational interdependence of the partners tends to increase as the relationship continues over time. Based on "traditional" views from the transaction cost economics based governance approach, one would expect that in equity-based collaborative settings that come close to hierarchical control structures, inter-organizational trust between partnering companies is likely to develop gradually up to the level where firms would engage in repeated ties. In contrast to this, contractual R\&D agreements are by definition incomplete contracts, and given the uncertainty surrounding the legal protection of partners in incomplete contracts, one could propose that a possible lack of inter-organizational trust between the partnering companies is likely to prohibit these firms from engaging in repeated ties.

However, according to Gulati (1995a), inter-organizational trust could, after an initial phase of equity participation, just as well develop in contractual agreements as in equity-based partnerships. In this view, contractual agreements are based on knowledge of each other developing interorganizational trust between the partnering companies, which develops through repeated ties between the same partners. In these situations, equity investments are no longer required as a means to protect the partners in the alliance against potential opportunism.

We include several variables to control for the effect of the preference for contractual forms of R\&D partnerships on subsequent partnering behaviour, indicating the relevance of contractual agreements vis-à-vis equitybased safeguards (see also Dyer and Singh, 1998; Gulati, 1995a). The contractual nature of $R \& D$ partnerships expresses the average share (percentage) of contractual agreements in the total number of $R \& D$ partnerships of both partners in pairs of pharmaceutical biotechnology companies, 
until the end of the five-year period preceding a given year. This variable is calculated to reflect the extent to which pairs of companies engage in contractual agreements or equity-based partnerships, both within the pharmaceutical biotechnology industry and in other industries. We also include separate variables (intra-sector and inter-sector contractual nature of R\&D partnerships) that express the degree to which pairs of companies concentrate these different forms of partnerships in pharmaceutical biotechnology or in other industries.

Another control variable refers to the role played by international partnerships that seem to behave quite differently from partnerships within the same international tracling block (Buckley and Casson, 1988; Contractor and Lorange, 1988b; Dyer and Singh, 1998). Firms do not usually possess the same amount of information on potential "foreign" partners as they have on possible partners within the same region. In addition, the costs for obtaining valuable information on international partners are typically much higher. Furthermore, companies could find it more difficult to control international partnerships than to control regional partnerships while opportunistic behaviour is more likely to occur when the partners are located in different continents. For these reasons, companies could prefer regional partnerships, particularly when the sharing of sensitive R\&D activities is part of the agreement.

We control for the regional nature of R\&D partnerships as the average percentage of all the regional $R \& D$ partnerships of both companies in their total number of R\&D partnerships during the five-year period preceding the given year. This variable reflects the extent to which pairs of companies engage in regional partnerships, both within the pharmaceutical biotechnology industry as well as in other industries. Regional partnerships are registered according to the region of origin (North America, Europe, Asia, and other regions) in which the headquarters of companies are located. 
We also include intra-sector and inter-sector regional nature of R\&D partnerships to control for the degree to which pairs of companies concentrate regional partnerships in pharmaceutical biotechnology or in other industries. ${ }^{11}$

In addition, we control for size differences between the companies in a pair. Several researchers have already shown that the size of companies influences their R\&D partnering behaviour (Hagedoorn, 1996a; Mytelka, 1991). The variable size ratio records the total number of employees of the largest company in a pair divided by the total number of employees of the smallest company in the pair. This ratio is calculated for each year that precedes the year for which the dependent variable is calculated. Small biotechnology firms typically employ mainly R\&D specialists and therefore they have, compared to large pharmaceutical firms, lower numbers of employees in many other functional areas, such as production, marketing, sales, etc. We therefore transformed these size ratios into a logarithmic scale (natural logarithm) to account for size differentials, which are unrelated to the technological activities of companies.

Finally, we control for the time since the last R\&D partnership was established. We assume that the more years have passed since pairs of pharmaceutical biotechnology companies have formed their last common partnership, the less likely they will engage in new R\&D partnerships (see also Gulati, 1999). The variable duration was constructed to record the time elapsed since the prior partnership of pairs within the five-year period preceding the year for which the dependent variable is calculated. This wariable is set to zero at the outset.

\footnotetext{
"We do not differentiate between conestic and crossmorder, international partners, because, for instance in the case of European companies, wo firms located at very close distance, e.g., one phamacentical company in the South of Germany and another in Switzerland, wonld be counted as international partners whereas two US companies on both sides of the condinent. would be considered domestic. In other words, this measure takes into accont the current rate of internationalisation, the effect of economic integration, and the large size differences amongst countries.
} 


\subsection{Statistical method}

We model partnership formation by means of binomial logit models for panel clata. A panel data set follows a given sample of cases (pairs of pharmaceutical biotechnology companies) over time and thus provides multiple observations on each of the cases in the sample. One advantage of panel data sets over traditional cross-sectional or standard time-series data sets is that they typically provide researchers with a larger number of data points, thereby reducing the collinearity among independent variables (see. amongst others Baltagi, 1995; Hsiao, 1985 and 1986; Klevmarken, 1989; Solon, 1989).

Apart from this important advantage, panel data sets also enable us to handle a key statistical problem that often arises in empirical studies, i.e. the problem of "unobserved heterogeneity" (Baltagi, 1995; Hsiao, 1986; Wansbeek, 2001). This problem occurs when the actual reason for finding or not finding certain effects is due to the role of omitted (misspecified. unobserved) variables that are correlated with the independent variables (see also Baltagi and Levin, 1992; Black, Moffitt, and Warner, 1990; Chintagunta, Kyriazidou, and Perktold, 2001; Hajivassiliou, 1987; Heckman, 1981). This is also of concern for our study where we suggest that interorganizational trust in pairs of partnering companies affects the likelihood of subsequent partnership formation. This expected effect might occur, because we manage to capture a genuine effect of inter-organizational trust. building in pairs of pharmaceutical biotechnology companies on their future preferences for forming R\&D partnerships. There is, however, another possibility that could lead us to make statistical inferences with respect to our sample on the basis of spurious results: pairs of pharmaceutical biotechnology companies may differ in their propensity to form R\&D partnerships, not because of real differences in the level of inter-organizational trust that has developed amongst these companies, but because of unobserved effects in our data set that are not captured by any of the independent variables 
in the model. We may then conclude that inter-organizational trust is an important determinant of subsequent partnership formation, merely because the independent variables serve as proxies for omitted variables that affect the formation of R\&D partnerships. Through the use of data on both individual characteristics of the pairs of companies in our sample and on the inter-temporal dynamics (panel data), we are better able to control for the effects of omitted variables.

To address concerns of heterogeneity, we employ fixed-effects logit models for our statistical analysis (see also Ahn, Lee, and Schmidt, 2001; Baltagi, 1995; Charlier, Melenberg, and van Soest, 2001). Fixed-effects models treat the unobserved pair effect as a constant over time. This method entails computing a separate constant term for each pair of pharmaceutical biotechnology companies and including a dummy variable for each of these pairs. A frequently used fixed-eflects logit model for panel data is the one proposed by Chamberlain (1980 and 1984), in which a variable's positive coefficient inclicates that it promotes the occurrence of an event (see Charlier, Melenberg, and van Soest, 2000), in our case, the formation of a new R\&D partnership, where:

$$
P\left(y_{i t}=1\right)=\frac{e^{X_{i t}^{*} \beta+\alpha_{i}}}{1+e^{X_{i t}^{\prime} \beta+\alpha \alpha_{i}}}
$$

In equation 5.1, $P\left(y_{i t}=1\right)$ is the probability that $y$ takes the value $\mathbb{I}$ at time $t$ for pair $i$. This probability is a function of a time-varying vector of explanatory variables $\left(X_{i t}^{\prime}\right)$, which characterizes pair $i$, and a vector of unknown parameter $\beta . \alpha_{i}$ is a separate time-invariant intercept (dummy variable), computed for each pair $i$. Fixed-effects models cannot contain any variables, which are the same in every period (other than pair-specific eflects). 


\subsection{Results}

Table 5.1 provides some descriptive statistics for all variables under study and it gives the correlations between these variables. Obviously, some of the relatively high correlations indicate possible multi-collinearity, in particular between the variable cluration and other explanatory variables. Therefore, we also estimated fixed-effects logit models for panel data excluding the variable duration. Table 5.2 displays the estimation results of these logit models using LIMDEP 7.0. We report the results of the moving window approach. The results of the cumulative approach turned out to be not significantlly different.

Hypothesis 1 argues that greater inter-organizational trust in pairs of partnering firms, expressed through increasing numbers of repeated ties in R\&D partnering, will increase the likelihood of their subsequent partnership formation. However, in models 1 and 2 (see table 5.2), interorganizational trust in pairs of pharmaceutical biotechnology firms has a significant, negative effect on their involvement with $R \& D$ partnering at a later stage. We allso hypothesized that increasing sector-specific interorganizational trust in pairs of companies, measured only through their repeated ties in pharmacentical biotechnology $R \& D$ partnering, will have a positive impact on the likelihood of their subsequent partnerships in this industry (hypothesis 2). The estimates of the indicator for intra-sector inter-organizational trust in models 3 and 4 (see table 5.2) are also negative and significantly different from zero. These results suggest that interorganizational trust in pairs of pharmaceutical biotechnology companies, expressed through their repeated ties in R\&D partnering; does not have the expected predicting power regarding the likelihood of subsequent partnerships of these pairs of companies. Thus, hypotheses 1 and 2 are not supported.

Following some other studies (Chung et al., 2000; Gulati, 1995a; Saxton, 1997), we undertook some additional analyses including squared terms 


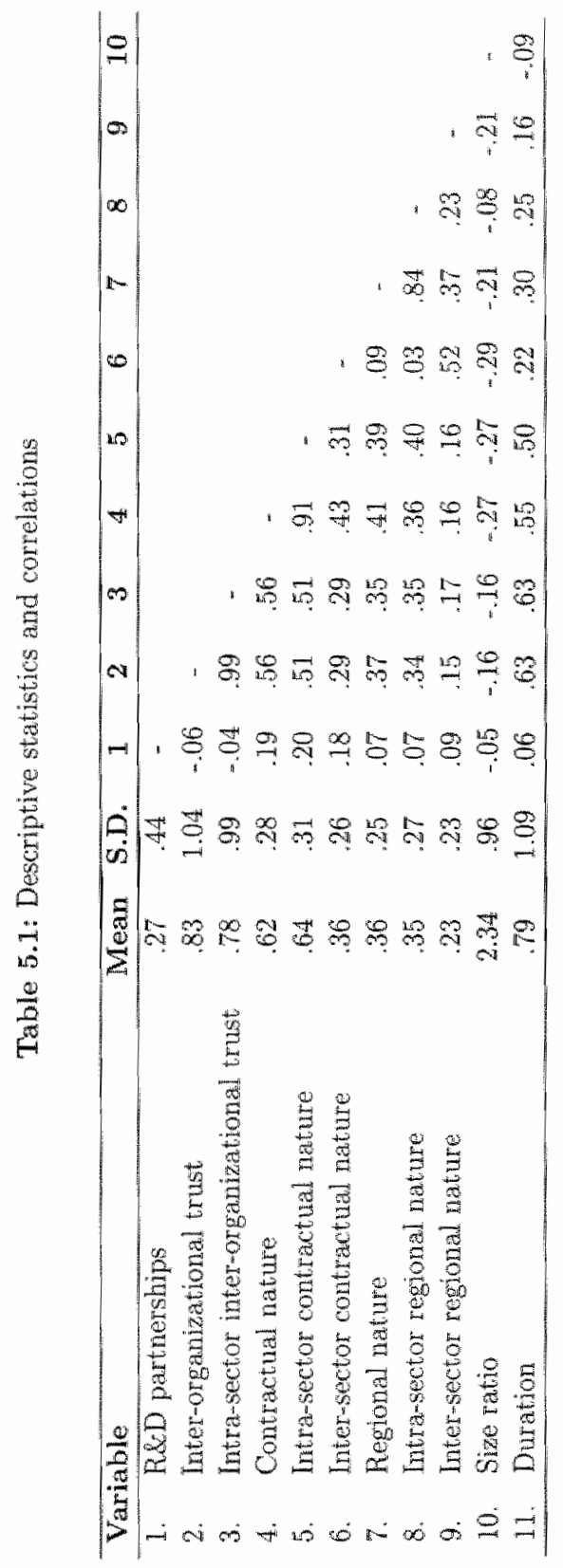


Table 5.2: Fred-effects panel logit estimates

\begin{tabular}{|c|c|c|c|c|}
\hline Variable & $\mathbb{1}$ & 2 & 3 & 4 \\
\hline Inter-orgenizational trust & $\begin{array}{c}-.96122^{*} \\
(.23145)\end{array}$ & $\begin{array}{c}-1.03001^{* * *} \\
(25074)\end{array}$ & & \\
\hline Iritra-sector inter-organizational trust & & & $\begin{array}{c}-.88506^{\text {榢** }} \\
(.22281)\end{array}$ & $\begin{array}{c}-.96122^{* *} \\
(.24641)\end{array}$ \\
\hline Contractial nature & $\begin{array}{c}3.46301 \\
(.91662)\end{array}$ & $\begin{array}{c}3.27530^{* *} \\
(.94290)\end{array}$ & & \\
\hline Intra-sector contractual nature & & & $\begin{array}{c}2.78001^{30} \\
(.77638)\end{array}$ & $\begin{array}{c}2.64864^{\text {K* }} \\
(.79516)\end{array}$ \\
\hline Inter-sector contractual nature & & & $\begin{array}{l}2.19001^{*} \\
(1.06327)\end{array}$ & $\begin{array}{l}2.20021 \% \\
(1.06216)\end{array}$ \\
\hline Rogional nature & $\begin{array}{c}-.25870 \\
(1.02635)\end{array}$ & $\begin{array}{c}-.26703 \\
(1.02299)\end{array}$ & & \\
\hline Intra-sector regional nature & & & $\begin{array}{l}-.62014 \\
(.98667)\end{array}$ & $\begin{array}{l}-.60376 \\
(.98719)\end{array}$ \\
\hline Inter-sector regional nature & & & $\begin{array}{c}-32464 \\
(1.28375)\end{array}$ & $\begin{array}{c}-.35001 \\
(1.28845)\end{array}$ \\
\hline Size ratio & $\begin{array}{l}-.79966^{\text {* }} \\
(.33240)\end{array}$ & $\begin{array}{l}-.80486^{*} \\
(.33310)\end{array}$ & $\begin{array}{l}-.70331^{*} \\
(.33406)\end{array}$ & $\begin{array}{l}-.69428 * \\
(.33438)\end{array}$ \\
\hline Duration & & $\begin{array}{c}.14290 \\
(.18434)\end{array}$ & & $\begin{array}{c}14623 \\
(.18678)\end{array}$ \\
\hline$N$ & 272 & 272 & 272 & 272 \\
\hline Log-likelihood & -97.83 & -97.53 & -95.59 & -95.29 \\
\hline
\end{tabular}

Standlard errors in parentheses; significance-levels * $p<.05 ; * * 0.01 ; \mathrm{N}=$ number of obserwtions. The dependent variable is 1 if the peir forms an R\&D partnership and 0 if not.

for both trust-related variables to detect a possible inverted U-shaped relationship between repeated ties and the likelihood of subsequent R\&D partnerships. It turned out, however, that, unlike in most other studies, the effects of these squared terms were insignificant.

As far as the control wariables are concerned, our findings show that in all four models in table 5.2 , the estimates of the specific terms that capture the regional nature of $R \& D$ partnering and the measure of duration are insignificantly different from zero. However, in all four models, the contractual nature of R\&D partnerships does have a positive, significant effect on the future involvement in R\&D partnering of pairs of pharmaceutical biotechnology companies. Finally, it is important to note that the control 
variable size ratio, which expresses the size differences between partnering companies, has a negative, significant effect on subsequent R\&D partinering, see also models $1-4$ in table 5.2 .

\subsection{Discussion}

The current management and organization literature on inter-firm collaboration pays extensive attention to the role of inter-organizational trust between companies when they are establishing new partnerships or when they continue their cooperation through a range of repeated ties. With the exception of the "traditional" transaction cost economics based governance approach (Williamson, 1975, 1985, and 1996), all the literatures cliscussed in this chapter, stress the crucial role of inter-organizational trust in understanding the existing and subsequent partnerships between companies. From a transaction cost economics perspective, it is possible for inter-organizational trust between companies to emerge in collaboration, but adequate legal, economic, and ownership safeguards are always necessary to prevent partnering companies from behaving in an opportunistic manner. Other literatures such as the relationship-centred approach (e.g., Ciborra, 1991; Hakansson and Johansson, 1993; Johansson and Mattson, 1987; Nooteboom et al., 1997), emphasize that if mutual trust between partnering companies is not an important element of their relationship from the very start of the partnership, it will be difficult to continue such a relationship and learning through shared activities, such as joint R\&D, may not even be possible.

A number of contributions take a stand in between the governance approach and the relationship-centred approach when they stress that interorganizational trust can gradually develop within the context of repeated ties between pairs of companies (e.g., Gulati, 1995a; Ring and van de Ven, 1992; Saxton, 1997; Zaheer et al., 1998). With the increasing frequency of collaboration between partners, the importance of using safeguards, such 
as equity participation, is expected to decrease over time. In other words, inter-organizational trust is gaining relevance as inter-firm partnering is becoming more important, both in terms of the overall number of partnerships and the degree to which specific pairs of companies demonstrate repeated ties.

Given this central role for inter-organizational trust in so many contributions and its almost standard operationalization in terms of repeated ties (see also appendix C), it is quite surprising that our findings do strongly suggest that inter-organizational trust is negatively related to subsequent R\&D partnering. This qualifies the many suggestions regarding the positive role of inter-organizational trust, as found in these different literatures; perhaps with the exception of the governance approach. However, the positive effect of the share of contractual R\&D agreements on the likelihood of subsequent partnership formation indicates that the role of equitybased partnerships, with their embodied equity-based safeguards, appears to carry little weight in the partnership formation process. Therefore, this dimension of a transaction cost economics based governance approach is of little help in explaining our findings.

So, if we would accept, as suggested by so much evidence from other studies, that inter-organizational trust generally does play a positive role in understanding the likelihood of subsequent partnerships, why does it have such an adverse effect in our study? We propose that an interpretation of this negative role for inter-organizational trust can be found in the context of understanding the specifics of R\&D partnering in a high-tech dual market structure, such as found in the pharmaceutical biotechnology industry. For this industry, we found a significant, negative effect of large size differentials in pairs of pharmaceutical biotechnology companies on the likelihood that they will continue to collaborate in the future. As already indicated in the introduction to this chapter, the majority of R\&D partnerships in pharmaceutical biotechnology are formed between large pharmaceutical companies and small biotechnology firms. In our sample, over 70 
percent of these pairs are large-small coalitions. These large pharmaceutical companies typically provide their many smaller partners with financial support and regulatory know-how, in return for which large companies acquire access to the research skills of these small biotechnology companies (Arora and Gambardella, 1990; Barley et al., 1992; Pisano, 1991; Powell, 1996; Shan et al., 1994).

We submit that inter-organizational trust does not have to develop in such a situation where partners are substantially different in tems of size and where both groups of companies play such a different role in the innovation process. It is also important to note that in this industry, large companies have a wide array of changing $R \& D$ partnerships whereas most small companies have a limited number of partnerships. In our sample, the average large pharmaceutical company had more than ten R\&D partnerships during the period 1991-1998; the average small biotechnology firm had only a couple of these partnerships. The actual number of partnerships of small biotechnology companies is even substantially lower, because of the necessarily strict selection criteria for our panel data sample. This excludes small companies entering the industry later during the period of investigation and small companies that went bankrupt or that were taken over. These small companies had even fewer R\&D partnerships than the small companies that were included in the sample.

Rousseau, Sitkin, Burt, and Camerer (1998) stress that interorganizational trust can only develop when there is mutual dependence between partners. In the pharmaceutical biotechnology industry, large companies are only partly dependent on small companies as a group, but quite independent from individual small companies. The position of individual small companies vis-à-vis large pharmaceutical companies, however, is rather weak. Many small R\&D companies concentrate on the same or somewhat similar technologies, so switching costs for large companies are relatively low. Also, many large companies use their R\&D partnerships to scan the technological environment and to collect information on new re- 
search topics and interesting, new technological developments (Arora and Gambardella, 1990; Hagedoorn, 1996a; Powell et al., 1996). For small biotechnology firms, these R\&D partnerships are not so much part of a scanning exercise, but a source of income and an important element in their survival strategy (Kenney, 1986; Saviotti, 1998). Consequently, mutual inter-organizational trust does not appear to be a major force in these R\&D partnerships (for related findings, see Hoang, Rothaermel, and Simac, 2003).

\subsection{Conclusions}

This chapter does not generate the results that one would expect based on existing theoretical and empirical work related to the issue of interorganizational trust in inter-firm partnering and the effects that the development of trust between companies may have on their subsequent partnership formation. Inter-firm R\&D collaboration in the pharmaceutical biotechnology industry does not seem to be stimulated by the development of inter-organizational trust in pairs of companies through repeated ties. In fact, when companies in this industry have collaborated with a specific partner at one point in time, they are not likely to cooperate with the same firm at a later date.

These findings seem to fly in the face of a large part of the management and organization literature that suggests that inter-organizational trust, which develops through repeated ties, is an important stimulus for subsequent partnership formation, or these results do at least qualify some major findings in previous research on this topic. We do accept that in the social sciences, each individual falsification of an established relationship does not necessarily make "tabula rasa" with common knowledge. However, a number of aspects of our contribution could warrant a second look at the accepted understanding of inter-firm partnering and the role of inter-organizational trust in terms of repeated ties. After all, the pharma- 
ceutical biotechnology industry is a sector where partnerships are known to flourish and it takes a relatively large share of the overall number of inter-firm partnerships. In addition, R\&D partnerships are an important group within this multi-faceted phenomenon.

In other words, the results found in this chapter are contrary to what could be expected based on the current literature and they might be counter-intuitive. However, an explanation within the specific context of the pharmaceutical biotechnology industry could be exemplary for an understanding of the role of inter-firm partnerships in high-tech industries. Therefore, it seems interesting for subsequent work to focus on the effect of inter-organizational trust on inter-firm partnering within the context of other high-tech industries with diverging dual market structures and specific groups of partnering companies. 
G

\section{THE ROLE OF MULTIPLE PARTNERING CAPABILITIES AND TECHNOLOGICAL COMPETENCES ${ }^{12}$}

\subsection{Introduction}

Company experience with the formation of inter-firm partnerships plays an important role in the current management and organization literature on repeated inter-firm partnering (see e.g., Anand and Khanna, 2000; Kale and Singh, 1999; Rothaermel and Deeds, 2001). In order to contribute to this body of literature, this chapter will broaden the analysis of the role of experience by considering multiple partnering capabilities and technological competences of companies in a high-tech environment. These partnering capabilities and technological competences are both expected to influence the probability that companies will continue to form interfirm R\&D partnerships. In combining externally oriented partnering capabilities with internal technological competences, we analyse the effect of both the internal and the external absorptive capacity of companies on their propensity to engage in future R\&D partnerships. This chapter also stresses the importance of understanding the role of multiple partnering capabilities, i.e., the general-purpose partnering capabilities of companies, their specific strategic network positioning, and the efficiency with which they arrange their partnerships.

The particular high-tech environment that we study is the pharmaceutical biotechnology industry where there is an abundance of inter-firm partnerships (Hagedoorn, 1996a; Rothaermel and Deeds, 2001; Shan et al., 1994). This industry is also characterized by a large number of inter-firm

${ }^{2}$ This chapter was selected for consideration for the sixth anmal McKinsey/SMS Best Conference Paper Prize at the Strategic Management Society 23rd Anmual International Conference in Baltimore, Maryland, USA. 
R\&D partnerships, i.e., the particular group of partnerships that we study in this chapter.

In section 6.2 , we will first discuss the role of experience and learning in relation to the capabilities of companies and we will place this in the context of inter-firm R\&D partnering. This provides us with a background for understanding the hypotheses on multiple partnering capabilities and technological competences. This general outline of the role of experience, learning, and capabilities in R\&D partnering is followed by a further discussion of a number of hypotheses that stipulate the expected effect of different aspects of partnering capabilities and technological competences on future inter-firm partnering. In order to test the hypotheses, we constructed a relatively large panel data set that contains information about the inter-firm R\&D partnerships and innovative activity of pharmaceutical biotechnology companies over time. In section 6.3 , we describe our sample, we discuss the variables used in this study, we present our data sources, and we outline the use of a logit approach to the analysis of panel data. This methodological section is followed by a presentation and discussion of the results of our study. Finally, in section 6.6 , we present some of the major conclusions to be drawn from this chapter.

\subsection{Background and hypotheses}

\subsubsection{Experience, learning, and capabilities}

We understand the experience that a company has with respect to any of its basic functions to create certain endogenous capabilities which it, if successful, gradually develops further in order to perform economic functions more efficiently or more effectively (Cyert and March, 1963; Nelson and Winter, 1982; Teece, Pisano, and Shuen, 1997). This experience is in fact a stock of accumulated knowledge of an explicit and a tacit nature, which is somewhat difficult to access for other companies (Kogut and Zander, 
1992). This accumulated knowledge base also creates an absorptive capacity that enables a company to learn from a variety of both internal and external sources, such as those related to technological development (Cohen and Levinthal, 1990; Lane and Lubatkin, 1996; Mowery et al., 1998; Stock, Greis, and Fischer, 2001; Tsai, 2001).

Inter-firm R\&D partnerships are clear examples of such external sources that can be used by a company to externally acquire technological knowhow in order to complement its existing knowledge. This existing knowledge base of a company refers to its internal sources of technological knowhow such as its in-house R\&D, its stock of codified knowledge, and its learning capabilities. These internal competences are not only a major sonrce of the technological performance of a company, they also play an important role in attracting external capabilities through $R \& D$ partnerships (see Teece, 1992). Relevant technological experience is a crucial element in developing such technological capabilities as experience with developing capabilities creates opportunities for further learning. This does not only apply to the internal nature of capabilities, it also refers to external capability development. In the following, we will focus on the development of externally oriented partnering capabilities.

It is well known from the literature that inter-firm partnering is difficult to manage, because of its complicated nature and because it is practically impossible to specify the concrete results of joint efforts in advance (Anand and Khanna, 2000; Chung et al., 2000). Furthermore, inter-firm R\&D partnerships are by definition linked to more than one company where shared responsibilities increase the potential managerial complexity. Considerable scope for learning by a company exists in the opportunity to improve its ability to anticipate and effectively respond to contingencies that may unfold as it interacts with R\&D partners. This learning experience through R\&D partnerships can be developed further through interactions with a number of different partners (Gulati, $1995 \mathrm{~b}$ and 1999; Heide and Miner, 1992; Larson, 1992; Levinthal and Fichman, 1988). As also discussed by 
Ring and van de Ven (1992), the frequency with which companies interact with other companies will increase their stock of information on how to manage partnerships. This information will help them forge new inter-firm partnerships with an increasing number of companies.

The more experienced a company is in establishing inter-firm partnerships, the more it will. know how to react to new and unexpected events in its future links to other firms. Beyond learning how to manage interfirm R\&D partnerships in general, firms with more partnerships may also increase their specific knowledge about when to form a partnership, whom to partner with, and how to value external technological knowledge (Cohen and Levinthal, 1990; Levinthal and March, 1993). We also expect that firms with more experience in setting up and managing partnerships may improve their reputation as a partner, because they can contribute to the legitimacy of the partnership. Opportunities to enter into future partnerships are, therefore, more readily available to companies with more experience in inter-firm partnering than to those with fewer prior links to other firms (Dyer and Singh, 1998; Gulati, 1995b; Oster, 1992; Powell et al., 1996). This experience with setting up inter-firm partnerships in itself raises the potential for further cooperation of companies, increasing their already existing experience even further. However, as indicated in the above, this experience does not only reflect the general-purpose partnering know-how of companies, but it also includes the more specific intelligence regarding network settings and the choice for particular R\&D partners.

\subsubsection{Multiple partnering capabilities and future R\&D partnering}

Following the discussion in section 6.2.1, we expect that once a firm starts to build up its partnering experience, it improves its ability to anticipate and effectively react to unexpected events that may occur in its links to other firms (see Gulati, 1995b and 1999; Heide and Miner, 1992; Larson, 1.992; Levinthal and Fichman, 1.988). Through increasing interactions with 
R\&D partners, companies develop a number of general-purpose partnering capabilities in managing these relationships (Lyles, 1988). Knowledge of how to manage inter-firm partnerships will help companies establish partnerships with other companies (Ring and van de Ven, 1992) and improve the likelihood of success of these future relations (Anand and Khanna, 2000; Barkema, Shenkar, Vermeulen, and Bell, 1997; George and Farris, 1999; Kale and Singh, 1999; Ohmae, 1989; Rothaermel and Deeds, 2001; Simonin, 1999).

This ability to form inter-firm partnerships is relevant in all industries, but particularly in high-tech industries such as the pharmaceutical biotechnology sector. High-tech industries are characterized by rapid technological change and unforeseen technological changes that have a major effect on the management of innovation, not only within companies, but also in their partnering activities (Eisenhardt and Bird-Schoonhoven, 1996; Hagedoorn, 1993; Powell, 1996). The ability of high-tech companies to determine the value of external sources of technological knowledge (i.e., choose a competent $R \& D$ partner) allows them to quickly respond to promising new technological opportunities. The more companies develop general-purpose partnering capabilities, the more these capabilities are expected to be helpful in choosing partners.

Our understanding of the effect of general-purpose partnering capabilities, developed through prior experience with inter-firm R\&D partnering, suggests that companies enter into further partnerships, because their experience enables them to build up capabilities for managing these relationships. As such, this indicates a positive effect of experience-based, general-purpose partnering capabilities of companies on their future partnering activities. Hence:

Hypothesis 1: The larger the experience-based, general purpose partnering capabilities of a company, the higher the probability that it will engage in future partnering activities. 
Recent contributions point at a possible curve linear relationship be tween the degree to which companies have established inter-firm partnerships in the past and their future partnership formation. Chung et al. (2000), Gulati (1995b), Hamel, Doz, and Prahalad (1989), and Saxton (1997) indicate that there seem finite opportunities for inter-firm partnering caused by fears of over-dependence on partners and gradually diminishing information gains through additional interaction. This suggests a gradual lowering of the propensity of companies to engage in future interfirm partnerships. The literature usually refers to this non-monotonic effect in the context of pairs of companies (see also chapter 5). However, this effect might also take place in a high-tech environment with a history and an abundance of inter-firm R\&D partnerships within a relatively small group of companies. In that case, a large number of $R \& D$ partnerships within a limited group of companies can dampen subsequent partnering activities. This decreasing propensity to form partnerships will result in an inverted U-shaped relationship between the number of past partnerships of a company and its interest in forming new partnerships. This also indicates that experience-based, general-purpose partnering capabilities could be subject to gradually decreasing learning opportunities through repeated interactions. Hence:

Hypothesis 2: There is an inverted U-shaped relationship between the experience-based, general-purpose partnering capabilities of a company and the probability that it will engage in future partnering activities.

Partnering capabilities can also be understood in terms of the particular ability of a company to place itself in a central position in a broader network of inter-firm partnerships with multiple companies. We expect that a company with specific networking capabilities is able to position itself in such a. way that it can draw information and learn from a variety of inter-firm R\&D partnerships. In terms of social network theory (Burt, 1992; Freeman, 1979; Keik, 1992), this implies that a company with well-developed networking capabilities acts as a strategic player that can manoeuvre itself 
in a central position in between other companies. In a network of $R \& D$ partnerships, a company that is able to occupy a central position also has the potential to control the flows of information between a number of other companies (Freeman, 1979; Knoke and Kuklinski, 1982; Wasserman and Faust, 1994). Companies in such central positions in inter-firm R\&D networks are expected to develop specific partnering capabilities that not only give them control over information Hows in the network, but this information also enables them to use their visible position to attract and select future partners (Gulati, 1999). Also, a central network position shapes a company's reputation as a skilled and knowledgeable partner, producing access to new knowledge through an increasing number of partnerships (Brass, Butterfield, and Skaggs, 1998; Powell et al, 1996).

It is well established that research-intensive, high-tech environments are, given the redundancy of "old" contacts and the need to scan a variety of options, characterized by a high turnover in relatively short-term partnerships (Hagedoorn, 1993; Powell et al, 1996). In that context, it is important to not only maintain a status-quo based central network position, but it is even more valuable to continuously search for new partnerships in order to have timely access to new technologies. A company with a central network position in between other companies is expected to have developed specific networking capabilities that will enable it to use these capabilities to enter into future partnerships. Hence:

Hypothesis 3: The larger the specific network centrality-based partnering capabilities of a company, the higher the probability that it will engage in future partnering activities.

We can also identify specific partnering capabilities in terms of the efficiency that a company has learned to use in choosing its R\&D partners. We expect that a company gradually develops skills that enable it to increase its efficiency in terms of avoiding the maintenance of redundant inter-firm partnerships that carry little additional information (Burt, 1992). Specific efficiency-based partnering capabilities then indicate the degree to which a 
company has learned to optimize its inter-firm R\&D partnerships within a group of other companies, avoiding redundant partnerships. In a network of companies, each firm should, according to social network theory, be well connected to others without sustaining a dense, redundant local network. Efficiency-based partnering capabilities reflect both the experience that a company needs in order to learn which R\&D partners to select (i.e., determine the value of additional information or technological know-how) and its ability to act as a strategic player who is able to create its own efficient network of partnerships. We expect that a company that has developed these specific partnering capabilities necessary to create a strategic network position in between other companies, will employ these capabilities to enter into useful, new R\&D partnerships. Hence:

Hypothesis 4: The larger the specific network efficiency-based partneming capabilities of a company: the higher the probability that it will engage in future partnering activities.

\subsubsection{Technological competences and future $\mathbb{R} \& D$ partnering}

Technological competences are necessary for companies to create competitive advantages, using both internally developed competences and externally acquired resources (Teece, 1992). Inter-firm R\&D partnerships have become a major source of these external resources (Hagedoorn, 1993). However, the opportunities for a company to form R\&D partnerships and the probability that it will continue to partner are partly dependent on its own technological competences (Ahuja, 2000; Forrest, 1996).

Given the complexities of advanced technologies and the long-term nature of the innovation process in research-based industries, such as the pharmaceutical biotechnology sector, the technological competences of companies in these industries are almost, by definition based on accumulated stocks of knowledge. In other words, the nature of advanced technologies demands that a successful company builds an accumulated stock 
of knowledge that enables it to explore a variety of technological options (Cohen and Levinthal, 1990). Therefore, this stock of knowledge not only indicates the past technological performance of a company, but given the continuous nature of knowledge accumulation, it also signals its existing technological competences (Powell, 1996).

A company with a proven track record of technological performance will have developed technological competences that enable it to successfully participate in the "innovation game" with both internal and external resources. For its use of external resources through partnerships, the technological competences of a firm not only make it an attractive partner to other companies, it also gives the firm a strong position in terms of choosing from a range of possible partners (Stuart, 1998). Alternatively, companies with underdeveloped technological competences are companies without a proven track record that can be expected to have some difficulty in finding partners as they have so little to offer (Ahuja, 2000). Hence:

Hypothesis 5: The larger the technological competences of a company, the higher the probability that it will engage in future partnering activities.

\subsection{Research methods}

\subsubsection{Sample}

We chose the international pharmaceutical biotechmology industry as the primary setting for the analysis, because of the large number of inter-firm R\&D partnerships and the substantial R\&D partnering activity that characterizes this high-tech industry (Barley et al., 1992; Hagedoorn, 1996a; Powell et al., 1996; Rothaermel, 2000). The group of pharmaceutical biotechnology companies that forms the starting point for this research comprises a total of nearly 600 companies that are participating in 1764 R\&D partnerships during the period 1991-1998. Using information from 
Disclosure, we checked whether R\&D partners are indeed separate companies and not connected through common governance.

We study balanced panels, that is, all companies in our sample were in the risk set during the entire period of observation. This means that they are assumed to have had the opportunity to form partnerships during the entire period. Therefore, we had to exclude companies that were established since 1992 and companies that ceased to exist during this period, either through a take-over or due to bankruptcy. After these selection criteria were applied to the initial set of cooperating companies, the sample analysed in this chapter was reduced to 1325 inter-firm partnerships and 230 pharmaceutical biotechnology companies that are cooperating through multiple partnerships leading to 1840 observations.

\subsubsection{Main variables}

The dependent variable, R\&D partnerships, is a dichotomously coded variable for the accurrence of an R\&D partnership for each year duxing the period 1991-1998. Each dependent variable takes the value of one when a pharmaceutical biotechnology company entered into at least one R\&D partnership and the value of zero if this did not occur.

For each company, we calculated various measures of their generalpurpose and specific partnering capabilities and one indicator of their technological competences as the independent variables for each year during the period 1991-1998. These measures were calculated until the end of the fiveyear period preceding the given year, so the starting year for measuring these independent variables is 1986 . We use this five-year moving window approach, because we assume that only during these few previous years, the partnering capabilities of companies and their technological competences are likely to affect current partnership formation (Gulati, 1995b). Furthermore, this five-year moving window approach enables us to control for left censoring in the data set. In addition to this, we will also apply a curmulative approach, which assumes that all firm activity that has taken 
place until the year before the given year can influence partnership formation. In that case, new partnership formation is affected by the long-term partnering experience of companies.

Experience-based, general-purpose capabilities of pharmaceutical biotechnology companies are measured as the total number of inter-firm $R \& D$ partnerships of companies in the pharmaceutical biotechnology industry. We include a squared term for this general-purpose experience variable to detect a possible inverted U-shaped relationship between the number of past R\&D partnerships and the probability of future partnerships.

Specific centrality-based partnering capabilities of companies refer to the relative betweenness measure of network centrality as suggested by Freeman (1977 and 1979). This measure is based on the idea that companies control information exchange between other companies in a network to the extent that they are positioned on the geodesic path or shortest path between these companies. Freeman (1977) proposes a measure of betweenness based on the geodesics between all companies. Assuming that two companies $i$ and $j$ are indifferent as to which geodesic is used, the probability of using any one is $\frac{1}{g_{i j}}$ where $g_{i j}$ is the number of geodesics linking $i$ and $j$. If company $m$ lies between companies $i$ and $j$ on a geodesic, the number of such geodesics that involve $m$ is $g_{i m j}$ (Knoke and Kuklinski, 1982; Wasserman and Faust, 1994). Freeman (1977) has shown that the maximum value of betweenness centrality is achieved by the central company in a star-shaped network. That value is $\frac{N^{2}-3 N+2}{2}$ for undirected networks. We assume undirected networks of cooperating companies as inter-firm R\&D partnerships in our data set are characterized by mutual exchanges of technological knowledge. An appropriate measure of relative betweenness centrality for company $m$ is the following ratio, $C_{B}\left(\right.$ firm $\left._{m}\right)$, adapted from Knoke and Kuklinski (1982: 53):

$$
C_{B}\left(\text { firm }_{m}\right)=\frac{2 \sum_{i}^{N} \sum_{<j}^{N} \frac{g_{i m, j}}{g_{i j}}}{N^{2}-3 N+2} \quad i \neq j
$$


This relative betweenness centrality is expressed in percentages where values range between 0 percent and 100 percent, with higher scores indicating greater firm centrality in a network relative to other network partners. We use this relative centrality measure, because an absolute measure of betweenness cannot be used to compare firm centralities of networks with different numbers of companies. This measure is calculated using UCINET 5 (Borgatti, Everett, and Freeman, 1999), a software package that allows for the computation of various network-related measures. The basic source of information for UCINET is a binary, symmetric adjacency matrix containing the partnerships between the companies in a network. We computed separate matrices for each year for which the dependent variable is calculated, including all R\&D partnering activity among panel members throughout the five-year period preceding the given year.

The indicator for the specific efficiency-based partnering capabilities of pharmaceutical biotechnology companies is based on Burt's (1992) hierarchy measure, which is in fact an adjustment of the constraint measure. Constraint indicates redundancy in the inter-firm partnerships of a company in the sense that it measures the extent to which the company has partners that also cooperate intensely among themselves. In that case, the constraint posed by a single partner on a focal company is likely to be highest if the partner is part of a completely connected local network or clique. If the company is also related to other clique members, the probability that the company will gain access to new knowledge through its relationship with this partner, is relatively low. Hierarchy then measures the extent to which the aggregate constraint on a company is concentrated in its partnership with a single other company.

This hierarchy measure can be calculated using the following two-step procedure. First, for each partner $j$ of company $i$, we compute the ratio of partner-specific constraint to the average level of constraint per partner, $R C_{i j}$, which tells us how much one particular partner $j$ is a more severe 
source of constraint to company $i$ than any of its other partners. This ratio can be formulated as follows:

$$
R C_{i j}=\frac{c_{i j}}{C / N}
$$

In equation $6.2, c_{i j}$ measures the constraint posed on company $i$ by partner $j, N$ is the total number of inter-firm partnerships of company $i, C$ is the sum of constraint across all $N$ partnerships, and $C / N$ is the average constraint per partner. The constraint ratio is 1 for partmer $j$ posing an average level of constraint on company $i$.

As a next step, we apply the Coleman-Theil disorder index to generate the actual hierarchy measure. This method multiplies the sum of all partner-specific constraint ratios by its natural logarithm and divides the outcome by the maximum sum possible. For company $i$, the hieraxchy measure, Hier, can thus be stated as follows:

$$
\text { Hier }_{i}=\frac{\sum_{j}\left(\frac{c_{i j}}{C / N}\right) \ln \left(\frac{c_{i j}}{C / N}\right)}{N \ln (N)}
$$

This measure equals 0 when constraint is the same for each partiner of a company. It measures 1 when all constraint is concentrated in a single partnership. In other words, higher values of hierarchy indicate that a company is more efficient in choosing its partners in terms of the contribution that new partners can make to the body of knowledge that the company already has access to through its existing inter-firm partnerships. Lower values of hierarchy, in contrast, indicate more redundancy in a company's partnerships through duplication of information Hows. This measure is also calculated using UCINET 5 (Borgatti et al., 1999).

As a measure for the technological competences of pharmaceutical biotechnology companies, we use the total number of US patent applications of each of these companies. Natural logarithms are taken to correct for the large number of patent applications of large pharmaceutical companies relative to small biotechnology firms. Patents are widely accepted 
in the management and organization literature as appropriate indicators of the technological competences and learning capabilities of companies (Acs and Audretsch, 1989; Patel and Pavitt, 1991). Narin, Noma, and Perry (1987) and Powell and Brantley (1992) describe patents as accurate "signals" of technological competences and learning capabilities in the pharmaceutical biotechnology industry.

\subsubsection{Control variables}

The first control variable that we introduce, relates to the possible effect of the non-biotechnology partnering experience of pharmaceutical biotechnology companies on the probability of their future inter-firm R\&D partnerships. This variable considers the number of $R \& D$ partmerships of firms in other industries than the pharmaceutical biotechnology sector, until the end of the five-year period preceding a given year. We include this control variable, because the experience of companies with partnerships in other industries might add to their general-purpose partnering capabilities or routines in managing these relations (Lyles, 1988; Ring and van de Ven, 1992).

The contractual nature of inter-firm R\&D partnerships is a variable that controls for the effect of the experience of companies with equitybased partnerships or contractual agreements on new partnership formation (Dyer and Singh, 1998; Gulati, 1995a; Osborn and Hagedoorn, 1997). In chapter 3 , we already found that most of the recently formed R\&D partnerships in the pharmaceutical biotechnology industry are of a contractual nature (see also Hagedoorn, 1996a). The degree to which pharmaceutical biotechnology companies have experience in forming contractual agreements might affect their future partnership formation that, in all likelihood, is dominated by these contractual agreements. This variable measures the share (percentage) of contractual agreements in the total number of pharmacentical biotechnology partnerships of companies, until the end of the five-year period preceding a given year. 
We also control for the regional nature of inter-firm R\&D partnerships of companies as the share of all the regional $R \& D$ partnerships in their total number of pharmaceutical biotechnology R\&D partnerships, until the end of the five-year period preceding the given year. Regional partnerships are registered according to the region of origin (North America, Europe, Asia, other regions) of the headquarters of companies. The degree to which companies use international partnerships is one of the most widely used control variables in this line of research. It refers to the role played by international partnerships that seem quite different from $R \& D$ partnerships within the same trading block (Buckley and Casson, 1988; Contractor and Lorange, 1988b; Dyer and Singh, 1998). Firms do not usually possess the same amount of information on potential "foreign" R\&D partners as they would on possible partners within the same region and the costs involved with obtaining valuable information on international partners are typically much higher. Given the current degree of internationalisation of inter-firm partnering (see also chapter 3), the experience of companies with regionally concentrated partnerships might affect their experience-based partnering capabilities and their future inter-firm R\&D partnering.

Finally, we assume that the more years have passed since pharmaceutical biotechnology companies have formed their last R\&D partnership, the less likely they will engage in new R\&D partnerships (Gulati, 1999). The variable duration was constructed to control for the time elapsed since the prior partnership of firms and set to zero at the outset.

Several researchers have already shown that both the size of companies and their R\&D efforts influence the extent to which they form inter-firm R\&D partnerships (Mytelka, 1991; Powell and Brantley, 1992). Our sample of pharmaceutical biotechnology companies includes many small biotechnology firms. Unfortunately, we could not obtain yearly information on the size (i.e., revenues or numbers of employees) and R\&D expenses of most of these, often privately held, small companies. One solution would be to focus our study on a subset of only the largest pharmaceutical com- 
panies for which these kinds of yearly data are more readily available. In that case, our findings would not be representative for the pharmaceutical biotechnology industry at large. However, the variable on the technological competences (patents) of companies does to a large extent also express the size and R\&D efforts of companies (Acs and Audretsch, 1989; Griliches, 1998). For this study, we found a correlation of 0.92 between the number of patents of pharmaceutical biotechnology companies and their revenues for about 40 percent of the companies in the sample, for which we were able to find data on their size.

\subsubsection{Data sources}

Data for the dependent variable, various indicators of the general-purpose and specific partnering capabilities of companies, and the control variables were obtained from the MERIT-CATI database (see appendix A), a comprehensive data set that comprises information on inter-firm R\&D partnerships (Hagedoorn, 1993; Mowery et al., 1998). This databank contains information on each R\&D partnership and some information on companies participating in these partnerships.

The data on patents, which we use as a measure of technological competences, are taken from the US Patent and Trademark Office (USPTO) database of the US Department of Commerce. Although this US data could imply a bias in favour of US-based pharmacentical biotechnology companies and against non-US firms, the patent literature suggests severall reasons to choose US patent data (see e.g., Patel and Pavitt, 1991). Frequently mentioned motivations are the importance of the US market, the genuine patent protection offered by US authorities, and the level of technological sophistication of the US market, which makes it almost compulsory for non-US companies to file patents in the USA. These reasons are particularly relevant for the pharmaceutical biotechnology industry (Powell, 1996). 


\subsubsection{Statistical method}

The data that we analyse in this chapter refer to a panel data set. A panel data set follows a given sample of cases (in our case, pharmaceutical biotechnology companies) over time and thus provides multiple observations on each of the cases in the sample. An important advantage of panel data sets over traditional cross-sectional or standard time-series data sets is that they typically provide researchers with a larger number of data points, thereby reducing the collinearity among independent variables (see amongst others Baltagi, 1995; Hsiao, 1985 and 1986; Klevmarken, 1989; Solon, 1989).

Discrete choice models can be applied to panel data when, as is the case in this chapter, the dependent variable represents the occurrence of a specific event. In the context of this chapter, a pharmaceutical biotechnology company either forms an R\&D partnership in a given year $\left(y_{i t}=1\right)$ or it does not $\left(y_{i t}=0\right)$. As $P\left(y_{i t}=1\right)$ is the probability at time $t$ of the announcement of a partnership of company $i$, we can model new partnership formation as follows:

$$
P\left(y_{i t}=1\right)=E\left\langle y_{i t} \mid X_{i t}\right\rangle=F\left(X_{i t}^{\prime} \beta\right)
$$

In this chapter, we employ binomial logit models for panel data in order to relate new partnership formation of companies to their general-purpose and specific partnering capabilities and their technological competences. In that case, the function $F$ in equation 6.4 represents the logistic distribution function so that the actual models used in this chapter can be stated as follows:

$$
P\left(y_{i t}=1\right)=\frac{e^{X_{i}^{\prime} \beta}}{1+e^{X_{i}^{\prime} \beta}}
$$

In equation $6.5, P\left(y_{i t}=1\right)$ is a function of a time-varying vector of explanatory variables $\left(X_{i t}^{\prime}\right)$, which characterizes company $i$, and a vector of unknown parameter $\beta . \beta$ also includes a time-invariant intercept, which 
is the same for all pharmaceutical biotechnology companies. This particular logit model specification provides us with an interesting alternative to Chamberlain's (1980 and 1984) fixed-effects model (see Cecchetti, 1986). Due to limitations of the extensive panel data set underlying the analyses in this chapter, we were unable to apply the Chamberlain model to our data set.

\subsection{Results}

Table 6.1 provides some descriptive statistics for all variables under study and it gives the correlations for these variables. Table 6.2 displays the estimation results of the various logit models for panel data using LIMDEP 7.0. We only report the results of the moving window approach, because the results of the cumulative approach turned out to be not significantly different. In models 1-4 (see table 6.2), we estimate the partial effects of the different partnering capabilities of pharmaceutical biotechnology companies and their technological competences on the probability of future inter-firm R\&D partnerships of companies. In model 5, we include a squared term for the variable indicating experience-based, general-purpose partnering capabilities of companies to detect a possible inverted U-shaped relationship between these general-purpose partnering capabilities and new partnership formation. In models 6-8, we measure the effects of separate partnering capability variables in combination with technological competences on the probability of future R\&D partnerships ${ }^{13}$. Mlodels 9 and 10 include multiple variables for the partnering capabilities of companies and their technological competences. Model 11 represents the full (reference) model with all relevant variables for partnering capabilities and technological competences.

\footnotetext{
13 We also estimated the effects of the interaction of several combinations of different partnesing capabilities of companies with their technological competences. However, none of these interaction effects turned out to be statistically significant.
} 


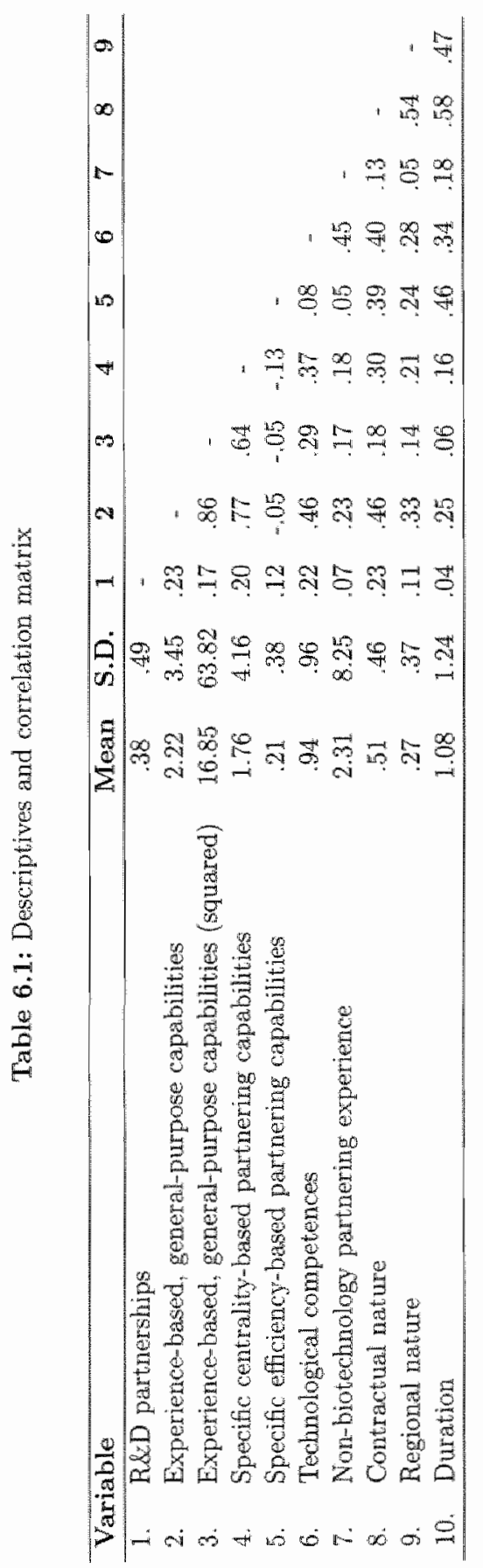


Table 6.2: Panel logit estimates

\begin{tabular}{|c|c|c|c|c|c|}
\hline Variable & 1 & 2 & 3 & 4 & 5 \\
\hline Constant & $\begin{array}{l}-1.04196^{* 35} \\
(.08975)\end{array}$ & $\begin{array}{c}-1.02410^{* 330} \\
(.08050)\end{array}$ & $\begin{array}{c}-1.00702^{\text {* }}(1 / 2 \\
(.07992)\end{array}$ & $\begin{array}{l}-1.19417^{* * *} \\
(.08688)\end{array}$ & $\begin{array}{c}-1.03382^{* 3 *} \\
(.08118)\end{array}$ \\
\hline $\begin{array}{l}\text { Experience-based, } \\
\text { general-purpose } \\
\text { capabilities }\end{array}$ & $\begin{array}{l}.10039^{*} * 0 \\
(.01904)\end{array}$ & & & & $\begin{array}{c}.05147 \\
(.04825)\end{array}$ \\
\hline $\begin{array}{l}\text { Experience-based, } \\
\text { generat-purpose } \\
\text { capabilitisa (squared) }\end{array}$ & & & & & $\begin{array}{r}.00346 \\
(.00326)\end{array}$ \\
\hline $\begin{array}{l}\text { Specific centrality-based } \\
\text { parthering capabilities }\end{array}$ & & $\begin{array}{l}.06777^{* * 3} \\
(.01360)\end{array}$ & & & \\
\hline $\begin{array}{l}\text { Specific efficiency-based } \\
\text { pentnering capabilities }\end{array}$ & & & $\begin{array}{l}42081^{* * *} \\
(.14707)\end{array}$ & & \\
\hline $\begin{array}{l}\text { Techmological } \\
\text { competences }\end{array}$ & & & & $\begin{array}{l}41095^{* * *} \\
(.06279)\end{array}$ & \\
\hline $\begin{array}{l}\text { Non-bioted hology } \\
\text { partnering experience }\end{array}$ & $(.00637$ & $\begin{array}{l}.00865 \\
(.00615)\end{array}$ & $(.01491 *$ & $\begin{array}{l}-.00512 \\
(.00666)\end{array}$ & $\begin{array}{l}.00654 \\
(.00619)\end{array}$ \\
\hline Contractual aature & $\frac{1.16017^{* *}}{(.15761)}$ & $\begin{array}{c}1.30629 \% * \\
(.15191)\end{array}$ & $\begin{array}{c}1.37589^{* * *} \\
(.14982)\end{array}$ & $\begin{array}{l}1.25553^{*} * \\
(.15099)\end{array}$ & $\begin{array}{r}1.23655 * \\
(17224)\end{array}$ \\
\hline Regional aature & $\begin{array}{l}-.80560 \\
(.16399)\end{array}$ & $\begin{array}{l}-.00850 \\
(.16250)\end{array}$ & $\begin{array}{l}.08082 \\
(.16088)\end{array}$ & $\begin{array}{l}-.01627 \\
(.16290)\end{array}$ & $\begin{array}{r}-.06336 \\
(.16462)\end{array}$ \\
\hline Duration & $\begin{array}{l}-.25674^{\text {k* }} \\
(.05573)\end{array}$ & $\begin{array}{c}-.27146^{* * *} \\
(.05608)\end{array}$ & $\begin{array}{r}-.32815 * * \\
(.05794)\end{array}$ & $\begin{array}{r}-31195^{* *} \\
(05601) \\
\end{array}$ & $\begin{array}{r}-25255^{* *} \\
(.05584) \\
\end{array}$ \\
\hline $\mathrm{N}$ & 1840 & 1840 & 1840 & 1840 & 1840 \\
\hline $\begin{array}{l}\text { Log-likehihood } \\
\text { Log-hikelihood change } \\
\text { Chi square }\end{array}$ & -1141.04 & -1143.43 & -1153.19 & -1135.51 & $\begin{array}{c}-1140.39 \\
(5)-(1) \\
1.30\end{array}$ \\
\hline
\end{tabular}

Siandard errors in parentheses; significance-levels ${ }^{*} \mathrm{p}<05 ;{ }^{* *} \mathrm{p}<.01 ; \mathbb{N}=$ mumber of observations. The wependent variable is 1 if the firm forms an R\&D partnership and 0 if not.

The results of the chi-squared test for improvement of subsequent models (see models 5-11) are also reported in table 6.2. The test results show that by including a squared term of the experience-based, general-purpose partnering capabilities variable, model 5 does not gain explanatory power as compared to the restricted model 1 . However, models 6-8, which include the combined effects of several partnering capabilities of pharmaceutical biotechnology companies with their technological competences, do provide us with significantly better fit than models $1-3$, which comprise only one of the indicators for the partnering capabilities of companies. Models 9 and 10, with multiple partnering capability variables, also generate significantly 
Table 6.2 (conturned)

\begin{tabular}{|c|c|c|c|c|c|c|}
\hline Variable & 6 & 7 & 8 & 9 & 10 & 1.1. \\
\hline Constant & $\begin{array}{c}-1.18766^{\text {** }} \\
(.08689)\end{array}$ & $\begin{array}{c}-1.18237^{*} \\
(.08686)\end{array}$ & $\begin{array}{r}-1.22669 \\
(.08774)\end{array}$ & $\begin{array}{c}-1.23271^{*} \\
(.08802)\end{array}$ & $\begin{array}{c}-1.22275 \times 1 \\
(.08781)\end{array}$ & $\begin{array}{c}-1.22862^{* *} \\
(87988)\end{array}$ \\
\hline $\begin{array}{l}\text { Experience-based, } \\
\text { general-purpose } \\
\text { capabilities }\end{array}$ & $\begin{array}{l}.07282^{*} \\
(.01945)\end{array}$ & & & $\begin{array}{l}.10747^{*} \\
(.02198)\end{array}$ & & $\begin{array}{l}.07145 * * \\
(.02915)\end{array}$ \\
\hline $\begin{array}{l}\text { Experience-based, } \\
\text { general-purpose } \\
\text { capabilities (squared) }\end{array}$ & & & & & & \\
\hline $\begin{array}{l}\text { Spesific centraliby-based } \\
\text { parthering capabilities }\end{array}$ & & $\begin{array}{l}.05023^{*} \\
(.01394)\end{array}$ & & & 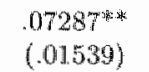 & $\begin{array}{l}.03711^{3 * 1 *} \\
(.02054)\end{array}$ \\
\hline $\begin{array}{l}\text { Specific efficiency-based } \\
\text { partnering capabilities }\end{array}$ & & & $\begin{array}{l}.59271 .{ }^{*} \times c \\
(.15038)\end{array}$ & $\begin{array}{l}.83392^{* *} \\
(.15744)\end{array}$ & $\begin{array}{l}81316^{\text {*2* }} \\
(.15731)\end{array}$ & $\begin{array}{l}.86561^{* * *} \\
(.15868)\end{array}$ \\
\hline $\begin{array}{l}\text { Technological } \\
\text { conpetences }\end{array}$ & $\begin{array}{l}.33739 * * \\
(.06551)\end{array}$ & $\begin{array}{l}.35200^{\text {tiks. }} \\
(.06474)\end{array}$ & $\begin{array}{l}.45228^{* * *} \\
(.06401)\end{array}$ & $\begin{array}{l}.36440^{* * *} \\
(.06626)\end{array}$ & $\begin{array}{l}.38508^{*} \\
(.06547)\end{array}$ & $\begin{array}{l}.35975 * \\
(.06631)\end{array}$ \\
\hline $\begin{array}{l}\text { Non-biotechnology } \\
\text { partnering experience }\end{array}$ & $\begin{array}{l}-.00693 \\
(.00668)\end{array}$ & $\begin{array}{l}-.00586 \\
(.00665)\end{array}$ & $(.00596)$ & $\begin{array}{l}.00881 \\
(.00673)\end{array}$ & $\begin{array}{l}.00731 \\
(.00667)\end{array}$ & $\begin{array}{l}-.00861 \\
(.00673)\end{array}$ \\
\hline Contractual mature & $\begin{array}{c}1.07453^{* *} \\
(.15806)\end{array}$ & $\begin{array}{l}1.17116^{* * *} \\
(.15328)\end{array}$ & $\begin{array}{l}1.12410^{* *} \\
(.15248)\end{array}$ & $\begin{array}{l}80807^{\text {水* }} \\
(.16392)\end{array}$ & $\begin{array}{l}.95273^{*} \\
(.15656)\end{array}$ & $\begin{array}{l}82602^{*} \\
(.16448)\end{array}$ \\
\hline Regional nature & $\begin{array}{l}-.10297 \\
(16536)\end{array}$ & $\begin{array}{l}-.05362 \\
(.16406)\end{array}$ & $\begin{array}{l}.00576 \\
(.16281)\end{array}$ & $\begin{array}{l}-.10855 \\
(.16475)\end{array}$ & $\begin{array}{l}-.36776 \\
(.16372)\end{array}$ & $\begin{array}{l}-.09297 \\
(.16522)\end{array}$ \\
\hline Muration & $\begin{array}{c}-.28781^{* *} \\
(.05621)\end{array}$ & $\begin{array}{c}-.29973^{*} \\
(.05635)\end{array}$ & $\begin{array}{c}-37770^{* *} \\
(05858) \\
\end{array}$ & $\begin{array}{l}-37223^{* *} \\
(.05851)\end{array}$ & $\begin{array}{c}-38562^{* * *} \\
(.58930) \\
\end{array}$ & $\begin{array}{l}-.37759^{* * *} \\
(.05875)\end{array}$ \\
\hline $\mathrm{N} \longrightarrow-2$ & 1840 & 1840 & 1840 & 1840 & 1840 & 1840 \\
\hline $\begin{array}{l}\text { Log-likelihood } \\
\text { log-likelihood change }\end{array}$ & $\begin{array}{c}-1127.75 \\
(6)-(1)\end{array}$ & $\begin{array}{l}-1128.54 \\
(7)-(2)\end{array}$ & $\begin{array}{l}-1127.67 \\
(8)-(3)\end{array}$ & $\begin{array}{c}-1113.53 \\
(9)-(6)\end{array}$ & $\begin{array}{l}-111498 \\
(10)-(7)\end{array}$ & $\begin{array}{c}-1111.84 \\
(11) \times(9)\end{array}$ \\
\hline Chi square & $26.58^{*}$ & $29.78^{3}$ & $51.04 *$ & $28.44 *$ & $27.12^{* k}$ & 3.38 \\
\hline
\end{tabular}

better fit than models 6 and 7 that contain fewer variables of partnering capabilities.

Hypothesis 1 argues that a company is more likely to engage in future inter-firm R\&D partnerships to the extent that it has built up generalpurpose partnering capabilities through its prior experience with R\&D partnerships. In model 1 (see table 6.2), the experience-based, generalpurpose capabilities of pharmaceutical biotechnology companies in setting up R\&D partnerships have a significant, positive effect on their involvement with partmering at a later stage. In model 6 where we include the technological competences of companies, general-purpose partnering capabilities developed through prior experience also have a positive and significant 
effect on future partnering of companies. Similar results are found after adding the specific efficiency-based partnering capabilities variable (model 9).

To detect a possible inverted U-shaped relationship between the experience-based, general-purpose partnering capabilities of companies and the probability of future R\&D partnerships (hypothesis 2), we included a squared term for the experience-related variable in model 5. However, the results show that the effect of this squared term is insignificant. We therefore cannot accept hypothesis 2 .

We also argue that the specific network centrality-based partnering capabilities of companies will have a positive impact on the probability of their future partnering activities (hypothesis 3 ). The estimates of the indicator for specific centrality-based partnering capabilities in model 2 and the extended models 7 and 10 (see table 6.2) are positive and significantly different from zero.

Hypothesis 4 argues that the larger the specific network efficiency-based partnering capabilities of companies, the higher the probability that they will form new inter-firm R\&D partnerships. In model 3 , the estimate of the indicator for specific efficiency-based partnering capabilities of companies has a significant, positive effect on the probability of their future R\&D partnering. If we include measures of the technological competences of these companies (see models 8-10) and their specific centrality-based partnering capabilities (model 10), their specific network efficiency still has a positive and significant effect on the probability that companies will form partnerships at a later stage. These results suggest that the partnering capabilities of pharmaceutical biotechnology companies, expressed through their general-purpose experience with inter-firm partnering, their network centrality, and their efficiency in choosing R\&D partners, have the expected predicting power regarding the probability of future interfirm R\&D partnerships of these companies. Thus, hypotheses 1,3 , and 4 are supported. 
Hypothesis 5 argues that the probability of future R\&D partmerships of companies is positively influenced by the extent to which these compamies have built up technological competences through prior innovative activity. In model 4 (see table 6.2), the indicator of the technological competences of companies has a significant, positive effect on their future R\&D partnerships. Also in models 6-10 where we include various measures of the partnering capabilities of companies, the estimates of the indicator for technological competences are positive and significantly different from zero. These results indicate that the technological competences of pharmaceutical biotechnology companies have a positive influence on their future R\&D partnering. Furthermore, we can improve our understanding of the partnership formation of these companies by not only looking at their generalpurpose and specific partnering capabilities, but also at their technological competences. We thus find strong support for hypothesis 5 .

Model 11 represents the full model that has to be interpreted with some caution, due to the possible multi-collinearity, caused by the relatively high correlation ( 0.77 ) between the experience-based, general-purpose partnering capabilities of companies and their specific centrality-based capabilities $^{14}$. However, comparing these results with models 6 -10 indicates that all three variables indicating different aspects of partnering capabilities are, in combination with the variable for technological competences, very relevant for understanding repeated inter-firm R\&D partnering in the pharmaceutical biotechnology industry.

As far as the control variables are concerned, our findings show that the estimates of the particular term that captures the non-biotechnology R\&D partnering experience of pharmaceutical biotechnology companies is insignificant in most models (see table 6.2). In model 3, however, we find a positive effect of this variable on future inter-firm partnerships of companies, however, only at the 5 percent significance-level. The measure for the regional nature of inter-firm R\&D partnerships is insignificantly different.

14 The high correlation between these two variables may also explain why modol 11 does not provide us with significantly better fit than the restricted model 9 . 
from zero in all models. However, the contractual nature of R\&D partnerships does have a positive, significant effect on the future involvement of companies in inter-firm partnering. Also, in all models, the variable duration has a significant, negative effect on the probability of future partnerships of companies. This implies that the more time has elapsed since a company established an inter-firm partnership, the smaller the probability that it will engage in future partnerships.

\subsection{Discussion}

This chapter examines company-specific factors that influence the formation of inter-firm R\&D partnerships by companies operating in the hightech pharmaceutical biotechnology industry. We use a broad set of theoretical arguments to interpret new partnership formation in terms of both the general-purpose and specific partnering capabilities and the technological competences of the companies involved in this sector. It is clear that the set of wariables concerning the different partnering capabilities of companies and the indicator of their technological competences play a significant role in determining the formation of R\&D partnerships with other companies. This supports the idea that both the firm"s accumulated stock of knowledge about how to partner and its internal technological know-how create crucial opportunities for future learning. This can be discussed further in the context of three main findings.

First, our results suggest that multiple partnering capabilities of pharmaceutical biotechnology companies, in terms of their general-purpose experience with inter-firm R\&D partnering, their network centrality, and their efficiency in choosing R\&D partners, enables them to continue entering into new partnerships. The important role for each of these partnering capabilities can be clearly understood within the context of the learning capabilities that companies develop in their R\&D partnerships (see Anand and Khanna, 2000; Powell et al., 1996). Companies involved in partner- 
ships can improve the opportunity for learning in the sense that their experience with the formation of these partnerships enables them to anticipate and effectively respond to contingencies that may unfold as they interact with their R\&D partners. This partnering experience of companies clearly has to be of an up-to-date nature as our analysis shows that older expertise loses its value for learning, because it has a negative effect on the formation of future inter-firm partnerships. Furthermore, learning opportunities for partnering companies become clear in their ability to place themselves in a central network position in between other companies, which gives them access to multiple sources of information from the network. Also, companies that engage in inter-firm R\&D partnering gradually learn to create their own efficient network of partnerships, selecting new $R \& D$ partners who can contribute to the body of technological knowledge that is already present in their local network. Both the general-purpose and the specific partnering capabilities of pharmaceutical biotechnology companies allow these companies to benefit from their existing and future R\&D partnerships (Oster, 1992; Rothaermel and Deeds, 2001). The visibility that is inherent to these capabilities will help companies forge further partnerships with a variety of R\&D partners, thus improving their opportunities for learning even further (Dyer and Singh, 1998; Gulati, 1995b; Ring and varı de Ven, 1992; Teece, 1992).

Second, we find no evidence of a curve linear relation between the degree to which companies have established inter-firm R\&D partnerships in the past and their future partnerships. This finding is not in congruence with what we would expect on the basis of existing contributions (Chung et al., 2000; Gulati, 1995b; Saxton, 1997) that all indicate that the propensity of companies to form inter-firm partnerships is likely to gradually decrease due to fears of over-dependence on partners and diminishing information gains through new partnerships. We can explain our finding within the context of the pharmaceutical biotechnology industry where the direction of technological development is still unclear and there is consequently a 
high level of uncertainty (OTA, 1991; Senker, 1998). In this specific industrial setting, companies are highly dependent on their R\&D partnerships for timely access to the latest advances in science and technology. As long as technological uncertainty prevails in this industry, timely access to continuing flows of new information will remain crucial and pharmaceutical biotechnology companies are expected to continue scanning the technological environment through their multiple partnerships.

Third, our results indicate that, besides the general-purpose and specific partnering capabilities of companies, their technological competences also play a significant role in explaining their future R\&D partnering activities. This finding is consistent with the idea that high-tech companies that are successful innovators will develop technological competences that enable them to also be actively involved in innovation in the future (Ahuja, 2000; Stuart, 1998). In fact, the accumulated technological knowledge base of a high-tech company creates an absorptive capacity (Cohen and Levinthal, 1990) that enables this company to learn from a variety of $R \& D$ partners. Also, companies with a well-established history of technological performance make attractive partners that are able to access external sources of state-of-the-art technological knowledge through their partnerships with an increasing number of partners.

Our findings clearly show that the general-purpose and specific partnering capabilities of pharmaceutical biotechnology companies in a sollid combimation with their technological competences play a crucial role in setting up future inter-firm R\&D partnerships. We submit that an interesting interpretation of this important role for these multiple firm capabilities can be found in the context of understanding the specifics of R\&D partnering in high-tech industries, such as the pharmaceutical biotechnology sector.

In general terms, high-tech industries can be characterized by their evershortening technology development cycles and the short product life cycles that form a constant pressure on companies to respond quickly to changing market needs and new technological opportunities (Eisenhardt and Bird- 
Schoonhoven, 1996). As mentioned before, timely access to new technologies and state-of-the-art scientific knowledge that is developed outside the boundaries of the firm is crucial to competitive success in these industries. Due to a number of factors, i.e., the globalisation of markets, the increasing complexity of technologies, and the increasing costs of R\&D, even the largest firms are no longer able to individually monitor all the technological and scientific developments that are important for their core markets (Hagedoorn, 1993). Collaboration with a wide variety of $\mathbb{R} \& D$ partners enables companies to simultaneously detect several scientific and technological developments as well as respond quickly to the most promising new opportunities. As companies undertake joint $R \& D$ with several other companies, they learn how to manage such inter-firm partnerships, position themselves for access to numerous sources of information, and how to optimally select partners in terms of their knowledge contribution. These multiple partnering capabilities not only make them attractive partners to other companies, but also allow them to choose from a wide range of possible R\&D partners. The stock of technological knowledge that companies accumulate through their prior innovative activity also adds to their reputation as a partner but, more importantly, it creates an absorptive capacity that allows these companies to evaluate a variety of technological options and ultimately internalise the most promising one. Based on their general-purpose and specific partnering capabilities and their technological competences, companies are thus able to create a portfolio of inter-firm R\&D partnerships that allows them to tap into many different sources of promising new research.

This broad portfolio of partnering options is clearly available in the pharmaceutical biotechnology industry where the majority of R\&D partnerships are formed between large pharmaceutical companies and small, R\&D-intensive biotechnology firms (Kenney, 1986; Powell, 1996; Rothaermel, 2000). For instance, in our sample, about 26 percent of the companies are large pharmaceutical companies and nearly 67 percent of these 
companies are small biotechnology firms. In terms of R\&D partnerships, about 68 percent are large-small coalitions. Large pharmaceutical companies typically provide their many smaller partners with financial support and regulatory expertise, in return for which large companies gain access to the specific research skills of these small biotechnology firms (Arora and Gambardella, 1990; Barley et al., 1992; Pisano, 1991; Powell, 1996; Shan et al., 1994). Large pharmaceutical companies can secure their future access to promising new biotechnologies by building up their stock of knowledge about how to partner and developing their absorptive capacity through internal innovative activity. For small biotechnology firms, it is their variety of partnering capabilities and their visibility as a partner that possesses state-of-the-art technological know-how and technological competences that allow them to enter into future partnerships with a variety of other companies.

\subsection{Conclusions}

Both internal and external sources of capabilities play an important role in understanding the likelihood that pharmaceutical biotechnology companies will engage in future inter-firm R\&D partnerships. Apparently, it is not only the general-purpose experience of these companies with $R \& D$ partnering, but also their specific strategic positioning in R\&D networks and the efficiency with which they use their partnerships that increase the probability that companies will continue to form new partnerships. The combination of these general-purpose and specific partnering capabilities with adequate technological competences of companies increases the probability of new partnership formation even further.

Obviously, there are a number of options for further study of the role of these company-specific capabilities. The current study merely looks at one particular high-tech industry, i.e., the pharmaceutical biotechnology sector. Further study of other high-tech industries can reveal whether these 
effects are also found in a larger group of industries. Similarly, a broader set of capabilities and competences and a wider range of different forms of partnering, preferably placed in the context of other industries than high-tech sectors, can improve our understanding of the role that these company capabilities play in establishing inter-firm partnerships. Given this research agenda, our current contribution has certain limitations, but it also provides us with some interesting answers to a number of relevant questions. 


\section{CONCLUSIONS ${ }^{15}$}

\subsection{Introduction}

The main purpose of this concluding chapter is to reach beyond the individwal theories that were developed in each consecutive chapter by discussing some of the results found in this thesis within the context of a broader theoretical setting. Researchers first began to recognize the importance of understanding inter-firm collaboration for explaining individual firm behaviour in the early $1980 \mathrm{~s}$, when a large number of interesting contributions emerged on the formation, evolution, operation, and outcomes of inter-firm partnerships and inter-organizational networks. The background against which most scholars have studied this variety of issues reflects a mix of theoretical perspectives, several methodological approaches, and distinct foci in terms of industrial background, modes of cooperation, and international patterns (see amongst others Axelsson and Easton, 1992; Badaracco, 1991; Contractor and Lorange, 1988b and 2002; Doz and Hamel, 1998; GomesCasseres, 1996; Grabher, 1993; Harrigan, 1985; Jarillo, 1993; Lewis, 1990; Lorange and Roos, 1992; Nohria and Eccles, 1992; Pfeffer and Salancik, 1978; Porter, 1990).

Within the range of theoretical approaches and methodologies used, we can distinguish two broad-based, diametrically opposed, approaches to the study of inter-firm partnerships: the firm-based view and the network-or partner-oriented perspective (see also Gulati, Nohria, and Zaheer, 2000; Hagedoorn and Osborn, 2002; Osborn and Hagedoorn, 1997). Whereas the firm-based approach stresses such issues as independence, the use of

${ }^{15}$ This chapter is based on Roijakkers, $N$. and Hagedoom, J. Strategic and organizational understanding of inter-firm partmerships and networks. In H. Hanusch and A. Pyka (ods.), Elgor Companion to Neo-Sohwmpeterian Economics. Cheltenham: Edward Elgar (forthooming). 
detailed contracts, and the crucial role of opportunism in partnerships, the network-oriented approach emphasizes the more positive aspects of alliances, such as complementarity, the development of inter-orgamizational trust, and mutual gain. While a complete review of twenty years of research in this field is beyond the scope of the current chapter, we do intend to provide a clear understanding of the theoretical premises underlying each perspective (see table 7.1). This will enable us to discuss both our theoretical and empirical findings in light of these opposing views with reference to their particular understanding of the purpose of the high-tech firm, the organization of high-tech industries, and the specific features characterizing inter-firm R\&D partnerships (see table 7.2).

In the next section, we will first discuss the main characteristics of both the firm-based view and the network-oriented perspective on partnerships and networks. Within the context of both perspectives, section 7.3 reviews the major findings of this thesis in terms of motives, organizational setting, players, and the main determinants of inter-firm R\&D partnerships in the pharmaceutical biotechnology industry. The final section presents some conclusions to be drawn from this chapter.

\subsection{Two different perspectives for explaining inter-firm collaboration}

Standard market transactions of unrelated companies and, full or partial, integration by means of mergers and acquisitions were, until recently, considered by many as the only stable forms of interaction between companies. Most observers viewed inter-firm partnerships where companies can maintain their independence, but at the same time share some of their activities with others, as a relatively unstable and temporary aspect of company behaviour. The upsurge in inter-firm partnerships in the 1980s, however, stimulated scholars to develop a number of theories explaining inter-firm collaboration as a more lasting characteristic of companies in many im- 
dustries. See Contractor and Lorange (1988a), Hagedoorn and Osborn (2002), and Osborn and Hagedoorn (1997), for an elaborate review of both economics-and strategy-based perspectives on partnerships and networks.

Several interesting theories emerged in the 1980s and 1990s that can all be classified into one of two basic categories depending on whether they view inter-firm collaboration as the primary purpose of the firm or as a strategic tool that enables companies to improve their competitive position. The main characteristics of these different approaches are summarized in table 7.1. As both perspectives allow us to position some of the major findings of this thesis within the context of existing theories on inter-firm partnering, we will discuss these perspectives somewhat further.

Table 7.1: Main characteristics of the two most important perspectives on inter-firm collaboration.

\begin{tabular}{|c|c|c|}
\hline Theorical premises & Firm-based view & Network-based view \\
\hline Main purpose of the firm & Competition & Cooperation \\
\hline $\begin{array}{l}\text { Organization of the } \\
\text { industry }\end{array}$ & $\begin{array}{l}\text { Stand-alone, gomitalone } \\
\text { companies }\end{array}$ & $\begin{array}{l}\text { Networked, highly integrated } \\
\text { companies }\end{array}$ \\
\hline $\begin{array}{l}\text { Chameteristics of inter- } \\
\text { fru partinerships }\end{array}$ & $\begin{array}{l}\text { Firm-oriented } \\
\text { Independence } \\
\text { Internalisation of core activities } \\
\text { such as R\&D } \\
\text { Short-term, oriented towards } \\
\text { fulfilling immediate corporate } \\
\text { needs } \\
\text { Opportunism, unequal power } \\
\text { betlanoe } \\
\text { Contracts } \\
\text { Promotion of self-interest }\end{array}$ & $\begin{array}{l}\text { Partner- or network-oriented } \\
\text { Interdependence } \\
\text { Specialization, complementarity, } \\
\text { and network-lewel coordination } \\
\text { Long-term }\end{array}$ \\
\hline
\end{tabular}

\subsubsection{Firm-based view}

In this section, we will elaborate on the firm-based view of inter-firm collaboration, a research trajectory that has led and, to some extent, is still 
leading the field of inter-firm partnership and network research (see also Contractor and Lorange, 1988a, 1988b, and 2002; Gulati et al., 2000; Hagedoorm and Osborn, 2002; Osborn and Hagedoorn, 1997). A basic research issue that is being dealt with in this field is what type of relationship companies should maintain with their suppliers, customers, competitors, or other organizations in their competitive environment. Although a number of researchers were already struggling with this complex question some decades ago (see amongst others Hymer, 1960; MacMillan and Farmer, 1979; Pfeffer and Salancik, 1978; Warren, 1967), most contributions to this field began to appear more recently. In answering this question, researchers have typically chosen to view companies as autonomous entities, striving for competitive advantage from either the unique set of skills and capabilities they possess internally (e.g., Barney, 1986 and 1.991), or from externally located industry sources (e.g., Porter, 1980 and 1985). We can label this particular perspective "firm-oriented," because most of these scholars share the presumption that companies are atomistic actors, competing for profits against each other in an impersonal, hostile market environment. The underlying assumption that it is best for companies to be primarily competitive in their relationships with others is what clearly differentiates this view from the other perspective, the network-oriented perspective on firms and the nature of their relations (see table 7.1).

Researchers employing a firm-based view generally agree that all types of inter-firm relationships are largely competitive in nature (see e.g., Badaracco, 1991; Doz and Hamel, 1998; Hamel, 1991; Hamel, Doz, and Prahalad, 1989; Harrigan, 1985; Perlmutter and Heenan, 1986; Porter, 1990; Porter, Enright, and Tendi, 1990; Prahalad and Hamel, 1990; Reich and Mankin, 1986). Drawing on central concepts from neo-classical economics, they argue that individuals, and the companies they form, are primarily motivated by self-interest and that competition is therefore an important feature of the industrial landscape. In other words, with a firmbased view, companies are assumed to be complex organizations of indi- 
viduals with multiple, partially conflicting interests and/or goals where all companies need to compete to further their immediate, firm-specific needs. Whereas established companies will consistently strive to enhance their competitive advantage vis-à-vis rivals with the aim of earning superior profits, new entrants and manufacturers of substitute products will attempt to strengthen their competitive position in order to ultimately replace existing firms (Porter, 1980 and 1985). In such a hostile, competitive environment, each company should try to obtain a high level of market power, enabling it to effectively deal with competitive threats as well as capitalize on some of the most relevant commercial opportunities. The most powerful companies, in this respect, are the ones that remain independent agents and interact with other companies only through arm's length market transactions (see table 7.1). By "going-it-alone," these companies can avoid becoming overly dependent on specific other firms in their environment, which enhances their effective market power in relation to these companies (Hamel, 1991; Hamel et al., 1989; Porter et al., 1990; Reich and Mankin, 1986).

A large number of researchers within the firm-based tradition began to recognize the extensive use of inter-firm partnerships by predominantly large, established companies in the 1980s. To the extent that specific modes of inter-firm collaboration, such as equity-based partnerships, would compromise the independence and market power of the companies involved, these inter-firm relations were viewed as a second-best option to performing certain tasks independently (Bettis, Bradley, and Hamel, 1992; MacDonald, 1995; Porter, 1990; Porter et al., 1990; Reich and Mankin, 1986). As Porter (1990) has so clearly pointed out, inter-firm partnerships are hardly ever an optimal solution, because no company can rely on others for skills and capabilities that are critical to its competitive position. In this respect, most observers tended to regard a prominent form of interfirm collaboration, i.e., R\&D partnerships, with substantial suspicion for two main reasons. First, R\&D constitutes a core activity for most high- 
tech companies and, as such, it was not often considered a sound basis for inter-firm collaboration. Second, inter-firm R\&D partnerships are often subject to the hazard of opportunism (Harrigan, 1985 and 1988). Due to the ultimately competitive nature of these relationships, R\&D partners will be tempted to serve their own interests to the detriment of others, by manipulating, bargaining, or the use of power to achieve results (see also table 7.1). Inter-firm collaboration, it was therefore concluded, is a form of competition that is negatively related to the long-term survival prospects of companies (Bettis et al., 1992; Hendry, 1995; MacDonald, 1995; Reich and Mankin, 1986; Sapienza, 1989). While a highly competitive environment stimulates companies to continuously improve themselves and innovate, inter-firm partnerships would merely lead to mediocrity and competitjve weakness (Porter et al., 1990).

As some contributions were thus highly cautionary in nature and focussed on the numerous problems involved in managing partnerships and networks, others described the circumstances under which it would be beneficial for companies to engage in cooperation (Badaracco, 1991; Bleeke and Ernst, 1991; Dyer, 1996; Dyer and Ouchi, 1993; Hamel, 1991; Hamel et al., 1989; Kanter, 1994; Lewis, 1990; Nishiguchi, 1994; Ohmae, 1989; Parkhe, 1991; Prahalad and Hamel, 1990). These authors also acknowledge that inter-firm partnerships are fraught with substantial problems and risks, but unlike some of the contributions described in the above, they view these partnerships as a potentially useful tool for improving the firm's competitive position. By selecting a specific alliance option and crafting each partnership to serve immediate corporate needs, managers can use inter-firm partnerships to further the competitive interests of their firms (see table 7.1). Hamel et al. (1989), for instance, argue that companies can substantially benefit from inter-firm partnerships with competitors to the extent that they are able to gain access to their partner's knowledge and skills. However, Hamel et al. (1989) do caution managers that the use of inter-firm partnerships should be based on a sound understanding 
of what is to be learned from specific partners, a well-developed capacity to learn, and strong defenses against their partner's probing of their skills and technologies.

As many authors recognize the risk of surrendering crucial competitive knowledge, researchers propose that inter-firm partnerships be based on detailed contracts, stipulating the expected behaviour of partners and the preferred outcomes of the agreement (see e.g., Kawasaki and MacMillan, 1986). In this line of research, specific modes of cooperation, such as contractual agreements, are thus characterized by their strengths and weaknesses in helping companies ward off competitive threats and capitalize on opportunities to improve their competitive advantage in relation to other firms (see amongst others Bleeke and Ernst, 1991; Doz and Hamel, 1998; Dyer, 1996; Dyer and Ouchi, 1993; Hamel, 1991; Hamel et al., 1989; Kanter, 1994; Teece, 1992; Williamson, 1996).

In this section, we have attempted to establish a clear view of the firmoriented perspective on inter-firm collaboration by discussing part of the research in this field (see also table 7.1). Researchers within this traclition view companies as independent entities, interacting with other companies in a highly competitive environment. They describe the competitive situation as atomistic, that is, each "selfish" individual company strives to satisfy its own needs, leading to intensive rivalry. Under such circumstances, short-term partnerships are mostly contractual in nature where each partner will try to learn as much as possible from the other and, at the same time, limit access to competitive knowledge. Although this particular view was clearly dominating partnership research in the 1980 s, researchers increasingly considered this view inadequate for explaining the partnering behaviour of a large number of companies that were embedded in dense networks of inter-firm relations. This ultimately led to the development of the network-oriented perspective of inter-firm collaboration, which will be described in the next section. 


\subsubsection{Partner- or network-based view}

As pointed out in the preceding section, the basic assumption underlying most of the relevant theoretical and empirical work in the firm-based tradition is that companies are primarily motivated by self-interest and that, therefore, competition drives all interaction between companies. Researchers applying a partner- or network-oriented perspective, however, do not share this particular view of companies and the nature of their relations. Instead, they tend to characterize inter-firm relationships as a dynamic, constantly evolving process where companies adopt a mix of both competitive and cooperative postures in their relationships with other firms. Specifically, in the network-oriented perspective, it is argued that companies are embedded in dense, tightly connected networks of interorganizational relations (see table 7.1). In such a network, the interests and goals of the participating companies are hardly ever totally conflicting or fully aligned. In their relations towards other firms in their environment, therefore, companies must find an optimal balance between competitive and cooperative behaviour, depending on the prevailing circumstances. In some situations, they may find it more beneficial to create long-term, trustful partnerships while under different circumstances they may view a competitive posture as a more suitable approach. Whereas researchers employing a firm-based view thus adopt a rather atomistic view of companies where inter-firm collaboration is regarded as just another competitive tool, most scholars taking a network-oriented perspective view inter-firm partnerships and inter-organizational networks as a real alternative way of dealing with other companies (see amongst others Axelsson and Easton, 1992; Burt, 1992; Ciborra, 1991; Contractor and Lorange, $1988 \mathrm{~b}$ and 2002; Galaskiewicz and Zaheer, 1999; Gomes-Casseres, 1996; Grabher, 1993; Granovetter, 1985; Gulati, 1998; Gulati et al., 2000; Hagedoorn, 2002; Hakansson and Johansson, 1993; Jarillo, 1993; Johansson and Mattsson, 1987; Larson, 1992; Lorenzoni and Baden-Fuller, 1995; Miles 
and Snow, 1992; Powell et al., 1996; Ring and van de Ven, 1992; Thorelli, 1986).

The main theoretical premise underlying the network-based view is that additional benefits may accrue to those companies that intentionally embed themselves in dense networks of long-term collaborative relationships with other companies (Axelsson and Easton, 1992; Barley et al, 1992; Chung et al., 2000; Ciborra, 1991; Gomes-Casseres, 1996; Gulati, 1999; Lorenzoni and Baden-Fuller, 1995; Lyles, 1988 and 1994; Powell and Brantley, 1992; Powell et al., 1996). Specifically, in the network-based view, it is argued that companies can substantially benefit from taking part in a cooperative network to the extent that the network is able to accomplish more than any of the individual partners can achieve independently. The related notion that most companies are willing to accept a relatively high level of interdependence for mutual gain towards common goals gained prominence particularly in the technology and organizational learning views of interfirm collaboration (see e.g., Auster, 1992; Ciborra, 1991; Contractor and Lorange, 1988b and 2002; Hagedoorn, 1993 and 2002; Kale et al., 2000; Osborn and Baughn, 1990; Teece, 1986) (see also chapter 6 of this thesis for a discussion of part of the learning literature).

In these literatures, innovative output is considered to be one of the most prominent outcomes of inter-firm partnerships from which cooperating companies can all benefit. Indeed, researchers studying a number of positive outcomes of inter-firm collaboration, such as learning and innovation, for the most part have often argued that embeddedness in a highly integrated network of equity-based partnerships enables companies to effectively respond to radical changes in their technological environment (see also table 7.1). To the extent that these changes require the development of a whole new set of technological skills and capabilities, inter-firm R\&D partnerships with other, specialized companies are an important part of a learning process for high-tech firms, a process in which they actively search for new opportunities in a network setting of a multitude of inter-firm part- 
nerships (Ciborra, 1991; Hagedoorn, 2002). The companies in such knowledge networks tend to align their research strategies, or even develop their strategies jointly, in an effort to accrue network-wide benefits, such as those pertaining to common access to complementary, specialized technological knowledge, to the advantage of all network partners (Best, 1990; Chung et al., 2000; Jarillo, 1993). The fact that strategic coordination takes place within networks has led several researchers to describe them as an organizational form that exists at a higher level of aggregation than individual companies where the network (also sometimes referred to as group, clique, or constellation) as a whole may compete against other networks or build up collaborative relationships where appropriate (see e.g., Gomes-Casseres, 1994 and 1996; Powell, 1990; Thorelli, 1986).

Another important stream of network-oriented research related to the technology and inter-organizational learning views comes under the heading of inter-organizational trust (see chapter 5 for an elaborate discussion of the main literatures dealing with the subject of inter-organizational trust). In the network-oriented perspective, trust in relationships between companies is viewed as an important element in understanding the nature of inter-firm partnerships and inter-organizational networks (Gulati, 1995a; Hakansson and Johansson, 1993; Herrigel, 1993; Johansson and Mattsson, 1987; Kale et al., 2000; Lazerson, 1993; Ring and van de Ven, 1992; Saxton, 1997; Staber, 1998; Zaheer et al., 1998). In fact, at the core of the networkoriented perspective, we find an understanding of inter-firm collaboration where the interaction between companies is based on inter-organizational trust and mutual adaptation (see table 7.1). To the extent that two or more companies have shaved interests and common goals, they are likely to engage in inter-firm collaboration where they adapt to each other's demands within a number of long-term, trustful partnerships (Johansson and Mattsson, 1987). Several authors within this research tradition have argued that inter-organizational trust is so basic to any partnership and network relation that without trust, a number of positive outcomes of inter-firm 
collaboration, such as innovation, will not emerge if trust does not play an important role in these collaborative relationships between companies. In this respect, inter-organizational trust in a group of cooperating companies, that are more or less "equals" in terms of their (market) power, size, and the level of complementarity in their knowledge base, is an important precondition for the occurrence of inter-organizational learning and innovation (Ciborra, 1991; Hagedoorn, 1993; Lyles, 1988 and 1994; Mowery et a.1. 1998; Mytelka, 1991).

We can thus state that researchers employing a network-based view consider the neo-classical theoretical assumption of atomistic, opportunistic competition to be a serious mischaracterization of the nature of inter-firm relationships. In their view, companies may adopt a competitive posture in some of their relations, but these companies are also characterized by their embeddedness in dense networks of long-term, reciprocal relationships where all network partners strive to attain common goals. The question that we wish to answer in this chapter is, therefore, whether partner- or network-oriented strategies are actually formed by companies operating in the high-tech pharmaceutical biotechnology industry. More specifically, did pharmaceutical companies handle a radical change in technology by maintaining their independence and building on their unique, firm-specific capabilities? Or did they deal with the discovery of biotechnology by embedding themselves in dense, tightly connected networks of trustiful R\&D partnerships? We will deal with these issues at length in the next section.

\subsection{R\&D collaboration in pharmaceutical biotechnology: firm-based or network-oriented?}

This section will review some of the major findings of this thesis in light of both perspectives examining inter-firm partnerships and networks. By discussing our findings in the context of these two diametrically opposed views of inter-firm collaboration, a better understanding of the issues un- 
der study should be gained. In the following, our results will be further discussed and finally summarized in table 7.2 .

\subsubsection{Motives}

The existing literature on inter-firm partnerships and inter-organizational networks pays extensive attention to the nature of inter-firm relationships. and the primary motives underlying most of these relationships between companies. Many of the literatures that we discussed in previous sections, employing either a firm-based view or a network-oriented perspective, typically explain inter-firm collaboration by drawing on a well-defined set of assumptions regarding the main purpose of the high-tech firm.

In the firm-based view, we find an understanding of the high-tech firm and the nature of its relations that is for the most part based on neoclassicall notions of competition. Although researchers in this view tend to disagree about whether core activities, such as R\&D, should be the object of cooperation (see e.g., Hamel et al., 1989; Ohmae, 1989; Porter, 1990; Reich and Mankin, 1986), inter-firm partnerships are generally regarded as just another competitive tool to help strengthen the firm's position vis-à-vis its rivals. Like all other relations between separate companies, short-term inter-firm partnerships are largely motivated by self-interest where each of the participating companies tries to use the alliance to serve its own, firm-specific needs (see table 7.1). In contrast, in the network-oriented perspective, it is argued that the behaviour of high-tech companies and the interaction between different firms is driven as much by cooperation as it is by competition (Axelsson and Easton, 1992; Contractor and Lorange, 2002; Gulati, 1998; Hagedoorn, 1995, Powell et al., 1996). As most of these researchers have so clearly pointed out, companies may choose to cooperate with others in a wide range of core activities where each partner is willing to forego individual goals for the purpose of achieving a number of common, otherwise unreachable, objectives. As such, the motives underlying interfirm partnerships are viewed as partner- or network-oriented in the sense 
that cooperating companies set aside their immediate competitive interests for the benefit of the alliance as a whole (see also table 7.1). Given these different assumptions regarding the nature of inter-firm relationships and the underlying motives, it seems interesting to review some of the findings of this thesis that are related to these issues.

In chapter 2, we analysed the historical development of the high-tech pharmaceutical biotechnology industry in terms of major technological shifts, the companies that brought about these technical changes, and the dramatically changing nature of inter-firm relationships over time. An inportant result of this historical analysis, which is clearly in line with the most critical assumptions underlying the firm-based view, is that interfirm R\&D collaboration did not play an important role in the traditional, organic chemistry-based pharmaceutical industry. On the basis of a large number of historical background articles, we argued that the most dominant innovators in the 1950s and 1960s were following a drug research strategy that involved hardly any formal collaborative relationships with other companies. Although we have been able to identify a few concrete examples of inter-firm R\&D partnering in the years following the Second World War, such as the penicillin consortium and the large number of partnerships in later stages of the drug development process, the majority of inter-firm relationships in this high-tech industry were of a competitive nature (see also Cockburn and Henderson, 2000; Faulkner and Orsenigo, 1989; Freeman, 1990; Galambos and Sturchio, 1998; Hacking, 1986; Marstrand, 1981; Taggart, 1993). As we so clearly pointed out in chapter 2, state-of-the-art drug research and technological know-how are critical to the competitive success of large pharmaceutical companies and, as such, R\&D is not an activity these companies were willing to share with others (Bogner and Thomas, 1994; Cool et al, 1999; OTA, 1991; Reekie and Weber, 1979; Schwartzman, 1976; Taggart, 1993; Walsh and Galimberti, 1993). In support of these findings, our descriptive analysis of the MERIT-CATI database in chapter 3 shows that inter-firm R\&D partnering 
in the pharmaceutical industry did not take off until the second half of the $1970 \mathrm{~s}$, indicating also a very low number of these partnerships prior to the 1970s. Inter-firm relationships in the traditional pharmaceutical industry can thus be most accurately characterized as firm-based or firm-oriented in the sense that each company would typically carry out its core activities internally while they would adopt a predominantly competitive posture in their relations with others.

With the discovery of recombinant DNA technology and hybridoma technology in the first half of the 1970s, however, the pharmaceutical industry witnessed a rather dramatic change in the mix of relationships between companies. As a result of radical developments in science, technology, and drug discovery, pharmaceutical companies were more or less "forced" to adapt their research strategies to also include large numbers of inter-firm R\&D partnerships. Consequently, the relationships between large pharmaceutical companies and small, new biotechmology firms are no longer solely oriented towards competition, but they also involve various sorts of R\&D partnerships between these two groups of companies. In congruence with the network-oriented perspective, chapter 4 shows that the sharply increasing frequency of $R \& D$ partnerships has led to dense networks of cooperation where companies undertake joint research with several other companies (see also Hagedoorn, 1990 and 1993; Kenney, 1986; Powell ot al. 1996).

As we can largely explain inter-firm R\&D partnering in the modern pharmaceutical biotechnology industry within the context of the networkoriented perspective, some of the more traditional insights from the firmbased literature still do apply if we consider the motives underlying these partnerships. In chapter 3 , we outlined some of the rationales for $R \& D$ partnering that are important for both large pharmaceutical companies and small biotechnology firms. For large pharmaceutical companies, their motives to enter into short-term R\&D partnerships are frequently related to a number of immediate company needs, such as the need to gain access 
to the new biotechnological knowledge base, the need to cope with the dramatic rise in $\mathrm{R} \& \mathrm{D}$ costs (see chapter 2), and the need to maintain their strong competitive position as dominant innovating companies (Arora and Gambardella, 1990; Barley et al., 1992; Hagedoorn and Roijakkers, 2002; Powell, 1996 and 1998). In a similar manner, small biotechnology firms use their partnerships with large pharmaceutical companies to serve their own, firm-specific needs, such as the immediate need to finance their R\&D activities and gain access to the larger firms" marketing expertise and regulatory know-how (see also Della Valle and Gambardella, 1993; Larson, 1992; Rothaermel, 2000; Senker and Sharp, 1997). On the basis of this outline, it appears that for both groups of cooperating companies, interfirm R\&D partnerships are primarily motivated by self-interest and the need to fulfil immediate competitive interests.

\subsubsection{Organizational setting}

Besides the main purpose of the high-tech firm and the nature of its relations, both theoretical streams have also developed a well-defined set of assumptions regarding the organization of high-tech industries and the consequent organizational features of inter-firm relationships in this type of industry.

Researchers apjlying a network-oriented perspective have typically argued that the organization of most high-tech industries is fundamentaly based on dense, tightly connected networks of relationships between a number of highly integrated, interdependent companies (see table 7.1). Hightech companies that participate in these knowledge networks are willing to sacrifice part of their independence as embeddedness in such networks enables these companies to accomplish more than they could achieve on an individual basis (Barley et al., 1992; Chung et al., 2000; Gomes-Casseres, 1996; Gulati, 1999; Lorenzoni and Baden-Fuller, 1995; Lyles, 1994; Powell and Brantiey, 1992; Powell et al., 1996). Indeed, several of these authors 
have pointed out that high-tech firms can substantially benefit from taking part in a highly integrated network of equity-based R\&D partnerships to the extent that learning and innowation within the network allow these companies to effectively deal with their rapidly changing technological environment (see Auster, 1992; Ciborra, 1991; Contractor and Lorange, 2002; Hagedoorn, 1995; Osborn and Baughn, 1990). In contrast, in the firmbased view, it is generally agreed upon that high-tech industries consist of large numbers of independent, "go-it-alone" companies where the boundaries between these separate companies are fairly distinct (see also table 7.1). Most researchers employing this perspective have chosen to view hightech companies as autonomous actors, striving for competitive advantage in an impersonal, hostile market environment. Because a high level of integration and dependence on specific other companies may compromise the competitive position and market power of individual companies, it is not considered to be beneficial for high-tech firms to cooperate in R\&D through equity-based partnerships (see amongst others Bettis et al., 1992; Hamel, 1991; Hamel et al., 1989; MacDonald, 1995; Porter, 1990; Porter et al., 1990; Reich and Mankin, 1986).

In chapter 4 , we examined the structural development of interorganizational R\&D networks in the pharmaceutical biotechnology industry over time. One of our main findings is that the formation of large numbers of R\&D partnerships between large pharmaceutical companies and small, new biotechnology firms has led to the development of dense networks of inter-firm R\&D collaboration where both groups of companies share some of their innovative activities through specific types of agreements. Furthermore, the network maps that we presented in this chapter clearly show that these knowledge networks have become increasingly dense over time. However, in contrast to what could be expected on the basis of the network-oriented perspective, intensive cooperation in this high-tech industry has not resulted in tightly connected networks of relationships 
between highly integrated pharmaceutical biotechnology companies. As found in chapter 4 , repeated R\&D partnering between increasingly net worked pairs or groups of companies is indeed very low. In a similar manner, the results found in chapter 3 also indicate a relatively low degree of integration where the majority of inter-firm R\&D partmerships between large pharmaceutical companies and small biotechnology firms are of a contractual nature with only a few of these partnerships being based on equity participation (see also Hagedoorn, 1996a; Hagedoom and Narula, 1996).

An explanation for the high absolute number of non-equity, contractual agreements and the relatively large share of this particular mode of cooperation in the total number of pharmaceutical biotechnology R\&D partnerships was found in the general preference for flexibility and independence in this high-tech industry. In fact, various types of contractual agreements, such as research contracts and joint R\&D agreements, are used extensively by large pharmaceutical companies in order to raise their ability to switch from research in one technology to another while maintaining their position as independent innovating companies (Barley et al., 1992; Obleros and MacDonald, 1988). Alike many other high-tech industries, the pharmaceutical biotechnology industry is characterized by rapid scientific and technological changes and a significant rise in R\&D costs where even the largest, financially strong companies are no longer able to monitor all technological developments that are important for their core markets. Cooperation through flexible types of agreements enables these companies to monitor several technological developments, and at the same time, let them concentrate on a few, most promising, projects internally (Harrigan, 1985 and 1988). If certain technologies turn out to be less successful, contractual agreements can be terminated relatively easy with only a small financial loss. In line with the assumptions underlying the firm-based view, large pharmaceutical companies thus handle rapid changes in science and 
technology by maintaining their independence and cooperating in research mostly through flexible, non-equity types of R\&D partnerships. This ensures a high level of flexibility, which these companies need to successfully compete in the rapidly changing environment in which they operate.

\subsubsection{Players}

As we have already discussed several interesting characteristics of inter-firm R\&D partnerships in previous sections, such as the motives underlying such partnerships and their organizational setting, our discussion now turns to the companies participating in these inter-firm relationships. Albeit at a different level of analysis, this discussion is very much related to some of the arguments formulated in the previous section in the sense that we focus once more on the issue of interdependence between individual companies or groups of cooperating companies. Researchers in both the firm-based view and the network-oriented perspective have addressed the subject of mutual dependence between high-tech companies by focusing on the question of whether these companies should carry out their R\&D activities indepenclently or in cooperation with others (see table 7.1).

As mentioned before, researchers employing a firm-based view stress the crucial role of inclependence in high-tech industries where all compamies need to conduct their R\&D activities internally (see Bettis et al., 1992; Hamel, 1991; Hamel et al., 1989; MacDonald, 1995; Porter, 1990; Porter et al., 1990; Reich and Mankin, 1986). Particularly, most of these authors have argued that high-tech companies should not rely on others for skills, capabilities, and technologies that are important to their position as strong, independent innovators. In these literatures, managers are typically cautioned about the use of inter-firm R\&D partnerships, which may seriously weaken their firm's independent competitive position vis-à-vis its research partners. By contrast, researchers in the network-oriented perspective claim that interdependence between high-tech companies forms 
the basis of all network relationships between these companies. In these centrally coordinated R\&D networks, each of the participating companies play specialized, complementary roles in the innovation process, leading to a high level of mutual dependence between all research partners. The nothon that high-tech companies can thus tap into many sources of specialized, state-of-the-art research in various technologies has led many researchers to conclude that participation in R\&D networks gives these companies a significant edge over competitors that are not involved in cooperative research (Barley et al., 1992; Chung et al., 2000; Ciborra, 1991; Gomes-Casseres, 1996; Hagedoorn, 1995; Jarillo, 1993; Lorenzoni and Baden-Fuller, 1995; Powell and Brantley, 1992; Powell et al., 1996).

Besides the evolution of inter-firm R\&D networks, chapter 4 also studies the changing roles of large pharmaceutical companies and small biotechnology firms in these cooperative networks. As found in this chapter, the majority of inter-firm R\&D partnerships in the pharmaceutical biotechnology industry are actually formed between these two groups of cooperating companies. More specifically, large-small coalitions take up a steady share of more than 40 percent in all pharmaceutical biotechnology R\&D partnerships during the entire period of analysis (see Hagedoorn, 1993; Kenney, 1986; Powell et al., 1996). This share is significantly higher than the share found for R\&D partnerships between large companies or those between small firms. In line with the network-oriented perspective of inter-firm collaboration, we argued that the basis for these dense network relationships between large pharmaceutical companies and small biotechnology firms is to be found in the variety of resources, specialized capabilities, and complementary innovative expertise that are possessed by these different types of companies. In their numerous partnerships, large pharmaceutical companies typically provide their many, smaller partners with financial support and regulatory know-how, in return for which large companies acquire access to the research skills of these small biotechnology firms (see also Arora 
and Gambardella, 1990; Barley et al., 1992; Laamanen and Autio, 1996; Pisano, 1991; Powell, 1996; Shan et al., 1994; Slowinski et al., 1996).

Notwithstanding the complementary, specialized roles of both large pharmaceutical companies and small biotechnology firms in inter-firm R\&D networks, these obvious complementarities in innovation do not appear to have led to a high level of interdependence between these two groups of cooperating companies. In chapter 5, we explained the lack of interorganizational trust between large and small companies by pointing out that mutual dependence does not have to develop in a situation where R\&D partners are so different in terms of their sheer size and market power (see also Rousseau et al., 1998). In the pharmaceutical biotechnology industry, large companies are only partly dependent on small biotechnology firms as a group, but they are quite independent from individual. small firms. By contrast, the bargaining power of individual small firms in their partnerships with large companies is relatively low. Indeed, many small R\&D firms concentrate on the same or somewhat similar technologies, so switching costs for large companies are rather low. In accordance with these theoretical arguments, one of our major findings in chapter 4 is the observation that large pharmaceutical companies have come to play a significantly more important role in inter-firm R\&D networks than smali biotechnology firms. Particularly, our results show a strong increase in the R\&D alliance-intensity for large companies that far exceeds the intensity found for small firms in the 1990s. This changing role of large companies indicates a relatively low dependence of these companies on small firms where large companies have obviously been able to retain their dominant position as independent players in pharmaceutical innovation. In line with the theoretical premises underlying the firm-based view, mutual dependence does not seem to be a major force in pharmaceutical biotechnology R\&D partnerships where large companies have typically used their arm's length, contractual partnerships with small firms to serve their own competitive interests. 


\subsubsection{Drivers of alliance formation}

As a final important characteristic of inter-firm $R \& D$ partnerships, we will examine some of the motivating forces behind the formation of these partnerships (see table 7.1). In the firm-based view, it is argued that R\&D partnership formation is primarily driven by the competitive, opportunistic behaviour of the companies that are participating in these research agreements. Due to the ultimately competitive nature of all types of relationships between high-tech companies, inter-firm R\&D partnerships are subject to the hazard of opportunism where all research partners will use their unique, firm-specific capabilities and market power to strengthen their competitive position in relation to other companies (see Dyer, 1996; Dyer and Ouchi, 1993; Hamel, 1991; Harrigan, 1988; Kanter, 1994; Lewis, 1990; Ohmae, 1989; Parkhe, 1991; Prahalad and Hamel, 1990). In this respect, researchers in this view have also stressed the crucial role of formal, detailed contracts in inter-firm R\&D collaboration where cooperating companies need to minimize the risk of leaking competitive, technological knowledge to their partners (see e.g., Kawasaki and MacMillan, 1986). Researchers in the network-oriented perspective, however, generally agree that inter-organizational trust rather than opportunism is the most important determinant of $R \& D$ partnership formation in most high-tech industries (Hakansson and Johansson, 1993; Herrigel, 1993; Lazerson, 1993; Ring and van de Ven, 1992; Saxton, 1997; Staber, 1998; Zaheer et al., 1998). Specifically, these authors have argued that a number of positive outcomes of inter-firm R\&D partnerships, such as inter-organizational learning and innovation, are largely dependent on the development of trust in pairs or groups of cooperating companies that are highly similar in terms of their size and market power (Lyles, 1994; Mowery et al., 1998; Mytelka, 1991).

In chapters 5 and 6 of this thesis, we examined a large number of potential determinants of pharmaceutical biotechnology R\&D partnerships 
and the possible effects of these different factors on subsequent partnership formation in this high-tech industry. In chapter 5, we found that inter-organizational trust, as an important, partner-oriented driver of allliance formation, does not seem to play its expected role in inter-firm R\&D partnerships between companies of different sizes. Specifically, our results show that one of the most widely used indicators of trust, i.e., repeated ties between cooperating companies (see Ahuja, 2000; Chung et al., 2000; Gulati, 1999; Nooteboom et al., 1997; Saxton, 1997), has a significant, negative effect on subsequent $R \& D$ partnerships between large pharmaceutical companies and small biotechnology firms. These findings strongly support our main argument regarding the clearly competitive, opportunistic nature of inter-firm R\&D partnerships in this industry where large pharmaceutical companies typically use their arm's length agreements with small firms to further their own, firm-specific interests. If the partnership has served its purpose, or the smaller partner cannot live up to the agreement, large companies can terminate their research contracts relatively easy and move on to the next source of technology. At this point, it is important to note that the large number of contractual agreements also signals the crucial role of opportunism in pharmaceutical biotechnology R\&D partnering (see chapter 3). Indeed, the important finding that pharmacentical biotechnology companies predominantly cooperate through this particular type of agreement indicates the importance of tightly regulated interaction between groups of cooperating companies that are bound to exhibit opportunistic behaviour.

Besides this partner- or network-oriented driver of alliance formation, in chapter 6, we studied a number of important firm-based determinants of pharmaceutical biotechnology R\&D partnerships. These factors include the set of unique, firm-specific partnering capabilities and technological competences that cooperating companies possess internally. Our findings clearly show that these different capabilities of pharmaceutical biotech- 
nology companies, including their ability to effectively manage inter-firm R\&D partnerships, position themselves for access to multiple sources of technology, and their ability to optimally select partners in terms of their knowledge contribution, are highly important driving forces behind the formation of partnerships in this industry. These results similarly suggest that inter-firm R\&D collaboration is mostly of a competitive nature in this particular high-tech industry where timely access to new technologies and state-of-the-art scientific knowledge is crucial to the competitive success of pharmaceutical biotechnology companies. Indeed, the development of a unique set of partmering capabilities through experience with a large number of inter-firm R\&D partnerships is clearly oriented towards the maximization of firm benefit from these partnerships. In this respect, many large pharmaceutical companies have typically used their firm-specific partnering capabilities, technological resources, and complementary assets (see chapter 2) to gain access to a wide variety of technological sources and thus strengthen their competitive position in end markets.

In the pharmaceutical biotechnology industry, we can thus conclude that having a large number of different R\&D partnerships appears to be more important than building inter-organizational trust with other companies. Cooperation with a wide variety of research partners enables companies to simultaneously detect several scientific and technological developments as well as respond quickly to the most promising new opportunities. Large pharmaceutical companies that are competing in this high-tech industry may therefore perceive the risk of loosing out on important technological advances as potentially more threatening than the risk of leaking competitive, technological knowledge to other companies. Inter-organizational trust through repeated ties with a small number of partners will not necessarily protect a company from undesired knowledge transfer, but experience with setting up $R \& D$ partnerships with a variety of partners will hellp a company develop the necessary partnering capabilities. 
Table 7.2: Major theoretical and empirical findings of this thesis.

\begin{tabular}{ll} 
Theorical premiges & \multicolumn{1}{c}{ Firm-based wiew } \\
\hline Competition or & Prior to the 1970s: goit-alone \\
conperation? & (research) strategy number of \\
& inter-firm (R\&D) partnerships is \\
negligible (chapters 2 and 3 )
\end{tabular}

Organization of the indidisury

Firm-based or networkoriented?

Internalisation or

spectalization?

Opportunism or interorganizational trust?

Contracts or informal controls?

Geaflinterest or mutial gain?

Low degrae of integration, few equity-besed partnerships, few tightly connected pairs or groups of companios over time (chapters 3 and 4)

Major detterminants of R\&D partnerships: firm-specific. capabilities and resources, developed to optinise and maximize firm benefit (chapter b)

Independence or mutual Majority of R\&D partnerships are Formed between large pharmaceutical companies and small biotechnology firms: low degree of interdependence, unequally distributed bargaining power (chapters $2,3,4$, and 5 ) High number of contractual. agreements: importance of independence and flexibility (chapter 3 )

Lack of inter-organizational trust betweon lange companies and small firms (chapter 5)

High number of contractial agreements indicat importance of tightly regulated interaction (chapter 3)

Short-term R\&D partnerships are oriented toward fulflling immediate company needs: gain access to new knowlenge base, share costs, access to complementary assets, maintenance of competitive position (chapters 2,3 , and 4 )
Intensive cooperation in $\mathrm{R} \& \mathrm{D}$, a core activity that forms the basis of competitive advantage Large compasies and small firms play complerwentary roles in the innovation process indicaling a relatively high degree of specialization (chapter 4 )
1970 (discowery of

biotechnology) and beyond:

dramatic increase in the mumber of inter-fim $R \& D$ partuersaips. increasingly densw R\&D networks (chapters 2,3, and 4 )

Dense netwotks of RRD partnerships as whe new locus of innovation (chapter 4 ) 


\subsection{Final remarks}

The purpose of this concluding chapter was to discuss some of the main theoretical and empirical findings of this thesis within the context of two broad-based, diametrically opposed, approaches to the study of inter-firm partnerships and inter-organizational networks: the firm-based view and the partner-or network-oriented perspective. Specifically, in this chapter, we have made an attempt to provide an answer to the question whether companies in the high-tech pharmaceutical biotechnology industry are following firm- or network-oriented partnering strategies to deal with the specifics of their rapidly changing technological environment. It has become obvious from our discussion throughout this chapter that the answer to this question is rather straightforward. While we have been able to explain some of our findings in light of the network-oriented perspective, the more traditional firm-based view appears to provide us with a far more adequate context within which we can interpret most of our results (see table 7.2).

As shown in table 7.2, some of our most important findings appear to fit very well within the broad-based theoretical context of the networkoriented perspective. However, most of the socially based, network-oriented concepts, such as interdependence, inter-organizational trust, and mutual gain, apparently do not apply to the pharmaceutical biotechnology industry where the vast majority of companies use their R\&D partnerships as a strategic tool to maintain or improve their competitive position. In other words, we can explain the extensive use of inter-firm R\&D partnerships, the increasingly dense R\&D networks, and the clearly complementary, specialized roles of both large and small companies in these networks, within the context of the network-ariented perspective. However, the more traditional firm-based view is clearly more helpful in explaining the competitive nature of inter-firm R\&D collaboration in this high-tech industry where the formation of large numbers of non-equity, contractual R\&D partnerships between 
highly independent companies are largely motivated by firm-specific needs, interests, and capabilities (see also table 7.2). 
$\mathrm{A}$

\section{The MERIT-CATI DATABANK}

The MERIT-CATI databank (see Hagedoorn, 1993) contains information on nearly 10,000 cooperative agreements in various sectors, ranging from high-tech sectors such as information technology and pharmaceutical biotechnology to less technology-intensive sectors such as chemicals and heavy electrical equipment. Systematic collection of inter-firm partnerships started in 1987. If available, many sources from earlier years were consulted to establish a retrospective overview. In orcier to collect detailed information about inter-firm partnerships, various sources are consulted: newspaper and journal articles, books dealing with the subject, and in particular specialized journals, which report on business events.

This method of information gathering has some drawbacks and limitations due to the lack of publicity for certain arrangements, low profile of certain groups of companies, and fields of technology. Despite these shortcomings, which are difficult to circumvent even by extensive and large-scale data collection, we have been able to obtain a clear overview of the joint efforts of many companies. This enables us to perform empirical research, which goes beyond single-firm case studies.

The databank contains information on each cooperative agreement and some information on companies participating in these agreements. Cooperative agreements are defined as mutual interests between independent industrial partners that are not linked through majority ownership. In the CATI databank, only those agreements are being recorded that involve either a technology transfer or some form of jointly undertaken R\&D. Information is also collected on joint ventures in which new technology is received from at least one of the partners or on joint ventures having some R\&D program. Other types of agreements such as production and marketing alliances are not included. In other words, this material is primar- 
ily related to R\&D collaboration and technology cooperation, i.e., those agreements for which a combined innovative activity or an exchange of technology is at least part of the agreement.

We regard as relevant information for each partnership: the number of companies involved; names of companies; year of establishment; modes of cooperation. Important information on participating companies includes their location and the names of parent companies. 


\section{NETWORK PARTICIPANTS APPEARING IN THE MDS GRAPHS}

\begin{tabular}{|c|c|c|c|c|c|}
\hline Label & Conpany name & Sixe & Label & Compary name & 5120 \\
\hline aH & $\begin{array}{l}\text { Mintinesota Mining rand } \\
\text { Marafucturing }\end{array}$ & Lingerge & WNOGEN & Inomagnedins & StuEl \\
\hline $\mathrm{ABOT}$ & Abbeth Luboratontes & Lurge & WNGULANMI & Instalin Mimelice & Smal \\
\hline$A C A D E D S$ & $\begin{array}{l}\text { Acade Diangrostite } \\
\text { Systems }\end{array}$ & $\operatorname{Sin} 24$ & NWECL & 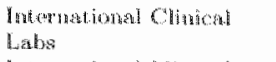 & Modiculu \\
\hline ADV-TS & $\begin{array}{l}\text { Advanced Thistre } \\
\text { Schences }\end{array}$ & Somati & INT-MaC & $\begin{array}{l}\text { Ioternational Minderal } \\
\text { and Chamical Company }\end{array}$ & Large \\
\hline EDY DIOTC & $\begin{array}{l}\text { Adwanced Birshormpy } \\
\text { Concepts }\end{array}$ & Snazuln & INTERL-2 & 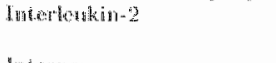 & Smanli \\
\hline$A \mathrm{DN} M \mathrm{MCN}$ & Adranded Mathotics & Small & INTEREL & 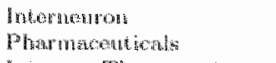 & Snutl \\
\hline$A F \mathrm{GMAX}$ & Afymax & Simat.11 & INTORGEM & Introgen Ther anpeldtobs & Simalt \\
\hline$\triangle \mathrm{GOONOON}$ & $\begin{array}{l}\text { Agovirom } \\
\text { Pharmacenticals }\end{array}$ & Smonll & ISTLS-PH & Isis Tharnaceuticala & Sirqatl \\
\hline$A \times 2 O$ & Akao Noben & Lafinge & LXYS & Txisy & Smanl \\
\hline ALBAMV-M & $\begin{array}{l}\text { Abany Molectlow } \\
\text { Perseatch }\end{array}$ & Smatl & $J \mathbb{L}$ & Jrhinsiun and Johnson & Large \\
\hline AlESTONP & Alexing Toramacentiogls & Small & JACOTEC & Jageter & Smat: \\
\hline ATKRRAMS & Alkerwiong & Smaill & MOHASHOP & $\begin{array}{l}\text { Jolme Hoplans Hestith } \\
\text { System }\end{array}$ & Lurge \\
\hline AHLANALX & Aldinex & Small & JOUVEINA & Jonพrimal & Modium \\
\hline ALLELIK & $\begin{array}{l}\text { Allelix } \\
\text { Biophamacenticnls }\end{array}$ & Wedinen & $\triangle P N-T O B$ & Japan Tobaceo & Librge \\
\hline ALLENGOO & Allen and Company & Small & LABH & Kabi Pluarmacia & Sunall \\
\hline 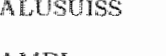 & Swiss A Amminimen & Lateres & KANEGAEU & $\begin{array}{l}\text { Kinmegafudi Chemical } \\
\text { Industry }\end{array}$ & Medim \\
\hline MAI & Applied Micmobiology & Smatt & KARO-BOO & Karn Bio & Small \\
\hline$M O M A N$ & American Oyanamid & Large & KODAK & Bestemat Kodah & Latga \\
\hline AMERSHAM & Amershan & Medium & KYOWA-HK & Kyowet Wakko liogyo & Latigo \\
\hline AMGEN & Amgen & Mediuma & KYOWM-MC & Kyowa Medex & Simall \\
\hline ANHOMEPT & $\begin{array}{l}\text { Anerican Home } \\
\text { Prosucts. }\end{array}$ & Latage & LOREAL & 5. Orat & Latrece \\
\hline 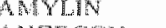 & 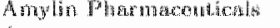 & Small & MASOANON & Laborateden C Colon & Small \\
\hline A & Allergent & Snand & U.AOLLA & 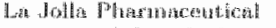 & Shinill \\
\hline $\mathrm{WW} W \mathrm{~B} A$ & Anesenta & Smant! & LASUTE & lankinge and Crawford & small \\
\hline ANTLOAN & Anticionarest: & Stratl & LEOFONOH & leo bonder & Mstitutar \\
\hline AIMSCL & $\begin{array}{l}\text { Applied lenwane } \\
\text { Sciences: }\end{array}$ & SHarzen! & L.AAND & 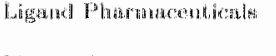 & Smatl \\
\hline$\triangle P O L L O-G$ & Apolon Centelios & Smull & LIMACR & Mingegrang & Wheres \\
\hline MOLAOM & Apollag & $\sin 31$ & LIPOTECH & 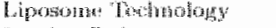 & Shrall \\
\hline APOTEX & Apotox & Small. & LRC & 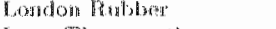 & 1. ing \\
\hline$A \mathrm{~F}^{2} \mathrm{~W}$ & $A$ pre & Larget & LYNX-TH & 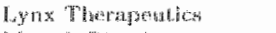 & Somel \\
\hline MEES-SER & Ares Skenono & Meditim & 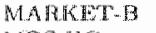 & Martok Binectoners & Shrotll \\
\hline$A \mathrm{AOULH}$ & Arquale & Small & MDS-HG & MLS Hextell & Mediuga \\
\hline A PER & Arris Pluarmacenthent & Snall & MED 1 & $\begin{array}{l}\text { Medicat Resentoh } \\
\text { Batemomidomat }\end{array}$ & SHatil \\
\hline A S A ACU CH & Asale Chemical thidustry & LAFBe & MEQYU & Modevin & Maditario \\
\hline ATHA & Astrot & Targe & MODIMMUN & Medianmonate: & $\operatorname{Sin} a ! l$ \\
\hline ASTIHAM & Astrit Mrack & 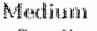 & MHOTHOM & Martlatonto & I.tange \\
\hline ATHAM & Ahena Nequosiences & Sntranl & MLECABOOS & Meysabios & SMMLA \\
\hline EOTMMU & A.stionimatume & Smant & MEIJISK & Meiji Selkas Kanthom & L.tinger \\
\hline MULON & Aviron & Small & MENARINH & 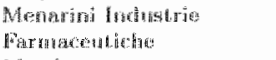 & Lange \\
\hline 眇 & Baker Cummins & Snall & MEFCK & Merck & l.aFge \\
\hline DANANCE & Batance Pharmacteticals & Srinall & WETRA & Metrat Bigsystemito & Sintint \\
\hline $\mathrm{HAF}$ & BASF & fastre & MI-KASEI & 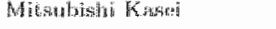 & intiges \\
\hline
\end{tabular}




\begin{tabular}{|c|c|c|c|c|c|}
\hline PATELLE & 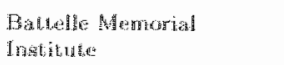 & Lenger & MCOOCHO & 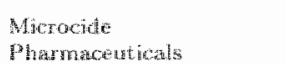 & Smarhl \\
\hline BAOSCHEL & Bungeh and Lomb & Lasger & MOROGEN & Mieragen & Smath \\
\hline $13.4 \mathrm{TENT}$ & Whatar Throwol Lalus & Latage & MCDON & Mhoromet & Small \\
\hline BAYH:D & Basyer & latge & MLLLNINH & $\begin{array}{l}\text { Milleribin: } \\
\text { mharmacedicals }\end{array}$ & Sman \\
\hline $\mathrm{BBC}$ & Bratish Botechnology & Srant & MITOTLX & Mitol $2 x$ & Sman \\
\hline BECTOEN & Deaton Dickingon & 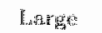 & MTTSUERS & Mitsutishi & Large \\
\hline G10- $\mathrm{RlBSP}$ & Bio Flosponge & Small & MTSUI & Mitsui & Larae \\
\hline BIOCMEN & Bhochem Phan & Sniall & MOCHIDA & Mochida Pharmacem ingl & Medinim \\
\hline DIOCOMPA & 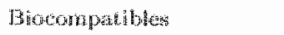 & Sulatil & MOLBI & Mollecular Biosysters & STruthill \\
\hline 110CON & Bixcona & Survall & MONSANTO & Monsanatio & Latige \\
\hline AlOCORE & Bhocuer & Sinall & MOHPHO & Mopphosys & Small \\
\hline BIOGHEN & Bogen & Sonall & AYCO-PH & Myco Pharmacenticalts & Shall \\
\hline BOCHAOO & Biosonren Crenetics & Sriall & MYRHADG & Myriad Getuetics & Gmanl \\
\hline BIONVST & Biwinest & Smantl & NEDREX & Nevrox & Snteil! \\
\hline DOMATH & Bomatrix & Shomat! & NEUROCR & Newoctine Bionotencos & Sritall \\
\hline MOMWT' & Bionat. & Mealinum & NOUROGLN & Meturagen & Small \\
\hline BOONICHE & Bon âthe & Smatl & NEUROSEA & Nebrosearch & Srant \\
\hline BIOPHARM & $\mathrm{A}$ Btoputarm & Sxancli & NEXACEN & Nexagen & Smant \\
\hline BIOKAD & 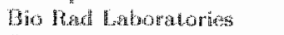 & Matilinim & NH-KAYA & Nippon Kryykn & Medium \\
\hline BHOAES & Fiores & Snmail & $\mathrm{NHT} A$ & Notia Golatim & Medium \\
\hline Blos & Bios Gorporation & Sranall & MORSK-HY & Norsk Hydra & Largat \\
\hline $\mathrm{BIOT} \mathrm{LCW}^{2}$ & 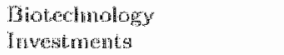 & Smalt & NOWAPHAR & Nova Phanturacatical & Smats \\
\hline MIOTWCLL & Piotech hesseard leabsi & Small & NOWO-NOR & Mono Nordisk & latage \\
\hline BOTHENA & Biotherapentics & Snat!! & $\mathrm{NPI}$ & 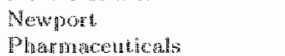 & Smatl \\
\hline BROLANS & Bictratilasplant & Small & NPM & 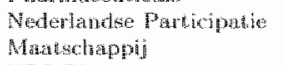 & Simall \\
\hline BIOVEST & Bonest Patumes & Shall & NPS-PHAR & NPS PHarmacedteds & Small \\
\hline BOEHRI-S & Bodhinger Sotn & Large & NYU & $\begin{array}{l}\text { State University of livew } \\
\text { York }\end{array}$ & $\begin{array}{l}\text { Ac/gon } \\
\text { inst. }\end{array}$ \\
\hline BOHR-NG & Bowhinger Ingelhoint & larage & 005 & Oxford Glycosystemus & Smanl \\
\hline BOSTON-L & Boston Lifk Soiences & Snall & OMEGA & Omega Bublogicals & Small \\
\hline BRET M M & Briatol Wyers Squbb & Darge & ONCOCEN & Oncogen & Srrualt \\
\hline MRIST MYY & Bristol Myers & Lange & ONCOOENE & Oncogene Scierce & Smonal \\
\hline BTQ & $\mathrm{BTCH}$ & Small & ONO & Ono Phamacentical & Mediuma \\
\hline CADUS & Cadue Pharmacetical & Srmall & ONYX & Onyx Phamacenticals & Smethl \\
\hline CALEBIO & $\begin{array}{l}\text { Cahiforma } \\
\text { Biotechongg }\end{array}$ & Smatil. & ORTHOD & $\begin{array}{l}\text { Orblo Clinical } \\
\text { Diagnostics }\end{array}$ & Medilum \\
\hline CANIBOSC: & Canbridge Busedentes & shombll & $95 \mathrm{MON}$ NCS & Osmonics & Madium \\
\hline SAMH & 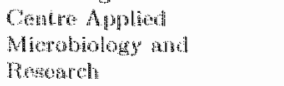 & $\begin{array}{l}\text { A.t. Jgove } \\
\text { insist. }\end{array}$ & OSTMIO & Osteomater Thotack & Srrind \\
\hline CNNIII & Crimsiji & Symall & oTsukA & Otsnka phamenculcal & Largo \\
\hline CANTAB & 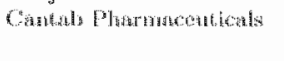 & Sinn: & TABAER & $\begin{array}{l}\text { Pietre Pabre } \\
\text { Particigations }\end{array}$ & L. $\operatorname{singe}$ \\
\hline CAHDOCMN & Curatoris & Smant & PACLIA & Parifhe litalsons & Smath \\
\hline$(" N \mathrm{~T}$ & 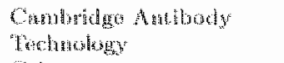 & Sin:till & PADABIO & Phermadigne biascionoes & Sman \\
\hline GH,OBN & Colemto: & Small & PARACEL & Paracestats & Smutat \\
\hline Ghas & Cellents & Suall & PARMIB & Parnilb & Sounall \\
\hline HEAGLKA & Gell Gomass & Smatl & PASTHER & Pasteur Mratum & Medinth \\
\hline CELAO & reflow & Sincall & $P A Z$ & $P \Lambda Z$ & Sominll \\
\hline CEHLEROH & cellifin:h & Stmall & $\mathrm{PDC}$ & $\begin{array}{l}\text { Pharimacentiral } \\
\text { Discowery Corporation }\end{array}$ & Semiant \\
\hline CHATIR & 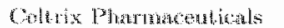 & Smatl & PEP THER & Peptide Ther ansentas & Smitl \\
\hline CENTMUI & 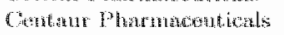 & Small & PEPTRDI: & Peptide Teentrobgy & Srimall \\
\hline CWTOOOF & Cexpecon & small & PEPTOR & Peptor: & Sningll \\
\hline CWHALON & Oethinatong & Sinall & PHIZER & Pfozer & Large: \\
\hline Cmmon & obiron & Medinga & PHAAR-RES & $\begin{array}{l}\text { Phamunceltical } \\
\text { Resources. }\end{array}$ & Smail \\
\hline CHmosol & Chrosenenes & $5 \mathrm{mall}$ & PHARM-UP & Pharrancis and Opojoline & Large \\
\hline CHROMAX & Ohromarome & Small & PHARMANP & Pharme Patch & Small \\
\hline
\end{tabular}




\begin{tabular}{|c|c|c|c|c|c|}
\hline CHUGAI & Chugai Pharmacentacal & Medinan & PHANACl & Phatracia & Lange \\
\hline DHA & Cibs Gety & Latrge & PHATMAGE & Planmathanenios & small \\
\hline COACORN & $\begin{array}{l}\text { Cita Cornoing } \\
\text { Diagnostics }\end{array}$ & Sinall & PHARMAY & Pharmangme & smant \\
\hline MEALPH & Clal Isratel & Laver & PHA DWECO & 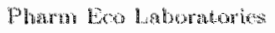 & Shathl \\
\hline CLINIC-S & Chinical Sciences & Small & PHABMOS & Phan & Sungall \\
\hline MONETIC & Clontics & Small & PHYTERA & Phytera & Suatinll \\
\hline COOEWSYS & Coconsys & Smanll & MVTON & Plyyon Callatylic & smant \\
\hline COLLAGEN & Collaburative Genetics & Sinntl & PHYTOM & Phyton & Snmull \\
\hline COLLARES & Collabor alive Reserarch & Srgan & PHYWOPA & Phyoularmencentionals & Siment \\
\hline COOPER-1 & The Cooper Companiss & Meditum & POWEROO & $\begin{array}{l}\text { Powar Corparaticus of } \\
\text { Cankath }\end{array}$ & Lunger \\
\hline COA-TUER & Cor 'llapapentios & Small & PFL THED & PPC. Therapentics & Sniball \\
\hline COMANGE & Contarate & Large & PROCENT & Procent. & Sinant \\
\hline COMDA & Corixia & Smatl & PROCORMN & Procondis Nora & Werteo \\
\hline QORMING & Conning Glass Works & Large & PROCHKOA & Procter and Gandlobe & Lafage \\
\hline CORTECH & Cortech & Simall & PROMGEN & $\begin{array}{l}\text { Progevises } \\
\text { Phatratacentinds }\end{array}$ & Smath \\
\hline COHWAS-I & Corvas: & Stmanl & PROMEGAB & Promega & Swoth \\
\hline GOHMTAUL & Conrtands & Larane & QlT & QLT Phototherapentuses & Siltall \\
\hline CREATBIO & Creative Bubroleculas & smull & QUDEL & Quidas & Simatl \\
\hline cos. & CSL & Merdian & ReC & Werkit and Colmus? & Labrugo \\
\hline GULTOR & Cultor $\mathrm{Oy}$ & Modium & RABOBVI & 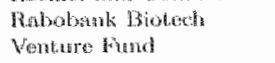 & somall \\
\hline CVTTHER & CW Thurapentirs & Small & REGENER & $\begin{array}{l}\text { Pegerveron } \\
\text { Phwarnacenticals }\end{array}$ & Sumali \\
\hline GXNOUS & $\begin{array}{l}\text { Cygtrus Therapentio } \\
\text { Systems }\end{array}$ & Stmanll & $\mathrm{RENT} \times A \mathrm{AZ}$ & $\begin{array}{l}\text { Dr Hentichlor } \\
\text { Arareinutitel }\end{array}$ & Small \\
\hline ONTEL & Cyted & Smatl & DEPLIGEN & Replinges & Simal! \\
\hline $\mathrm{CYTO}$ & Gytotherapentica & Sunall & RESSI & Remsinil & Sinall \\
\hline CHOGLN & Oytogen & Sinnatl. & RETPOP-S & Rerroperfusion Systems & Surandll \\
\hline OYTOMED & Cylomed & Sirmall & RHONE & 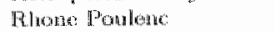 & Laticge \\
\hline DADUE & Divde & Large & RHBGENE & Rithogena & Smenll \\
\hline DAINIPPH & $\begin{array}{l}\text { Dainippon } \\
\text { Pharmaceutical }\end{array}$ & Medium & JiBOOZ WME & 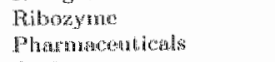 & Smail \\
\hline 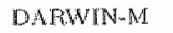 & Donswin Molectilar & Small & ROCHE & Roghe & larige \\
\hline DEGUSSA & Degussa & Lange & S-OIL $\mathrm{IN}$ & Anowo & Large \\
\hline DELLA-W & Belta Wiest & Simall & SANDOZ & Shanduz & Lenge \\
\hline DEPOTWCH. & Mepotech & Small & $S A N O-A$ & Sang A Plowana & Snall \\
\hline DENATRA-L & Dextrat Laboratories & Small & SANKYO & Sank $<$ yo & 1. $2 \mathrm{arge}$ \\
\hline DHAGNON & Diatg non. & Snmali & SANWA & SHWwh & Lrargo \\
\hline DIAGPROD & 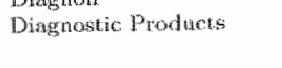 & Madil:m & SEMP & $\begin{array}{l}\text { Snow Brand Millz } \\
\text { Pooductus }\end{array}$ & laturge \\
\hline MCOME & Digenat & Small & SCHHIN-P & Setwetr Pharmencented & Meditura \\
\hline$D K B$ & Da lohi Kangyo bank & Lutange & SEHEI-PI & Schlonirat Flestugh & finclue? \\
\hline Dow & Dow Chentical & Janges & SCHEMLI & Rip Shorer & Mireling \\
\hline DHWUG RC & $\begin{array}{l}\text { Drug Royalty } \\
\text { Comporation }\end{array}$ & Snan & STFEMEWH & Sehosen Ulogithesure & 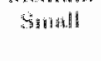 \\
\hline DSM & $\mathrm{DSM}$ & Large & SCHERTNG & Suhathitg & Lstinge \\
\hline DUPONT & Dupsart. E I De Nemotara & Large & SCHWARZ & 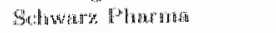 & Mefiun \\
\hline DURA-PH & Dorat Phormaceuticals & Sunall & SCOOIIA-I & Soulina & Simall \\
\hline EDTTEK & Ediluta & Sirta: & SWIKAGAK & 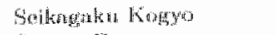 & Shont \\
\hline EDSAI & Eisizi & Medium & SWOSLIS & 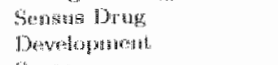 & Sinatll \\
\hline EHACORP & P:y & Medium & SWPAAQOT & Gequnsm & sinfll \\
\hline$B H-A Q U$ & Elf Agyateraine & Lavge: & $5 \mathrm{EQUUA}$ & 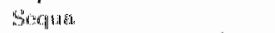 & Large: \\
\hline WLILLLY & Dhi LAly & Latge & SWOUNA & Seipurat Therapentucs & Stivall \\
\hline NMDOCON & Womocon & Smanl & 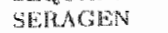 & Serpugan & Small \\
\hline ENTOTRON & Erdotronics & Sintitil & SHILL & SHL: & Large \\
\hline LNE EMICS & Crygentichs & Sntull & SHIt:D & Shind Diagrantick & Small \\
\hline EN & $\begin{array}{l}\text { Ente Niagionale } \\
\text { Celmocarburi }\end{array}$ & Large & SHONOGI & SHionoget & Lutate: \\
\hline WN20 & Eqzon & Smaill & SIBA & 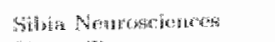 & \\
\hline EON-LABS & Eon Labs & stmall & IGMA-T & Sigrwat Thet & Mcollonta \\
\hline & Epilange & small & SHOAOCEN & Sino Gerietire & Barnetil \\
\hline
\end{tabular}




\begin{tabular}{|c|c|c|c|c|c|}
\hline HECA & nascageneticas & Small & SMUTHBN & Smenth and Neputar & Lotrye \\
\hline WIOHOLCD & fothical Holdingses & Small & SNKBEFCH & Shuthlaline Eefecham & Lintege \\
\hline EXOCLUL & Exisceall & Srasal & SOLWAY & Solvay & 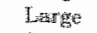 \\
\hline HWHANTA & Formentua & Medituma & SOMATIX & Somwatix Therapy & Srtwiall \\
\hline $\mathbb{W A T}^{2}$ & Fine & Latage & SOMATOGN & Sommatagen & Small \\
\hline FMUI & 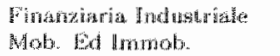 & Modiam & SPOTHAB & Spectra Biomedioal & Strinal \\
\hline FOCAL & Fockl & Srrosint & SS-PHAFM & SS Phanmaceutica! & Med III IR: \\
\hline POURNAT & 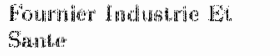 & Madiuns & STERITEC" & Steritech & Snatal \\
\hline FRERENAL & Preseninu & Meddurâ & STRESSOL & Strengen & Smatll \\
\hline FUUSHOH & Fujp Hersy lndustres & Large & $\mathrm{SUCB}$ & Sugen & Smiriti \\
\hline FUMSAWA & 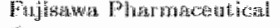 & Laragge & SIMITOMO & Suntitamo & Large \\
\hline luYo & Fuyo: & 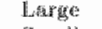 & SUNTORY & Suntory & Large \\
\hline GALACBH & Galaryen & $5 \mathrm{mat}$ & SUPRAGEN & Sulpragen & SHAth! \\
\hline 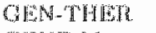 & Genetio Jherngy & Simall & SWEDBACL & SBL Varcin & Strant! \\
\hline CPISW Fis & Genomedicino & small & SYMBOLL & Symbollon & Small \\
\hline $\mathrm{GHNEM}$ & Gent: Pinalutiog & Smeth & SYMPHAN & Sympheser & Smatil: \\
\hline $\mathrm{RHEALAS}$ & Genalabs Tacheolones & small & GYNAFTIC & $\begin{array}{l}\text { Synaptic } \\
\text { Plyatmacentionals }\end{array}$ & STiatl. \\
\hline GlWEX & Genex & smatl & SYNBIOT & Synbiaticas & Smail]. \\
\hline GHEONO & Genova & Small & SYNERGEN & Synergen & Stwall \\
\hline 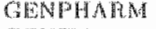 & Genphuirm & Small & SYNTHX & Syntex. & Large \\
\hline GHNGL & Gensia Phamentanticals & Smal! & SYNTRO & Syntro & Sonall \\
\hline GENTA & Gent:ki & Sranll & T"WOELL & T Cell Scrences & Small \\
\hline GHSZYME & Gengyne & Medium & "TALO & Tatho Pharmacentiont & Medtuma \\
\hline GHETECH & Gontech & Bเร็นl & TAKAAA & Thaknatian Shuzo & Medherain \\
\hline GHON & Geron & Simathl & $1 \mathrm{AKOA}$ & 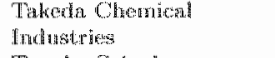 & Large \\
\hline GIILAD & Gileat birincess & STrand & TANABE & Thusalbe Seiyatal & Large \\
\hline CLST.BRO & Gist. Brockatliks & Large & $\mathrm{TAP}$ & TAP Phatomecutheds & Medium \\
\hline GLAOO & Glaxo Holdings & Letafge: & $\mathrm{THC}$ & Texas Biotechnology & Sathat! \\
\hline GLANOW & Claxo Wellowme & Large & MCHWIOL & Techniclone? & Saranll \\
\hline GLATECH & Gliatech & Sarball & TEL 1OS-P & Telios Pharmaceuticath & Smal! \\
\hline GHOOMOD & Glycoried & Small & TEXACO & Testiteo & Latugen \\
\hline GLYCORLXX & Glycuns & Smanll & 'T'HERAGEN & Therengen & Small \\
\hline CHAEEN-CR & Green Cross & Warge & THERATEC & Theratexch & Smat! \\
\hline GUENNW-P & $\begin{array}{l}\text { Creenwich } \\
\text { Phanmabeuticats: }\end{array}$ & Smanlt & THEREXS & Therexsys & Smat! \\
\hline GHUNWNTH & Gruenemtial & Mrdium & "I"LLIPOCO & The Liposmine Company & Smant! \\
\hline Garphon & 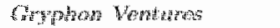 & Girya & $T K T$ & Thataskaryotio Therapies & Simath \\
\hline RAYPHOHS & Gryptom Seronces & Sunall & TOWER-PH & 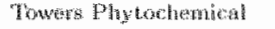 & Small \\
\hline GUIABT & Colatbel & Meditum & $\mathrm{OYOBO}$ & Dyo Woseki & Lenere \\
\hline HANONET" & Hatmoradics. & Modibum & 10YOSODA & $\begin{array}{l}\text { Dopes Sodaz } \\
\text { Mantafacturimg }\end{array}$ & Lationge \\
\hline MAUSGl6 & $\begin{array}{l}\text { Hetuser Chandest } \\
\text { Rosentoh }\end{array}$ & Sinall & HIRCE & Thace Conmputers & Snatn \\
\hline MYASH-10 & Hoynghibita Hocherical & Simutill & "HANSCEL & Transcol Tentuologies & Simant \\
\hline MUEAOY Y & Holosynthose & Stanal & WRANGGN & Thausgerene? & Smatl \\
\hline FIOH-AES & Hen lestatrol & Simall & lapos & Tripos & Smath \\
\hline MHOMSOL & Henosol & Smantl & DPUMURA & 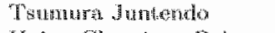 & Mediame \\
\hline HARCULES & Herculas & Langere & $\mathbb{U C B}$ & Whish Chenigue Betge & Latititge \\
\hline HEXAL & Hexall laburata & Smat & UN-TECHN & Writed Terhologies & Lange \\
\hline HOECABST & Wonethet & Latage & UNC & $\begin{array}{l}\text { Una warkity of Nonth } \\
\text { Carcolsted. }\end{array}$ & $\begin{array}{l}\text { Acc } / \mathrm{gow}^{4} \\
\text { inst. }\end{array}$ \\
\hline HOR $\mathrm{ROCH}$ & Holphantan Lathe & Linga & UNIIAX & Univar Bhologics & Smatil \\
\hline HOUGHTON & Hongentoron & Small & QS-BIOMA & USbonterintis & Smaมี \\
\hline HUMUAN-C & $\begin{array}{l}\text { Hombll Gentomo } \\
\text { Sciances }\end{array}$ & Smela & VANGUARD & 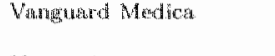 & Sแกะเ \\
\hline HYBMDON & Hybrotom & Smatl & VECTORPH & Vectorpharma & Sumall \\
\hline HVGHACS & $\begin{array}{l}\text { Hygenahs } \\
\text { Phatrmanceticalsa }\end{array}$ & 3 mall & VERTEX & Wertes Phamenticats & Smat! \\
\hline $10 \%$ & $10 \%$ & Large & VKSTAR & Westan" & Smant \\
\hline ICN-PEAA & 1CN Pharmacthticals & Meditun & VIACENE & Vingeme & Small \\
\hline HD. VMO & ID Varocitite & Small & VICAL & Wical & Smalt \\
\hline
\end{tabular}




\begin{tabular}{|c|c|c|c|c|c|}
\hline IDB & $10 \mathrm{D}$ & Small & VHOGEN & Virogereics & Smant \\
\hline WDEC & IDEC Phamaceulicats & Small & MRUSH & Vimas Pesenrch fustitute & Small \\
\hline IDETEK & Idetak & Smant & VOLNO & Volvo & Large: \\
\hline LDUP $-\mathrm{P}$ & ddun Pharamoeutionals & Senall & WARNER-L & Warner Lambert & LêA \\
\hline TGE & Igene Biotednology & Smal! & WELEOCONE: & Welloone Grone & I.wrige \\
\hline MCERA & Inteerat & Large & WHIT-ASS & 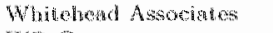 & Sminal \\
\hline MCHONE & Imclone Systems & Smatl & WR.GAACE & WR Gatace & Lirge \\
\hline MUMLOGI & $\begin{array}{l}\text { Tmmalogic } \\
\text { Phatamaceutical }\end{array}$ & Small & XOHEH & Xochen & Smal \\
\hline HMUUMY: & Tmanunicon & Singll & XEMONA & Xenowa & Simall \\
\hline MMUNO-T & Imumanokech & Srmel & XONA & Xominth & Snull \\
\hline MMUNSWS & lmamonusystentin & Smalf & MAMAMOUC & $\begin{array}{l}\text { Yamanouda } \\
\text { Pharrabedatiogal }\end{array}$ & Madian \\
\hline TMAMSOL & $\ln \pi$ mtisol & Small & ZELTA & Zeltith & Smatl \\
\hline mTC & $M T C$ & Small & ZENECA & Zenem & Luage \\
\hline INCELE & Incell & Small & $2 \mathrm{~TB}$ & $\mathrm{ZTB}$ & Sinuall \\
\hline DCERTEY & Incentive & Large & ZWMOCHN & Zymogenetics & Smal! \\
\hline MOVTEP & Incyte Pharmaceuticals & Srubl & ZY NAXIS & zytuakis & Simnl \\
\hline MHALETS & $\begin{array}{l}\text { Irobalo Therapeutio } \\
\text { Systemss }\end{array}$ & Smanl & & & \\
\hline
\end{tabular}





\section{EXAMPLES OF THE MEASUREMENT OF INTER-ORGANIZATIONAL TRUST IN TERMS OF REPEATED TIES IN CONTRIBUTIONS TO LEADING JOURNALS}

\begin{tabular}{|c|c|c|}
\hline Antibuors & Empirical setting & loun \\
\hline $1 . \quad$ Ahuja (2000) & 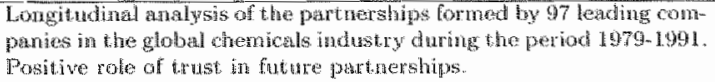 & 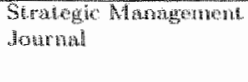 \\
\hline
\end{tabular}

2. Chate at al. (2)

3. Dyer and Chas (2000)

4. Gutat (1995a)

i. Gulatio (1995)

6. Gntat (1990)

i. Gialabi and singh (1908)

8. Thele, singert, and Per]menter (2000)

1). 1-arsen (1992)

10. Nooketroom ell 4. $(1997)$

1. $\mathrm{H}$ Perke (1993)

12. Shko and Nolper (1908)

13 Srator (1997)

14. Fotng-Yban

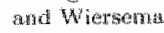
(1909)

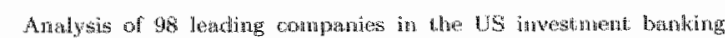
industry during the period 1980-1989. Positive offed of illuen" arganzational trust on subsequent patherchip fonatiow.

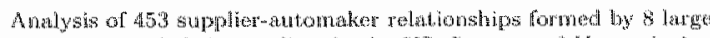

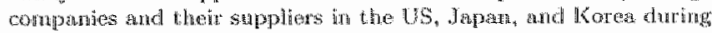
the perion 1992-1994.

Multindnetry andysis of $2400 \mathrm{Rg} D$ partineships formed by $1 \mathrm{~s}$ Eutopean, ard Japanese companies during the periond $1970-1980$

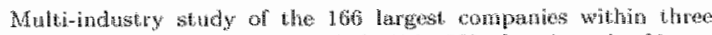

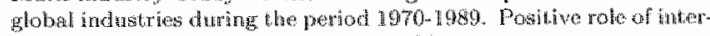
organizational fruse in future partinembips.

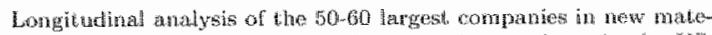

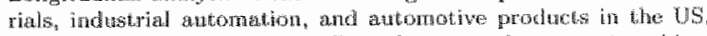

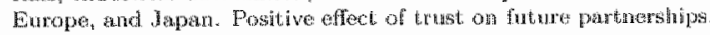

Mulfindentry analysis of 1570 patnerships formed by US, Euro-

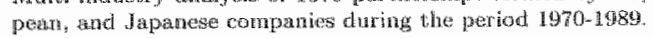

Cross-sectional study of 212 of the largest 135 bnated comprnes in

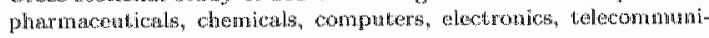
cathions, and serwices.

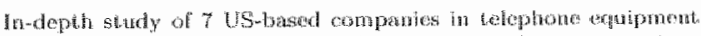

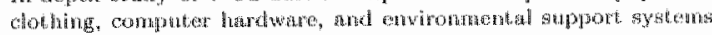
doring the periont $1986-1587$.

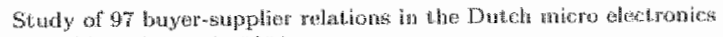

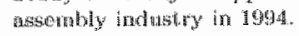

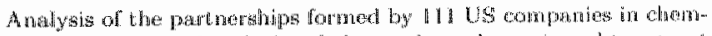

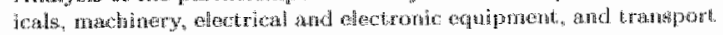

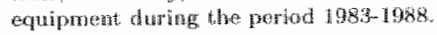

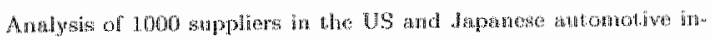
dustry in $199 \mathrm{~s}$.

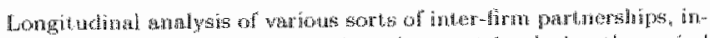

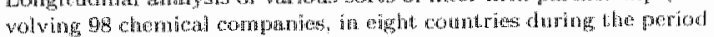
1994.1955

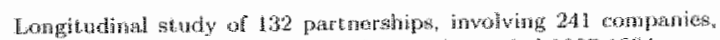

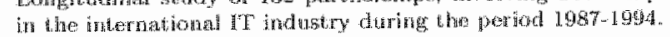

Stratspic Mrangentent Moutumal:

Joman of theteration Busingss Statiog

Acatorithy k.

Manghanent: Jomarnal

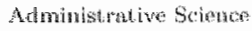
Qmituterty

Stathogio Mangenthen Aourmat

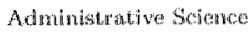
Quaterly

Strangre: Magngentert Jowraral

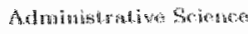
Ounterting

Arod derry ci

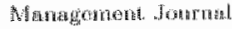

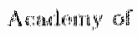

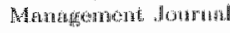

Jonatual of Loonomat Behawbis arded Ongatalen ions

Agnaray of

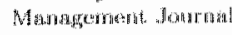

Orguabainory Scince 



\section{REFERENCES}

A

Achilladelis, B. and Antonakis, N. 2001. The dynamies of techological innovation: the case of the pharmaceutical industry. Research Policy, 30: 535-588.

Acs, $Z$. and Audretsch, D. 1989. Patents as a measure of inmovative activity. Kohlos, 42: 171-180. Alm, S., Lee, $Y$., and Schmidt, P. 2001. GMM estimation of linear panel data models with time-varying individual effects. Joumal of Econometrics, 101: 219-255.

Ahuja, G. 2000. The duality of collaboration: inducements and opportunities in the formation of inter-firm linkages. Strategic Management Joumal, 21: $317-343$.

Alnua, $\mathrm{G}$. and Lampert, C. 2001. Entrepreneurship an the large corporation: a longitudinal study of how established firms create breakthrough inventions. Strategic Monogement Joumal, 22: $521-543$.

Amand, B. and Khanna, T. 2000. Do firms learn to create value? The case of alliances. Strategic Management Journal, 21: 295-315.

Aror:a, A. and Gambardella, A. 1990. Complementarity and external linkages: the strategies of the large firms in biotechnology. Joumal of Industrial Economics, 38: $361-379$.

Auster, E. 1987. International corporate linkages: dynamic forms in changing enviromments. Columbia Joumal of World Businzess, 22: 3-13.

Auster, F. 1992. The relationship of industry evolution to patterns of technological linkages, joint ventures, and direct investment between US and Japan. Monagement Science, 17: 1-25. Averitt, R. 1968. The dual economy: the dynamics of American industry structure. New York: Norton.

Axelsson, $\mathbb{B}$, and Easton, G. 1992. Industrial networks: a new wiew of reality. Chichester: Wiley.

B.

Badaracco, J. 1991. The knowledge ink: how firms compete through strutegic alliances. Boston: Harvard Business School Press.

Baltagi, B. 1995. Econometric analysis of panel data. Chichester: Wiley.

Baltagi, B. and Levin, D. 1992. Cigarette taxation: raising rovenues and reducing consumption. Structural Change and Economac Dynomics, 3: $3211-335$.

Barkena, H., Shenkar, O., Vermenten, F, and Bell, J. 1997. Working abroad, working with others: how firms learn to operate international joint ventures. Academy of Management Jouryal, 40: 426-442.

Barley, S., Freeman, J, and Hybels, R. 1992 . Strategic alliances in commercial biotechnology. In N. Nohria and R. Eccles (eds.). Networks and organzations: structure, form, and action. Boston: Harvard Business School Press, $311-347$.

Barmey, J. 1986. Strategic factor markets: expectations, luck, and business strategy. Maragement Science, 32: 1231-1241.

Baraey, J. 1991. Firm resources and sustained competitive advantage. Joundal of Monagenent, 17: $99-120$.

Bartlett, C., Doz, Y., and Hedlund, G. 1990. Managing the global firm. London: Rontledge. 
Banm, 1. 1996. Organizational ecology. In \$. Clegg, C. Hardy, and W. Nord (eds), Handhook of organization studies. London: Sage Publications, 77-114.

Banmler, E. 1968. A century of chemistry. Düsseldorf: Econ Verlag (translated by D. (Goodman).

Beer, J. 1959. The emergence of the German dyo industry. Urbana: University of Illinois Press.

Behnisch, R. 1986. From dyes to drugs. In M. Pamhan and J. Bruinvels (eds.), Discoveries in phatmacology. Amsterdam: Elsevier, 253-284.

Berg. S., Duncan, J., and Friedman, P. 1982. Joint venture strategies and corporate innonaton. Cambridge: Oelgeschlager, Gunn, and Hain.

Best, M. 1990. The new competition: institutions of industrial restructuring. Cambridge: Folity.

Bettis, R., Bradley, S., and Hamel, G. 1992. Outsourcing and industrial decline. Academy of Management Executive, February: $7-22$

Black, M., Moffit, R, and Warner, I. 1990. The dymamics of job separation: the case of federal employees. Jounal of Applied Econametrics, 5: 245-262.

Bleeke, J. and Ernst, D. 1991. The way to win in cross-border alliances. Harvard Business Review, Nowember/December: 127-135.

Bogner, W. and Thomas, H. 1994. Core competence and competitive advantage: a model and illustrative evidence from the pharmaceutical industry. In G. Hamel and A. Heene (eds.), Competencebased competition. Chichester: Wiley, 111-144.

Borgati, S., Everett, M., and Freeman, L. 1999. Ucinet 5 for Windows: software for social network analysts. Natick: Analytic Technologies.

Bowring, J. 1986. Competition in a dual economy. Princeton: Princeton University Press.

Brass, D., Butberfield, K., and Skaggh, B. 1998. Relationships and unethical behaviour: a social network perspective. Acadeny of Management Review, 23: 14-31.

Buckley, P. and Casson, M. 1988. A theory of cooperation in international business. In $F$. Contractor and P. Lorange (eds.), Coopentive strategies in international business. Lexington: Lexington Books, 31-54.

Burt, R. 1992. Structural holes: the social structure of competition. Cambridge: Harvard University Press.

$\mathrm{C}$

Cantwell, J. 1991. The intermational agglomeration of technological activity. In M. Casson (ed.). Global research strategy and international competitiveness. Oxford: Blackwell Publishing, 133-182.

Cechetti, S. 1986. The frequency of price adjustment: a study of the Newsstand prices of magazines. Jotwral of Econometrics, 31:255-274.

Chamberlain, G. 1980. Analysis of covariance with qualitative data. Revieu of Economic Studies, 47: $225-238$.

Chamberlain, G. 1984. Panel data. In A. Griliches and M. Intriligator (eds.), Frandbook of econometrics. Amsterdam: North-Holland, 1247-1318.

Charlier, E., Melenberg, B., and van Soest, A. 2000. Estimation of a censored regression panel data model using conditional moment restrictions efficiently. Journal of Econometrics, 95: $25-56$.

Charlier, E., Melenberg, B., and wan Soest, A. 2001. An analysis of housing expenditure using semiparametric models and panel data. Jourral of Econometrics, 101: 71-107. 
Chesnais, F. 1988. Technical cooperation agreements between fims. STI Reviet, 4: 51-120.

Chintagurta, P., Kyriazidou, E., and Perktold, J. 2001. Panel data analysis of household brand choices. Jourtual of Econometrics, 103: 111.153.

Chung, S., Singh, H., and Lee, K. 2000. Complenentarity, status similarity, and social capital as drivers of alliance formation. Strategic Management Jounal, 21: 1-22.

Ciborra, C. 1991. Alliances as leaming experiments: cooperation, competition, and change in high-tech industries. In L. Mytelka (ed.), Strategic partmerships and the world economy. London: Pinter Publishers, 51-77.

Cockburn, I, and Henderson, R. 2000. Untangling the origins of competitive advantage. Strategic Management Journat, 21: 1123-1146.

Cohen, S. Chang, A., Boyer, H., and Helling, R. 1973. Consiruction of biolagically functional bacterial plasmids in vitro, Proceedings of the National Academy of Sciences, 70: 3240-3244.

Cohen, M. and Levinthal, D. 1989. Innovation and learning: the two faces of R\&D. Economic Jourval, 99: $569-596$.

Cohen, W. and Levinthal, D. 1990. Absorptive capacity: a new perspective on learning knd innovation. Administrative Science Quarterly, 35: 128-152.

Contractor, F. and Lorange, P. 1988a. Why should firms cooperate? The strategy and economics basis for cooperative ventures. In $\mathrm{F}$. Contractor and $\mathrm{P}$. Lorange (eds.), Cooperative strategies in intergational business. Lexington: Lexington Books, 3-30.

Contractor, F", and Lorange, P. (eds.) 1988b. Cooperative strategies in international business. Lexington: Lexington Books.

Contractor, F and Lorange, P. (eds.). 2002. Cooperative strategies and alliances. Amsterdam: Elsevier.

Cool, K., Roller, L., and Leleux, B. 1999. The relative impact of actual and potential rivalry on firm profitability in the pharmaceutical industry. Strategic Management Journal, 20: 1-14. Cyert, R. and March, J. 1963. A behavioural theory of the firm. Malden: Blackwell Publishing.

D

Das, S., Sen, P., and Sengupta, S. 1998. Impact of strategic alliances on firm valuation. Academy of Managenent Jowrnal, 41: 27-41.

D'Aveni, R. 1994. Hypercompetitive rivalries. New York: Free Press.

Deeds, D. and Hill, C. 1996 . Strategic alliances and the rate of new product development: an empirical study of entrepreneurial biotechnology frms. Jounal of Business Venturing, 2: $41-55$.

Della Valle, F. and Gambardella, A. 1993. Biological revolution and strategies for innovation in pharmaceutical companies. R6D Management, 23: 287-301.

DiMasi, J. 1995. New drug development: cost, risk, and complexity. Drug Infomation Joumal, 29:375-3844.

Dosi, G. 1982. Technological paradigms and technological trajectories. Research Poltcy, 11: $147-162$.

Dowgherty, D. and Heller, T. 1994. The illegitimacy of successful product innovation in established firms. Organizakion Science, 5: 200-218.

Doz, Y. 1988. Technology partnerships between larger and smaller firms: some critical issues. In $\mathrm{F}$. Contractor and $\mathrm{P}$. Lorange (eds.), Cooperatave strategies in international business. Lexington: Lexington Books, 317-338. 
Dot, $\mathrm{Y}$. and Hamel, G. 1998. Allance adwantage: the art of creating value through partnering. Boston: Harvard Business School Press.

Dunnings: J. 1988. Multinationals, technology, and competitiveness. London: Unwin Hyman.

Duming, J. 1993. Multinational enterprises and the global economy. Wokingham: AddisonWesley Publishing Company.

Dussauge, P. and Carrette, B. 1999. Cooperative strategy - competing saccessfully through strategic alliances. Chichester: Wiley.

Duysters, G. and Hagedoorn, J. 1996. Intemationalisation of corporate technology through strategic partnering: an empirical investigation. Research Policy, 25: 1-12.

Duysters, G. and Hagedoom, J. 2000. International technological collaboration: implications for NIEs, In L. Kim and R. Nelson (eds.), Technological leaming and economic development: the experience of the Asian newly industrialized countries. Cambridge: Cambridge University Press, 193-215.

Dyer, J. 1996. Specialized supplier networks as a source of competitive advantage: evidence from the auto industry. Strategic Maragement Journal, 17: 271-291.

Dyer, J. and Chu, W. 2000. The deteminants of trust in supplier-automaker relationships in. the US, Japan, and Korcam Joumal of Irternational Business Studies, 31: 259-285.

Dyer, J and Ouchi, W. 1993. Japanese-style partnerships: giving companies a competitive edge. Sloan Management Review, Fall: 51-63.

Dyer, J. and Singh, H. 1998. The relational view: cooperative strategy and sources of inter-organizational competitive advantage. Academy of Managenent Review, 23: 660-679.

\section{E}

Eisenhardt, K. and Bird-Schoonhoven, C. 1996. Resource-based view of strategic alliance formation: strategic and social effects in entrepreneurial firms. Organization Science, 7 : $136-150$.

F

Fathner, W. and Orsenigo, L. 1989. UK and Italian policy for biotechmology. In U. Hilpert (ed.), State policies and techno-industrial innowation. London: Routledge, 159-184.

Fildes, R. 1990 . Strattegic challenges in commercialising biotechnology. Califorma Managenent Raview, Spring: 63-72.

Forrest, J. 1996. Japanese/US technological competitiveness and strategic alliances in the biotechology industry. RED Management 26: 141-154.

Fansman, M. 1991. Biotechnology: generation, diffusion, and policy. Matastricht: UNU/INTECH.

Freman, C. 1990. Technical innovation in the world cliemical industry and changes of the techno-economic paradigm. In C. Freeman and L. Soete (eds.), New explorations in the economics of technological change. London: Pinter Publishers, 74-91.

Freeman, C. and Hagedoorn, J. 1994. Catching up or falling behind: patterns in intemational inter-firm technology parthering. World Development, 22: 771-780.

Freeman, L. 1977. A set of measures of centrality based on betweenness. Sociometry, 40: 35-41.

Freeman, L. 1979. Centrality in social networks: conceptual clarification. Socina Networks, 1: $215-239$. 


\section{G}

Galambos, L. and Sturchio, J. 1998. Pharmaceutical firms and the transition to biotechnology: a study in strategic innowation. Business History Review, $72 ; 250-278$.

Galaskiewicz, J, and Zaheer, A. 1999. Networks of competive adwantage. In S. Andrews and D. Knoke (eds.), Reseanch in the sociology of arganizations. Greemxich: JAI Press, $237-261$.

George, V. and Farris, G. 1999. Performance of alliances: formative stages and changing organizational and enviromental influences. RED managentent, 29:379-389.

Gomes-Casseres, B. 1994. Group versus group: how alliance networks competa. Hamard Business Review, July/August: 62-74.

Gomes-Casseres, B. 1996. The allance revolution: the new shape of business rivalry. Cambridge: Harvard University Press.

Gort, M. and Klepper, S. 1982. Time paths in the diffusion of product innovations. Economic Joumal, 92: 630-653.

Grabher, G. (ed.). 1993. The embedded firm. London: Routledge.

Grabowski, H. and Vernon, J. 1994. Innovation and structural change in pharmaceuticals and biotechnology. Industrial and Corporate Change, $3: 435-449$.

Granovetter, M. 1985. Economic action and social structure: the problem of embeddedness. American Journal of Sociology, 91: 481-501.

Greis, N., Dibner, M., and Bean, A. 1995. External partnering as a response to innowation barriers and global competition in biotechnology. Research Policy, 24: 609-630.

Griliches, Z. 1998. RGD and productivity The econometric evdence. Chicago: University of Chicago Press.

Gulati: R. 1995a. Does familiarity breed trust? The implications of repented ties for contractual choice in alliances. Academy of Management Jowmal, 38: 85-112.

Gulati, R. 1995b. Social structure and alliance formation pattems: a longitudinal analysis. Administrative Science Quaterly: 40: 619-652.

Gulati, R. 1998. Afliances and networks. Strategic Management Journal, 19: 293-317.

Gulati, R. 1999. Network location and learning: the influence of networls resources and firm capabilities on alliance formation. Strotegic Management Joumal, 20: 397-420.

Gulati, R., Nohria, N., and Zaheer, A. 2000. Strategic networks. Strategic Managenum Jour $\mathrm{wal}^{2}$ 21: 203-215.

Gulati, R. and Singh, H. 1998. The architecture of cooperation: managing coordination costs and appropriation concerns in strategic alliances. Administrative Science Quarterly, 43 : 781.814.

\section{HI}

Hacking, A. 1986. Economic aspects of biotechnology. Cambridge: Cambridge Uniwersity Press.

Hagedoorn. J. 1990. Organizational modes of inter.firn cooperation and technology transfer. Technovation, 10: 17-30.

Hagedoorn, J. 1993. Understanding the rationale of strategic techology partnering: interorganizational modes of cooperation and sectoral differencess. Strategic Management Jowrmal, 14: $371-385$.

Hagedoorn, J. 1995. A note on intemational market leaders and networks of strategic technology partnering. Strategic Management Jourral, 16: $241-250$. 
Hagedoorn, J. 1996a. Trends and patterns in strategic technology partnering since the early seventies. Review of Industrial Organization, 11: 601-616.

Hagedoom, J. 1996b. Innowation and entrepreneurship: Schumpeter revisited. Indastrial and Corporate Change, 5: $883-896$.

Hagedoorn, J. 2002. Inter-firm R\&D partnerships: an overview of major trends and patterns since 1960. Hesearch Policy, 31: 477-492.

Hagedoom, J., Link, A., and Vonortas, N. 2000. Research partnerships. Research Policy, 29: $567-586$.

Hagedoom, J. and Narula, R. 1996. Choosing organizational modes of strategic technology partnering: international and sectoral differences. Joumal of Intemational Business Studies, 27: 265-284.

Hagedoorm, J. and Osborm, R. 2002. Inter-firm R\&D partnerships: major theories and trends since 1960 . In $\mathrm{F}$. Contractor and P. Lorange (eds.), Cooperative strategres and alliances. Amsterdam: Elsevier, 517-542.

Magedoon, J. and Rojjakkers, N. 2002. Small entrepreneurial firms and large companies in inter-firm R\&D networks - The international biotechnology industry. In $M$. Hitt, $R$. Ireland, S. Camp, and D. Sexton (eds.), Strategic entrepreneurship: creating a new integrated mindset. Oxford: Blackwell Publishing, 223-252.

Hagedoorn, J. and Schakenraad, J. 1990. Inter-firm partnerships and cooperative strategies in core technologies. In C. Freeman and L. Soete (eds.), New explorations in the economics of Lechological change. London: Pinter Publishers, 3-37.

Hagedoom, J. and Schakenraat, J. 1992. Inter-company cooperation and technological developments: leading companies and networks of strategic alliances in information technologies. Research Policy, 21: 163-1990.

Hair, J., Anderson, R., Tatharn, R., and Black, W. 1994. Multwariate data analysis. New York: MacMillan,

Hajivassilion, V. 1987. The external debt repayments problems of LDC's: an econometric model based on panel data. Journal of Econometrics, 36: 205-230.

Hakansson, H. and Johansson, J 1993. The network as a govermance structure. In G. Grabher (ed.), The embedded furm. London: Routledge, 35-51.

Hakansson, P., Kjelberg, H., and Lundgren, A. 1993. Strategic alliances in global biotechnology - a network approach. International Business Review, 2; 65-82.

Haklisch, C. 1986. Technical allances in the semaconductor andustry, Mimeo, New York University.

Hamel, G. 1991. Competition for competence and inter-partmer learning within international straticgic alliances. Strategic Management Journal, 12: 83-102.

Hamel, G., Doz, Y., and Prahalad, C. 1989. Collaborate with your competitors and win. Harward Business Rewiew, Janwary/February: 133-139.

Hamilton, W., Vila, J., and Dibner, M. 1990. Patterns of strategic choice in emerging firms: positioning for innovation in biotechnology. Califorma Management Revew, Spring: 73-86.

Hannan, M. and Freeman, J. 1977. Population ecology of organizations. American Journal of Soctology, 82: $929-964$.

Hannan, M. and Freeman, J. 1989. Organizational ecology. Cambridge: Harvard University Press.

Harrigan, K. 1985. Strategies for joint ventures. Lexington: Lexington Books. 
Harrigan, K. 1988. Joint ventures and competitive strategy. Stratcgic Management Jaurnal, 9: $141-158$.

Harrigan, K. and Newman, W. 1990. Bases of inter-organizational cooperation, propensity, power, persistence. Journal of Management Studies, 27: 417-434.

Heckman, J. 1981. Statistical models for discrete panel data. In D. McFadden and C. Manski (eds.), The econometrics of panel data. Cambridge: MTT Press, 114-178.

Heide, J. and Miner, A. 1992. The shadow of the future: effects of anticipated interaction and frequency of contacts on buyer-seller cooperation. Academy of Management Jommal, 35: 265- 291.

Henderson, R. 1993. Under-investment and incompetence as responses to radical innovation: evidence from the photolithographic allignment equipment industry. Rand Joumal of Economics, 24: 248-270.

Henderson, R. and Clark, K. 1990. Architectural imovation: the reconfiguration of existing product technologies and the failure of established firms. Administrative Scienca Quarterly. 35: 9-30.

Henderson, R. and Cockburn, I. 1996. Scale, scope, and spillovers: the determinants of research productivity in drug discovery. Rand Jownat of Economics, 27: 32-59.

Hendry, J. 1995. Culture, community, and networks: the hidden cost of outsourcing. Buropean Management Joumat, 13: 193-200.

Hergert, M. and Morris, D. 1988. Trends in international collaborative agreements. In F. Contractor and P. Lorange (eds.), Cooperative strategies in international business. Lexington: Lexington Books, 99-110.

Herrigel, G. 1993. Power and the redefinition of industrial districts: the case of BadenWuerttemberg. In G. Grabher (ed.), The embedded fim. London: Routledge, $227-252$.

Hirschey, R. and Caves, R. 1981. Internationalisation of research and transfer of technology by multinational enterprises. Oxford Bulletin of Economics and Statistics, 42: 115-130.

Hitt, M. and Ireland, D. 2000. The intersection of entrepreneurship and strategic management research. In D. Sexton and H. Landström (eds.), Handbook of entrepreneurship. Oxford: Blackwell Publishing, 45-63.

Hladik, K. 1985. International joint ventures. Lexington: Lexington Books.

Hadik, K. 1988. R\&D and international joint ventures. In F. Contractor and P. Lonnge (eds.), Cooperative Strotegies in International Business. Lexington: Lexington Books, $187-207$.

Hoang, H., Rothaermel, F, and Simac, S. 2003. The impact of general and partner specific alliance experience on collaborative RBD performance, working paper.

Hsiao, C. 1985. Benefits and limitations of panel data. Econometric Revieves, 4: 121 174.

Hsiao, C. 1986. Analysis of panel data. Cambridge: Cumbridge University Pross.

Hymer; S. 1960. The international operations of national firms: a study of foreign direct investment. Cambridge: MT Press.

\section{I}

Jarillo, J. 1993. Strotegic networks: creating the bonderless organtzation. Oxford: ButterworthHeinemann. 
Johansson, J. and Mattsson, L. 1987. Inter-organizational relations in industrial systerns: a network approach compared with the transaction-cost approach. International Studies of Management and Onganization, 17: 34-48.

K

Kale, P. and Singh, H. 1999. Bulding allince capabrities: a knowledge-based approach. Acaderny of Management Best Paper Proceedings, Chicago.

Kale, P. Singh, H., and Perlmutter, H. 2000. Learning and protection of proprietary assets in strategic alliances: building relational capital. Strategic Management Journal, 21: 217-237.

Kamien, M. and Schwartz, N. 1982. Market structure and innovation. Canbridge: Cambridge University Press.

Kanter, R. 1994. Collaborative advantage: the art of alliances. Harward Business Revieus, July/August: 96-108.

Kaufman, H. 1971. The limits of organizational change. Alabama: University of Alabama Press.

Kawasaki, S. and MacMillan, J. 1986. The design of contracts: evidence from Japanese subcontractitg, Mimeo, University of Westem Ontario.

Keik, R. 1992. New directions for network exchange theory: strategic manipulation of network linkages. Social Networks, 14: 309-323.

Kenmey, M. 1986. Schmpeterian imovation and entrepreneurs in capitalism: a case study of the US biotechnology industry. Research Policy, 15: 21-31.

Klevmarken, N. 1989. Panel studies: what can we learn from them? Introduction. Suropean. Economic Rewiew, 33: 523-529.

Knoke, D. and Kuklinski, J. 1982. Netwom analysis. Newbury Park: Sage Publications.

Kogut, B. and Zander, U. 1992. Knowledge of the firm, combinative capabilities, and the replication of technology. Organization Science, 3: 383-397.

Kruskal, J. and Wish, M. 1978. Multidimensional scaling. Beverly Hills: Sage Publications.

L.

Laamanen, T. and Autio, E. 1996. Dominant dymamic complementarities and technologymotivated acquisitions of new, technology-based firms. International Joumal of Technology Management, 12: 769-786.

Liene, P. and Lubatkin, M. 1996. Relative absorptive capacity and inter-organizational leaming. Strategic Monagement Jounal, 19: 461-477.

Larson, A. 1992. Network dyads in entrepreneurial sottings: a study of the governance of exchange relationships. Administrative Science Quarteny, 37: 76-104.

Layman, P. 1988. Global pharmacentical industry undergoing major shifts. Chemical and Engunering News, 66: 16-17.

Lazerson, M. 1993. Factory or putting out? Knitting networks in Modena. In G. Grabher (ed.), The embedded firm. London: Routledge, 203-226.

Lesch, J. 1993. Chemistry and biomedicine in an industrial setting: the invention of the sulfa drugs. In S. Mnuskopf (ed.), Chemical sciences in the rnodern world. Philadelphia: University of Pennsylvania Press, 158-215.

Levintha, D. and Fichman, M. 1988. Dynamics of inter-organizational attachments: auditorclient relationships. Administrative Science Quarterly, 33: 345-369. 
Levinthal D. and March, 3. 1993. The myopia of learning. Strategic Managenent Joumal, 14: $95-112$.

Lewis, I. 1990. Partnerships for profit: structuring and monaging strategic alliances. New Yorik: Free Press.

Link, A. and Bauer, L. 1989. Cooperatore reseorch in US manufoctuning assessing policy initiatwes and corporate struteques. Lexington: Lexington Books.

Lorange, P. and Roos, J. 1992. Strategic alliances: formation, implenuentation, and evolution. Oxford: Blackwell Publishing.

Lorenzoni, G. and Baden-Fuller, C. 1995. Creating a strategic conter to manage a web of partners. Calforniw Management Review, 37: 146-163.

Lorenzoni, G. and Lipparini, A. 1999. The leweraging of inter-firm relationships as a distinctive organizational capability: a longitudinal study. Stotegic Management Joumal, 20: $317-338$.

Lumerman Oliver, A. and Porter Liebeskind, J. 1997. Three levels of networking for sourcing intellectual capital in biotechnology: implications for studying inter-organizational networks. International Studies of Management and Organization, 27: 76-103.

Lundvall, B-A. 1993. Explaining inter-firm cooperation and innowation: limits of the transaction-cost approach. In G. Grabher (ed.), The embedded firm. London: Rontledge, $52-64$.

Lyles, M. 1988. Learning among JV-sophisticated firms. In F. Contractor and P. Lorange (eds.), Cooperatuve strategies in international business. Lexington: Lexington Books, $301-316$.

Lyles, M. 1994. The impact of organizational learning on joint venture formations. International Business Review, 3: 459-467.

MI

MacDonald, S. 1995. Too close for comfort? the strategic implications of getting close to the customer. California Management Review, 37: 8-27.

MacMillan, $\mathbb{K}$. and Farmer, D. 1979. Redefining the boundaries of the firm. Joumol of Itrdustrial Economics, $27: 277-285$.

Madhok, A. 1995. Opportumism and trust in joint venture relationships: an exploratory stady and model. Scandinavion Joumal of Management, 11: $57-74$.

Mann, R. 1984. Modern drug use: an inquiry on historical principles. Lancaster: MTP Press.

Marco, L. 1985. Entrepreneur et innovation: les sources trançases de Joseph Schumpeter. Economies et Societés, 19:89-106.

Marstrand, P. 1981. Patterns of change in biotechnology. Sussex: SPRU-University of Sussex.

McMillan, G, Narin, F, and Deeds, D. 2000. An analysis of the critical role of public science in innovation: the case of biotechnology. Research Policy, 29: 1-8.

Miles, R. and Snow, C. 1992. Canses of failure in network organizations. Califomia Management Review, Summer: 53-72.

Mowery, D. (ed). 1988. International collaborative ventures in US manufacturing. Cambridge: Ballinger.

Mowery, D., Oxley, J., and Silverman, B. 1998. Technological overtap and inter-firm cooperam tion: implications for the resource based wew of the firm. Research Policy, 27 : $507-523$. 
Mytelka, L. (ed.). 1991. Strategic partnerships and the world economy. London: Pinter Publishers.

\section{N}

Narim, F., Noma, E., and Perry, R. 1987. Patents as indicators of corporate technological Brrength. Research Policy, 16: 143 155.

Nartila, R. 1999. Choosing between whernal and non-internal RBD activities: some technological and economic factors, MERTT working paper 2/99-024.

Nelson, $\mathbb{R}$ and Winter, S. 1982. An evolutionary theory of economic change. Cambridge: Belknap Press.

Nishiguchi, T. 1994. Strategic industral sourcing: the Japanese advantage. New York: Oxford Uniwersity Press.

Nohria, N. and Eccles, $\mathbb{R}$. (eds.). 1992. Networks and organizations: structure, form, and action. Boston: Harvard Business School Press.

Nooteboom, B. 1999. Inter-fim alliances - anolysis and design London: Routledge.

Nooteboorn, B., Berger, H, and Noorderhaven, N, 1997. Effects of trust and governance on relational risk. Academy of Managenent Joumal, 40: $308-338$.

$\mathrm{O}$

Oakey, R. 1990. New firms in the biotechnology industry: their contribution to innonation and growth. London: Pinter Publistiers.

Oakey, R. 1993. Predatory networking: the role of small firms in the development of the British biotechnology industry. International Small Business Joumal, 11: 9-22.

Oakey, R., Faulkner, W., Cooper, S., and Walsh, V. 1990. New firms in the biotechnology industry. London: Pinter Publishers.

Obleros, F. and MacDonald, R. 1988. Strategic alliances: managing complementarity to capitalize on emerging techuologies. Technovation, 7: 155-176.

OECD (Organisation for Economic Cooperation and Development). 1989. Biotechnology: economic and wider impocts. Paris: OECD.

OECD. 1992. Technology and the wconomy. Paris: OECD.

OECD. 1993. The OECD in figures: statistics on the member countries. Supplement to OECD Observer, no. 182, June-July.

OECD. 2001. Science, technology, and indwstry scoreboard: towards a knowledgebosed eonomy. Paris: OECD.

Ohmak, K. 1985. Thad power. New York: Free Press.

Ohmae, K. 1989. The global logic of strategic alliances. Harnard Bustmess Review, 67: 143-154.

Ohmne, $\mathbb{K}$. 1990. The borderless world. New York: Harper.

Orsenigo, L. 1989. The emengence of biotechnology: institutions and markets in industriat ingovation. London: Pinter Publishers.

Osborn, R. and Baughn, C. 1990 . Fonms of inter-organizational governance for multinational alliances. Academy of Management Journal, 33: 503-519.

Osborn, R. and Hagedoorn, J. 1997. The institutionalisation and evolutionary dynamics of inter-organizational alliances and networks. Academy of Management Joumal, 40. 216-278.

Oster, S. 1992. Modern competitive analysis. Mew York: Oxford University Press. 
OTA (Office of Techmology Assessment). 1984. Commercial biotechology: an intermational analysis. Washington: US Govemment Printing Office.

OTA. 1988. New developments in biotechnology: US imestment in biotechnology. Washington: US Govermment Printing Office.

OTA. 1991. Brotechnology in a global cconomy. Washington: US Government Printing Office.

OTA. 1993. Phamaceutical ReD: costs, risks, and rewards. Washington: US Gowernment Printing Office.

\section{$P$}

Parkhe, A 1991. Inter-fim diversity, organizational leaming, and longevity in global strategic alliances. Journal of International Busigess Studies, 22: 579-601.

Parkhe, A. 1993. Strategic alliance structuring: a game theoretio and transaction cost examination of inter-firm cooperation. Academy of Managenemt Joumal, 36: 794-829.

Patel, P. and Pavit, K. 1991. Large firms in the production of the world's technology: an important case of non-globalisation. Joumal of International Business Studies, 22: 1-21.

Pearce, R. 1989. The internationalisation of research and development by multinational enterprises. London: MacMillan.

Perlmntter, H. and Heenan, D. 1986. Cooperate to compete globally. Harmard Business Review, 64: $136-162$.

Pfeffer, J. and Salancilk, G. 1978. The extemal control of organizations. Naw York: Haper and Row.

PhRMA (Pharmaceutical Research and Manufacturers of America). 2001. Pharmaceutical industry profite 2001. Washington: PhRMA.

PhRMA. 2002. Pharmaceutical industry profle 2002. Washington: PhRMA.

Pisano, G. 1990. The R\&D boundaries of the firm: an empirical analysis. Administative Science Quarterly, 35: 1.53-177.

Pisano, G. 1991. The govemance of innovation: vertical integration and collaborative arrangements in the biotechnology industry. Research Policy, 20: $237-249$.

Pismno, G. 1994. Knowledge, integration, and the locus of learning: an empirical analysis of process development. Strategic Management Jownal, 15: 85-100.

Pisano, G., Shan, W., and Teece, D. 1988. Joint ventures and collaboration in the biotechnology industry. In D. Mowery (ed.), International collaborative ventures in OS manafacturing. Cambridge: Ballinger, 183-222.

Pisano, $\mathrm{G}$ and Wheelwright, S. 1995. The new logic of high-tech R\&D. Harvard Business Review, 73: 93-105.

Porter, M. 1980. Competitive strategy: techniques for andysing industries and competitors. New Kork: Free Press.

Porter, M. 1985. Competitine adiantage. New York: Free Press.

Porter, M. 1990. The competitive adoontage of nations. London: MacMillan.

Porter, M. Enright, M. and Tendi, P. 1990. The competitive adwantage of nations. Harvard Bustness Revieu, 68: 73-93.

Porter Liebeskind, J., Lumerman Oliver, A., Zucker, L, and Brewer, M. 1996. Social networks, learning, and flexibility: sourcing scientific knowledge in new biotechuology firms. Organization Seience, $\pi$ : $428-443$ 
Powell, W. 1990. Weither market nor hierarchy: network forms of organization. Research in Organizational Behaviowr, 12: 295-336.

Powell, W. 1996. Inter-organizational collaboration in the biotechnology industry. Journal of Institutional and Theoretical Economics, 1.52: 197-215.

Powell, W. 1998. Learning from collaboration: knowledge and networks in the biotechnology and pharmaceutical industries. California Management Review, 40: 228-240.

Powell. W. and Brantley, P. 1992. Competitive cooperation in biotechnology: learning through networks? In N. Nohria and R. Eccles (eds.), Networks and onganizations: structure, form, and action. Boston: Harvard Business School Press, 366-394.

Powell, W. Koput, K., and Smith-Doerr, L. 1996. Inter-organizational collaboration and the locus of innowation: networks of learning in biotechnology. Administrative science Quarterly, 41: 116-145.

Prahalad, C. and Hamel, G. 1990. The core competence of the corporation. Hartard Business Review, May/June: 79-91.

$\mathbb{R}$

Reche, W. and Weber, M. 1979. Profits, politios, and drugs London: MacMillan.

Reich, R. 1990. Who is US? Homard Business Remew, 68 : $53-64$.

Reich, R. 1991. The work of nations. New York: Vintage Books.

Reich, R. and Mankim, D. 1986. Joint ventures with Japan give away our future Hormard Business Rewiew, 64: 78-86.

Reinganum, J. 1983. Uncertain innovation and the persistence of monopoly. American Economic Revew, 73: 741-748.

Reinganum, J. 1989. The timing of imovation: research, development, and diffusion. In R. Schmalensee and R. Willig (eds.), Handbook of industrial onganization. New York: North-Holland, $849-908$.

$\mathbb{R i n g}, \mathbb{P}$. and wan de Ven, A. 1992. Structuring cooperative relationships between organizations. Strategic Managenent Journal, 13: 483-498.

Roberts, P. 1999. Product innovation, product-market competition, and persistent: profitability in the US pharmaceutical industry. Strategic Management Jowrral, 20: 655-670.

Rosenbloom, R. and Christensen, C. 1998. Technological discontinuties, organizational capabilities, and strategic commitments. In G. Dosi, D. Teece, and J. Chytry (eds.), Technology, orgrizations, and competitiveness: perspecthes on industrial and conporate change. Oxford: Oxford University Press, 215-245.

Rothaermel, F. 2000. Techological discontinuities and the nature of competition. Technology Analysis and Strategic Management, 12: 149160.

Rothaermel, $F$. 2001. Incumbent's advantage through exploiting complementary assets via inter-firm cooperation. Strategic Management Joumat, 22: 687-699.

Rothaermel, F. and Deeds, D. 2001. More good things are not necessarily better: an empirical study of strategic allinces, expersence effects, and innovative oupat in high-technology slaxt-ups. Academy of Manemgement Proceedings 2001.

Rousseau, D., Sitkin, S., Burt, R., and Camerer, C. 1998. Not so different after all: a cross-discipline view of trust. Academy of Management Review, 23: 393-404. 


\section{S}

Sako, M. and Helper, S. 1998. Determinants of trust in supplien relations: evidence from the automotive industry in Japan and the United States. Joumal of Economic Behantow and Organization, 34: 387 417.

Santarell, E. and Pesciarelli, E. 1990. The emergence of a vision: the development of Schumpeter's theory of entrepreneurship. History of Political Economy, 22: 677-696.

Sapienza, A. 1989, R\&D collaboration as a global competitive tactic: biotechnology and the ethical pharmaceutical industry. R6D Management, 19: 285-295.

Savioti, P. 1998. Industrial structure and the dymamics of knowledge generation in biotechnology. In J. Senker (ed.), Biotechnology and competitive advantage: Europe's firmus and the US challenge. Cheltenham: Edward Elgar, 1943.

Saxton, "T. 1997. The effects of partner and relationship characteristics on alliance outcomes. Academy of Management Journel, 40: 443 461.

Scherer, F. 1984. Innovation and growth - Schumpeterian perspectives. Cambridge: MTT Press.

Schumpeter, J. 1934. The theory of economic development. London: Oxford University Press.

Schumpeter, J. 1942. Capitalism, socialism, and democracy. New York: Hatper and Row.

Schwartzman, D. 1976. Innovation in the phamnaceutical industry. Baltimore: Johns Hopkins University Press.

Segers, J. 1992. Region-specific technology policy in Belgium: the significance of new technology based startups. Small Business Economics, 4: 133-140.

Senker, J. 1996. National systems of innowation, organizational learning, and industrial biotechnology. Technovation, 16: 219-230.

Senker, J. (ed.). 1998. Biotechnology and competitive advantage: Europe's firms and the US challenge. Cheltenham: Edward Elgar.

Senker, J. and Sharp, M. 1997. Organizational learning in cooperative alliances: some case studies in biotechnology. Technology Analysis and Strategic Management, 9: 35-52.

Shan, W., Walker, G., and Kogut, B. 1994. Inter-firm cooperation and start-up innovation in the biotechnology industry. Strategic Management Journal, 15: $387-394$.

Sharp, M. 1990. Technological trajectories and corporate strategies in the diffusion of biotechnology. In E. Deiaco, E. Homell, and G. Vickery (eds.), Technology and investment: critical issues for the 1990s. London: Pinter Publishers, 93-114.

Sharp, M., Patel, P., and Pavitt, K. 1996. Europe's phamaceutical industry an movation profile. Sussex: SPRU-University of Sussex.

Simonin, B. 1999. Ambiguity and the process of knowledge transfer in strategic alliances, Strategic Management Jowrnal, 20: 595-623.

Slowinski, G., Seelig, G, and Hull, F. 1996. Managing technology-based strategic alliances between large and small firms. S.A.M. Advanced Managenent Journal, 61: 42-47.

Smith, J. and Fleck, V. 1988. Strategies of new biotechnology firms. Larg Range Planning, 21: 51-59.

Sneader, W. 1985. Drug discoveny: the evolution of modern medicines. Chichester: Wiley.

Solon, G. 1986. Effects of rotation group bias on estimation of unemployment. Jourval of Business and Economic Statistics, 4: 105-109.

Staber, U. 1998. Inter-firm cooperation and competition in industrial districts. Orgonization. Studies, 19: 701-724. 
Stock, G., Greils, N, and Fischer, W. 2001. Absorptive capacity and new product development. Journal of High Technology Managenent Research, 12: 77-91.

Sthart, T. 1998. Network positions and properties to collaborate: an investigation of strategic alliance formation in a high-technology indnstry. Admimistrative Science Queterty, 43: 668 698 .

$T$

Taggart, J. 1993. The world pharmaceutical industry. London: Routledge.

Teece, D. 1986. Profiting from technological innovation: implications for integration, collaboration, licensing, and public policy. Research Policy, 15: 285-305.

Teece, D. 1992. Competition, cooperation, and innowation: organizational arrangements for regimes of rapid technological progress. Journal of Economic Behaviaur and Organization, $18: 1-25$.

Teece, D., Pisano, G., and Shuen, A. 1997. Dynamic capabilities and strategic management. In N. Foss (ed.), Resources, firms, and strategies. Oxford: Oxford University Press, $268-285$.

Temin, P. 1990. Taking your medicine: drug regulation in the US. Cambridge: Harvard University Press.

Thorelli, H. 1986. Networks: between markets and hierarchies. Strategic Management Joury al, 7 : $37-51$.

Tolbert, P. and Zucker, L. 1996. The institutionalisation of institutional theory. In S. Clegg, C. Hardy, and W. Nord (eds.). Handbook of organization studies. London: Sage Publications, $175-190$.

Tsai, W. 2001. Knowledge transfer in intra-organizational networks: effects of network position and absorptive capacity on business unit innovation and performance. Academy of Maragement Journal, 44: 996-1005.

Tushman, M. and Anderson, P. 1986. Technological discontinuities and organizational environments. Administrative Science Quarterly, 31: 439-465.

U

Utterback, J, and Suárez, F, 1993. Imnovation, competition, and industry structure. Research Policy, 22: 1-21.

V

Van Vliet, R. 1998. Introduction. In J. Senker (ed.), Biotechnology and competitive advantage: Europe's firms and the US challenge. Cheltenham: Edward Elgar, 1-5.

Verg, E. 1988. Milestones: the Bayer stary, 1863-1988. Lewerkusen: Bayer (translated by w. Wicks).

Vernon, R. 1966. International investment and international trade in the product cycle. Quarterly Jowrial of Economics, 88: 190-207.

Vermon, R. 1979. The product cycle hypothesis in a new international environment. Oxford Bultetin of Economics and Statistics, 41: 255-267. 


\section{W}

Walker, B. and Walker, S. 1986. Thends and changes in drug research and development. Proceedings of the Society for Drug Research (Twentieth muiversary meeting). London: Kluwer

Walsh, V. 1984. Invention and innovation in the chemical industry: demand-pull or discovery-push? Research Policy, 13: 211-234.

Walsh, V. and Galimbert, I. 1993. Firm strategies, globalisation, and new technological. paradigms: the case of biotechnology. Ir M. Humbert (ed.). The mpact of globalisation an Europe's firms and industries. London: Pinter Publishers, 175-190.

Walsh, V., Niosi, J., and Mnstar, P. 1995. Small-fim formation in biotechnology: a comparison of France, Britain, and Canada. Technovation, 1:3: 303-327.

Wansbeek, T. 2001. GMM estimation in panel data models with measurenent error. Joumal of Econometrics, 10: 259-268.

Warden, W. 1979. The history of drug discovery, development, and regutation. In $R$. Chien (ed.), Issues in pharmaceutical economics. Lexington: Lexington Books, 151-187.

Waring, G. 1993. Industry differences in the persistence of competitive advantage, unpublished doctoral dissertation, Los Angeles, University of Califorma.

Warren, R. 1967. The inter-organizational field as a focus for investigation. Administrative Science Quarterly, 12: 396-419.

Wasserman, S. and Faust, K. 1994. Social network analysis: methods and applications. Cambridge: Cambridge Uniwersity Press.

Williamson, O. 1975. Markets and hierarchies. New York: Free Press.

Williamson, 0 . 1985. The economic institutions of capitalisn, frms, markets, relational contracting. New York: Free Press.

Williamson, 0 . 1996. The mechanisms of governance. Oxford: Oxford University Press.

\section{$\mathbf{Y}$}

Yoshino, M. and Rangan, U. 1995. Strategic alliances. Boston: Harvard Business School Prass.

Young-Ybarra, C. and Wiersema, M. 1999. Strategic fexibility in information technology alliances: the infuence of transaction cost economics and social exchange theory. Oryanization Science, 10: 439459 .

\section{$\mathrm{Z}$}

Zaheer, A., McEvily, B., and Perrone, V. 1998. Does trust matter? Exploring the effects of inter-organizational and interpersonal trust on performance. Organization Science, 9 : $141-159$

Zucker, L. and Darby, M. 1996. Costly information: firm transformation, exit, or persistent railure. American Behawioural Scientist, 39: 959 974,

Zucker, L. and Darby, M. 1997. Present at the biotechnological revolution: transfonmalion of technological identity for a large incumbent pharmaceutical firm. Research Polvcy, 26 : $429-446$. 



\section{NEDERLANDSE SAMENVATTING \\ R\&D allianties in de farmaceutische biotechnologie industrie}

\section{Introductie}

Dit proefschrift bestudeert de specifieke aard van samenwerkingsverbanden tussen hoogtechnologische bedrijven op het gebied van onderzoek en ontwikkeling. In het bijzonder handelt dit proefschrift over de onderliggende motieven van deze zogenaamde $R \& D$ allianties, hun organisatorische kenmerken, de betrokken bedrijven, alsmede de belangrijkste factoren die het aangaan van deze allianties bepalen. De industriële context, waarbinnen deze verschillende aspecten van $R \& D$ allianties bestudeerd worden, is de internationale hoogtechnologische farmaceutische biotechnologie industrie. De algemene onderzoeksvraag, die aan dit proefschrift ten grondslag ligt, luidt: kunnen R\&D allianties tussen hoogtechnologische farmaceutische biotechnologie bedrijven het beste worden omschreven als bedrijfsgeoriënteerde relaties of als netwerkgeoriënteerde relaties?

Teneinde antwoorden op deze vraag te verkrijgen, is dit proefschrift hoofdzakelijk gebaseerd op longitudinale empirische analyses van het MERIT-CATI informatiesysteem. Deze uitgebreide database bevat informatie over hoogtechnologische farmaceutische biotechnologie bedrijven en de R\&D allianties die deze bedrijven gedurende de periode 1975-1998 zijn aangegaan. Als theoretisch kader voor de interpretatie van de verkregen onderzoeksresultaten is gebruik gemaakt van een aantal theorieën die handelen over de functie van hoogtechnologische bedrijven, de organisatie van hoogtechnologische industrieën en de belangrijkste kenmerken van R\&D allianties. Elk van deze theorieën benaclert deze verschillende onderwerpen ofwel vanuit een bedrijfsgeoriënteerd perspectief ofwel met een netwerkgeoriënteerde insteek. 


\section{Verschillende theoretische benaderingen van samenwerking}

In de bedrijfsgeoriënteerde onderzoekstraditie worden zowel de functie van hoogtechnologische bedrijven als de onderlinge relaties tussen deze bedrijven belicht vanuit de neoklassieke economische verhandelingen over concurrentiestrijd. Vanuit dit traditionele perspectief wordt de specifieke organisatie van hoogtechnologische industrieën veelal bepaald door de hevige concurrentiestrijd tussen een groot aantal onafhankelijke bedrijven, die ernaar streven een zo voordelig mogelijke concurrentiepositie te verwerven. Hoogtechnologische bedrijven, die in een dergelijke vijandige marktomgeving opereren, gaan dan ook voornamelijk R\&D allianties aan met het oog op eigen belang en zij gebruiken deze relaties met anderen om hun individuele concurrentiepositie te verstevigen. Aangezien een hoge mate van integratie en wederzijdse afhankelijkheid van alliantiepartners de concurrentiepositie van de partners kan verzwakken, baseren hoogtechnologische bedrijven hun samenwerking met anderen eerder op flexibele contracten dan op het nemen van een belang ("equity") in hum partner. Contractuele allianties, waarbij het gedrag van de alliantiepartners tot in de details wordt vastgelegd in formele contracten, kumnen de partners bovendien beschermen tegen opportunistisch gedrag en het ongewild weglekken van concurrentiegevoelige technologische kenmis.

In tegenstelling tot de traditionele bedrijfsgeoriënteerde onderzoekstraditie, baseren de meeste netwerkgeoriënteerde theorieën zich op het inzicht dat het gedrag van hoogtechnologische bedrijven en hun onderlinge relaties niet alleen worden bepaald door concurrentiestrijd maar, in zeer belangrijke mate, ook door samenwerking. Volgens deze nieuwere theom rieën bestaan hoogtechnologische industrieën veelal uit dichte netwerken van $R \& D$ allianties, waarbinnen integratie (d.m.v. "equity"), vertrouwen en wederzijdse afhankelijkheid van netwerkpartners centraal staan. Hoogtechnologische bedrijven, die hun onderzoeksactiviteiten uitwoeren binnen het kader van een netwerk, zijn bereid hun eigen belang tijdelijk aan de kant te schuiven en een deel van hun onafhankelijkheid op te geven, ondat. 
zij als netwerkpartner meer kunnen bereiken dan als onafhankelijk opererend bedrijf. In centraal gecoördineerde kemisnetwerken vervullen alle netwerkpartners bovendien een gespecialiseerde rol in het innovatieproces. De complementariteit, die daaruit voortvloeit, geeft in de meeste gevallen aanleiding tot een hoge mate van vertrouwen en wederzijdse afhankelijkheid van netwerkpartners. Kennisnetwerken stellen hoogtechnologische bedrijven aldus in staat technologische kennis op te doen via een groot aantal gespecialiseerde onderzoekspartners, hetgeen deze bedrijven in een voordeligere concurrentiepositie plaatst dan bedrijven die hun krachten niet op een dergelijke manier bundelen.

\section{Motieven}

Hoofdstuk 2 van dit proefschrift bestudeert de belangrijkste technologische verschuivingen die zich, ten tijde van de vorige eeuw, in cle hoogtechnologische farmaceutische biotechnologie industrie hebben voltrokken, alsmede de, als gevolg hiervan, sterk veranderende relaties tussen bedrijven in deze industrie. Een belangrijk resultaat van deze historische analyse is de bevinding dat hoogtechmologische bedrijven in de traditionele, op organische chemie gebaseerde, farmaceutische industrie van de vijftiger en zestiger jaren hun onderzoeksactiviteiten vooral intern uitvoerden, en dat hun relaties met anderen gericht waren op concurrentiestrijd. De relaties tussen bedrijven in de traditionele farmaceutische industrie kunnen aldus het beste worden omschreven als bedrijfsgeoriënteercle relaties. Echter, na de radicale ontdekking van biotechnologie in de zeventiger jaren zagen grote farmaceutische bedrijven zich genoodzaakt hun onderzoeksstrategieën aan te passen door naast hun interne onderzoeksactiviteiten ook steeds vaker samen te werken met nieuwe, kleine biotechnologische bedrijven middels vele soorten van $R \& D$ allianties.

Terwijl de sterke toename van het aantal R\&D allianties in de moderne farmaceutische biotechnologie industrie (zie hoofdstuk 3) alsmede de, als gevolg hiervan, steeds dichter wordende kennisnetwerken (zie hoofdstuk 
4) passen binnen het theoretisch kader van de netwerkgeoriënteerde theorieën, kunnen de onderliggende motieven van allianties beter verklaard worden met behulp van de bedrijfsgeoriënteerde theorieën. In hoofdstuk 3 bleek dat de kortstondige $R \& D$ allianties van grote farmaceutische bedrijven voornamelijk gericht zijn op het snel vervullen van bedrijfsspecifieke behoeften, zoals de behoefte om toegang te verkrijgen tot nieuwe biotechnologische kennis, de behoefte om de stijgende R\&D kosten het hoofd te bieden (zie hoofdstuk 2), en de behoefte om een sterke concurrentiepositie te handhaven. Ook kleine biotechnologische bedrijven gaan vaak R\&D allianties aan met het oog op eigen belang, waarbij deze bedrijven hun allianties met grote bedrijven vooral gebruiken om hun onderzoeksactiviteiten te bekostigen en toegang te verkrijgen tot de noodzakelijke kennis van marketing en wetgeving.

\section{Organisatorische kenmerken}

In tegenstelling tot wat men zou verwachten op basis van de netwerkgeoriënteerde theorieën, toont hoofdstuk 4 van dit proefschrift aan dat de grote aantallen R\&D allianties tussen grote farmaceutische bedrijven en kleine biotechnologische bedrijven en de steeds dichter wordende kennisnetwerken niet hebben geleid tot een hoge mate van integratie in de vele allianties tussen netwerkpartners. De verkregen empirische resultaten in hoofdstuk 3 wijzen eveneens op een zeer geringe mate van integratie aangezien hoogtechnologische farmaceutische biotechnologie bedrijven hun R\&D allianties vrijwel altijd baseren op flexibele contracten en bijna nooit op het nemen van een belang in hun alliantiepartner.

De belangrijke rol die contractuele allianties spelen in de hoogtechnologische farmaceutische biotechnologie industrie kan worden verklaard aan de hand van de sterke voorkeur voor flexibiliteit en onafhankelijkheid, die grote farmaceutische bedrijven lijken te hebben. In de meeste gevallen, gebruiken grote farmaceutische bedrijven hun flexibele contractuele allianties om snel over te stappen van de ene technologie naar de andere, 
zonder dat hum onafhankelijke concurrentiepositie daarbij in het geding komt. De industriële context, waarbinnen deze bedrijven opereren, wordt gekemmerkt door snelle technologische veranderingen en een sterke stijging van de R\&D kosten, waardoor zelfs de grootste farmaceutische bedrijven niet meer op de hoogte kunnen blijven van alle belangrijke ontwikkelingen. Door middel van een groot aantal contractuele allianties zijn deze bedrijven echter wel in staat de vele technologische ontwikkelingen op de voet te volgen, terwijl ze hun interne onderzoeksactiviteiten kunnen beperken tot de meest veelbelovende onderzoeksprojecten. Indien een bepaalde technologie minder interessant blijkt te zijn dan verwacht, kunnen flexibele contracten relatief snel en vrijwel kosteloos worden ontbonden. In overeenstemming met de bedrijfsgeoriënteerde theorieën, bieden grote farmaceutische bedrijven het hoofd aan hun snel veranderende technologische omgeving door hun flexibiliteit en onafhankelijkheid te handhaven en samen te werken op basis van flexibele contracten.

\section{Samenwerkende bedrijven}

Naast een uitgebreide analyse van de structurele evolutie van kennisnetwerken over de tijd, besteedt hoofdstuk 4 van dit proefschrift eveneens aandacht aan de veranderende rollen van zowel grote farmaceutische bedrijven als kieine biotechnologische bedrijwen in deze netwerken. In overeenstemming met de inzichten die ten grondslag liggen aan de meeste netwerkgeoriënteerde theorieën, toont dit hoofdstuk overduidelijk aan dat de intensieve samenwerking tussen deze twee groepen van samenwerkende bedrijven grotendeels wordt bepaald door hun gespecialiseerde technologische capaciteiten en hun complementaire kenmis van het innovatieproces.

Ondanks de hoge mate van specialisatie en complementariteit in de R\&D allianties tussen grote farmaceutische bedrijven en kleine biotechnologische bedrijven, heeft de intensieve samenwerking tussen grote en kleine bedrijven niet geleid tot wederzijdse afhankelijkheid van deze bedrijven. In hoofdstuk 5 werd het gebrek aan vertrouwen en wederzijdse afhanke- 
lijkheid van grote en kleine bedrijven verklaard door te wijzen op de grote verschillen tussen deze bedrijven, die vanwege hun verschillende grootte en machtspositie niet van elkaar afhankelijk hoeven te zijn. Alhoewel grote bedrijven in meer of mindere mate afhankelijk zijn van kleine bedrijven als groep, zijn zij in het geheel niet afhankelijk van individuele kleine bedrijwen. Echter, in hun relaties met grote bedrijven, bekleden de meeste kleine bedrijven wel een zwakke afhankelijkheidspositie. Deze theoretische argumenten worden nog eens versterkt door de empirische bevindingen in hoofdstuk 4 die blijk geven van het feit dat grote bedrijven een steeds belangrijkere rol zijn gaan spelen in kennisnetwerken. Deze veranderende rol van grote bedrijven wijst erop dat deze bedrijven erin geslaagd zijn hun onafhankelijke concurrentiepositie te handhaven, en dat zij slechts in geringe mate afhankelijk zijn van kleine bedrijven. Binnen het kader van de bedrijfsgeoriënteerde onderzoekstraditie, speelt wederzijdse afhankelijkheid aldus geen belangrijke rol in de hoogtechnologische farmaceutische biotechnologie industrie waar grote bedrijven hun "arm's length" contractuele allianties gebruiken om hun onafhankelijke concurrentiepositie te verstevigen.

\section{Bepalende factoren in het tot stand komen van R\&D allianties}

In hoofdstuk 5 en 6 van dit proefschrift worden de specifieke effecten van een groot aantal mogelijke bepalende factoren van R\&D allianties tussen grote farmaceutische bedrijven en kleine biotechnologische bedrijven onderzocht. Uit de empirische analyses in hoofdstuk 5 is gebleken dat er geen sprake is van een vertrouwensrelatie tussen grote en kleine bedrijven, en dat deze belangrijke netwerkgeorienteerde determinant van alliantievorming geen significante rol speelt in de samenwerkingsverbanden tussen deze bedrijven. Deze empirische bevindingen alsmede de observatie dat het merendeel van de R\&D allianties in de hoogtechnologische farmaceutische biotechnologie industrie gebaseerd is op formele gedetailleerde contracten (zie hoofdstuk 3), wijzen op de belangrijke rol van opportunisme in de veelal 
bedrijfsgeoriënteerde relaties tussen farmaceutische biotechnologie bedrijven, die hun contractuele allianties met anderen voormamelijk gebruiken om hun bedrijfsspecifieke behoeften te vervullen.

Hoofdstuk 6 analyseert een groot aantal mogelijke bedrijfsgeoriënteerde determinanten van alliantievorming in de hoogtechnologische farmaceutische biotechnologie industrie, te weten de unieke bedriffsspecifieke alliantievaardigheden van de partners alsmede hun technologische capaciteiten. Zoals verwacht op basis van de bedrijfsgeoriënteerde theorieën, wijzen de verkregen resultaten duidelijk uit dat de bedrijfsspecifieke technologische kennisbasis van hoogtechnologische farmaceutische biotechnologie bedrijven en hun unieke alliantievaardigheden, die deze bedrijven in staat stellen optimaal te profiteren van elke nieuwe R\&D alliantie, belangrijke bepalende factoren zijn in het tot stand komen van allianties. Vooral grote farmaceutische bedrijven gebruiken hun bedrijfsspecifieke capaciteiten om toegang te verkrijgen tot nieuwe biotechnologische kennis en aldus hun sterke concurrentiepositie in een snel veranderende technologische omgeving zeker te stellen.

\section{Slotopmerkingen}

Een aantal theoretische bevindingen en empirische resultaten van dit proefschrift, zoals de sterke toename van het aantal R\&D allianties in de hoogtechnologische farmaceutische biotechnologie industrie, de steeds dichter wordende kennisnetwerken, en de hoge mate van specialisatie en complementariteit in deze netwerken, kunnen verklaard worden binnen het theoretisch kader van de netwerkgeoriënteerde onderzoekstraditie. Echter, de traditionele bedrijfsgeoriënteerde theorieen verschaffen duidelijk meer inzicht in de specifieke aard van relaties tussen hoogtechnologische bedrijven in deze interessante industrie, waar onafhankelijke bedrijven grote aantallen contractuele allianties aangaan op basis van hun bedrifsspecificke behoeften, belangen en capaciteiten. 



\section{Curriculum Vitae}

Nadine Roijakkers was born in 1976 in Maasbracht, the Netherlands. After finishing secondary school at the Bisschoppelijk College in Echt in 1994, she studied International Business Studies at Maastricht University, specializing in Intemational Strategy/Organization and Innovation Management. In the academic year 1997-1998, she studied International Economics at the Leopold Franzens University in Imsbruck, Austria. While in Innsbruck, she conducted a study into the influence of personality traits on students' choice behaviour, which formed the basis for her Master's thesis. The results of this study will be published in the Journal of Career Development in 2004. After her graduation in 1998, she started her Ph.D. research at Maastricht University. Since October 2002, she has been employed as a researcher at the Maastricht Economic Research Institute on Innovation and Technology (MERTT). In this capacity, she is participating in the "Science, Technology, Innovation Network Indicators" project, a two-year research program sponsored by the European Commission.

Nadine Roijakkers werd in 1976 geboren te Maasbracht. In 1994 behaalde zij als best geslaagde haar VWO diploma aan het Bisschoppelijk College te Echt. Van 1994 tot 1998 studeerde zij Internationale Bedrijfskunde aan de Universiteit Maastricht, waar zij voornamelijk vakken volgde op het gebied van Strategie, Organisatie en Innovatie Management. In het academische jaar 1997-1998 studeerde zij Internationale Economie aan de Leopold Franzens Universiteit te Imnsbruck in Oostenrijk. Tijdens haar verblijf in Innsbruck deed zij tevens onderzoek naar de invloed wan persoonlijkheid op het keuzegedrag wan studenten. Dit onderzock, waarvan de resultaten in 2004 zullen worden gepubliceerd in Journal of Career Development, vormde de basis van haar doctoraalscriptie. Na hasir afstuderen in 1998, begon zij als assistant-in-opleiding aan haar dissertatieonderzoek bij de Universiteit Maastricht. Vanaf oktober 2002 is zij werkzam als post doc onderzoeker bij MERIT. In deze hoedanigheid is zij betrokken bij het: "Science, Technology, Innovation Network Indicators" project, een tweejarig onderzoeksproject dat gefinancierd wordt door de Europese Commissie. 